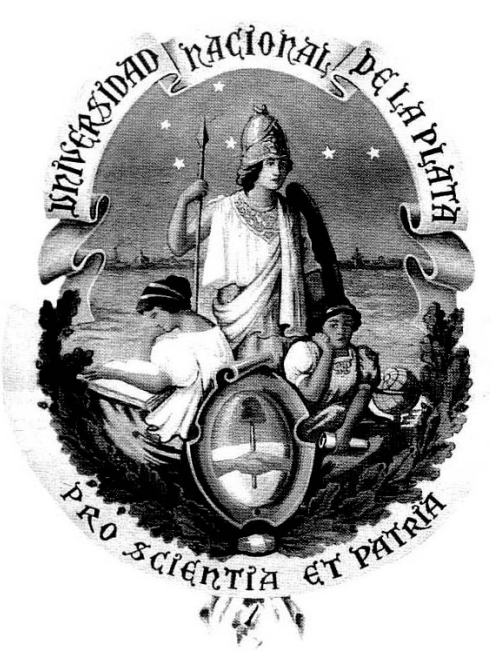

Universidad Nacional de La Plata

Facultad de Ciencias Astronómicas y Geofísicas de La Plata

TESIS PARA OBTENER EL GRADO ACADÉMICO DE DOCTOR EN ASTRONOMÍA

\title{
La población de Centauros: su relación con los objetos transneptunianos y los cometas
}

Lic. Luis Antonio Mammana

Director: Dr. Ricardo A. Gil-Hutton

Codirector: Dr. Rubén Á. Vázquez

La Plata

Argentina

OCTUBRE DE 2015 

A mi padre que me trasmitió su interés por

la Ciencia y su pasión por la Música.

A mi madre por su incondicionalidad.

A mis hermanos, por todo lo demás.

Y a mi recordado amigo, el Dr. Alfredo Novelli. 



\section{Prefacio}

Esta tesis fue realizada en cumplimiento a la requisitoria para la obtención del grado académico de Doctor en Astronomía de la Universidad Nacional de La Plata y fue desarrollada bajo la dirección del Dr. Ricardo Gil-Hutton y la codirección del Dr. Rubén Vázquez.

Luis Antonio Mammana

lmammana@casleo.gov.ar

San Juan, octubre de 2015 



\section{Resumen}

En esta tesis se presentan los resultados de los estudios realizados sobre la relación entre la población de Centauros y las poblaciones de los objetos transneptunianos (TNOs) y los cometas de la Familia de Júpiter (JFCs), caracterizando su distribución de tamaños y estudiando las posibles consecuencias que pudiera tener la variación de la heliosfera en sus albedos y colores.

Para lograr estos objetivos, en primer lugar se ajustó la Función Acumulativa de Luminosidad (CLF) de la población desarrollando un programa de búsqueda específicamente diseñado para estudiar la población de Centauros. A partir de dicho ajuste se pudo estimar la Distribución Acumulativa de Tamaños (CSD), la que constituye una poderosa herramienta a la hora de comprender la evolución colisional de una población. En segundo lugar, se realizó un estudio teórico mediante simulaciones numéricas, para analizar la posible influencia de las variaciones en la posición de la heliosfera en la bimodalidad de colores observada en la población de Centauros.

Se entiende por programa de búsqueda a un conjunto de imágenes obtenidas en el marco de una búsqueda sistemática, ordenada y bajo ciertas condiciones metodológicas, de objetos que comparten características en común. La interpretación de los datos provenientes de un programa de búsqueda astronómico es una tarea que requiere un especial cuidado y resulta un trabajo muy complejo que implica adoptar un modelado que responda tanto a las propiedades dinámicas como a las propiedades físicas de los objetos estudiados, lo que implica enfrentarse a una serie de problemas sutiles que deben ser bien comprendidos (Petit et al., 2008).

Todos los Centauros descubiertos hasta la fecha han sido el subproducto de programas de búsqueda que tenían como principal objetivo la detección y el estudio de objetos de otras poblaciones, tales como asteroides del Cinturón Principal (MBA), Objetos Cercanos a la Tierra (NEOs), cometas, TNOs, etc. En el caso de aquellos programas optimizados para detectar objetos lejanos, imponen a sus métodos y estrategias limitaciones en las velocidades de los objetos para así descartar aquellos con velocidades típicas de MBAs, los que inevitablemente aparecerán en gran cantidad en las imágenes dado que los campos de búsqueda preferenciales siempre están próximos a la eclíptica, pero ello los hace insensibles a objetos con velocidades típicas de Centauros. En el otro extremo y por motivos análogos, los programas de búsqueda pensados para objetos que se desplazan a altas velocidades sobre el fondo del cielo, son ineficientes en la detección de Centauros.

Para la realización de la parte observacional de esta tesis se llevo acabo el primer programa de búsqueda optimizado para la detección de Centauros con el objetivo de lograr un ajuste 
de la CLF de dicha población y derivar la CSD asociada con el fin de sacar conclusiones sobre los procesos evolutivos de la población. Para la implementación de dicho programa se desarrolló una técnica capaz de detectar objetos que no son visibles en las imágenes individuales pero que sí aparecen al concentrar toda la señal en una imagen única luego de coadicionar un cierto número de imágenes. La técnica utilizada permite detectar objetos con diferentes velocidades angulares y direcciones de movimiento, y compensa la pérdida de flujo por desplazamiento del objeto, posibilitando la detección de cuerpos en rangos de magnitudes indetectables por otros programas de búsqueda. Si bien la técnica de búsqueda desarrollada es muy trabajosa, gran parte del proceso se automatizó mediante códigos y scripts de desarrollo propios.

Las ventajosas características de la técnica utilizada permitió detectar objetos muy afectados por la pérdida de flujo debida al desplazamiento del objeto y completar una ventana de unas tres magnitudes presente en los anteriores ajustes de la CLF de la población de Centauros. Además, los datos aportados por esta tesis abren la posibilidad nunca antes planteada de que estemos frente a una CLF de Centauros que presentaría un cambio de pendiente, análogamente a lo que le sucedería a las poblaciones de TNOs (Weissman y Levison, 1996; Bernstein et al., 2004; Fraser et al., 2008; Fuentes y Holman, 2008; etc.) y JFCs (Weissman, 1982; Bailey y Stagg, 1988; Weissman, 1990; Fernández et al., 1999; Meech et al., 2004; etc.), poblaciones que están en los extremos evolutivos de la dinámica de todo Centauro (Fernández, 1980; Duncan et al., 1988; Holman y Wisdom, 1993; Levison y Duncan, 1997; Morbidelli, 1997; Jewitt, 2002; Di Sisto y Brunini, 2007; Volk y Malhotra, 2008; Melita y Licandro, 2012; Perna et al., 2014; Duffard et al., 2014b; etc.). En el futuro será posible profundizar el estudio de la población de Centauros ampliando la búsqueda a una mayor superficie en el cielo, pero también será posible aplicar el método desarrollado en la detección de miembros de otras familias o grupos del Sistema Solar (SS).

Dado que la variación de los albedos afecta la relación entre la CLF y la CSD de una población (por ejemplo, Frasser et al., 2008), un mayor conocimiento de dicha variación y de los colores de una población, ayudará a interpretar correctamente los resultados de todo programa de búsqueda. Por ello, y en el marco de la presente tesis, se decidió abordar un aspecto particularmente sensible para la población de Centauros como es la mencionada bimodalidad de colores observada y que aún no ha sido debidamente comprendida. Con el fin de aportar una posible explicación de este fenómeno, se realiza un estudio teórico mediante simulaciones numéricas, sobre la posible influencia del comportamiento de la heliosfera ante encuentros con medios de distintas densidades, y a partir del mismo obtener conclusiones sobre los efectos de la radiación interestelar en las superficies de los miembros de esta población. El estudio deja claro que la cantidad de Centauros que abandonan periódicamente la protección de la heliosfera y que superan las dosis de radiación recibidas desde el medio interestelar (ISM) necesarias para modificar sus superficies, no crece de manera continua por simple acumulación a medida que pasa el tiempo; que por sí sola una reducción de tamaño experimentada por la heliosfera en el cruce de un medio típico dado, desprotegiendo así parte de dicha población, no alcanza para que se genere en ella la bimodalidad de colores que se observa; que la mera existencia de la heliosfera y su propiedad protectora ante los rayos provenientes del ISM sería suficiente para definir dos ambientes diferentes capaces de generar una bimodalidad de colores si se integra durante tiempos suficientemente prolongados; y por último, que es muy probable que a medida que se puedan determinar índices de color de Centauros con órbitas con distancias perihélicas superiores a las $20 \mathrm{UA}$, la proporción neutros/rojos observada en la 
actualidad se modifique. Estos estudios teóricos pueden ser aplicados del mismo modo para analizar los efectos de la variación heliosférica en estrellas con sistemas exoplanetarios, que en caso de reducciones extremas podría afectar a planetas relativamente cercanos a la estrella, o a su zona de habitabilidad, lo que podría tener decisivas consecuencias astrobiológicas.

Se estructuró la presentación de este trabajo de tesis de la siguiente manera:

En un primer capítulo se desarrolla una extensa introducción que pretende contextualizar al lector en el problema que se decidió abordar.

En el segundo capítulo se desarrolla el trabajo observacional realizado, describiendo el programa de búsqueda empleado, el cual está basado en un método original de desarrollo personal.

En el siguiente capítulo se presentan los objetos descubiertos y la nueva estimación de la CSD de la población de Centauros que los mismos hicieron posible.

El cuarto capítulo desarrolla un estudio teórico mediante simulaciones numéricas, que trata sobre la posible influencia del comportamiento de la heliosfera en el albedo de los Centauros.

Y finalmente, en un último capítulo, se desarrollan las conclusiones y las perspectivas futuras. 



\section{Agradecimientos}

En primer lugar quisiera agradecer a mi director de tesis, el Dr. Ricardo Gil-Hutton por su ayuda incondicional, su generosidad en compartir sus conocimientos, y su permanente predisposición y esfuerzo para ejercer la dirección desde San Juan, venciendo la distancia que nos separó durante estos años, una tarea a veces engorrosa a la hora de trasmitir ideas complejas.

A mi codirector de tesis, el Dr. Rubén Vázquez por su permanente apoyo.

A la Dra. Marcela Cañada Assandri por su permanente apoyo y generosidad en mis estadías temporarias en San Juan mientras realizaba la tesis, compartiendo su oficina.

A mis padres y hermanos por siempre estar presentes. 



\section{Índice general}

Dedicatoria $\quad$ I

$\begin{array}{lll}\text { Prefacio } & \text { III }\end{array}$

Resumen $\quad$ V

$\begin{array}{ll}\text { Agradecimientos } & \text { IX }\end{array}$

$\begin{array}{ll}\text { Listado de símbolos y abreviaturas } & \text { XVII }\end{array}$

1. Introducción $\quad 1$

1.1. Discos protoplanetarios y formación estelar . . . . . . . . . . . . . 1

1.2. La formación de sistemas planetarios . . . . . . . . . . . . . 7

1.3. El origen y la evolución del Sistema Solar . . . . . . . . . . . . . . . . . . 11

1.4. El Espacio Transneptuniano . . . . . . . . . . . . . . . . . . . . . 22

1.4.1. Breve historia de la Región Transneptuniana . . . . . . . . . . . . . 22

1.4.2. Las clases dinámicas de las poblaciones transjovianas . . . . . . . . . . 30

Los objetos cisneptunianos . . . . . . . . . . . . . 30

Los objetos transneptunianos . . . . . . . . . . . . . . 35

1.5. La Nube de Oort . . . . . . . . . . . . . . . . . . . . . . . . . . . . 40

1.6. Evolución de los TNOs hasta objetos de la JFC . . . . . . . . . . . . . . 45

1.7. La Función Acumulativa de Luminosidad . . . . . . . . . . . . . . . . . . 59

1.8. La Distribución Acumulativa de Tamaños . . . . . . . . . . . . . . . . . . . . 67

2. Programa de búsqueda de Centauros $\quad \mathbf{7 5}$

2.1. Caracterización del instrumento . . . . . . . . . . . . . . . . 75

2.1.1. Las observaciones para la caracterización del instrumento . . . . . . . 78

2.1.2. Resultados ... . . . . . . . . . . . . . . . . 84

2.2. Las observaciones para el programa de búsqueda . . . . . . . . . . . . . 86

2.2.1. El procesamiento de las imágenes . . . . . . . . . . . . . . . . . . . . . . . . 92

2.3. Estrategias de búsqueda . . . . . . . . . . . . . . . . . . . 95

2.4. El método de búsqueda . . . . . . . . . . . . . . . . . . . . . . 101

2.4.1. Búsqueda a distintas profundidades para una dirección dada . . . . . 103

2.4.2. Variando las direcciones de desplazamiento de las imágenes . . . . . . 117

2.5. Estimación de la eficiencia de detección del programa de búsqueda . . . . . . 121

3. El descubrimiento de nuevos Centauros y una nueva determinación de la 
CLF de la población $\quad \mathbf{1 2 3}$

3.1. Los Centauros descubiertos y otros objetos menores . . . . . . . . . . . . 123

3.2. Estimaciones previas de las Funciones Acumulativas de Luminosidad de Cen-

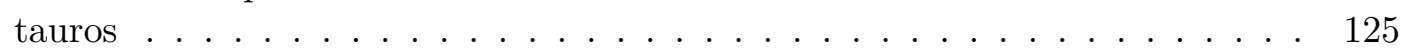

3.3. Estimación de nuevas CLF y CSD para la población de Centauros . . . . . . 130

4. La heliosfera y los colores de los Centauros 139

4.1. La heliosfera . . . . . . . . . . . . . . . . . . . . . . . . . . 140

4.2. El albedo y el color de las superficies . . . . . . . . . . . . . . . . . . . 141

4.3. Procesos que modifican las superficies . . . . . . . . . . . . . . . . 143

4.4. El entorno interestelar del SS . . . . . . . . . . . . . . . . . . 146

4.5. Las simulaciones numéricas . . . . . . . . . . . . . . . . . . 152

4.5.1. Condiciones iniciales . . . . . . . . . . . . . . . . . 152

4.5.2. Los modelos incluidos en las simulaciones . . . . . . . . . . . . . . 152

4.5.3. Los escenarios de encuentro . . . . . . . . . . . . . . . . . . . . . . . . . . . . . . 154

4.5.4. Resultados . . . . . . . . . . . . . . . . . . 155

Experimento $1 \ldots \ldots \ldots \ldots \ldots \ldots \ldots$

Experimento $2 \ldots \ldots \ldots \ldots \ldots \ldots$

Experimento $3 \ldots \ldots \ldots \ldots \ldots 16 \ldots \ldots \ldots$

5. Conclusiones y perspectivas futuras $\quad 165$ 


\section{Índice de figuras}

1.1.1. Imágenes de discos de polvo alrededor de estrellas jóvenes o en formación . . 3

1.1.2. Disco de polvo alrededor de la estrella AU Microscopii . . . . . . . . . . . 4

1.1.3. Disco protoplanetario afectado por fotoevaporación debido a la cercanía de una estrella tipo $\mathrm{O} \ldots \ldots \ldots \ldots \ldots \ldots \ldots$

1.1.4. Representación de un disco protoplanetario alrededor de la estrella central . 6

1.2.1. Energía específica de disrupción para objetos helados . . . . . . . . . . . . 10

1.3.1. Condensación de distintos materiales en función de la distancia heliocéntrica. 12

1.3.2. Variación temporal de los semiejes de los cuatro planetas jovianos por intercambio de momento angular con los planetesimales . . . . . . . . . . . . 15

1.3.3. Simulación realizada con el Modelo de Niza: Evolución orbital de los gigantes gaseosos . . . . . . . . . . . . . . . . . . . . 17

1.3.4. Etapas en la evolución del SS según el Modelo de Niza . . . . . . . . . . . . 19

1.3.5. Comparación en el plano $(q \times i)$ entre SDOs reales y clones . . . . . . . . . . 20

1.3.6. Distribución de semiejes y excentricidades en el $\mathrm{TNb}$. . . . . . . . . . . . . 21

1.4.1. Disco protoplanetario rodeando a la estrella LH Tau . . . . . . . . . . . 23

1.4.2. Imágenes del Centauro (2060) Chiron . . . . . . . . . . . . . . . 28

1.4.3. Clasificación cometaria de Levison y Duncan, según $T_{J} \ldots \ldots$. . . . . . . 32

1.5.1. Distribución de las recíprocas de los semiejes mayores de las órbitas originales de cometas cuasi-parabólicos . . . . . . . . . . . . . . 41

1.5.2. Función de distribución de probabilidades de cambio de energía de cometas en sus perihelios. . . . . . . . . . . . . . . . . . . .

1.5.3. Plano ecliptical mostrando los cometas atrapados en "nubes de Oort" generadas bajo distintas condiciones iniciales. . . . . . . . . . . . . . . . 43

1.5.4. Esquematizaciones de la $\mathrm{OC} \ldots \ldots \ldots \ldots \ldots$

1.6.1. Semiejes e inclinaciones de cometas con $P<200$ años en función de $T_{J} \ldots \quad 48$

1.6.2. Evolución de una partícula con origen en el $\mathrm{TNb} \ldots \ldots$. . . . . . . . . . 49

1.6.3. Órbita de una partícula en el plano $(Q \times q) \ldots \ldots \ldots \ldots$. . . . . . 50

1.6.4. Relación entre los cosenos de las inclinaciones de los cometas y sus perihelios desde su evolución del $\mathrm{TNb} \ldots \ldots \ldots \ldots$. . . . . . . . . . . . 51

1.6.5. Relación entre los elementos orbitales de cometas visibles y sus órbitas iniciales 53

1.6.6. Distribución de los tiempos de vida dinámica medios en la zona de Centauros de los SDOs de las simulaciones . . . . . . . . . . . . . . .

1.6.7. Inclinación inicial en función del tiempo de vida dinámica medio en la región de Centauros . . . . . . . . . . . . . . . . 56 
1.6.8. Tiempo de vida dinámica medio de los SDO que llegan a la zona de Centauros con $q(U A)$ menor que un valor dado . . . . . . . . . . . . . .

1.6.9. Cantidad de Centauros con $R>1 \mathrm{~km}$ en función de $q(U A) \ldots \ldots$. . . .

1.6.10. Tiempo de permanencia de la población de Centauros representado en el

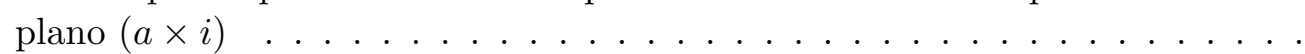

1.6.11. Tiempo de permanencia de los Centauros representado en el plano $(Q \times q)$

1.7.1. Listado de los programas de búsqueda que cumplen los requisitos pedidos por Petit et al. (2008) . . . . . . . . . . . . . . . . . . . .

1.7.2. Listado de los programas de búsqueda que no cumplen los requisitos pedidos por Petit et al. (2008)

1.7.3. Diversos ajustes intentados por el grupo de Bernstein . . . . . . . . . . . .

1.7.4. Ajuste de la CLF con una doble ley de potencias para la población de Objetos Excitados la población $\mathrm{CTNb} \ldots \ldots \ldots \ldots \ldots$

1.7.5. Gráficos de las CLF de TNOs realizados por distintos autores . . . . . . . 66

1.7.6. Sumario de las pendientes estimadas de la CLF para la población de TNOs $\quad 67$

1.8.1. Sumario de las pendientes de la CLF de la población JFC . . . . . . . . 72

2.1.1. Telescopio ASH emplazado en el Cerro Burek (CASLEO, San Juan, Argentina) 76

2.1.2. Características de la cámara SBIG 11000M del ASH . . . . . . . . . . . 76

2.1.3. Curva de eficiencia cuántica del detector Kodak KAI-11000M. . . . . . . . . 77

2.1.4. Curva de transmisión del filtro de Luminancia . . . . . . . . . . . . . . . 78

2.1.5. Imágenes combinadas para la caracterización del ASH . . . . . . . . . . . . 80

2.1.6. Incrementos en las magnitudes en relación a la magnitud máxima alcanzada integrando 180 segundos . . . . . . . . . . . . . . . 83

2.1.7. Resultados finales para $V \operatorname{mag}_{\text {lím }}$ en distintas condiciones . . . . . . . . . . . 85

2.1.8. Evolución de la magnitud límite alcanzable con el ASH en función de los tiempos de exposición . . . . . . . . . . . . . . 85

2.2.1. Características de los campos relevados . . . . . . . . . . . . . 86

2.2.2. Esquema Sol-Tierra-objeto y el ángulo $\omega \ldots \ldots$. . . . . . . . . . . . . 89

2.2.3. Velocidad angular aparente en el plano del cielo en dirección a la oposición en función de la distancia heliocéntrica . . . . . . . . . . . . . . . . . . . 90

2.2.4. Parámetros y características del programa de búsqueda . . . . . . . . . . . . 91

2.2.5. Imagen descartada por exceso en la dirección E-W . . . . . . . . . . . . . 93

2.2.6. Imagen descartada por elongaciones en todas las estrellas del campo . . . . 94

2.3.1. Diferentes detalles en una imagen a analizar luego de una coadición . . . . . 97

2.3.2. Imágenes coadicionadas de las series obtenidas en dos noches consecutivas . 99

2.3.3. Imágenes coadicionadas para la detección de objetos a $6.7 \mathrm{UA}$, moviéndose en un ángulo $\alpha=17^{\circ} \ldots \ldots \ldots$. . . . . . . . . . . . . . . . 99

2.3.4. Resultado de restar las imágenes de la figura anterior luego de alinearlas . . 100

2.4.1. Las cinco profundidades bases . . . . . . . . . . . . . . . . . . 101

2.4.2. Secuencia de imágenes para concentrar todas las señales de (2085) Henan . . 102

2.4.3. Las doce imágenes a comparar para una determinada dirección y las cinco profundidades base . . . . . . . . . . . . . . . . . . . 103

2.4.4. Una de las imágenes a comparar con la malla-guía y la plantilla de objetos catalogados por el MPC . . . . . . . . . . . . . . . . . . . . . . 104

2.4.5. Celda $A_{1}$ centrada en la pantalla en la primera imagen a comparar . . . . . 105 
2.4.6. Anomalías en imágenes individuales y que se propagan en las imágenes coadicionadas a comparar . . . . . . . . . . . . . . . . .

2.4.7. Secuencia de la formación de una imagen puntual por superposición de extremos de trazos débiles . . . . . . . . . . . . . . . . . . 108

2.4.8. Esquema del eclipse de una estrella por un Centauro . . . . . . . . . . . . . 109

2.4.9. Imágenes alineadas y listas a desplazar . . . . . . . . . . . . . . . . . . 110

2.4.10. Causa de la aparición de un particular trazo en la imagen coadicionada . . 111

2.4.11. Aunque no veamos moverse al objeto, podemos deducir su vector desplazamiento . . . . . . . . . . . . . . . . . 111

2.4.12. Forma práctica de obtener la longitud de un trazo . . . . . . . . . . . . 112

2.4.13. Conocida $\vec{d}$ se puede obtener una imagen puntual del objeto buscado . . . 113

2.4.14.Una situación real: construcción de la imagen puntual de un asteroide $\left(1981 E \mathrm{EH}_{2}\right) 114$

2.4.15. Trazo de tres asteroides del MBA en una imagen coadicionada . . . . . . . 115

2.4.16. Secuencia de dieciséis imágenes para recrear $1981 \mathrm{EH}_{2}$ en una imagen puntual116

2.4.17. Detalle de la secuencia anterior centrado en $1981 E H_{2}$. . . . . . . . . . . 117

2.4.18. La cantidad de direcciones a considerar dependen de la longitud del trazo . 118

2.4.19. Direcciones calculadas por el código para cada distancia . . . . . . . . . . . 119

2.5.1. Eficiencia de detección del método de búsqueda . . . . . . . . . . . . . . . 122

2.5.2. Interpolación de los datos obtenidos del estudio de la eficiencia de detección del programa de búsqueda . . . . . . . . . . . . . . . . . . . . . 122

3.1.1. C02: Secuencia de imágenes coadicionadas en distintas direcciones . . . . . . 124

3.1.2. Circunstancias y características de los tres Centauros descubiertos . . . . . 125

3.2.1. CLF de Centauros estimada por Sheppard et al., 2000 . . . . . . . . . . 127

3.2.2. CLF de Centauros estimada por Larsen et al., 2001 . . . . . . . . . . . . . . 128

3.3.1. Estimación del error del punto aportado por el presente programa de búsqueda a la CLF de Centauros. . . . . . . . . . . . . . . . . . . . 130

3.3.2. Sumario de las CSD de Centauros de diferentes publicaciones . . . . . . . 131

3.3.3. CLF de Centauros que incluye los resultados de la presente tesis . . . . . . . 132

3.3.4. CSD de Centauros derivada de la CLF estimada en esta tesis . . . . . . . . . 133

3.3.5. Gráficos cualitativos de las CLF y CSD de TNOs, Centauros y JFCs . . . . 134

3.3.6. CLF de Centauros ajustada con una doble ley de potencia. . . . . . . . . . 136

3.3.7. CSD de Centauros ajustada con una doble ley de potencia. . . . . . . . . . . 137

4.1.1. BS y heliotails observados en distintas estrellas . . . . . . . . . . . . . . . 140

4.3.1. Distintos procesos que pueden provocar cambios superficiales . . . . . . . . . 144

4.4.1. Mapa de la LB: Cortes normal y tangencial en el entorno solar . . . . . . . . 149

4.4.2. Ploteo de las $\sim 10^{5}$ galaxias más cercanas al Sol . . . . . . . . . . . . . 150

4.4.3. Entorno local del Sol . . . . . . . . . . . . . . . . . . . . . . . 151

4.5.1. Heliosfera: Modelo abierto de Wilkin . . . . . . . . . . . . . . . . . 153

4.5.2. Línea de tiempo de una integración en siete etapas . . . . . . . . . . . 156

4.5.3. Experimento 1: Tabla de resultados . . . . . . . . . . . . . . . . 158

4.5.4. Experimento 1: Histograma de la cantidad de Centauros que sobrevive en cada etapa y sus dosis recibidas . . . . . . . . . . . . . . . . 158

4.5.5. Experimento 1: Porcentaje de Centauros que sobreviven al final de cada etapa y el rango de dosis recibida . . . . . . . . . . . . . . . . . . . 159 
4.5.6. Experimento 1: Porcentaje de SDOs al final de cada etapa y el rango de dosis recibida . . . . . . . . . . . . . . . . . . 159

4.5.7. Experimento 2: Porcentaje de Centauros y SDOs, luego de integrar $7 \times 10^{7}$ años con una heliosfera estática . . . . . . . . . . . . . . . . 160

4.5.8. Experimento 2: Histograma de la cantidad de Centauros sobrevivientes y sus dosis . . . . . . . . . . . . . . . . . . 160

4.5.9. Experimento 3: Evolución temporal de los Centauros PS . . . . . . . . . . 161

4.5.10. Centauros con índices (B-R) determinados . . . . . . . . . . . . . 162

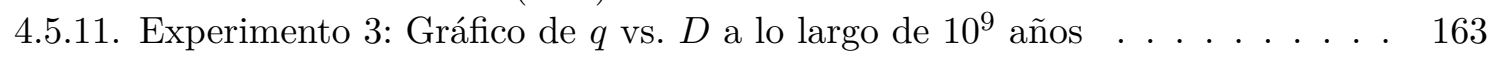

4.5.12. Experimento 3: Evolución temporal de los SDOs PS . . . . . . . . . . . 164 


\title{
Listado de símbolos y abreviaturas
}

\author{
UA : Unidad Astronómica $\left(\sim 1.49598 \times 10^{13} \mathrm{~cm}\right)$. \\ pc : Parsec $\left(\sim 3.0857 \times 10^{18} \mathrm{~cm}=206265 U A\right)$. \\ $\mathrm{M}_{\odot} \quad$ : Masa Solar $\left(\sim 1.9891 \times 10^{33} \mathrm{~g}\right)$. \\ $\mathrm{M}_{\oplus} \quad$ : Masa Terrestre $\left(\sim 5.9736 \times 10^{27} \mathrm{~g}\right)$. \\ $a, e, i$ : Semieje mayor, excentricidad e inclinación. \\ $\omega, \Omega, M$ : Argumento del perihelio, longitud del nodo ascendente, anomalía media. \\ $q, Q \quad: \quad$ Distancias perihélica y afélica. \\ AA : Asteroides Activos (Active Asteroids). \\ ACO : Asteroides en Órbitas Cometarias (Asteroids Comets Orbits). \\ ASH : Telescopio Astrograph for the Southern Hemisphere. \\ BS : Frente de choque (Bow Shock). \\ CAO : Cometas en Órbitas Asteroidales (Comets Asteroidals Orbits). \\ CLF : Función Acumulativa de Luminosidad (Cumulative Luminosity Function). \\ CLIC : Cúmulo de Nubes Interestelares Locales (Cluster of Local Interstellar Clouds). \\ CSD : Distribución Acumulativa de Tamaños (Cumulative Size Distribution). \\ CTNB : Cinturón Transneptuniano Clásico (Classic Transneptunian Belt). \\ DC : Nubes Difusas (Diffuse Clouds). \\ DSD : Distribución Diferencial de Tamaños (Diferential Size Distribution). \\ EDD : Disco Desprendido Extendido (Extended Detached Disc). \\ FWHM : Anchura a Media Altura de una función (Full-Wide at Half Maximum). \\ GMC : Nube Molecular Gigante (Gigant Molecular Cloud). \\ HS : Nubes de Alta Velocidad (High Speed Cloud). \\ ISM : Medio Interestelar (Interestellar Medium). \\ JFC : Cometa de la Familia Júpiter (Jupiter Family Comet). \\ JPL : Jet Propulsion Laboratory Horizons Ephemeris System. \\ LB : Burbuja Local (Local Bubble). \\ LHB : Bombardeo Intenso Tardío (Late Heavy Bombardment). \\ LIC : Nube Interestelar Local (Local Interestellar Cloud). \\ LISM : Material Interestelar Local (Local Interestellar Materials). \\ Lmag : Magnitud en el filtro Luminancia. \\ LPC : Cometas de Largo Período (Large Period Comets). \\ LSR : Local Standard of Rest. \\ MBA : Cinturón Principal de Asteroides (Main Belt Asteroids).
}


MBC : Cometas Activos del Cinturón Principal (Main Belt Comets).

MF : Campos Magnéticos Fuertes (Strong Magnetics Fields).

MMR : Resonancia de Movimientos Medios (Mean Motion Resonance).

MPC : Minor Planet Center.

NEO : Objeto Cercano a la Tierra (Near Earth Object).

OC : Nube de Oort (Oort Cloud).

OCE : Nube de Oort Exterior (Oort Cloud Exterior).

OCI : Nube de Oort Interior (Oort Cloud Inside).

PS : Partícula Sobredosificada (dosis $>100 \mathrm{ev} / 16 \mathrm{amu}$ ).

PSF : Función de Dispersión de Punto (Point Spread Function).

$R$ : Distancia heliocéntrica.

Rmag : Magnitud en el filtro R (Sistema Fotométrico UBVRI de Johnson-Cousins).

SD : Disco Disperso (Scattered Disc).

SPC : Cometas de Corto Período (Short Period Comets).

SS : Sistema Solar.

SSE : Sistema Solar Exterior.

SSI : Sistema Solar Interior.

SW : Viento solar (Solar Wind).

$T_{p}:$ Parámetro de Tisserand respecto del planeta $p$.

$\mathrm{TNb}$ : Cinturón Transneptuniano (Transneptunian Belt).

TNB : Transneptuniano Binario (Transneptunian Binarie).

TNO : Objeto transneptuniano (Transneptunian object).

TNR : Región Transneptuniana (Transneptunian Region).

TS : Frente de choque de terminación (Termination Shock).

$V m a g$ : Magnitud en el filtro V (Sistema Fotométrico UBVRI de Johnson-Cousins). 


\section{Capítulo 1}

\section{Introducción}

\subsection{Discos protoplanetarios y formación estelar}

Las estrellas se originan en las regiones más densas de las nubes moleculares gigantes (GMC) que pueblan las galaxias dado que es allí donde se dan las condiciones de presión y temperatura adecuadas para que colapse parte de su material. Son regiones muy irregulares que pueden extenderse hasta los $50 \mathrm{pc}$; poseen temperaturas típicas en el rango $T \sim 10-20 \mathrm{~K}$ y si bien sus densidades medias llegan hasta los $10^{3} \mathrm{~cm}^{-3}$, las subestructuras y las regiones más centrales -que apenas ocupan $\sim 1 \%$ de sus volúmenes totales (Yeghikyan y Fahr, 2006)-, pueden llegar hasta $10^{5} \mathrm{~cm}^{-3}$. Las masas de estas gigantescas nubes oscilan entre $10^{5}-10^{6} \mathrm{M}_{\odot}$ y ese hecho les permite contener material suficiente como para formar cientos de miles de estrellas. En ellas se han detectado una gran cantidad de moléculas orgánicas y compuestos ricos en $\mathrm{C}, \mathrm{H}, \mathrm{O}, \mathrm{N}$, que pueden incorporarse a los eventuales planetas que se formaran.

El material que constituye las GMC naturalmente no está distribuido uniformemente y sus regiones más densas están asociadas a regiones de formación estelar donde se originarán grumos concentrando grandes cantidades de materia que, cuando alcanzan cierto valor límite de densidad, producen un colapso gravitatorio (Criterio de Jeans). Dicho valor es mayor que la masa individual de una estrella por lo que la región nuclear de cada grumo se fragmenta dando origen a cúmulos abiertos: agrupaciones estelares que pueden ocupar un espacio de hasta $\sim 10 p c$ de diámetro. Por lo tanto, es altamente improbable que una estrella se origine de manera aislada. En el caso particular de una galaxia espiral, la formación estelar se da preferentemente en su plano galáctico, principalmente en sus brazos. Los cúmulos abiertos más jóvenes pueden estar contenidos aún por la nube molecular que les dio origen, irradiándola y originando regiones HII, pero con el paso del tiempo la presión de radiación proveniente de las estrellas del cúmulo provocará que la nube molecular se vaya disipando paulatinamente, estimándose que un $\sim 10 \%$ de su masa se condensará en forma de nuevas estrellas antes que dicha presión haya dispersado todo el gas. La ubicación de una estrella dentro de la nube molecular donde se originó y su interacción con el entorno cercano, son decisivos en la eventual formación de su sistema planetario.

Las primeras observaciones de nubes moleculares en el ISM datan de los comienzos de la década de 1970 cuando los científicos Wilson, Jefferts y Penzias (Wilson et al., 1970), real- 
izando un estudio sobre el monóxido de carbono presente en la Nebulosa de Orión, detectan un componente molecular en el ISM que consistía casi exclusivamente de hidrógeno molecular más algunas pequeñas cantidades de otras especies moleculares complejas. Posteriores observaciones en el infrarrojo (IR) han establecido la importancia astrofísica de las nubes moleculares como sitios de formación estelar (Storm et al., 1975; Yun y Clemens, 1990; Lada, 1992).

Dado que el gas en las nubes moleculares permanece en movimiento constante, cuando un núcleo protoestelar colapsa ese gas tiene demasiado momento angular para que el material forme un solo objeto y surgen así, o bien sistemas múltiples -mayoritariamente binarios-, o bien estrellas de presecuencia de tipo T-Tauri con una distribución de energía espectral muy diferente a las estrellas de secuencia principal. Efectivamente, en las estrellas T-Tauri se observan dos fenómenos: (a) exceso en el IR y en longitudes de onda de radio con respecto a la emisión de la fotosfera debido a que los discos que las rodean reprocesan la luz estelar; y (b) muestran un exceso en el IR y en longitudes de onda más cortas, lo que se debe a que la acreción viscosa calienta el disco y éste reemite dicha radiación. A medida que el disco evoluciona se hace cada vez más delgado, finaliza la acreción y así el disco deja de ser viscoso. En las estrellas T-Tauri muy jóvenes, llamadas Classical T-Tauri Star (CTTS), se dan ambos procesos, mientras que en las más viejas, conocidas como Weak-line T-Tauri Star (WTTS), sólo tiene lugar el primero de ellos. Las muy jóvenes son estrellas que permanecen en ese estado presecuencia entre $10^{5}-10^{7}$ años; se trata de objetos generalmente aislados que varían irregularmente; pertenecen a los tipos espectrales G, K o M; y poseen masas inferiores a las $2 M_{\odot}$. Además muestran fuertes líneas de emisión de Balmer, exceso en el ultravioleta (UV) y emisión en el IR. Fue precisamente esa fuerte emisión en el IR de estas particulares estrellas lo que hizo pensar en un disco de gas y polvo rodeándolas (Beckwith y Sargent, 1993), hecho que se confirmó con sucesivos estudios que finalmente revelaron que casi el $50 \%$ de ellas poseían discos protoplanetarios y presentaban espectros con absorciones de hielo de agua y silicatos, con tamaños característicos del orden de las $100 U A$ de diámetro (Hueso y Guillot, 2005). Los discos son a veces 10 veces más grandes que el que habría originado nuestro SS actual.

Las primeras evidencias observacionales de la existencia de estos discos protoplanetarios fueron provistas por el Infrared Astronomical Satellite (IRAS) que en la década de 1980 detectó un conjunto de estrellas brillantes de secuencia principal con edades entre $10^{8}-10^{9}$ años (Backman y Paresce, 1993) que mostraban un claro exceso de emisión en el IR por encima de lo que se esperaría para la fotosfera de una estrella normal. Dado que fue la estrella Vega ( $\alpha$ Lyrae) una de las primeras donde se detectó este fenómeno (Aumann et al. 1984), hoy es una más del grupo denominado "Estrellas Tipo Vega" junto con $\beta$ Pic, Fomalhaut $(\alpha P s A)$ y $\epsilon$ Eri. Ya en la década de 1990, con la puesta en órbita del Telescopio Espacial Hubble (HST), se sucedieron muchos hallazgos de estrellas con discos de gas y polvo a su alrededor, lo que dio sustento a la idea, hoy ampliamente aceptada, de que la formación planetaria está asociada a la formación misma de las estrellas (Figura 1.1.1). En aquellas que tienen edades mayores que $10^{7}$ años no se observan discos ópticamente gruesos, lo que permite estimar un límite superior para el tiempo de vida medio de una nebulosa protoplanetaria típica. 


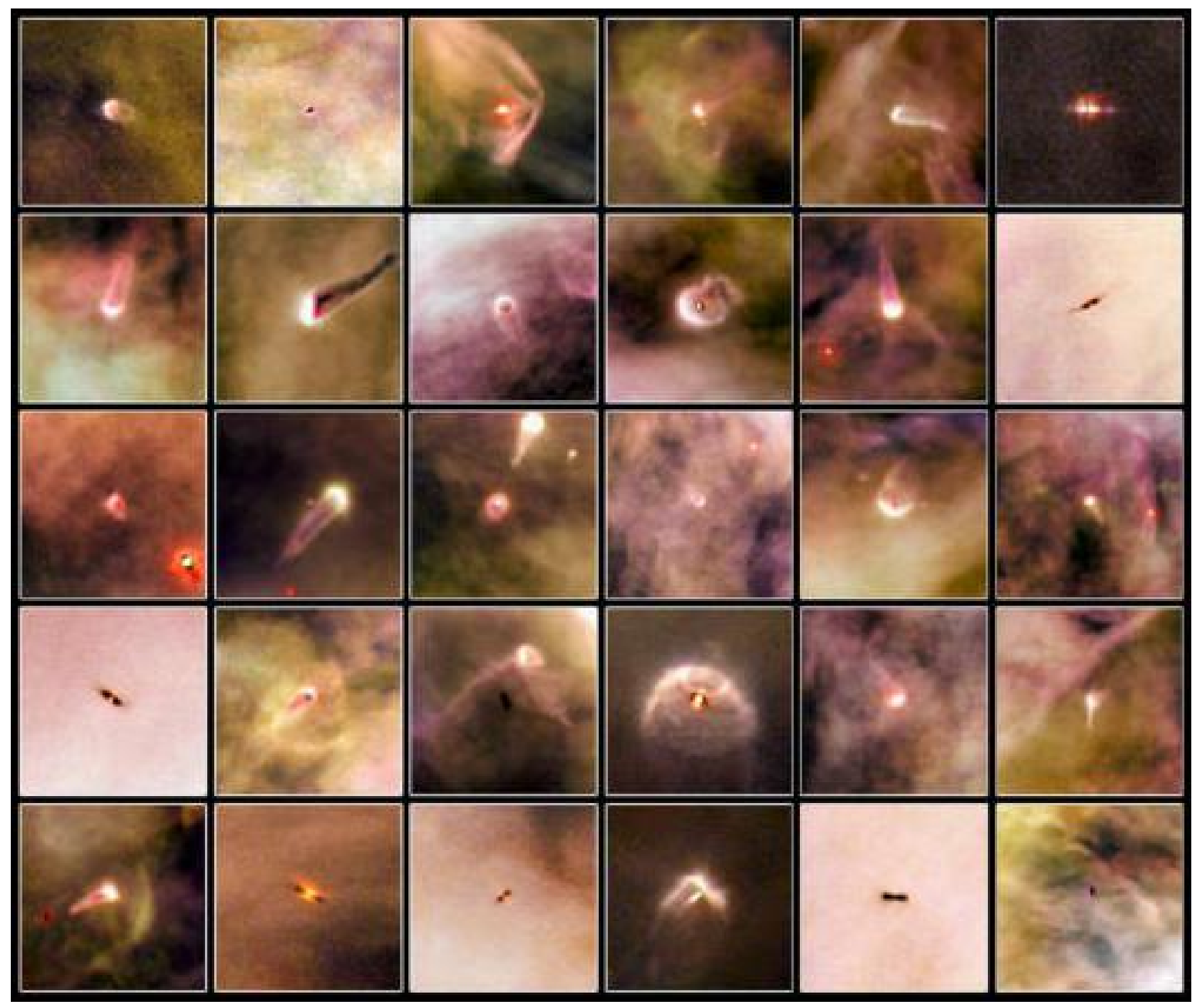

Figura 1.1.1. Imágenes de discos de polvo alrededor de estrellas jóvenes o en formación, obtenidas por el HST (NASA/ESA and L. Ricci-ESO-).

El material del que están constituidos los discos protoplanetarios poseen dos componentes, uno gaseoso y el otro de polvo, y podemos distinguir en los mismos tres regiones: (1) una región fría en el plano medio donde las temperaturas del gas y del polvo son las mismas, adoptando a $1 U A$ valores entre $300-400 \mathrm{~K}$ y donde hoy se sabe que el plano medio de polvo se forma rápidamente (Weidenschilling, 1977a, 1980; Dullemond y Dominik, 2005); (2) una capa intermedia, más caliente, donde tenemos polvo que se está asentando en el plano medio del disco mientras la radiación UV y de rayos X emitida por la estrella calienta el mismo causando que la temperatura del gas empiece a apartarse a la temperatura del polvo; y (3) una capa superficial muy tenue expuesta principalmente a la radiación proveniente de estrellas OB cercanas y al calentamiento por rayos $\mathrm{X}$, que hacen que las temperaturas del gas sean muy altas llegando incluso a los $10^{4} \mathrm{~K}$, ionizando el hidrógeno molecular.

En la Figura 1.1.2 se muestra el disco de polvo alrededor de la estrella enana AU Microscopii. 


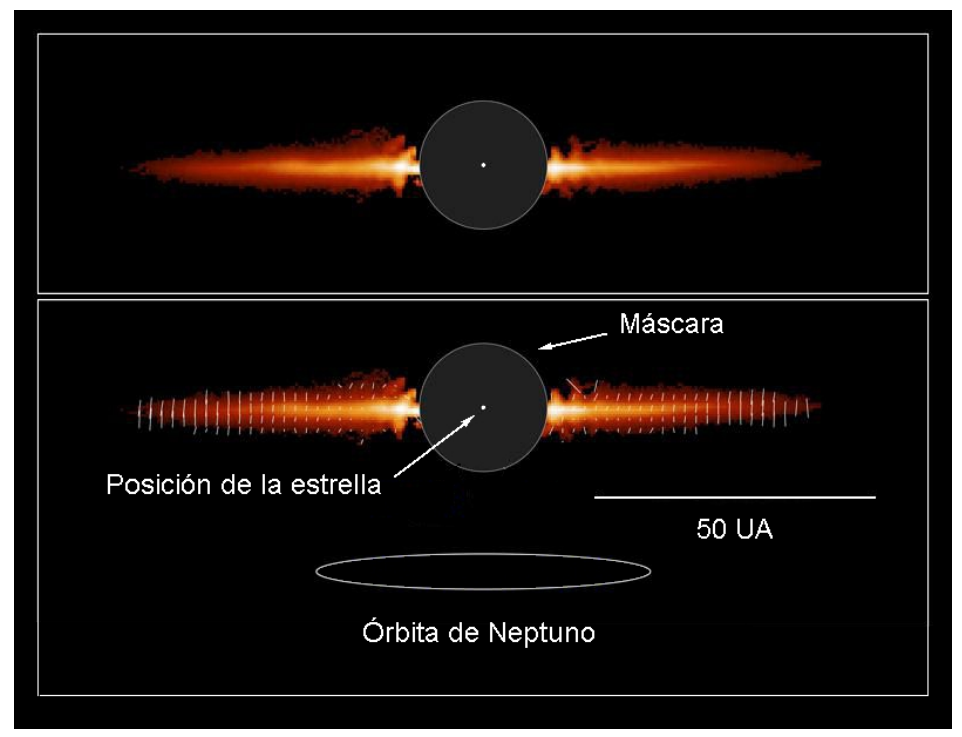

Figura 1.1.2. Disco de polvo alrededor de la cercana estrella enana AU Microscopii (HD 197481). La imagen fue adquirida con la cámara ACS del HST (Adaptado de NASA, ESA, Graham and Kalas -University of California, Berkeley-, and Matthews -Hertzberg Institute of Astrophysics-).

Las moléculas de gas constituyen más del $90 \%$ de la masa total del disco. En una primera etapa los dos procesos que lo gobiernan son los asociados a la acreción y a la fotoevaporación, aunque este último se hace más eficiente en las etapas finales de disipación del gas. El proceso de acreción remueve del disco tanto el gas como el polvo, ya que éste es arrastrado por el primero mientras que el proceso de fotoevaporación solamente remueve el gas y sólo se da en las regiones más externas del mismo $(>10 U A)$. En efecto, la radiación que proviene fundamentalmente de la estrella central excita las partículas en el disco cuando sus átomos absorben fotones UV, acelera y calienta el gas produciendo el desprendimiento de una capa de material que se pierde en el espacio interestelar. A este efecto también pueden contribuir algunas estrellas cercanas O y B muy energéticas. En la Figura 1.1.3 se aprecia cómo los poderosos vientos de una estrella tipo O (ubicada a unos 2450 años luz del SS) barren violentamente parte del material del disco de una estrella similar al Sol.

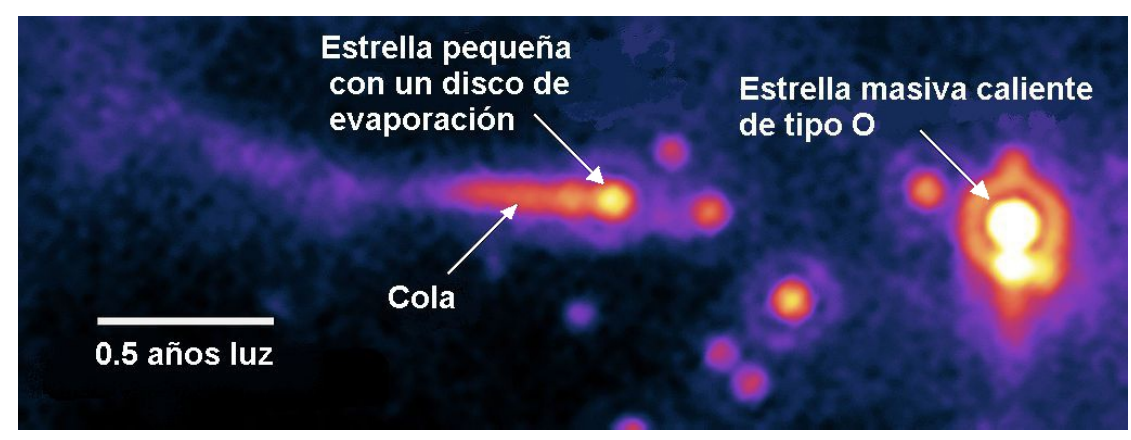

Figura 1.1.3. Disco protoplanetario afectado por la fotoevaporación causada por la cercanía de una estrella tipo O. Los pseudo-colores representan zonas frías-azul-y calientes -rojo(Adaptado de NASA's Spitzer Space Telescope). 
Este mecanismo explicaría la corta vida media de los discos alrededor de las estrellas más jóvenes (Hollenbach et al., 2000; Clarke et al., 2001). La irradiación del disco da lugar a una zona de estabilidad conocida como radio gravitacional o radio de evaporación, donde fuera del mismo las partículas pueden llegar a ser excitadas suficientemente como para escapar de la gravedad del sistema y evaporarse. Después de $10^{6}-10^{7}$ años la tasa de acreción viscosa cae por debajo de la tasa de fotoevaporación en dicho radio gravitacional y ello abre una brecha en torno al mismo: el gas que se halla en la región interna drena hacia la estrella mientras que el que se encuentra en la región más externa se evapora. Una vez que se forma dicha brecha, el exterior del disco se desvanece muy rápidamente. Entonces, dado que tales discos son inestables en escalas de tiempo comparativamente cortas con las edades de las estrellas -por lo que en relativamente muy poco tiempo el polvo y gas primordiales se disipan completamente-, Weissman (1984) propuso que si hoy se observan discos de polvo, entonces éstos deben estar siendo alimentados continuamente por el polvo producto de las colisiones de cuerpos del tamaño de cometas.

En un trabajo de Kurt Liffman (2003), el autor da una aproximación en UA para el radio de evaporación $R_{e}$, mediante la expresión,

$$
R_{e} \sim \frac{1.4 \times 10^{4} K}{T_{U A}} \frac{M_{\star}}{M_{\odot}},
$$

donde $M_{\star}$ es la masa de la estrella y $T_{U A}$ es la temperatura de la capa superficial del disco a $1 U A$, aquella donde decíamos que el gas era ionizado por las altas temperaturas a las que era sometido desde el exterior. El coeficiente $1.4 \times 10^{4} \mathrm{~K}$ de la ecuación (1.1.1), había ya sido estimado por Hollenbach et al. (1994) en $6.8 \times 10^{4} \mathrm{~K}$, un valor unas cinco veces mayor. La ecuación (1.1.1) es consistente con los resultados numéricos de Woods et al. (1996), los que analizaron la evaporación de discos asociados con núcleos galácticos activos. Por otro lado, también está en completo acuerdo con el trabajo de Begelman et al. (1983), quienes muestran que teóricamente vientos térmicos podrían surgir a partir de valores de $R_{e}$ que están bien aproximados por la ecuación (1.1.1).

Para el caso de una estrella de tipo solar, la temperatura de la capa más exterior del disco a $1 U A$ se estima en $T_{U A}=1300 \mathrm{~K}$, y por lo tanto el valor de quiebre del disco estaría en $R_{e}=10.8 U A$, límite que separa el interior del exterior del mismo.

Por su parte, el componente de polvo del disco está integrado inicialmente por partículas muy pequeñas. Si bien las partículas de polvo interestelar tienen tamaños del orden de $0.1 \mu \mathrm{m}$ (Wurm y Schnaiter, 2002), debido a la evaporación y recondensación en las regiones más densas de la nube, en un disco nebular llegan a tamaños típicos del orden de $1 \mu \mathrm{m}$. Este componente está dominado tanto por la atracción gravitatoria que ejerce la estrella central como por la fricción con el gas del disco, y como resultado de la interacción entre ambas fuerzas, rápidamente los granos de polvo forman un delgado disco que paulatinamente va siendo removido por diversos mecanismos. Uno de estos afecta a los granos más pequeños, los cuales al viajar acoplados al gas del disco mayormente terminan espiralando hacia el centro. Por otra parte, los fuertes vientos de la estrella central también hacen su aporte en este proceso de remoción. Un tercer proceso es la formación de los llamados agregados: estos son conglomerados de granos unidos por fuerzas superficiales muy débiles cuyas propiedades quedan definidas por su posición inicial en la nebulosa. Por último, otro mecanismo que influye en las primeras etapas de la formación de los sistemas planetarios, y particularmente en la 
estructura que tendrá su disco, es el truncamiento de éste debido a pasajes cercanos de otras estrellas.

En la Figura 1.1.4 se esquematiza el modelo de formación de un sistema planetario en sus primeras etapas.

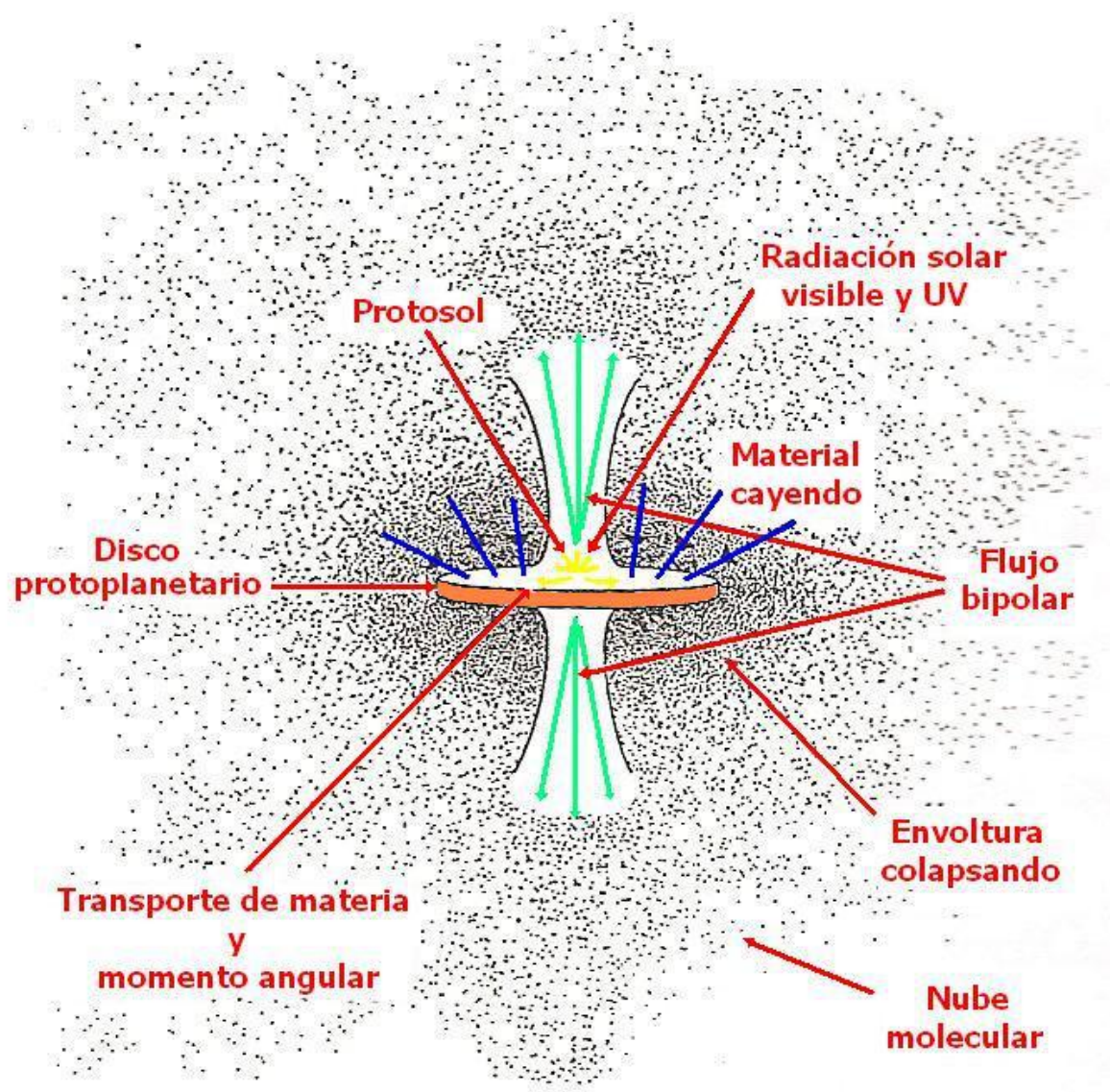

Figura 1.1.4. Representación de un disco protoplanetario alrededor de la estrella central (Adaptado de Fernández, 2005).

Por la conservación tanto del momento angular como de la energía, a medida que la estrella acreta masa del disco, el resto del material necesariamente debe ser transportado hacia el exterior, llevando consigo momento angular y facilitando la acreción (Lynden-Bell y Pringle, 1974). Además de la fotoevaporación, otro mecanismo que explica por qué el disco pierde masa es la acreción viscosa, por la cual la masa de éste fluye hacia la estrella. Es en este proceso donde los espectros de las estrellas T-Tauri muestran fuertes emisiones en las regiones del visible y el UV causadas por gas caliente que cae al centro, gracias al cual la estrella gana masa a expensas del disco hasta que llega un momento en el que se ha acumulado tanto material que éste debe encontrar una salida y lo hace por donde encuentra menor resistencia: las regiones polares, originándose así los jets bipolares o flujos bipolares tan característicos que se observan en las primeras etapas de formación de estos sistemas en estrellas muy jóvenes. 
A este hecho se suma que las interacciones magnéticas entre la estrella central y su disco generan vientos que eyectan chorros de material desde el plano del mismo a lo largo de las líneas del campo magnético, en una cantidad que puede llegar al $50 \%$ de la masa acretada por la estrella.

Aunque el tiempo de acreción viscosa no depende ni de la masa ni de la estructura del disco, sino que depende solamente de la masa de la estrella y de la distancia a la que se encuentre el material de la estructura central, en aproximadamente $10^{7}$ años la acreción viscosa y la fotoevaporación disipan totalmente el gas.

Este tipo de evolución de disco explicaría por qué los planetas de nuestro SS, en su configuración actual, contienen sólo el $0.1 \%$ de la masa del mismo, pero han retenido más del $99 \%$ de su momento angular.

\subsection{La formación de sistemas planetarios}

Aún es motivo de debate cuál es el proceso que lleva a formar cuerpos del orden de kilómetros partiendo de partículas de polvo del orden del micrón, proceso que implica un crecimiento de dichas partículas en al menos doce órdenes de magnitud (Armitage, 2014). Como la emisión del polvo en un disco protoplanetario proviene de las partículas más pequeñas que lo conforman, una merma en la emisión del disco implicaría una disminución de la presencia de dichas partículas en el disco. Entonces, dado que en estrellas con edades entre $10^{6}-10^{7}$ años se observa un remarcable descenso en el exceso de emisión en el IR, podemos inferir que los granos de polvo tuvieron que reagruparse en corpúsculos de mayor tamaño.

Básicamente podemos distinguir cuatro etapas en la evolución que va desde los granos hasta la formación de los planetas: (1) en primer lugar las colisiones entre las partículas producen grandes agregados que se desacoplan del gas y se depositan en una capa densa en el plano medio del disco; (2) el continuo crecimiento de esos agregados débilmente unidos conduce a la formación de planetesimales cuyos movimientos son relativamente independientes del gas en su conjunto; (3) un proceso oligárquico lleva a la formación de un embrión cuasi-planetario; y por último (4) tenemos la etapa de las grandes colisiones entre embriones que ahora tienen un tamaño comparable al de la Luna, etapa que termina, por fin, con la formación de los planetas.

Para los granos de polvo de radios $r \sim 0.01-0.1 \mu \mathrm{m}$ la turbulencia balancea la componente vertical de las fuerzas gravitatorias. A medida que los granos acretan, los que llegan a radios de $r \sim 0.1-1 \mathrm{~mm}$ se desacoplan de las turbulencias y se asientan en el plano medio del disco a escalas de tiempo que varían entre los $10^{3}$ años a $1 U A$ y los $10^{5}$ años a $40 U A$. Dado que el gas -que soporta ciertas presiones- orbita la estrella con velocidades más lentas que las keplerianas, la evolución dinámica de los granos de polvo en el plano es incierta ya que sienten un viento que los arrastra y hace espiralar hacia la estrella central (Adachi et al, 1976; Weidenschilling, 1984; Tanaka e Ida, 1999). Para objetos del tamaño de metros la escala de tiempo de arrastre a $40 U A$ es aproximadamente de unos $10^{5}$ años y ésta es comparable con la escala de crecimiento. Por lo tanto, no está claro si los granos pueden crecer por contacto directo hasta llegar a tamaños de kilómetros, antes que el gas los arrastre a la parte interior del disco. 
Afortunadamente los procesos dinámicos ofrecen alternativas a la aglomeración azarosa de los granos, como por ejemplo que el flujo de gas produce colisiones entre los granos porosos y ello conduce a la formación de planetesimales por acumulación directa (Wurm et al., 2004); o lo que surge de modelos donde estimaciones analíticas y simulaciones numéricas indican que los granos con radios $r \sim 1 \mathrm{~cm}$ también son fácilmente atrapados dentro de los vórtices en el disco (de la Fuente y Barge, 2001; Inaba y Barge, 2006), produciendo importantes aumentos en la relación sólido-gas dentro de los mismos, la cual permite la acreción para vencer la resistencia del gas y la formación de planetesimales de tamaños de kilómetros en $10^{4}-10^{5}$ años.

Si el plano medio del disco que contiene el polvo está en calma, se vuelve más y más delgado hasta que los grupos de partículas superan los límites impuestos por el Criterio Local de Jeans y sobreviene el colapso para formar objetos más grandes en escalas de tiempo dinámico de unos $10^{3}$ años a $40 U A$ (Goldreich y Ward, 1973; Youdin y Shu 2002; Tanga et al. 2004). Si bien este proceso es un camino muy prometedor para la formación de planetesimales, la turbulencia puede evitar la inestabilidad (Weidenschilling, 1995, 2003, 2006). Aunque el tamaño esperado para un objeto que se forma por colapso es del orden de la Longitud de Onda de Jeans, el rango de tamaños de los planetesimales que produce la inestabilidad es incierto.

Ahora bien, una vez que los planetesimales llegan a ser cuerpos con radios $r \sim 1 \mathrm{~km}$, la gravedad domina la dinámica de gases y las interacciones gravitatorias de largo alcance intercambian energía cinética (fricción dinámica) e impulso angular (turbulencia viscosa), redistribuyendo la energía orbital y el momento angular entre los planetesimales.

Para cuerpos de $1 \mathrm{~km}$ a $40 \mathrm{UA}$ las velocidades iniciales aleatorias son comparables con sus velocidades de escape ( $v_{\text {aleatorias }} \sim v_{\text {escape }} \sim 1 \mathrm{~m} \mathrm{seg}^{-1}$ ) (Weidenschilling, 1980; Goldreich et al. 2004). En este escenario, la energía específica de enlace gravitacional $\left(E_{g}\right)$ es aproximadamente $10^{4} \mathrm{erg} \mathrm{g}^{-1}$ y así resulta comparable con una típica energía específica de colisión $\left(E_{c}\right)$. Ahora, si se define como energía específica disruptiva $\left(Q_{D}^{*}\right)$ a aquella energía de colisión necesaria para remover la mitad de la masa de un par colisionante -la cual puede alcanzar valores entre $10^{5}-10^{7} \mathrm{erg}^{-1}$-, hay sobrados argumentos para afirmar que en el caso de materiales helados, tanto $E_{g}$ como $E_{c}$ son energías mucho menores que $Q_{D}^{*}$ (Davis et al., 1985; Benz y Asphaug, 1999; Ryan et al., 1999; Michel et al., 2001; Leinhardt y Richardson, 2002; Giblin et al., 2004) y en esas condiciones, las colisiones producen fusión de objetos en lugar de fragmentación.

Inicialmente la mayor parte de la masa se halla concentrada en los objetos pequeños y además éstos crecen lentamente. Para un gran conjunto de $n$ planetesimales cuyo radio promedio es $r$, si $\sigma_{c}$ es la sección transversal en el esquema de colisión y $v$ es la velocidad relativa, la tasa de colisiones será proporcional a $n \sigma_{c} v$. Ahora, si consideramos que $\sigma_{c}$ es la sección transversal geométrica $\pi r^{2}$ escalada por el factor de enfoque gravitacional $f_{g}$ que aproximamos mediante la expresión

$$
f_{g} \approx 1+\beta\left(\frac{v_{\text {escape }}}{e v_{k}}\right)^{2},
$$

donde $v_{k}$ es la velocidad orbital, $e$ es la excentricidad y $\beta \sim 2.7$ un coeficiente que asume que las órbitas están en tres dimensiones en un disco en rotación (Greenzweig y Lissauer, 1990; 
Spaute et al., 1991; Wetherill y Stewart, 1993), tendremos que

$$
\sigma_{c} \approx \pi r^{2} f_{g} \approx \pi r^{2}\left[1+\beta\left(\frac{v_{\text {escape }}}{e v_{k}}\right)^{2}\right] .
$$

Dado que en esta etapa $e v_{k} \sim v_{\text {escape }}$, los factores de enfoque gravitacional son pequeños y el crecimiento es lento y ordenado (Safronov, 1969). En cuanto $e_{S} v_{k} \ll v_{\text {escape }}$ (los subíndices $S$ y $L$ hacen referencia a pequeño y grande) los factores de enfoque gravitacional toman valores altos y el crecimiento se torna rápido y sin orden. A dicho crecimiento desordenado basado en la retroalimentación positiva entre la acreción y la fricción dinámica se lo denomina "crecimiento runaway" (Wetherill y Stewart, 1989; Kokubo e Ida, 1996). Es la etapa donde el crecimiento relativo de los objetos más masivos es mayor que para los cuerpos menos masivos y el cociente de masa entre ellos aumenta monótonamente.

La fricción dinámica produce un mayor $f_{g}$ para los objetos más grandes que crecen más y más rápido en relación con los objetos más pequeños y concentran una fracción cada vez mayor de la masa total. De esta manera, a medida que estos protoplanetas crecen, perturban a los planetesimales y las dispersiones de velocidades orbitales de los pequeños objetos poco a poco se van aproximando a las velocidades de escape de los protoplanetas. Con $e_{S} v_{k} \sim v_{\text {escape }}$ la tasa de colisión disminuye a medida que continúa el crecimiento runaway y esta etapa finaliza cuando los protoplanetas más grandes dominan la dinámica del disco de planetesimales.

Los protoplanetas y los planetesimales sobrantes finalmente entran en la llamada "fase de crecimiento oligárquico" (Kokubo e Ida, 1998), donde los objetos más grandes crecen de manera más lenta que como lo hicieron en la etapa runaway y donde ese crecimiento se da a expensas de los planetesimales sobrantes, los que crecen mucho más lentamente. En todo este proceso, el cociente de masas entre los cuerpos más grandes y los planetesimales, sigue aumentando.

Cada uno de los objetos más grandes tratará de acretar la mayor cantidad de material posible del anillo de su zona de alimentación (feeding zone) el cual posee el tamaño que impone su campo gravitatorio y la gravedad de los objetos vecinos, y cuando haya acretado toda esa masa llegará a su masa de aislamiento (isolation mass) (Lissauer, 1987; Kokubo y Ida, 1998, 2002; Rafikov, 2003; Goldreich et al., 2004). Como los objetos de mayor tamaño van acretando cada vez más masa y tendiendo a su masa de aislamiento, perturban a los planetesimales hasta que la mayoría de ellos llegan a velocidades disruptivas. Entonces ahora las colisiones en lugar de generar o propiciar fusiones, generan fragmentos y pequeños planetesimales. Las continuas colisiones disruptivas dan lugar a una cascada colisional donde parte de los planetesimales sobrantes, poco a poco, se van convirtiendo en polvo (Dohnanyi, 1969; Williams y Wetherill, 1994). Por su parte, la presión de radiación de la estrella central expulsa los granos de polvo con radios $r \leq 1-10 \mu m$, mientras que el efecto Poynting-Robertson hace espiralar hacia el centro a aquellos que son algo más grandes (Burns et al., 1979; Artymowicz, 1988; Takeuchi y Artymowicz, 2001).

Finalmente, con el tiempo los planetesimales son acretados por los objetos más grandes o reducidos a polvo.

Para evaluar la masa que necesita uno de estos grandes objetos para que se dé una colisión disruptiva, consideremos dos planetesimales con masas iguales, con lo cual la energía 
específica de colisión del centro de masa será,

$$
Q_{\text {impacto }}=\frac{v_{\text {impacto }}^{2}}{8},
$$

donde $v_{\text {impacto }}$ es la velocidad de impacto que satisface la ecuación (Kenyon et al., 2008),

$$
v_{\text {impacto }}^{2}=v^{2}+v_{\text {escape }}^{2} \text {. }
$$

Si $Q_{D}^{*}$ es entonces la energía necesaria para remover la mitad de la masa combinada de estos dos planetesimales, la colisión será catastrófica si $Q_{\text {impacto }}>Q_{D}^{*}$ y generará fusión si $Q_{\text {impacto }}<Q_{D}^{*}$.

Definiendo la masa disruptiva $\left(m_{D}\right)$ como aquella para la cual $Q_{\text {impacto }} \sim Q_{D}^{*}$, tendremos que para el caso de objetos helados a $30 U A$ (Kenyon et al., 2008),

$$
m_{D} \sim 3 \times 10^{-6}\left(\frac{Q_{D}^{*}}{10^{7} \text { erg g }^{-1}}\right)^{\frac{3}{2}} M_{\oplus} .
$$

Debido a que casi todos los modelos de disrupción colisional producen resultados similares para objetos con $r \geq 1 \mathrm{~km}$ (Kenyon y Bromley, 2004a), la masa disruptiva es bastante independiente de las incertidumbres teóricas. De esta manera, para valores típicos de energía específica disruptiva del orden de $Q_{D}^{*} \sim 10^{7}-10^{8} \mathrm{erg} \mathrm{g}^{-1}$ y objetos de $1-10 \mathrm{~km}$ (ver nacimiento de la curva continua en la Figura 1.2.1), los planetesimales comienzan a fragmentarse recién cuando los objetos más grandes alcanzan radios $r_{0} \sim 200-500 \mathrm{~km}$.

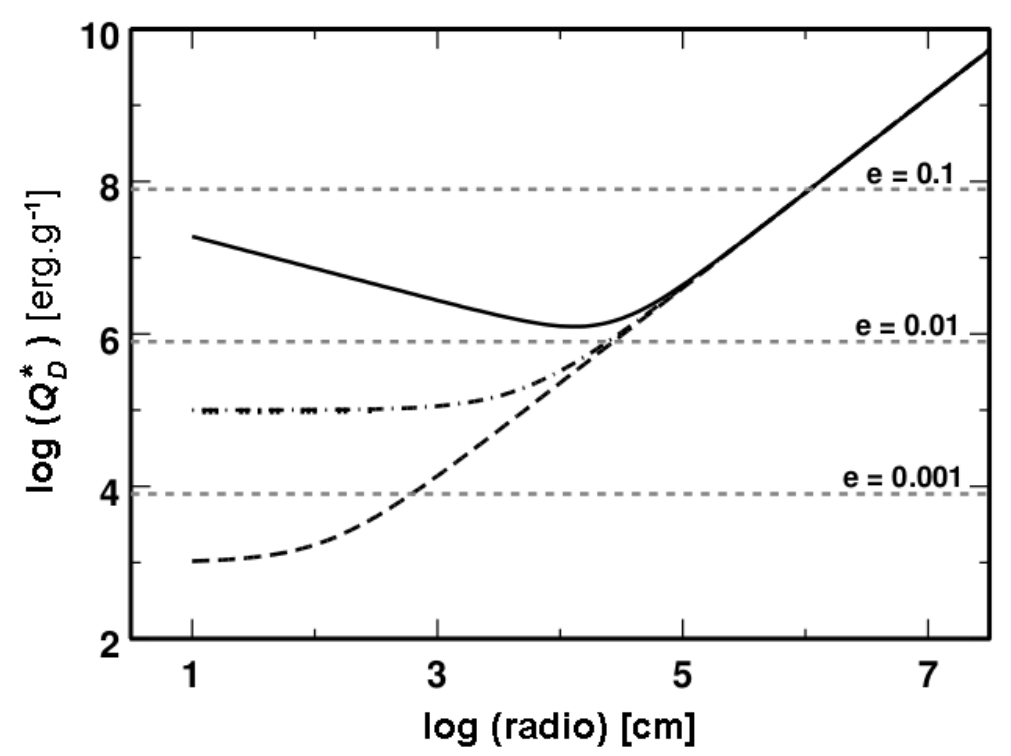

Figura 1.2.1. Energía específica de disrupción $\left(Q_{D}^{*}\right)$ para objetos helados. La curva de trazo continuo es un típico resultado derivado de simulaciones numéricas de un modelo colisional que incluye la ecuación de estado del hielo cristalino (Benz y Asphaug, 1999). Las otras curvas son ajustes usando modelos de rupturas de cometas, como el Shoemaker-Levy 9 (Asphaug y Benz, 1996). Las rectas horizontales muestran las $Q_{\text {impacto }}$ para objetos de masas iguales pero con distintas excentricidades (Adaptado de Kenyon et al., 2008). 
Una vez que comienza la disrupción, la masa final de los objetos más masivos dependerá de la escala temporal de la cascada de colisional (Kenyon y Bromley, 2004a, 2004b, 2004c; Leinhardt y Richardson, 2005). Si dichas colisiones disruptivas producen granos de polvo mucho más rápido que el crecimiento de los objetos más masivos por acreción de los planetesimales sobrantes, un objeto no puede crecer mucho más allá que el radio de disrupción $\left(m_{0, m a ́ x} \sim m_{D}\right)$. Sin embargo, si acretan granos y restos de planetesimales de manera efectiva, llegarán a la masa de aislamiento antes que las colisiones y la presión de radiación barran el material del disco circundante (Goldreich et al., 2004). La tasa relativa entre acreción y disrupción dependerá por un lado del equilibrio entre los procesos de colisión amortiguada y de frenado por fricción del gas -que frenan la cascada colisional- y por el otro, de los procesos de agitación viscosa y fricción dinámica -que aceleran la cascada colisional-. Sabemos que al final de esta etapa ya se han formado los planetas gigantes, pero la explicación de cómo se formaron es actualmente motivo de debate y los dos modelos que tratan de explicarla, la Teoría de la Inestabilidad Nuclear y la Teoría de la Inestabilidad Gravitatoria, son conceptualmente distintos y llevan a la formación de gigantes con estructuras internas diferentes.

Así termina la etapa de crecimiento oligárquico y comienza la última y más violenta de las etapas de la evolución planetaria, la de los grandes impactos. Ésta comienza cuando los pocos planetesimales que quedan y que tienen poca masa ya no pueden frenar las velocidades de los embriones formados en la etapa anterior. Este aumento de velocidades tiene dos consecuencias importantes: por un lado hace que baje la tasa de acreción casi por completo, disminuyendo así bruscamente el proceso de acreción; y por el otro, el aumento de sus velocidades aleatorias hace que se produzcan cruces orbitales con consecuencias catastróficas. Estos impactos gigantes serían muy comunes en esta etapa (Agnor et al., 1999) y determinantes en la definición de elementos orbitales y tasas de rotación.

En la región más interna del sistema -ya más despejado-, las partículas refractarias que fueron sobreviviendo a las distintas etapas que finalmente dieron origen a los planetas gigantes, forman agregados y acretan material hasta llegar a tamaños del orden de los kilómetros. Sus tamaños aumentan a medida que colisionan unos con otros y finalmente llegan a formar planetas rocosos.

\subsection{El origen y la evolución del Sistema Solar}

La teoría actualmente aceptada sobre el origen del SS nos dice que éste se habría formado conjuntamente con estrellas masivas de tipo espectral O y B hace unos $4.5-4.6 \times 10^{9}$ años a partir del colapso de una gran nube de gas y polvo que se encontraba orbitando el centro galáctico y de la cual el $\mathrm{H}$ habría representado $\sim 73 \%$ de su masa total mientras que el resto habría sido mayoritariamente He y una pequeña fracción de elementos más pesados. La causa de dicho colapso estaría en los efectos de la explosión de una supernova cercana de Tipo II (Cameron y Truran, 1977) cuyos rastros surgen del análisis de isótopos de corta vida hallados en meteoritos y los estudios de las llamadas "Ca-Al-rich inclusions" (CAIs) (Tachibana et al., 2006). Conforme fue evolucionando la nube luego del colapso, se formó en su centro un proto-Sol y un disco de polvo y gas. 
Si bien las ideas de la Teoría Nebular se remontan al siglo XVII (Descartes, 1644), los conceptos fundamentales se desarrollaron recién con los trabajos de Schmidt (1958) y principalmente con los de Safronov (1969) quien presenta el modelo de mayor aceptación en la actualidad, en el que propone que luego del colapso del núcleo nebular, la masa total del disco habría sido $\sim 0.01 M_{\odot}$ y que luego que el disco se enfriara y que el polvo se asentara en el plano medio, se habrían formado grumos que más tarde acretarían en planetas y cuerpos menores. Hoy sabemos que en los comienzos de nuestro SS entre las actuales órbitas de Mercurio y Venus condensaron los materiales más refractarios, algunos óxidos metálicos, sílice y silicatos y a mayores distancias, gradualmente condensaron materiales menos refractarios y compuestos carbonosos. Finalmente, en una cierta zona no bien especificada, condensó el agua. En un disco protoplanetario, el borde interior de la región donde la temperatura cae por debajo de la temperatura de condensación del agua se conoce como "línea de nieve" o "línea de hielo", aunque es más apropiado usar el término franja y no línea (Figura 1.3.1).

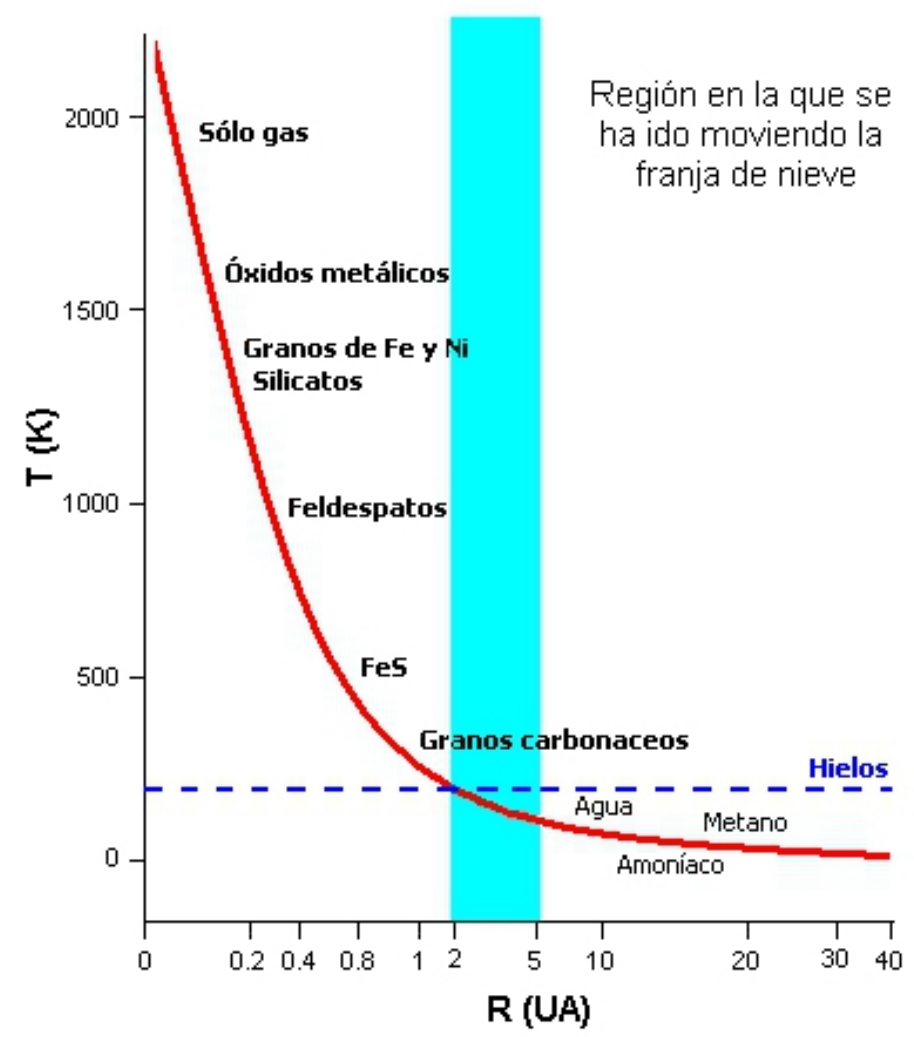

Figura 1.3.1. Condensación de distintos materiales en función de la distancia heliocéntrica. La franja de nieve pudo haber variado entre 2 - 5UA (Adaptado de Fernández, 2010).

Fuera de dicha franja, el hielo de agua aumenta la densidad superficial de los sólidos en un factor estimado por Anders y Grevesse (1989) en 2.09, y más recientemente por Lodders (2003) en 1.17. Observaciones del MBA sugieren que inicialmente la franja de nieve habría estado cerca de las 2.7 UA (Lecar et al., 2006), dividiendo al SS en dos regiones: una interna, donde se condensaron los elementos más refractarios (rocas, metales, silicatos, etc.); y otra, inmensamente más vasta, donde se pudo condensar el agua (y otras moléculas como dióxido 
de carbono, monóxido de carbono, metano, amoníaco, etc.), y dada la gran abundancia de ésta, convertirse en la materia prima de los objetos sólidos de esta región, en particular de los cometas. Así, los planetesimales que se formaron en la región interna del SS contenían pocos hielos (agua, metano, amoníaco, etc.) y los que se formaron en la regiones más alejadas, se componían de una mezcla de partículas refractarias de polvo y hielos. Sin duda, los distintos cambios en las condiciones físicas que iba experimentando el disco protoplanetario en su evolución hizo que la franja de nieve fuera cambiando su localización, variando su posición entre $2-5 U A$, lo que ha planteado en los últimos años una discusión sobre los Cometas Activos del Cinturón Principal (MBC).

Por fricción con el gas, los cuerpos de hielo con tamaños del orden del metro se adentraron rápidamente en la nebulosa y cuando sobrepasaron la franja de nieve se evaporaron depositando vapor de agua en ella. De esta manera, es muy probable que la región interna de la nebulosa se volviera más oxidante a medida que aumentaba el $\mathrm{O}$ proveniente del agua, para volver a ser químicamente reductora cuando el flujo de partículas disminuyó. Luego, dado que el vapor de agua difunde hacia el exterior, una vez superada la franja de nieve, se congeló nuevamente y así fue acretándose paulatinamente en los planetas que se iban formando. Finalmente, el viento solar (SW) disipó el gas dejando a las partículas más refractarias en la región más interna, donde las altas temperaturas no sólo causaron la sublimación del hielo sino también su enriquecimiento con hierro y óxidos de metales refractarios. Estas sucesión de acontecimientos explicaría por qué los planetas rocosos se formaron en la región interna del SS.

Por su parte, los planetas gaseosos también tienen un componente rocoso en sus regiones centrales que forman densos núcleos con masas de hasta $10 M_{\oplus}$, mientras que sus atmósferas, compuestas principalmente por $\mathrm{H}$, He y diversos compuestos moleculares, ocupan el mayor porcentaje del volumen total del planeta.

El estudio físico-químico del SS nos permite obtener datos sobre las características del disco primordial y modelarlo, y en particular nos permite estimar la masa mínima de la nebulosa solar a partir de la masa total de planetas, planetas enanos y cuerpos menores. El $90 \%$ de la masa de los planetas interiores está compuesta por $\mathrm{O}, \mathrm{Mg}$, Si y Fe. Incluso, Júpiter y Saturno, dos gigantes compuestos fundamentalmente por $\mathrm{H}$ y He, están enriquecidos con elementos más pesados que los que están presentes en el Sol. Cuando se agregan el H y el He desaparecidos durante la acreción, se obtiene una masa mínima para la nebulosa solar del orden del $1-2 \%$ de la masa solar, aunque dicho valor es incierto principalmente porque desconocemos la masa total de la región transneptuniana (TNR) y la verdadera composición interna de los planetas gigantes. Cabe señalar que los modelos teóricos actuales que tratan de reproducir la evolución de los sistemas planetarios nos muestran que la formación de planetas es un proceso muy ineficiente en el cual se pierde mucha masa, donde una parte de ésta cae al Sol y la otra es eyectada al ISM. Así, varios trabajos nos hablan de distintos mecanismos de pérdidas de masa en procesos de evolución planetaria, o al menos de cierta redistribución que la haría hoy inobservable (por ejemplo, Lin et al., 1996; Tanaka et al., 2002; Fogg y Nelson, 2007). Ello nos lleva a conjeturar que incluso esa cifra de masa inicial puede incrementarse hasta llegar al $10 \%$ de la masa solar si gran parte de la misma se perdió o no la estamos detectando hoy en día. Kenyon et al. (2008) afirman que para un disco con un radio exterior de $100 U A$ la masa mínima de la nebulosa solar debió ser de $\sim 0.03 M_{\odot}$, valor que está por debajo del estimado para discos circumestelares observados en estrellas jóvenes en las cercanías 
de las regiones de formación (Andrews et al., 2010).

El modelo estándar de disco protoplanetario se basa en un conjunto de leyes muy simples en función de la distancia heliocéntrica $R$-coordenada radial en el plano medio del disco-, que modelan la variación de la densidad de la temperatura $T$, la densidad $\rho$ y la variación de la densidad superficial $\Sigma: T=T_{0}\left(R / R_{0}\right)^{-m} ; \rho=\rho_{0}\left(R / R_{0}\right)^{-n} ; \Sigma=\Sigma_{0}\left(R / R_{0}\right)^{-l}$. El índice $m$ es ajustado en general entre 1 y 2 . Por otro lado, si se esparce idealmente la masa de los planetas en el disco protoplanetario y se hacen consideraciones sobre el $\mathrm{H}$, el $\mathrm{He}$ y los hielos hoy ausentes principalmente en la región de los planetas terrestres, puede estimarse $l \simeq 1.5$ (Weidenschilling, 1977b). Respecto al índice de la ley que modela la densidad, para una nebulosa en equilibrio radiativo será $n=0.5$, pero éste es un límite inferior debido a la opacidad del material nebular, con lo que puede conjeturarse con adoptar $n=1$ (Goldreich y Ward, 1973), lo que dará lugar a una gama de temperaturas dentro de la región planetaria consistente con la condensación de diferentes sustancias de importancia cosmogónica a diferentes distancias heliocéntricas. Finalmente, a partir de la ecuación de los gases ideales $p=\rho k T / \bar{\mu} m_{H}$, donde $\bar{\mu}$ es el peso molecular medio, puede derivarse la presión: $p=p_{0}\left(R / R_{0}\right)^{-q}$, donde $q=m+n$ (Fernández, 2005).

Estudiando el proceso de acreción del SS, Fernández e Ip (1984) encuentran que como producto del desequilibrado intercambio de momento angular entre los protoplanetas y los planetesimales, Saturno, Urano y Neptuno expanden sus órbitas mientras que Júpiter contrae la suya (Figura 1.3.2). 


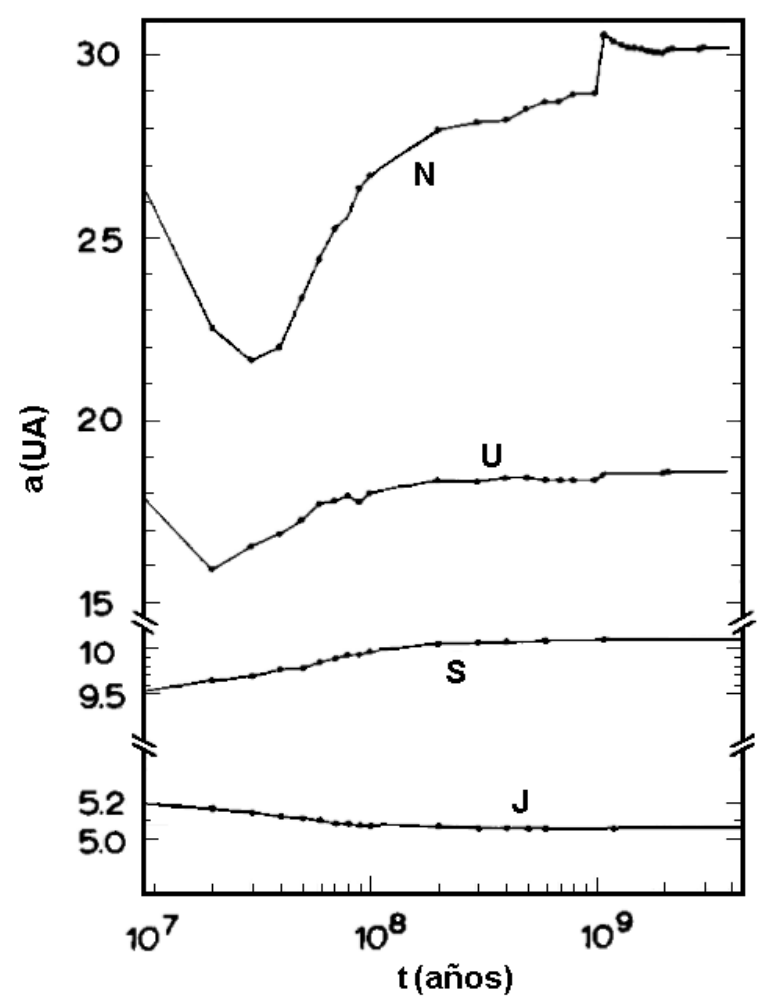

Figura 1.3.2. Variación temporal de los semiejes de los cuatro planetas jovianos como resultado del intercambio de momento angular con los planetesimales. Notar los incrementos en los casos de Saturno, Urano y Neptuno y el decrecimiento en el caso de Júpiter (Adaptado de Fernández e Ip, 1984).

Estos autores estudiaron numéricamente la etapa final de los procesos de acreción de Urano y Neptuno y si bien en el estado inicial de sus simulaciones asumen que tanto Júpiter como Saturno ya han alcanzado sus tamaños actuales, consideran que Urano y Neptuno sólo poseen un 0.2 de sus masas actuales. Así, al estudiar la variación orbital de los cuatro planetas gigantes debido al intercambio de momento angular con los planetesimales, encuentran importantes migraciones radiales principalmente para Urano y Neptuno durante sus procesos de acreción. Como consecuencia de este mecanismo de intercambio de momentos, Neptuno, Urano y Saturno ganan momento angular orbital y son desplazados hacia el exterior, mientras que Júpiter, como principal eyector de planetesimales, pierde momento angular, lo que lo lleva a migrar hacia el interior. Años después, varios autores corroboran esas migraciones (por ejemplo, Hahn y Malhotra (1999); Tsiganis et al., 2005; etc.).

El escenario de mayor aceptación actual -con sus objeciones- sobre el origen y la posterior evolución del SS se explica con lo que se conoce como el Modelo de Niza, que propone que la migración planetaria de los cuatro gigantes gaseosos se produjo a partir de una configuración inicial más compacta que la actual y que el cambio de dicha configuración se habría producido mucho después de la disipación del disco protoplanetario de gas. El núcleo original de este modelo tiene su base en tres artículos publicados en 2005 (Tsiganis et al., 2005; Gomes et al., 2005a y Morbidelli et al., 2005), y si bien siempre se hace referencia a esas tres publicaciones, 
el modelo se ha ido nutriendo de otros trabajos: Sheppard y Trujillo (2006) sugieren que la formación y la posible captura de Troyanos de Neptuno sería probablemente independiente del proceso de formación planetaria, y un mecanismo que lo explicaría es el propuesto por el modelo en Morbidelli et al., 2005; y las capturas de muchos de los satélites irregulares de los planetas externos, en Nesvorný et al. (2007). La migración planetaria de los gigantes gaseosos que propone este modelo es sustancialmente diferente a la de los modelos de migración fluida y de bajas excentricidades e inclinaciones propuestos anteriormente por Malhotra (1995), Gomes (2003) y Levison y Morbidelli (2003).

En las tres publicaciones originales del Modelo de Niza los autores proponían que, después de la disipación del gas y del polvo del disco primordial, los cuatro planetas gigantes se hallaban en órbitas casi circulares y coplanares entre $\sim 5.5 U A$ y $\sim 17 U A$, es decir, aproximadamente entre las actuales órbitas de Júpiter y Urano. La configuración espacial de los planetas gaseosos en ese entonces era, pues, mucho más compacta que la que poseen hoy en día y si bien la separación orbital original se discute en varios trabajos previos (Hahn y Malhotra, 1999; Gomes, 2003), es posible que Neptuno haya estado originalmente entre $15 \mathrm{UA}$ y $20 U A$ del Sol (Gomes, 2003; Tsiganis et al., 2005).

A partir de las ideas sobre la formación planetaria sabemos que en cierto momento inicial debió haber en el Sistema Solar Exterior (SSE) un disco de planetesimales que se extendió desde la región planetaria hasta el límite interno actual del cinturón transneptuniano (TNb), aproximadamente desde la órbita inicial de Neptuno hasta $\sim 35 U A$. Las distancias relativas entre planetesimales en tan vasta región dificultó enormemente los procesos de acreción, los que fueron lentos e ineficientes a la hora de permitir la formación de un planeta y de esta manera la nebulosa solar a esas distancias terminó por disiparse aún más, restándole al cinturón inicial densidad suficiente como para consolidarse en un cuerpo de dimensiones planetarias. Pero esa inmensa cantidad de planetesimales dispersados más allá de los planetas gigantes formaron una masa crítica que fue capaz de generar migraciones planetarias por intercambio de energía y momento angular entre ambos grupos, con consecuencias decisivas en el posterior desarrollo del SS. Una de ellas fue que luego de $5-6 \times 10^{8}$ años de formado el SS, Júpiter y Saturno entraron en Resonancia de Movimientos Medios (MMR) 2:1 (el modelo habla de un cruce resonante) provocando una gran inestabilidad gravitatoria en todo el sistema. El resultado de esa configuración se aprecia claramente en la Figura 1.3.3, donde puede observarse que luego de acontecido el hecho, Neptuno es perturbado fuertemente migrando hacia afuera al punto tal de, en muchas simulaciones, invertir con Urano el orden original de sus órbitas. 


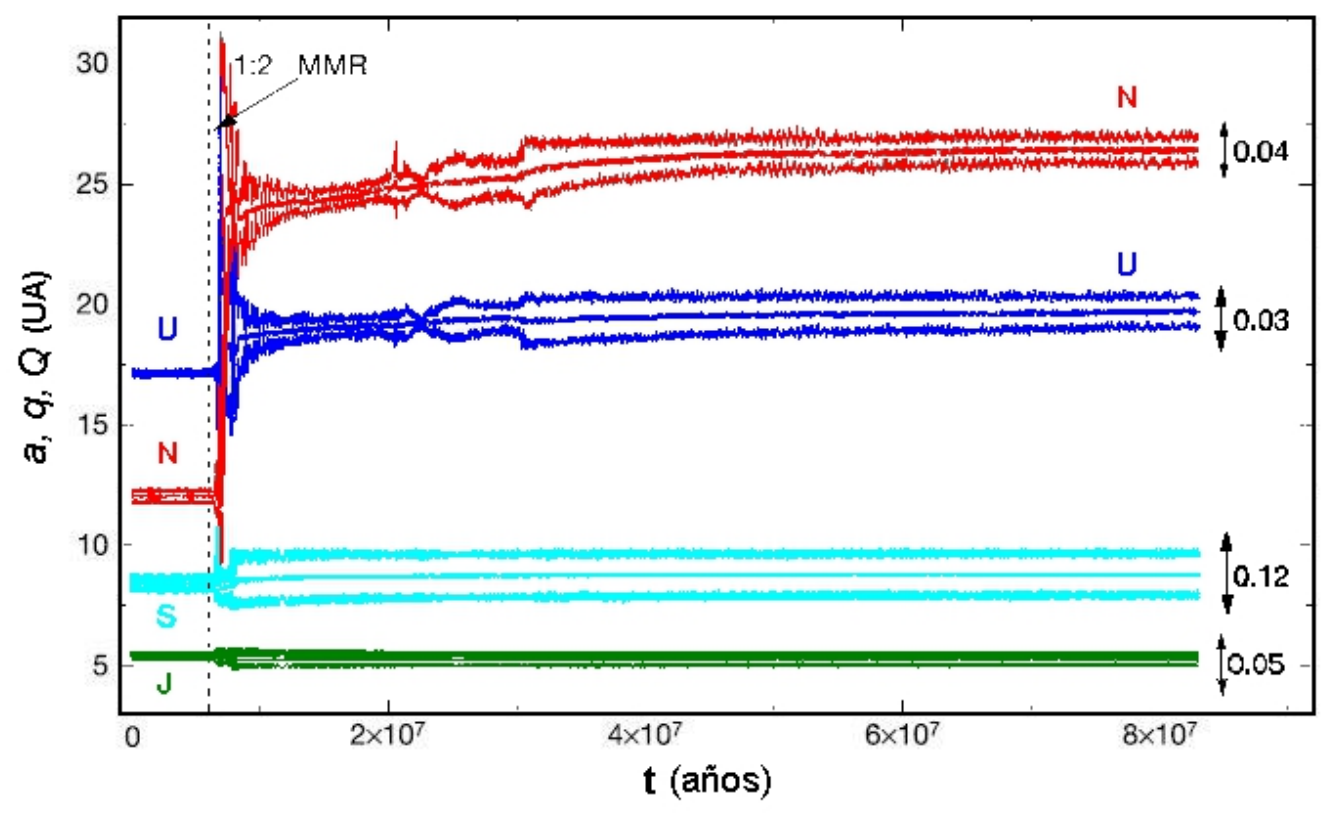

Figura 1.3.3. Simulación realizada con el Modelo de Niza: Evolución orbital de los gigantes gaseosos. Notar la inestabilidad que se genera luego que Júpiter y Saturno sufren el cruce resonante y cómo Neptuno y Urano invierten el orden de sus órbitas (Adaptado de Tsiganis et al., 2005).

De esta forma, con el acercamiento de Neptuno a la TNR interactuando dramáticamente con el denso TNb, la mayoría de los planetesimales fueron inyectados hacia el interior de su órbita hasta que muchos de ellos terminaron dominados por Júpiter, cuya gravedad obligó a gran parte de los mismos a ingresar al Sistema Solar Interior (SSI), ocasionando el Bombardeo Intenso Tardío (LHB) y causando así la mayoría de los cráteres que aún hoy observamos casi intactos en cuerpos como la Luna o Mercurio, dada la falta de erosión en los mismos. Incluso algunos de esos planetesimales encontraron una posición estable en el MBA o en la región de los Hildas y muchos otros fueron impulsados a los límites exteriores del SS o directamente eyectados del sistema. Este hecho explicaría la baja masa actual de las poblaciones más allá de Neptuno, lo que justificaría la existencia de muy pocos cuerpos tan masivos como (134340) Plutón, dado que para haberse formado por acreción se hubiera necesitado de mucha más masa de la que existiría actualmente en todo el TNb. Según esta idea, la Nube de Oort (OC) -que recibe su nombre en honor Jan Oort (1900-1992) quien postuló su existencia (Oort, 1950)-, estaría compuesta por esos cuerpos que fueron eyectados hacia el exterior, principalmente durante el proceso de formación de los gigantes gaseosos. Finalmente el Modelo de Niza propone que posteriormente, la fricción con el disco de planetesimales hizo que las órbitas de Urano y Neptuno se circularizaran.

En contraste con los planetas exteriores, no hay evidencia de que los planetas terrestres hayan tenido una significativa historia de migraciones.

Cuando cesó la migración planetaria, vio la luz una nueva población de objetos perturbados y dispersados por Neptuno a la que se llamó Disco Disperso (SD), formada a partir del remanente de una población original mucho más numerosa (Duncan y Levison, 1997). 
Emery y Brown (2004) sostienen que los asteroides Troyanos de Júpiter presentarían superficies pobres en agua y compuestos orgánicos, y Morbidelli et al. (2005) afirman que el Modelo de Niza podría explicar éste hecho notando que en sus simulaciones dichos objetos, antes de ser capturados en la región de Troyanos, experimentan una fase de altas excentricidades que los acercan al Sol hasta unas $2 U A$ y dado que a un cometa activo típico, miembro de los JFC, le lleva unos $10^{4}$ años perder toda actividad (Levison y Duncan, 1997), es posible que las superficies de los Troyanos de Júpiter pudieran haberse volatilizado durante dicha fase. Por otro lado, el modelo muestra que las capturas de las partículas en las regiones coorbitales con Júpiter que se produce en las simulaciones inmediatamente después del cruce de Saturno por la MMR 2:1 con Júpiter, tienen una distribución orbital notablemente similar a la de los Troyanos observados, e incluso la eficiencia de captura mostrada por el modelo explicaría el número total de éstos. Por todo ello, Morbidelli et al. (2005) no vacilan en sostener que los Troyanos de Júpiter son una evidencia observacional de dicho cruce de resonancia.

Las estimaciones de la masa del disco primordial de planetesimales van desde $50 M_{\oplus}$ (Hahn y Malhotra, 1999) hasta las $30 M_{\oplus}$, que es la predicha por los tres trabajos del Modelo de Niza y está basada en la dinámica de la migración de los planetas gaseosos en un disco truncado que los termina ubicando en sus posiciones actuales.

Trabajos con simulaciones numéricas del proceso de migración durante un tiempo similar a la edad del SS dan como resultado un disco actual remanente, el mencionado SD, de un $0.2-0.4 \%$ de la masa original del disco $\left(0.07-0.14 M_{\oplus}\right)$ (Gomes, 2003; Gomes et al., 2005b), mientras que por otro lado la simulación del Modelo de Niza que explicaría el origen del LHB da una masa total actual para la TNR de $0.14 M_{\oplus}$ (Gomes et al., 2008). Los valores extremos que figuran en la literatura son $0.01 M_{\oplus}$ (Bernstein et al., 2004) y $0.1 M_{\oplus}$ (Gladman et al., 2001). Por otra parte, Gomes et al. (2008) estiman que la masa del SD sería de $0.08 M_{\oplus}$. Teniendo en cuenta que el modelo supone una masa total inicial de planetesimales de $35 M_{\oplus}$, esos valores nos dicen que sólo un $0.4 \%$ de la masa inicial total del disco terminó finalmente en la TNR. El $0.23 \%$ de la masa inicial conformaría actualmente el SD, valor que concuerda con las estimaciones observacionales de la masa actual de dicho disco, y ese hecho avalaría un origen del mismo por interacción de un disco primordial de planetesimales interactuando con un Neptuno migrando al exterior.

En la Figura 1.3.4 se muestran los resultados de una integración de la evolución del SS según el Modelo de Niza adaptada del trabajo de Gomes et al. (2005a). 

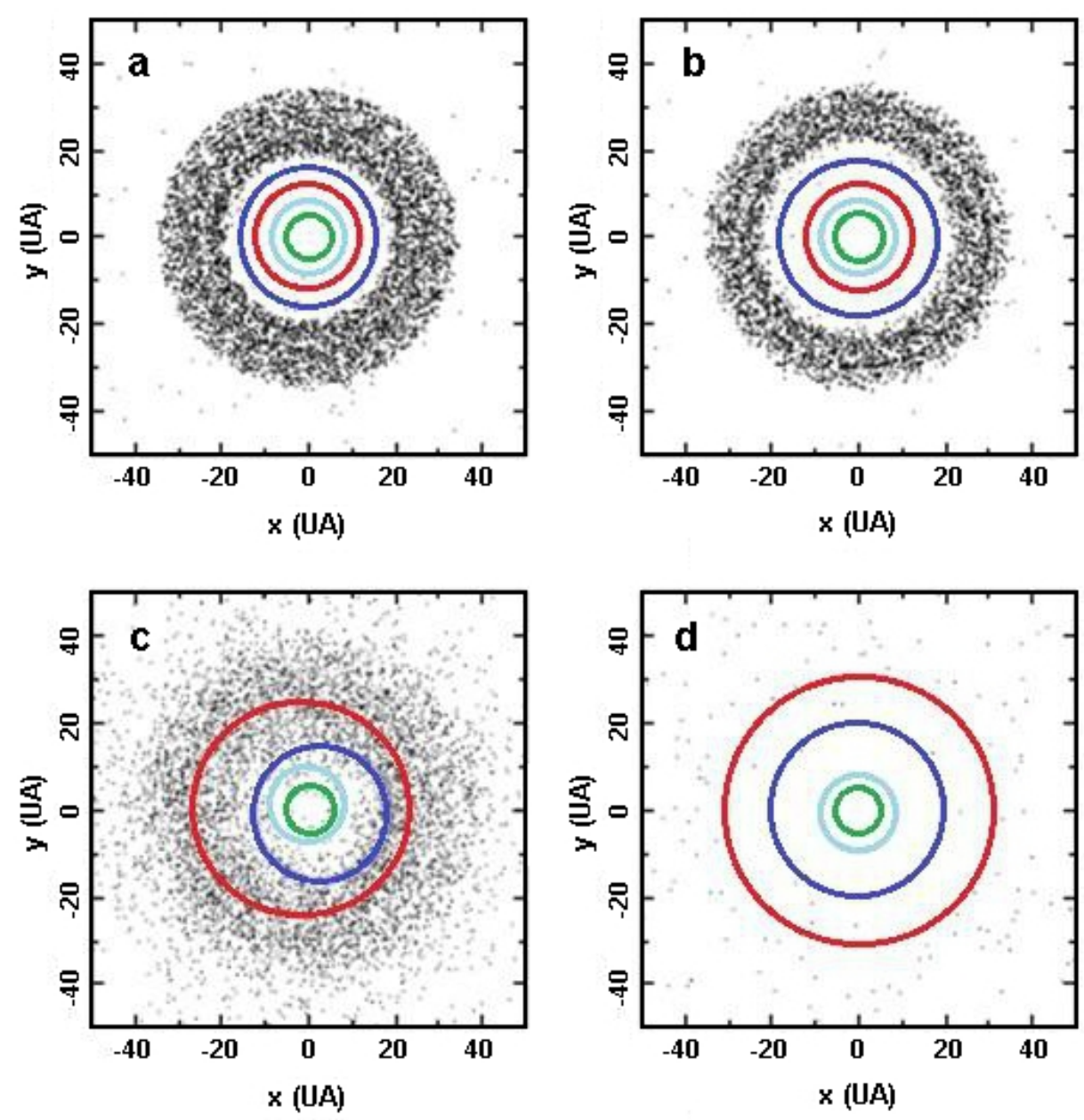

Figura 1.3.4. Etapas en la evolución del SS según el Modelo de Niza: (a): Momento cercano al principio del SS, luego de la disipación del gas. Las órbitas de los planetas gigantes (círculos concéntricos) son cuasi-circulares y coplanares y están muy cerca entre sí, rodeados por un disco de planetesimales (verde=Júpiter, celeste=Saturno, rojo=Urano, azul=Neptuno); (b): Momentos antes de la gran inestabilidad. Saturno está a punto de cruzar la resonancia 2:1 con Júpiter; (c): Momento de la inestabilidad. Notar que las órbitas de los planetas han aumentado sus excentricidades, haciendo que los planetas invadan el disco; (d): Después de la inestabilidad: Los planetas se han estabilizado en órbitas muy similares a las actuales en términos de separación, excentricidad e inclinación. El disco masivo de planetesimales ha sido destruido y sólo una pequeña fracción permanecen en el sistema en órbitas típicas de objetos del actual TNb (Adaptado de Gomes et al., 2005a).

Un test que se le puede hacer al modelo es estudiar si la distribución orbital de los objetos observados del SD, concuerda con aquella que predice. Prestando atención al gráfico de la Figura 1.3.5, vemos que si se comparan las distribuciones de las distancias perihélicas $q$ y de las inclinaciones $i$ de los objetos del SD observados y las mismas distribuciones obtenidas por integración numérica, se encuentra que ambas muestras ocupan aproximadamente el mismo espacio de elementos orbitales en el plano $(q \times i)$. Una diferencia que podría señalarse es que hay más inclinaciones bajas entre los SDOs reales que en los clones del modelo, pero 
ello puede deberse a un sesgo observacional. El objeto (90377) Sedna representado por un punto aislado, sería una excepción, lo que hablaría de un origen diferente.

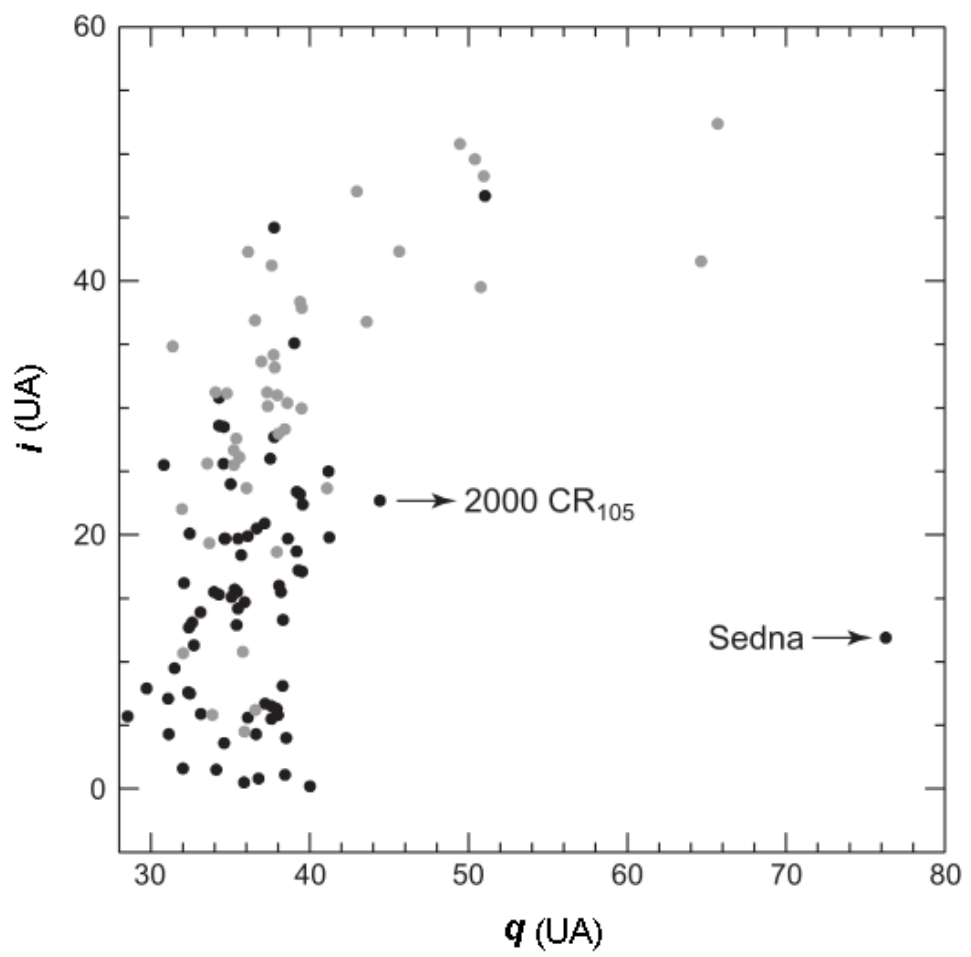

Figura 1.3.5. Comparación en el plano $(q \times i)$ entre SDOs reales (puntos negros) y clones (puntos grises) luego de haber integrado numéricamente a lo largo de la edad del SS (Adaptado de Gomes et al., 2008).

En el trabajo de Morbidelli et al. (2008) los autores hacen una interesante comparación (Figura 1.3.6) entre los resultados numéricos que obtienen Levison et al. (2008) en una de sus simulaciones durante $10^{9}$ años posterior a la inestabilidad y aplicando el Modelo de Niza (panel de la izquierda), y datos observacionales (panel de la derecha). Las líneas verticales indican la ubicación de las principales resonancias con Neptuno. La línea curvada de puntos marca la posición de los objetos con $q=30 U A$, mientras que la curva discontinua delimita la región a partir de la cual pueden ser estables objetos con altas inclinaciones u objetos resonantes a lo largo de la edad del SS. Podemos ver que la población de objetos con órbitas cuasi-circulares que llegan hasta las $45 U A$ y que poseen bajas inclinaciones, es consistente con las observaciones; como así también el déficit de objetos de excentricidades bajas en el anillo $45-48 U A$. También se observa un acuerdo en cuanto al límite exterior del Cinturón Transneptuniano Clásico (CTNb), que se ubica al final de la MMR 2:1 con Neptuno y que en breve se definirá con propiedad. Por último, si nos detenemos en los objetos con perihelios entre la MMR 3:2 con Neptuno y las $40 U$ A, notablemente el modelo reproduce una población que hoy conocemos como el Disco Desprendido Extendido (EDD) y que en un primer momento fue llamado Disco Disperso Extendido o Disco Disperso Fosilizado. Sin embargo, hay cuestiones que no se ajustan a las observaciones: en primer término queda en evidencia que en la simulación todas las MMR con Neptuno están superpobladas en relación a lo observado, 
hecho que es particularmente notorio en la MMR 2:1. También es notoria la alta densidad de puntos que se observa en la simulación en aquella región por encima de la curva discontinua que marca el límite de objetos estables. Por último, el modelo arroja para la población con $q>37 U A$ y que habita la región $42 U A<a<48 U A$, una excentricidad promedio $\bar{e} \sim 0.1$, mientras que los objetos observados en esos límites, rara vez superan $\bar{e} \sim 0.07$.
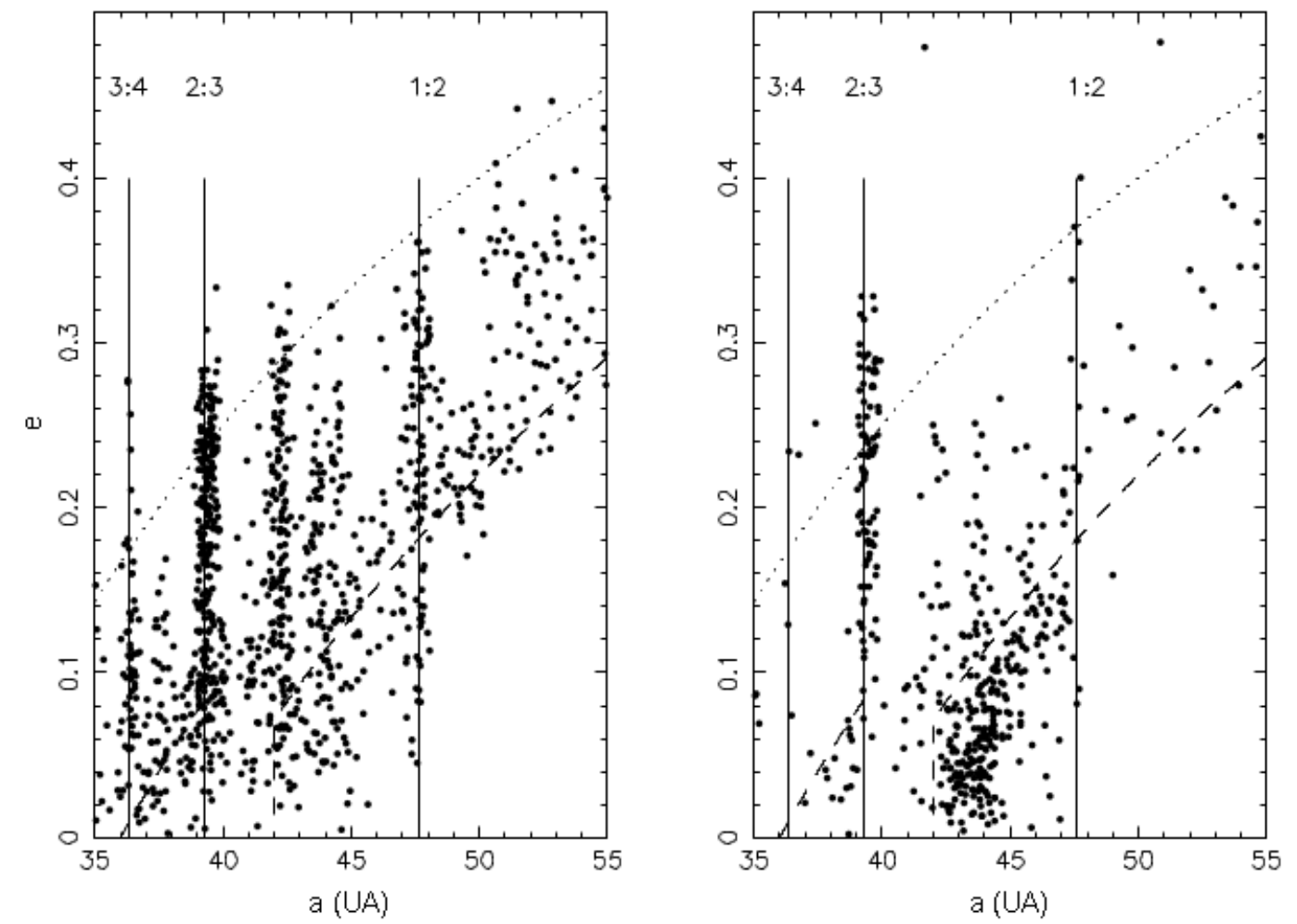

Figura 1.3.6. Distribución de semiejes y excentricidades en el TNb. A la izquierda, resultado del Modelo de Niza. A la derecha, los datos observacionales (Adaptado de Levison et al., 2008).

Parece claro que las predicciones del Modelo de Niza están aceptablemente de acuerdo con las observaciones: reproduce la arquitectura orbital de los planetas gigantes; explica la captura de los Troyanos de Júpiter y de Neptuno y la aparente carencia de agua y componentes orgánicos en las superficies de los primeros; y reproduce cuantitativamente la mayoría de las principales características que asocian el LHB con los planetas terrestres. Sin perjuicio de todo ello, hay que mencionar que posiblemente debido a ciertas simplificaciones hechas en las integraciones numéricas, no logra reproducir simultáneamente las altas inclinaciones observadas en TNOs y la aparición de una población dinámicamente fría (bajas inclinaciones). 


\subsection{El Espacio Transneptuniano}

Los posibles destinos de los objetos residuales de la formación planetaria conforman distintos escenarios. Claramente algunos cuerpos terminaron en el Sol en inmersiones directas o sublimándose por completo antes de llegar a él; otros fueron eyectados al espacio exterior y ese fue material que se perdió, y si éste es un hecho común en gran parte de las estrellas que desarrollan un sistema planetario, tenemos que presumir que hay una gran cantidad de objetos interestelares productos de la formación de cada sistema. Por último, un tercer destino posible fue el de aquellos que adquirieron órbitas ligadas y estables, que los llevaron más allá de la órbita de Neptuno.

Uno de los motivos que hace interesante el estudio de estos objetos radica principalmente en que podrían ser los remanentes fósiles más primitivos y mejor conservados de la formación del SS (Peixinho et al., 2012), representando así una oportunidad única para estudiar la historia de la nebulosa solar (Barucci et al., 2005), con órbitas que nos proveen información sobre el proceso de evolución orbital del SSE (Lykawka y Mukai, 2007).

\subsubsection{Breve historia de la Región Transneptuniana}

Uno de los primeros científicos en proponer la existencia de un TNO fue el físico francés Jacques Babinet (1794-1872). En efecto, en 1848 objetó los cálculos que dos años antes le habían permitido a Urbain Jean Joseph Le Verrier (1811-1877) predecir la existencia de Neptuno, hecho confirmado por el descubrimiento mismo del planeta que hoy comparte con John Couch Adams (1819-1892) quien independientemente realizó los mismos cálculos, y con Johann Galle (1812-1910) quien finalmente lo localizó. En base a ciertos residuos que dejaban los cálculos de Le Verrier, Babinet postuló que otro planeta de aproximadamente $12 M_{\oplus}$ tenía que existir más allá de Neptuno. Le Verrier defendió sus cálculos atacando ácidamente la hipótesis de Babinet al decir: "No hay absolutamente nada por lo cual se podría determinar la posición de otro planeta, salvo una hipótesis en la que la imaginación juega un papel muy grande" (Grosser, 1964). En 1908, el astrónomo norteamericano William Henry Pickering (1858-1938) vuelve a sugerir la existencia de un planeta transneptuniano, esta vez asignándole una masa dos veces la de la Tierra. Por su parte, el millonario bostoniano Percival Lowell (1855-1916) a instancias del cual W. Pickering instaló el primer telescopio del Flagstaff Observatory -donde luego se descubriría (134340) Plutón, primer TNO-, buscó sin éxito lo que él mismo denominó el planeta X entre 1905 y 1916, año de su muerte.

En 1929 Clyde Tombaugh (1906-1997) comenzó la búsqueda de un planeta más allá de Neptuno, la que el 18 de febrero de 1930 lo llevó al descubrimiento de (134340) Plutón. El método de búsqueda que utilizó Tombaugh se denomina blinking ( to blink = parpadear, destellar) o sencillamente comparación rápida de imágenes, el cual consiste básicamente en alternar rápidamente dos o más imágenes previamente alineadas y tratar de detectar objetos que cambian de posición de una imagen a la otra, delatando su presencia. Tombaugh continuó a lo largo de 13 años la búsqueda de otros TNOs llegando a cubrir un área total de $1530 \mathrm{grados}^{2}$, pero sin obtener ningún éxito, en el primer programa de búsqueda sistemático de esta población.

Inmediatamente después del descubrimiento de (134340) Plutón, en agosto de 1930 Fred- 
erick Charles Leonard (1896-1960) planteó que quizá el nuevo objeto no sea más que uno de tantos miembro de una familia de objetos ultra-Neptunianos u objetos ultra-Plutonianos utiliza ambos términos-, aún por descubrir (Leonard, 1930).

Pocos años después surgieron varios astrónomos que reflotaron la Teoría Nebular sobre el origen del SS que había sido formulada inicialmente por el filósofo y matemático francés René Descartes (1596-1650), y de manera independiente años después por el científico sueco Emanuel Swedenborg (1688-1772) (Swedenborg, 1734). Tanto uno como el otro esbozan sus ideas en forma muy general y quienes le dan verdadera consistencia y sustento científico son el filósofo y geógrafo alemán de la Ilustración Immanuel Kant (1724-1804), y posteriormente, Pierre-Simon Marqués de Laplace (1749-1827).

Por una parte, Kant desarrolla sus ideas sobre la formación del SS en su publicación (anónima) Allgemeine Naturgeschichte und Theorie des Himmels oder Versuch von der Verfassung und dem mechanischen Ursprunge des ganzen Weltgebäudes nach Newtonischen Grundsätzen abgehandelt ("Historia general de la naturaleza y teoría del cielo, o ensayo sobre la constitución y el origen mecánico de todo el edificio del mundo, tratado según principios newtonianos") (Kant, 1755). Como se desprende del título, la obra no era un conjunto de especulaciones filosóficas o metafísicas, sino que se basaba en los conceptos más avanzados y rigurosos que se tenía en la época sobre la Mecánica Celeste. Lo que se conocería finalmente como Teoría Nebular la desarrolla en el Capítulo 1 de la Segunda Parte. Según sus ideas, la formación de planetas podría entenderse como una consecuencia de la acumulación o condensación de numerosos cuerpos más pequeños en un disco protoplanetario que se extendió mucho más allá de las órbitas de los planetas conocidos.

El concepto equivalente que hoy tenemos sobre la nebulosa solar es el de disco protoplanertario de acreción. Tales discos o nebulosas protoplanetarias, como vimos, han podido ser observados alrededor de estrellas muy jóvenes, e inclusive recientemente con un detalle que sorprende por la corroboración de todas estas ideas formuladas desde la más pura teoría hace $\sim 260$ años, en un verdadero triunfo del positivismo (Figura 1.4.1).

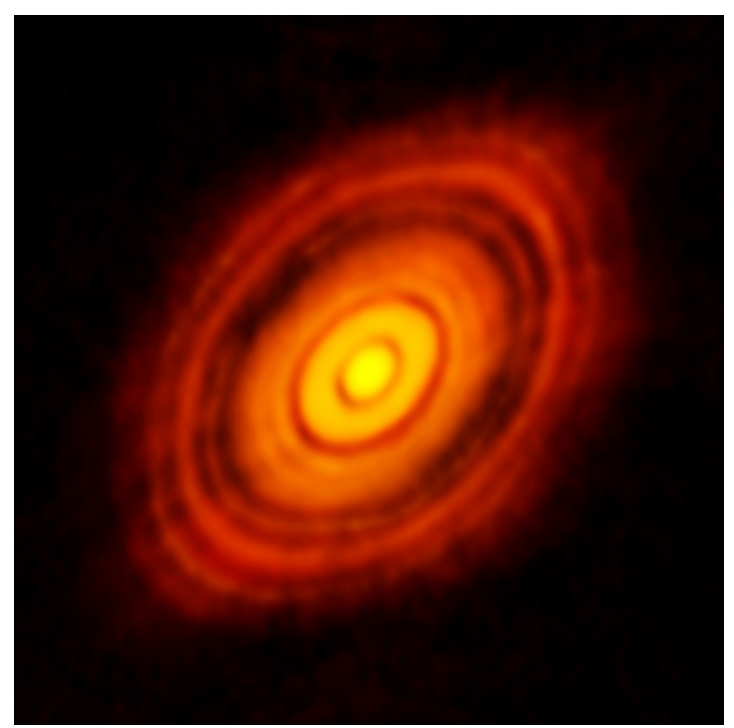

Figura 1.4.1. Disco protoplanetario rodeando LH Tau (ALMA/ESO/NAOJ/NRAO). 
Por su parte, 41 años después Laplace formuló de forma totalmente independiente una teoría más detallada, pero que en realidad no hacía aportes conceptuales muy diferentes a los presentados por Kant. La obra de Laplace en cuestión era "Exposition du système du monde". Una diferencia fundamental con Kant es que éste -en primer lugar por convicción y en segundo persuadido de que sus ideas serían duramente criticadas por el clericalismo imperante-, atribuyó a Dios la causa de la existencia primera de la nebulosa, mientras que Laplace juzgó innecesaria una intervención divina en las causas de origen ("Je n'avais pas besoin de cette hypothèse" -"Yo no necesité de esa hipótesis"-) (de una conversación con Bonaparte; De Morgan, 1872; Ball, 1888). Así, Laplace solamente se limita a dar una explicación estrictamente natural del funcionamiento de su "Sistema del Mundo", basando su modelo en cinco fenómenos observables en el SS (Laplace, 1769):

1. Los movimientos de los planetas son todos en el mismo sentido y, aproximadamente, en el mismo plano;

2. Los movimientos de los satélites son en el mismo sentido que en el de los planetas.

3. Los movimientos de rotación de todos esos cuerpos y el Sol van en el mismo sentido que sus movimientos de proyección y en planos poco diferentes.

4. La poca excentricidad de las órbitas de los planetas y de los satélites.

5. La gran excentricidad de las órbitas de los cometas, aunque sus inclinaciones hayan sido abandonadas al azar.

Finalmente, en honor a ambos científicos, la Teoría Nebular hoy es conocida como Teoría o Hipótesis de Kant-Laplace.

Ya en tiempos modernos, uno de los astrónomos que reflotó las ideas de esta teoría fue el astrónomo aficionado, economista y militar irlandés, Kenneth Essex Edgeworth (1880-1972), quien presentó el primer marco cuantitativo para un TNb basado en principios cosmogónicos. Luego de una exitosa carrera militar se retiró a la vida civil y comenzó a desarrollar una serie de ideas originales que se basaban en esos viejos conceptos, y los fue volcando en un manuscrito que intituló simplemente "The Evolution of the Solar System". La obra ya estaba en 1938 en varias casas editoriales (por ejemplo, George Allen and Unwin Ltd., Methuen and Co. Ltd.) (McFarland, 2004) y también llegó a manos de varios astrónomos destacados de la época como Willem Jacob Luyten (1899-1994), quien elogió el enfoque de la obra al mismo Edgeworth en una comunicación personal (Luyten, 1938). Finalmente la obra nunca se publicó y actualmente se encuentra como manuscrito en la Trustees of the National Library of Ireland, en Dublin.

Su obra publicada (Edgeworth, 1943, 1949) parece haber sido la primera investigación cuantitativa sobre la posible existencia de un gran número de cometas potenciales en un anillo ecliptical más allá de las órbitas de Neptuno y (134340) Plutón. La idea central -y más originalsostenía que en dicha región marginal del SS la densidad del anillo sería muy baja como para formar grandes objetos dado que la acreción en cuerpos individuales disminuiría rápidamente al aumentar la distancia heliocéntrica (Bailey, 1994). De esta manera, Edgeworth calculó que a grandes distancias los procesos de condensación producirían un sistema que comprendería un gran número de relativamente pequeños heaps of gravel (sic) (pila o montón de grava) que sobrevivirían hasta nuestros días. En su opinión, si estos cuerpos se observaran de cerca se 
mostrarían como grumos parcialmente condensados formados por un pequeño núcleo con un disco rodeándolos, similar a lo que ocurre con Saturno. Afirmaba también que si sus órbitas fueran perturbadas, muchos podrían precipitarse al Sol haciéndose visibles como cometas (Edgeworth, 1961).

En su manuscrito inédito también estimó órdenes de magnitud sobre la cantidad y tamaño de los cometas más allá de Neptuno, notando que eran más numerosos y más pequeños que la mayoría que los cuerpos que se observaban en el MBA. Estos cometas, sostenía, estarían distribuidos en una región entre $65 U A$ y algo más allá de las $260 U A$, y su cantidad era suficiente como para dar cuenta del flujo de cometas observado. A partir de sus cálculos, Edgeworth concluyó que Neptuno representa el caso límite para la formación de un gran planeta en el SSE: a menos que en su disco transneptuniano hubiera considerablemente más masa que la que él estimaba razonable, sería imposible formar un solo gran planeta transneptuniano. En sus trabajos alterna el estatus de (134340) Plutón entre el de un planeta y el de un satélite escapado de Neptuno. Justamente sobre (134340) Plutón escribió: "[Plutón], es demasiado pequeño para ser clasificado como un planeta mayor a pesar de su posición; se ha sugerido que es un satélite escapado de Neptuno y vamos a encontrar, en su debido momento, que hay buenas razones para colocarlo en esa categoría" (Edgeworth, 1938). Con esta observación, presumiblemente se estaba refiriendo a la publicación de Lyttleton (1936) donde se presenta un posible origen de (134340) Plutón (Davies et al., 2008). Sin embargo, en un libro que publica años después, lo lista entre los planetas (Edgeworth, 1961).

En su trabajo de 1949, Edgeworth analiza las ideas y teorías existentes sobre la formación y evolución del SS. Así, vemos que en el mismo: (1) toma la idea de Laplace sobre que el material que formó los planetas y satélites existió en forma de un fluido inmenso y que el único mecanismo capaz de crear la regularidad, es la fricción fluida; (2) sostiene que no parece razonable que el disco rotante original tenga un corte abrupto a partir de la órbita de Neptuno y que, por lo tanto, debería darse un decrecimiento paulatino; (3) menciona que no hay evidencia de la opacidad del material y que, en todo caso, fue insuficiente como para formar planetas; (4) sugiere que es razonable suponer que esta región esté ahora ocupada por grandes cantidades de pequeños cuerpos, constituyendo un vasto reservorio de potenciales cometas; y (5) especula que cuando uno de estos cuerpos es desplazado de su lugar, entra en las regiones más internas del SS y se convierte en un cometa visible.

Pese a todo, dada su posición de astrónomo aficionado es difícil saber hasta qué punto su análisis cuantitativo influyó en astrónomos profesionales. Sin embargo, está claro que tenía un conocimiento firme de la situación y una interesante variedad de puntos de vista independientes, al punto que varios autores han argumentado que debe dársele un mayor crédito por sus aportes (por ejemplo, Brück, 1996; McFarland, 1996, 2004; Green, 1999, 2004).

La siguiente contribución importante al estudio del origen de la TNR vino de la mano del astrónomo germano-americano Gerard P. Kuiper (1905-1973) con un trabajo aparecido en 1951 (Kuiper, 1951a). A pesar que luego Kuiper (1951b) afirmara que dicho trabajo ya había sido presentado para su publicación en noviembre de 1949 manifestando que había circulado en forma limitada en febrero de 1950, había incluido en él discusiones sobre trabajos que se publicaron con posterioridad a 1949, como los trabajos del astrónomo holandés Jan Oort (1950) y del astrónomo americano Fred Whipple (1906-2004) (1950a, 1950b) -efectivamente publicados ambos en el primer trimestre de 1950-. En su sección titulada "Comets and Un- 
known Planets", Kuiper hipotetizaba sobre un cinturón de material nebular más allá de Neptuno y que se extendía hasta la distancia del afelio de (134340) Plutón $(Q \sim 38-50 U A)$. En su segundo trabajo de ese año (Kuiper, 1951b), afirmaba que la temperatura de dicha región relativamente estable, debió estar entre $5-10 \mathrm{~K}$ antes que se disipara la nebulosa y que terminaran de formarse los planetas gigantes, para posteriormente llegar a unos $40 \mathrm{~K}$. En dicho contexto, sostenía que como a esas bajas temperaturas condensan, por ejemplo, vapores de agua, metano y amoníaco, debieron formarse copos de nieve que lentamente se fueron reagrupando entre si y que ese proceso debió continuar incluso mucho tiempo después de la disipación total de la nebulosa solar, por lo que al cabo de unos $10^{9}$ años se llegaron a formar objetos con diámetros medios del orden del kilómetro y diámetros extremos dos órdenes de magnitud mayor. En sus conclusiones reconoce la influencia de la mencionada publicación de Oort (1950), pero discrepa con éste sobre la fuente de los cometas que no provienen de la OC, y que Oort ubica entre Marte y Júpiter. Efectivamente, Kuiper propone la fuente de cometas de corto período en su cinturón, fundando su idea en que los cometas debieron formarse en regiones con temperaturas muy por debajo de las temperaturas reinantes en el MBA.

Años después Kuiper, en la Parte III de un artículo dividido en tres publicaciones, reafirma estas ideas con mayor profundidad (Kuiper, 1956) y concluye que el cinturón debe poseer una masa de $\sim 5 \times 10^{27} \mathrm{~g}$, afirmando que ello era compatible con la masa de $10^{27} \mathrm{~g}$ que Oort (1950) había calculado para su gigantesco reservorio esferoidal de $10^{11}$ cometas. También afirma que fue (134340) Plutón quien comenzó a dispersar gravitatoriamente a estos objetos y que luego las perturbaciones más fuertes de Neptuno y los otros planetas gigantes, los dispersaron aún más. Así, una cierta fracción de los cometas es expulsada hacia la OC donde las perturbaciones estelares redistribuyen los elementos orbitales, haciendo que el movimiento alrededor del Sol tenga orientaciones al azar. Hoy hay consenso en creer que esta hipotética nube poseería una estructura dual, formada por una nube exterior de simetría esférica y una nube interior de estructura toroidal asentada en el plano ecliptical.

Davies et al. (2008) creen identificar en el trabajo de Kuiper ideas que resuenan a trabajos anteriores de Whipple, principalmente los relacionados con su exitoso modelo de núcleo cometario como bolsones de hielo amalgamados (Whipple, 1950a y 1950b). Años después, es el mismo Whipple (1964) quien postula la existencia de un anillo de material con una masa $\sim 10-20 M_{\oplus}$ ocupando el espacio entre $40-50 \mathrm{UA}$ suponiendo que el mismo era la causa de las aparentes irregularidades de la órbita de Neptuno, y justificó el hecho de que no existieran indicios observacionales de ello afirmando que aun con una masa de $100 M_{\oplus}$ su brillo superficial quedaría enmascarado por la luz zodiacal y reforzó su postura advirtiendo que un objeto a esas distancias con una magnitud aparente de $m=22(\sim 500 \mathrm{~km})$ sería indetectable con el instrumental de la época. Posteriormente se trató de determinar la masa de la TNR por otros medios, como por ejemplo analizando el movimiento del cometa $1 \mathrm{P} /$ Halley cuyo afelio yace cerca de Neptuno. También se intentó medir la radiación IR proveniente, tanto de una distribución de cometas como del polvo generado en las colisiones entre los objetos del supuesto cinturón, pero pronto se advirtió que la radiación térmica del polvo transneptuniano quedaría por debajo del nivel de ruido de la luz zodiacal. Pese a que Stern (1996a) afirma que el producto de dichas colisiones puede ser observado directamente por la detección de nubes de polvo con magnitud obtenida con el filtro $\mathrm{R}(R \mathrm{mag})$ con valores $R$ mag $\lesssim 15$ alrededor de TNOs, incluso en años recientes un programa de búsqueda con instrumental y métodos tan avanzados como el emprendido por Sheppard et al. (2000), no obtuvo ningún éxito al 
intentar detectar nubes colisionales en la TNR. Y si bien, como se mencionó, IRAS fue capaz de detectar discos de polvo circumestelares en estrellas cercanas, no pudo lograr observar un anillo de polvo en el disco transneptuniano.

Los trabajos de Edgeworth y de Kuiper permanecieron mucho tiempo en el olvido hasta que en 1980 el astrónomo uruguayo Julio Ángel Fernández propone la existencia de un cinturón transneptuniano como solución a la necesidad de una fuente cercana para los JFC, en un trabajo que hoy es considerado pionero dentro de las Ciencias Planetarias (Fernández, 1980). Luego de este trabajo, en una exitosa asociación Fernández comenzó a trabajar con el astrónomo chino Wing-Huen Ip con quien realizó una serie de trece publicaciones entre 1981 y 1997 sobre la evolución orbital de planetesimales en la zona de acreción planetaria exterior (Fernández e Ip, 1981, 1983a, 1983b, 1983c, 1983d, 1984, 1988, 1991a, 1991b, 1996a, 1996b, 1997a, 1997b).

Con la excepción de (134340) Plutón y su luna Caronte, la población transneptuniana permaneció como una especulación teórica por varias décadas y, aunque se realizaron numerosos programas de búsqueda de TNOs, todos los resultados fueron negativos. El panorama dio un giro reavivando las esperanzas de hallar prontamente nuevos TNOs, a partir de los esfuerzos del astrónomo estadounidense Charles Thomas Kowal (1940-2011) -descubridor de numerosos asteroides, satélites de Júpiter, cometas y supernovas-, quien entre 1976 y 1985 realizó una búsqueda sistemática de pequeños cuerpos distantes del SS. En efecto, analizando imágenes adquiridas dos semanas antes con el "Samuel Oschin Telescope" del Mount Palomar Observatory, una cámara Schmidt de $1.22 \mathrm{~m}$, su empeño se vio compensado el 18 de octubre de 1977, día en el que descubre un objeto excepcional de magnitud $m=19$ con un movimiento muy lento sobre el fondo del cielo. Al analizar su órbita, resultó ser un cuerpo aparentemente asteroidal situado entre las órbitas de Saturno y Urano, con su perihelio dentro de la órbita del primero, pero alejado de Júpiter. Una búsqueda en placas fotográficas antiguas puso de manifiesto que con anterioridad, desde 1895 el objeto estaba presente en varias de ellas pero sin ser advertido. Aunque el propio Kowal indicó que podría tratarse de un cometa, al estimarse que su diámetro sería de unos $230 \mathrm{~km}$ se concluyó que era desmesuradamente grande para este tipo de objetos y se lo catalogó como asteroide, recibiendo la denominación provisional de 1977 UB siendo luego designado como (2060) Chiron. Mediciones recientes mediante un modelado termofísico usando datos del HST arrojó un diámetro de $218 \pm 20 \mathrm{~km}$ y un albedo de 0.16 (Fornasier et al., 2013). El 14 de febrero de 1996 alcanzó su perihelio y la sorpresa fue que comenzó a desarrollar una coma de gas y polvo indicando que se trataba de un objeto con actividad típicamente cometaria pero de unas dimensiones nunca vistas. Hoy sabemos que dicha coma varía con el tiempo tanto en tamaño como en brillo, siendo que en ocasiones su diámetro puede alcanzar hasta casi $2 \times 10^{6} \mathrm{~km}$, pudiendo fluctuar en un factor cuatro en tan sólo unas horas. Además, una atmósfera de polvo aparece suspendida en los primeros $1200 \mathrm{~km}$ de la coma y parece poseer una estructura que indicaría la existencia de erupciones en su núcleo. Fotografías tomadas antes de su descubrimiento indican que este peculiar objeto se mantuvo brillante a pesar de su gran distancia al Sol, indicando que puede existir actividad cometaria incluso a muy bajas temperaturas, lo que parece señalar la presencia de sustancias altamente volátiles tales como metano, monóxido de carbono y nitrógeno molecular. Hay dos hechos que indicarían que habría adquirido su órbita actual hace tan sólo unos pocos millones de años: el primero es que su órbita es inestable en escalas de tiempo de decenas de millones de años debido a las perturbaciones producidas por los grandes planetas; y el segundo surge 
de considerar la sublimación de los elementos volátiles de su superficie, dado que se estima que en su órbita actual estas sustancias deberían evaporarse completamente en unos pocos millones de años. Todo ello hace suponer que su origen debe buscarse en el TNb. Otro detalle a destacar es que recientemente se le ha detectado un sistema de anillos (Ruprecht et al. 2014; Gulbis et al. 2014).

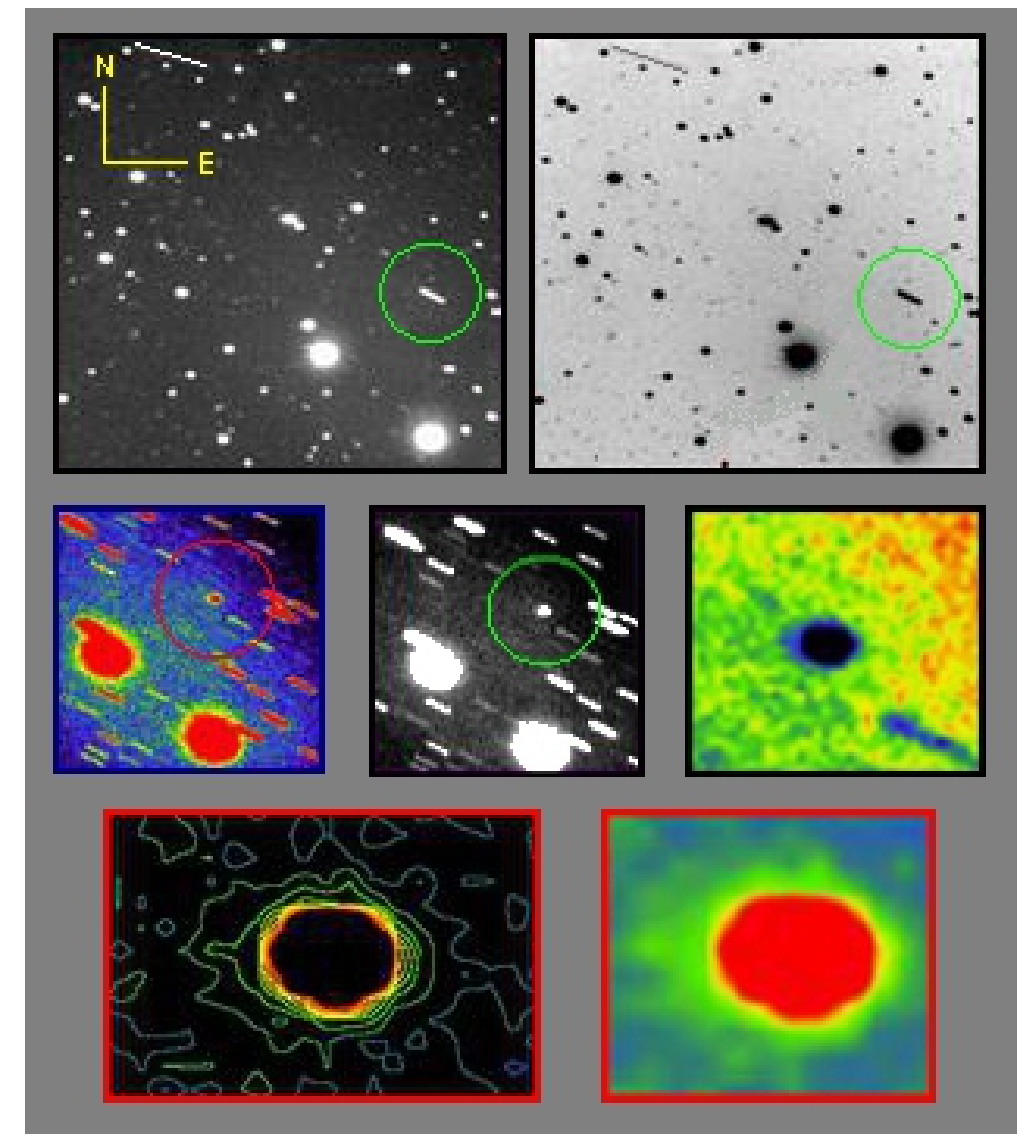

Figura 1.4.2. Imágenes del Centauro (2060) Chiron tomadas por Denis Bergeron, Canadá, en abril de 1995 con un telescopio Meade SCT LX-200 10" F10 y una cámara CCD SBIG ST-6. Todas las imágenes tienen un tiempo de exposición de 300 segundos (Adaptado de http://nssdc.gsfc.nasa.gov/planetary/chiron/html/bergeron-images.html).

Ante las evidencias de su actividad cometaria, fue reclasificado con la denominación de cometa 95P/Chiron, pero conservando su identidad de asteroide. Hoy es conocido como 95P/Chiron / (2060) Chiron. Su nombre proviene de la mitología clásica griega donde "Quirón" es un centauro hijo de Kronos (Saturno), y dicho nombre fue escogido muy imaginativamente por el mismo Kowal, teniendo en cuenta la dualidad de los mitológicos centauros, de naturaleza mitad humana y mitad equina; nombre muy apropiado para un objeto con comportamientos típicos de dos poblaciones diferentes. Luego, en enero de 1992 el programa Spacewatch realiza el descubrimiento de uno de los objetos más rojos del SS: (5145) Pholus, con $(B-R)=2.09$ (Hainaut y Delsanti, 2002), con un perihelio cercano a la órbita de Saturno, un afelio próximo a la de Neptuno, y una distancia media al Sol de $\sim 20 U A$. Ello probó que (2060) Chiron no era un objeto único, sino que es un representante típico de 
una clase dinámica de objetos. Estos descubrimientos forzaron la denominación de un nuevo grupo en el SS, del que (2060) Chiron sólo fue su primer representante: los Centauros. Actualmente no existe una definición única de lo que se entiende por Centauro, por lo que se han ensayado muchas definiciones -no menos de una docena-, que se tratarán más adelante. En la Figura 1.4.2 se muestran distintas imágenes de (2060) Chiron.

En rigor, el primer Centauro en ser descubierto fue (944) Hidalgo en el año 1920, pero sin embargo no fue reconocido como un miembro de una nueva población. El de mayor tamaño es (10199) Chariklo, que con sus $258.6 \pm 10.3 \mathrm{~km}$ de diámetro (Stansberry et al., 2008) y su sistema de anillos (Braga-Rivas et al., 2014; Duffard et al., 2014a; etc.), es tan grande como un asteroide del MBA. Sin embargo, se especula que el Centauro perdido $1995 S N_{55}$ puede ser algo más grande. Cuando éste fue descubierto estaba a unas $39 U A$ y sólo fueron reportadas 14 posiciones dentro de un lapso de 36 días (Buie, 1995; JPL), lo que constituye un arco muy pequeño que hace que su efemérides esté pobremente determinada. Por ejemplo, con un perihelio de unas $8 U A$, su afelio está estimado en valores tan dispares como $39.19 U A$ (JPL) y $91 U A$ (Buie, 1995).

Por fin en 1992 David Jewitt y Jane Luu utilizando el telescopio de $2.2 \mathrm{~m}$ de la Universidad de Hawaii (Mauna Kea, Hawaii) descubren el primer TNO de los tiempos modernos (Jewitt y Luu, 1993) y se le da el nombre provisorio de $1992 Q B_{1}$, denominación que dio origen al término cubewanos, en un intento de clasificar inicialmente a cierto tipo de objetos más allá de Neptuno, y que cayó en desuso en la nomenclatura actual. En el momento de su descubrimiento poseía una distancia heliocéntrica de $R=41.2 U A$, semieje mayor $a=43.82 U A$, excentricidad $e=0.08$ e inclinación $i=2.21^{\circ}$. Su magnitud en el filtro $\mathrm{R}$ resultó ser $R \operatorname{mag}=22.8$. Considerando un albedo geométrico visual típico de cometas de $p_{v} \simeq 0.04$ (Hartmann et al., 1987; Lamy et al., 2005), estaríamos en presencia de un objeto de unos $250 \mathrm{~km}$ de diámetro. Meses después, el mismo equipo descubre el segundo objeto de este tipo: (181708) $1993 \mathrm{FW}$.

A partir de esos dos descubrimientos un gran número de investigadores han realizado trabajos sobre la TNR para explorarla y comprender las propiedades físicas de sus miembros. Rápidamente se sucedieron más de 500 hallazgos en poco más de 10 años (por ejemplo, Jewitt et al., 1996; Jewitt et al., 1998; Sheppard et al., 2000; Larsen et al., 2001; Bernstein et al., 2004 ; etc.) y a la fecha se han superado los 1600 objetos descubiertos $\left(\mathrm{MPC}_{0}\right)$.

Hoy no quedan dudas que esta enorme región del SS más allá de la órbita de Neptuno, y que en un principio se creía vacía, está poblada por un gran número de objetos con una masa total que, según estimaciones de distintos autores varía, como se mencionó, entre $0.01 M_{\oplus}$ (Bernstein et al., 2004) y $0.1 M_{\oplus}$ (Gladman et al., 2001). Esa incerteza se debe principalmente a tres factores: (a) conversión de magnitudes absolutas a tamaños; (b) suposiciones sobre las densidades de los objetos; y (c) ambigüedades en la distribución de tamaños. Por otra parte, vimos que trabajos basados en simulaciones numéricas del proceso de migración durante lapsos del orden de la edad del SS da como resultado una masa actual de la TNR entre $0.07-0.14 M_{\oplus}$ (Gomes, 2003; Gomes et al., 2005b). Cualquiera sea la masa total real, parece existir un déficit considerable de dos a tres órdenes de magnitud con respecto a lo que los modelos predicen en referencia a la masa que debió haber existido en el TNb, para que los objetos se formen in situ. En particular, para que estos objetos que hoy observamos se hayan formado en un tiempo razonable $\left(\sim 10^{7}-10^{8}\right.$ años$)$, dicho cinturón debería haber contenido originalmente 
entre $10-30 M_{\oplus}$ de material sólido en un disco dinámicamente frío (Stern, 1996b; Stern y Colwell, 1997a, 1997b; Kenyon y Luu, 1998, 1999a, 1999b; Kenyon y Bromley, 2004b; etc.).

\subsubsection{Las clases dinámicas de las poblaciones transjovianas}

\section{Los objetos cisneptunianos}

En este apartado se hará referencia a los objetos que habitan principalmente las regiones más allá de la órbita de Júpiter, sin necesariamente llegar a ser objetos transneptunianos.

\section{a) Cometas}

Ya desde la antigüedad se especulaba si los cometas eran objetos celestes o eran simples fenómenos atmosféricos. Esa fue, en realidad, la primera discusión teórica sobre el origen y la naturaleza de dichos objetos. Pero luego que Isaac Newton (1643-1727) diera a conocer en 1685 su Teoría de la Gravitación Universal como culminación de una serie de estudios y trabajos iniciados mucho antes, ésta pudo aplicarse con éxito al cálculo de la órbita del cometa $1 \mathrm{P} /$ Halley prediciendo así su regreso, y despejando toda duda sobre la naturaleza de los cometas como objetos celestes. Actualmente es mucho lo que conocemos sobre la naturaleza física de los cometas e históricamente lo primero que aprendimos de ellos fue acerca de su dinámica. Hasta antes del descubrimientos de los Centauros la característica más notable que los diferenciaba de los demás objetos del SS eran su coma -atmósfera no ligada gravitacionalmente al núcleo- y sus vistosas colas que, si bien en general se observan dos -una de partículas y la otra de iones-, hubo casos como el C/1995 O1 (Hale-Bopp) donde llegó a distinguirse una tercera, una cola de sodio, e incluso se han llegado a observar cometas con hasta cuatro colas de naturaleza diferente. Pero lo cierto es que en los últimos años además de los Centauros, como veremos, se vienen observado varios tipos de objetos que no se los tenía clasificados como cometas, y que sin embargo muestran una notable actividad de tipo cometario.

Históricamente a los cometas se los clasificaba según su período orbital $P$, en:

- Cometas de Corto Período (SPC): $P<200$ años. A este grupo pertenecen los JFC $(P<20$ años) y los Cometas Tipo Halley (20 años $<P<200$ años).

- Cometas de Largo Período (LPC): P > 200 años.

Dicha clasificación era a su vez consistente con la distribución de inclinaciones. Los SPC están confinados casi exclusivamente al plano medio de la eclíptica y no se han descubierto cometas de este tipo con $i>50^{\circ}$; los cometas Tipo Halley son preponderantemente objetos con órbitas directas $\left(i<90^{\circ}\right)$; y en los LPC se observa una distribución de inclinaciones isotrópica, aunque con cierto exceso de órbitas retrógradas.

A menos que un cometa muestre actividad, se hace muy difícil distinguirlo de un asteroide, pero gracias a un criterio basado en el parámetro de Tisserand, esa situación puede resolverse en la mayoría de los casos. Recordemos que dicho parámetro surge de consideraciones dinámicas en el Problema Plano Circular Restringido de los Tres Cuerpos, 
que en el caso Sol-planeta-planetesimal para un planeta $P$ dado, adopta la forma

$$
T_{P}(a, e, i)=\frac{a_{P}}{a}+2 \sqrt{\frac{a}{a_{P}}\left(1-e^{2}\right)} \cos i,
$$

donde $a, e, i$ son respectivamente el semieje mayor, la excentricidad y la inclinación de la órbita del planetesimal y $a_{P}$ es el semieje mayor de la órbita del planeta $P$.

La relación entre $T_{P}$ y la velocidad de encuentro planeta-planetesimal relativa al primero, está dada por

$$
v_{\infty}=\sqrt{3-T_{P}} .
$$

Es claro que planetesimales que cumplen la inecuación $T_{P}>3$ no pueden tener un encuentro con el planeta $P$, y es precisamente esa desigualdad aplicada al planeta Júpiter la que define el mencionado criterio (Kresak, 1979): la mayoría de los asteroides del MBA poseen un parámetro de Tisserand respecto de Júpiter que satisface $T_{J}>3$, mientras que en su gran mayoría los cometas cumplen la inecuación $T_{J}<3$ y poseen una velocidad de encuentro relativa a Júpiter, $v_{\infty}>0$. Pero dado que nunca se cumplen estrictamente las condiciones del Problema Plano Circular Restringido de los Tres Cuerpos, el criterio es poco confiable en general, y particularmente crítico para aquellos planetesimales con $T_{P} \sim 3$. Por otro lado, dado que la condición de encuentro $T_{P} \leq 3$ es necesaria pero no suficiente, ella no garantiza que el encuentro se vaya a dar efectivamente.

Tan es así la incertidumbre del criterio que las múltiples excepciones que presenta ha obligado a definir nuevas categorías de objetos. Por ejemplo, objetos con $T_{J}<3$ pero que no presentan ningún tipo de actividad cometaria son llamados Asteroides en Órbitas Cometarias (ACO) y a este respecto incluso hay autores que hablan de claras divisiones dentro de este grupo, considerando propiedades espectrales (Licandro et al., 2005) o distribuciones de tamaños (Álvarez-Candal y Licandro, 2006). Otro ejemplo son los Cometas en Órbitas Asteroidales (CAO) o Asteroides Activos (AA), objetos que presentan al menos temporariamente actividad cometaria y satisfacen la inecuación $T_{J}>3$. Además, se conocen objetos con $2<T_{J}<3$ que poseen órbitas similares a los JFCs; y por último podemos mencionar a los Damocloides caracterizados por cumplir la condición $T_{J}<2$ (Jewitt, 2005).

En 1994, H. Levison y M. Duncan realizan una serie de integraciones numéricas de todos los SPC conocidos y encuentran que muchos de ellos, en la mayor parte de su vida dinámica, se mueven entre las órbitas de los JFCs y los cometas Tipo Halley. Sin embargo, encuentran que el parámetro de Tisserand con respecto a Júpiter no varía sustancialmente a lo largo de sus integraciones (Levison y Duncan, 1994), lo que lo convierte en un parámetro confiable al momento de pensar en una nueva clasificación de familias cometarias. Es por ello que en 1997, en base a una iniciativa de Levison de 1996, revisan la clasificación histórica y proponen la siguiente clasificación basada en $T_{J}$, hecho que, ya había sido sugerido previamente por Carusi y Valsecchi (1987):

- Cometas Cuasi Isotrópicos: Son cometas provenientes mayoritariamente de la OC sin una dirección preferencial, y que cumplen con la condición $T_{J}<2$.

- Cometas Eclípticos: Poseen $T_{J}>2$ y se subdividen en: 
1. JFCs: $2<T_{J}<3$. Son cometas cuya dinámica está fuertemente dominada por Júpiter dado que tienen con éste encuentros de baja velocidad relativa. Hay una gran coincidencia entre este grupo y los JFCs definidos en base a sus períodos.

2. Cometas Tipo Encke: $T_{J}>3$-nunca cruzan la órbita de Júpiter- y $a<a_{J}$.

3. Cometas Tipo Chiron: $T_{J}>3$-nunca cruzan la órbita de Júpiter- y $a>a_{J}$ -órbitas exteriores a la órbita de Júpiter-. Los autores afirman que este tipo de objetos probablemente no sean otros que los Centauros.

En la Figura 1.4.3 se esquematiza la clasificación cometaria propuesta por Levison y Duncan (1997).

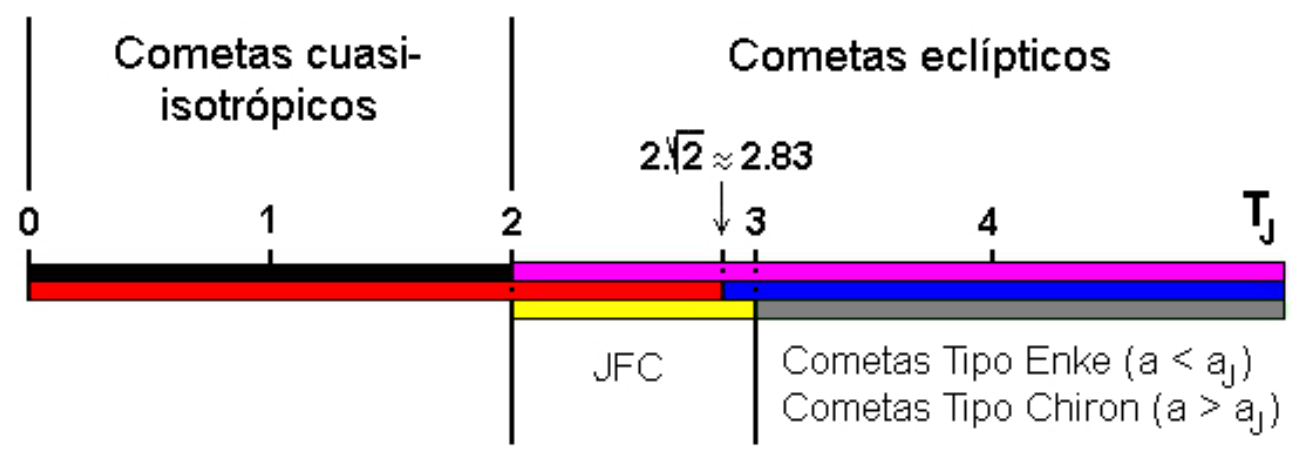
El cometa puede ser eyectado del sistema.
- El planeta no puede eyectar al cometa del sistema.
No puede haber encuentro entre el cometa y el planeta.

Figura 1.4.3. Clasificación cometaria de Levison y Duncan, según $T_{J}$. Se indica además, cuándo Júpiter puede o no eyectar a un planetesimal (ecuación 1.6.1) y cuándo el encuentro entre ambos no es posible (ecuación 1.4.2).

\section{b) Los Centauros}

La variedad de definiciones que existe sobre esta población supera toda discrepancia que pueda suscitar cualquier otra del SS, y como prueba de ello se dará a continuación una decena de ellas. Generalmente involucran uno o varios parámetros de la órbita del objeto como el semieje mayor $a$, la distancia perihélica $q$ o la distancia afélica $Q$, la distancia heliocéntrica $R$, su $T_{J}$, y hasta su velocidad angular en la oposición. Ello conduce a que las muestras de Centauros estudiadas por los diferentes autores varíen ligeramente según el criterio elegido por los mismos.

La más simple los define como aquellos objetos que no estando en MMR 1:1 con Júpiter, poseen órbitas con semiejes mayores $a$ que satisfacen $a_{J}<a<a_{N}$, donde los subíndices hacen referencia a Júpiter y Neptuno, respectivamente. Si bien existe un consenso general sobre la cota inferior para las órbitas de esta población -aunque Gladman et al. 
(2008) les fijan un límite en $q>7.35 U A$ para excluir objetos cuyas dinámicas están fuertemente controladas por Júpiter-, el límite superior es abierto a interpretaciones. Para Gomes et al. (2008) son aquellos objetos con origen en el SSE que se convierten en cruzadores de la órbita de Neptuno, es decir -aclaran- con $q<30 U A$. Tanto Elliot et al. (2005) como Chiang et al. (2006) los consideran como los objetos no resonantes con $q<a_{N}$ y los primeros aclaran que esa definición intenta ser sinónimo de cruzador planetario la cual, al sugerir tiempos de vida dinámica medios cortos, se acerca a la definición de Centauro como un objeto que orbita el Sol entre las órbitas de Júpiter y Neptuno. Otra definición nos dice que Centauro es todo objeto cuya órbita cumple que $5 U A<a<30 U A$, pero que cruza la órbita de al menos un planeta gigante (Jedicke y Herron, 1997; Larsen et al. 2001). Di Sisto y Brunini (2007) consideran Centauro a todo objeto que manteniéndose más allá de la órbita de Júpiter, posee distancia perihélica $q<30 U A$. Posiblemente la definición más difundida es la que afirma que son aquellos objetos cuyas órbitas tienen sus $a$ y $q$ entre $a_{J}$ y $a_{N}$ (Peixinho et al., 2012), condición a la que Jewitt (2009) agrega que los objetos no deben estar en MMR 1:1 con ningún planeta y que comparten Melita y Licandro (2012) y Duffard et al. (2013b). También se los define involucrando el parámetro de Tisserand con respecto a Júpiter, cuando Levison y Duncan (1997) sostienen que los cometas Tipo Chiron $\left(T_{J}>3\right.$ y $\left.a>a_{J}\right)$ y los Centauros son muy probablemente la misma población. Para Sheppard et al. (2000) son los objetos que en la oposición tienen velocidades en el plano del cielo entre 4 arcsec $r^{-1}$

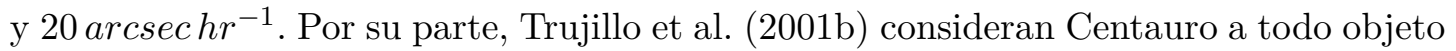
cuyo perihelio caiga entre las órbitas de Júpiter y Neptuno. Finalmente, puede definírselo como aquel cuerpo menor en una órbita inestable a largo plazo que cruza la órbita de un planeta gigante y que posee un semieje mayor entre 5.5UA<a<30.1UA (JPL), o como aquel cuyo perihelio es exterior a la órbita de Júpiter y su semieje mayor es interior a la órbita de Neptuno $\left(\mathrm{MPC}_{1}\right.$; Morais y Namouni, 2013).

En lo que sí hay consenso es en afirmar que los Centauros son una población de transición de objetos en órbitas inestables muy caóticas que provenientes de la TNR terminan sus días como JFCs (Fernández, 1980; Duncan et al., 1988; Holman y Wisdom, 1993; Levison y Duncan, 1997; Morbidelli, 1997; Jewitt, 2002; Di Sisto y Brunini, 2007; Volk y Malhotra, 2008; Bailey y Malhotra, 2009; Melita y Licandro, 2012; Perna et al., 2014; Duffard et al., 2014b; etc.), con su fuente principal en el SD, desde el cual ingresan periódicamente a la región planetaria permaneciendo en este estado intermedio por unas decenas de millones de años (Levison y Duncan, 1997; Dones et al., 1996; Tiscareno y Malhotra, 2003; Horner et al., 2004; Di Sisto y Brunini, 2007; Bailey y Malhotra, 2009).

Recientemente mediante simulaciones numéricas, se ha sugerido la existencia de una pequeña subpoblación de Centauros binarios que sobreviviría durante millones de años en tal condición (Brunini, 2014).

Una característica particular de esta población es que presenta una remarcable bimodalidad de colores no debidamente explicada y que es motivo de fecundos debates (Luu et al., 2000; Boehnhardt et al., 2001; Tegler et al., 2003; Peixinho et al., 2003; Peixinho et al., 2004; Doressoundiram et al. 2005; Tegler et al., 2008; Stansberry et al., 2008; Melita y Licandro, 2012; Peixinho et al., 2012; Perna et al., 2014; etc.), a lo que se suma la peculiaridad de que los Centauros más rojos poseen albedos más altos que los que son más grises, contrariamente a lo que intuitivamente se podría esperar (Stansberry et al., 
2008).

Actualmente la cantidad de Centauros descubiertos es $\sim 300$, pero naturalmente ese valor depende de la definición que se adopte. Se estima que un $10 \%$ de la población presenta algún tipo de actividad cometaria (Perna et al., 2014).

c) Los Satélites irregulares

Son aquellos satélites de planetas externos con órbitas de altas inclinaciones y grandes excentricidades y que se sospecha que no han sido el producto de acreción en un disco protoplanetario, dado que sus características orbitales no se condicen con ese origen (Canup y Ward, 2002; Canup y Ward, 2006). Generalmente sus órbitas están ubicadas más allá de las órbitas de los satélites regulares y es altamente probable que sean capturas de objetos originados en regiones distantes que, o bien no alcanzaron a ser eyectados del SS en las primeras etapas de su formación, o son objetos provenientes de la TNR. En algunos modelos de formación planetaria, como por ejemplo el mencionado Modelo de Niza, se observa que las interacciones gravitatorias entre planetesimales y planetas gigantes que migran dispersan una gran cantidad de partículas, lo que posibilitaría las capturas.

d) Los Troyanos de los planetas gigantes

Inicialmente se llamó asteroides Troyanos a aquellos cuerpos menores ubicados en los Puntos Lagrangianos de equilibrio estable $L_{4}$ y $L_{5}$ del Problema Plano Circular Restringido de los Tres Cuerpos, en el sistema Sol-Júpiter-asteroide, siendo así objetos que están en MMR 1:1 con Júpiter y por lo tanto coorbitando con éste e incursionando periódicamente fuera de su órbita. Luego se amplió el concepto y ahora todo objeto que orbita alrededor de dichos puntos de un sistema Sol-planeta-objeto, es llamado Troyano de dicho planeta.

Aún no se ha descubierto un Troyano de Saturno y es posible que nunca se lo encuentre dado que un cuerpo en los puntos $L_{4}$ o $L_{5}$ de Saturno estaría muy perturbado por Júpiter dada su cercanía, y en el mejor de los casos tendría una vida dinámica muy corta (Lykawka et al., 2010; Hou et al., 2014).

Si bien los Troyanos de Neptuno pueden considerarse una clase dinámica de la TNR, algunos autores la consideran una clase de la región que estamos analizando. El primer Troyano de Neptuno, $2000 Q R_{322}$, fue descubierto orbitando el punto $L_{4}$ por el Deep Ecliptic Survey (DES) (Chiang et al., 2003) y simulaciones numéricas basadas en modelos orbitales sugieren que el objeto posee una estabilidad orbital tal que pudo habitar la MMR 1:1 con Neptuno por un tiempo del orden de la edad del SS (Marzari et al., 2003; Brasser et al., 2004). Luego, con el correr del tiempo se fueron sucediendo otros descubrimientos, sumando hoy un total de doce, nueve orbitando $L_{4}$ y tres orbitando $L_{5}\left(\mathrm{MPC}_{2}\right)$.

Recientemente, un equipo encabezado por M. Alexandersen descubrió $2011 Q F_{99}$ (Alexandersen et al., 2013), el primer Troyano de Urano, un objeto pequeño orbitando $L_{4}$ que si se considera un albedo de 0.05 tendría unos $60 \mathrm{~km}$ de diámetro $(R m a g=24)$. El mismo equipo, mediante simulaciones numéricas encuentra que dicho Troyano ha permanecido en esa condición por más de $7 \times 10^{4}$ años y permanecerá en ella por cerca de un mil- 
lón años más antes de convertirse en un auténtico Centauro. Las mismas simulaciones conducen a que el $0.4 \%$ de los Centauros podría terminar como Troyano de Urano, mientras el $2.8 \%$ podría hacerlo como Troyano de Neptuno; y además encuentran que alrededor del $0.1 \%$ de los Centauros son temporalmente Troyanos de Urano (Alexandersen et al., 2013). El resultado es muy interesante y novedoso, dado que se creía que las perturbaciones de Saturno dificultarían una población estable de Troyanos de uno u otro planeta.

Actualmente en todo el SS han sido identificados como Troyanos 6276 objetos: 1 Troyano de la Tierra, 4 Troyanos de Marte, 6258 Troyanos de Júpiter $-L_{4}$ duplicando la población de $L_{5}$, fenómeno tratado en Di Sisto et al. (2013)-, 1 Troyano de Urano y 12 Troyanos de Neptuno $\left(\mathrm{MPC}_{2}\right)$.

\section{Los objetos transneptunianos}

Si bien tampoco existe un criterio unívoco sobre las definiciones de las distintas poblaciones que habitan la región más allá de la órbita de Neptuno, en la bibliografía hay acuerdo en dividirlas en cuatro tipos de clases dinámicas.

\section{a) Los Objetos Clásicos}

Son los objetos que no estando en MMR con Neptuno poseen órbitas casi circulares con excentricidades menores que 0.2 , semiejes mayores entre $42-48 U A$ y perihelios más allá de las $37 U A$ (Morbidelli et al., 2008). Conforman el ya mencionado CTNb. Aunque la excentricidad media actual de esta población es relativamente pequeña, en los comienzos del SS debió ser al menos un orden de magnitud menor. Considerando la estabilidad dinámica reinante actualmente en la región, es de suponer que sin mecanismos perturbadores adicionales las pequeñas excentricidades primordiales deben haberse preservado hasta el presente (Holman y Wisdom, 1993; Morbidelli et al., 1995; Morbidelli et al., 2008).

Un capítulo aparte merece la amplia distribución de inclinaciones que presenta esta población, donde las observaciones ponen en evidencia un agrupamiento bien marcado de objetos del CTNb con $i \leq 4^{\circ}$, coexistiendo con diversos objetos con inclinaciones mucho más altas, incluso hasta $i=30^{\circ}$. Si bien el sesgo observacional definitivamente incrementa cuantitativamente el grupo de objetos de bajas inclinaciones con respecto a la población de inclinaciones elevadas, el singular agrupamiento con bajas inclinaciones aún persiste cuando el sesgo es removido. En un importante trabajo realizado por M. Brown en 2001, éste argumentó que la distribución real de inclinaciones del CTNb es bimodal. En efecto, el autor realizó un extenso trabajo donde desarrolla un método para determinar la distribución de inclinaciones del TNb, utilizando solamente la inclinación y la latitud eclíptica en la fecha de descubrimiento de cada CTNbO de una muestra de 379 objetos (Brown, 2001). Sucede que las observaciones cerca de la eclíptica tienen un fuerte sesgo hacia el descubrimiento de objetos con bajas inclinaciones porque naturalmente son los objetos que pasan el mayor tiempo cerca de la misma. Por lo tanto, Brown concluye que la distribución de inclinaciones de los CTNbO observados no es representativa de la distribución total de los mismos. El método más directo para determinar 
la distribución de inclinaciones de ésta población sería muestrear un rango de latitudes eclípticas y medir la densidad de los CTNbO en cada latitud pero ello necesitaría mucho tiempo de telescopio y encontraría un número limitado de objetos, particularmente en latitudes altas donde la densidad de éstos es baja. Como una alternativa más eficiente, Brown desarrolla un método que básicamente tiene en cuenta el hecho de que cada CTNbO descubierto puede considerarse una prueba instantánea de la distribución de inclinaciones en la latitud a la cual se lo descubrió y para ello emplea todos los objetos conocidos de esta población y estima la distribución de inclinaciones de los 111 CTNbOs con $\beta<0.5^{\circ}$. Este análisis le permite advertir que una gaussiana simple ajusta pobremente los datos, y que obtiene un mejor ajuste a partir de la suma de dos gaussianas, multiplicadas por el seno de la inclinación. Una interesante conclusión de este trabajo es que cuando realiza el mismo estudio con los objetos que están en alguna de las MMR con Neptuno y los compara con el estudio en el CTNb, obtiene que las dos distribuciones no provienen de la misma distribución primordial (test con un 93.4\% de confiabilidad), lo que hablaría de poblaciones con orígenes diferentes.

A partir de dicho trabajo diversos autores comenzaron a diferenciar a la población clásica del TNb en dos subclases (Elliot, 2005; Gladman et al., 2001; Morbidelli et al., 2008): una población con $i<4^{o}$ a la que se llamó población fría (cold) y el resto, una población dinámicamente más excitada, fue llamada población caliente (hot). Anteriormente a este trabajo de Brown, Tegler y Romanishin (2000) habían hallado evidencias de que al CTNb podía dividírselo en al menos dos poblaciones: una con colores muy rojos y bajas inclinaciones y la otra con colores neutros e inclinaciones altas. Por su parte Levison y Stern (2001) habían sugerido que el CTNb se podía dividir en una población con magnitudes débiles y bajas inclinaciones y otra más brillante y con altas inclinaciones. Ambos parámetros -colores y magnitudes-, podrían estar relacionados con la distribución de inclinaciones (Brown, 2001).

El agrupamiento de objetos del CTNb visibles en el plano $(a \times i)$ a bajas inclinaciones desaparece si uno selecciona sólo objetos con magnitudes absolutas $H<6$ equivalentemente, $D>170 \mathrm{~km}$-, lo que implica que los objetos intrínsecamente brillantes están pobremente representados en la población fría (Levison y Stern, 2001). Grundy et al. (2005) han mostrado que los objetos de dicha población tienen en promedio un albedo mayor que aquellos de la población caliente, y la correlación encontrada por Levison y Stern implica además que la población caliente contendría objetos más grandes. Por otra parte, Bernstein et al. (2004) mostraron que la población caliente tiene una distribución de magnitudes absoluta $H$ más achatada que la de la población fría, lo cual es consistente con la ausencia de los objetos más grandes en esta última. Además, existe una correlación bien conocida entre el color y la inclinación, donde la población caliente muestra un amplio rango de colores, de rojos a grises, mientras que los objetos de la población fría son fundamentalmente rojos (Doressoundiram et al., 2007). En otras palabras, la población fría muestra un déficit significativo de objetos grises en relación a la población caliente. Las diferencias expuestas en las propiedades físicas, sugieren que estas poblaciones tendrían distintos orígenes.

b) Los Objetos Resonantes

A esta población pertenecen los objetos que están en MMR con Neptuno. La resonancia 
más estudiada con este planeta es la MMR 3:2, ubicada a una distancia heliocéntrica $\sim 39.4 U A$, y los objetos que la pueblan tienen una configuración estable con sus ángulos resonantes librando alrededor de $180^{\circ}$, hecho que explica por qué los objetos que cruzan la órbita de aquel planeta, no son fuertemente perturbados por él. Se han hallado TNOs en varias resonancias de órdenes menores que 4 (Elliot et al. 2005), pero éstas han sido objeto de menor atención. Un caso paradigmático de objeto en MMR 3:2 con Neptuno es (134340) Plutón, quien le da a la población que habita dicha resonancia el nombre de Plutinos.

Considerando tiempos comparables con la edad del SS, no todas las órbitas de los Plutinos son estables debido a que dicha estabilidad posee una gran dependencia con la excentricidad. Por ejemplo, para $e>0.35$ los Plutinos se convierten en cruzadores de Urano y en tales circunstancias son proclives a tener encuentros cercanos e incluso a colisionar con dicho planeta (Duncan et al., 1995; Morbidelli, 1997; Yu y Tremaine, 1999). Es interesante mencionar las correlaciones encontradas por Duncan et al. (1995) entre los tiempos de vida dinámica de los Plutinos en la resonancia y la amplitud de libración.

Otra región resonante destacada es la MMR 2:1 con Neptuno, a una distancia heliocéntrica $\sim 47.8 U A$ y ocupada por los Twotinos, nombre que actualmente cayó en desuso. Concentraciones más pequeñas de objetos resonantes se encuentran en las MMR con Neptuno, 5:3, 4:3, 7:5 y 7:4 a distancias heliocéntricas $\sim 42.3 U A, \sim 36.5 U A, \sim 37.7 U A$ $\mathrm{y} \sim 43.7 U A$, respectivamente. Cabe mencionar también como parte de la población resonante de la TNR, la dominada por los Troyanos de Neptuno (MMR 1:1).

Los mecanismos que condujeron a poblar estas resonancias no están claramente establecidos, pero las hipótesis que se manejan involucran la migración radial sufrida por los planetas debido al intercambio de momento angular con los planetesimales dispersados del disco protoplanetario (Fernández e Ip, 1984; Malhotra, 1995). En un trabajo publicado por Malhotra (1993) la autora presenta un mecanismo de captura que trata de explicar las peculiaridades de la órbita de (134340) Plutón. Dos años después extiende su análisis a todo objeto resonante de la TNR (Malhotra, 1995), donde sostiene que si el mecanismo de captura que propone en 1993 para (134340) Plutón se encontraba actuando durante la historia temprana del SS, la región entre $30-50 U A$ habría sido barrida por las MMR de primer orden con Neptuno. Por lo tanto, la captura en resonancia pudo ocurrir no sólo para este Plutino sino también para muchos otros TNOs. Malhotra presenta en este último trabajo una teoría que modela la distribución de los TNOs -con deficiencias en el modelado de las inclinaciones- y hace tres predicciones sobre la evolución de la estructura dinámica de la TNR: (a) la mayoría de los objetos que habitan el anillo entre $30-50 U A$ viven sólo en zonas muy estrechas situadas precisamente en resonancias orbitales con Neptuno, principalmente en la MMR 3:2 y la MMR $2: 1$; (b) estos objetos resonantes tienen excentricidades significativamente grandes; (c) los objetos que sobreviven en las resonancias tienen excentricidades típicas entre 0.1 y 0.3 , con lo cual sus distancias perihélicas pueden adentrarse tanto como $27 U A$ y por lo tanto se estaría en presencia de cruzadores de Neptuno, habitantes temporarios de la región de Centauros. Un año después, Malhotra afirma que debería haber la misma cantidad de objetos en ambas resonancias (Malhotra, 1996) y en un trabajo posterior la autora llega a esa misma conclusión (Malhotra et al., 2000). Pero sucede que ese hecho 
está en desacuerdo con lo observado, donde la MMR 3:2 parece estar notoriamente más poblada que la 2:1, en una relación de casi 7 a 1 , dado que mientras que el $\sim 24 \%$ de los TNOs parece estar en la resonancia 3:2 sólo el $\sim 3 \%$ ha sido observado en la resonancia 2:1 (Larsen et al., 2001). Este resultado no puede explicarse por un sesgo observacional. Por otro lado, diversos modelos numéricos (por ejemplo, Jewitt et al., 1998) sugieren que los Plutinos contendrían entre $5-10 \%$ de la población total de la TNR.

Realizando un estudio sobre la dinámica de la TNR, Duncan et al. (1995) llegan a la conclusión que hay Plutinos que escapan de la resonancia y tienen encuentros con Neptuno en tiempos comparables con la edad del SS. Ello implica que actualmente habría Plutinos que estarían abandonando la resonancia y teniendo encuentros con Neptuno, con posibilidades de convertirse en JFCs. Es por ello que los autores sugieren que los Plutinos podrían ser una fuente de los JFCs que observamos hoy, teniendo en cuenta la corta vida media de este tipo de cometas y que por lo tanto hace relativamente poco tiempo que se convirtieron en tales.

Morbidelli (1997) analiza la MMR 3:2 con Neptuno para bajas inclinaciones y encuentra que la misma posee una estructura dinámica muy compleja, donde las órbitas regulares son posibles sólo para excentricidades moderadas y pequeñas amplitudes de libración, mientras que para grandes amplitudes, la interacción entre las resonancias $\nu_{18}$ y de Kozai generan regiones caóticas que tienden a vaciarse rápidamente. Para el caso intermedio de amplitudes moderadas encuentra una región de difusión caótica lenta capaz de remover objetos sobre tiempos comparables con la edad del SS, lo que confirma los resultados de Duncan et al. (1995).

Por su parte, Melita y Brunini (2000) describen la estructura dinámica de las MMR 3:2, $5: 3$ y $2: 1$ con Neptuno y muestran que la primera presenta una zona muy estable, principalmente a bajas inclinaciones, lo que es corroborado por las observaciones. Además, sugieren que la existencia de Plutinos en regiones muy inestables puede explicarse por encuentros cercanos con otros Plutinos o por actividad colisional.

Focalizados en esos Plutinos que han abandonado recientemente la resonancia, Di Sisto et al. (2010) exploran numéricamente la evolución dinámica que sufren y analizan las rutas de escape. Encuentran que la gran mayoría de los Plutinos escapados tienen encuentros con Neptuno y que éste rige su evolución dinámica. Estiman que la tasa actual de escape de la resonancia es de 1 a 10 cada 10 años. Tanto la tasa de inyección como el número de objetos que ingresan a la zona de Centauros por este mecanismo, son mucho menores -de uno a dos órdenes de magnitud- que las contribuciones del SD estimadas por Di Sisto y Brunini (2007). Concluyen que los Plutinos que terminan en la región de Centauros constituyen el $6 \%$ de esa población y sobreviven en ella un tiempo de vida medio de $1.08 \times 10^{8}$ años, que es un tiempo de vida medio mayor que los $7.2 \times 10^{7}$ años de aquellos Centauros con origen en el SD (Di Sisto y Brunini, 2007).

De lo expuesto se desprende que los Plutinos son una fuente secundaria de la población de Centauros.

c) Los Objetos del Disco Disperso

El término Disco Disperso o Dispersado fue el nombre que originalmente se le dio a los 
TNOs que fueron precisamente dispersados a órbitas con altas excentricidades $(e>0.2)$ y perihelios cercanos a la órbita de Neptuno, pero que no eran resonantes con éste. Luego se amplió su definición incluyendo a los objetos con perihelios entre $30-39 U \mathrm{~A}$.

Dado que el origen de esta población no es claro, Gladman et al. (2008) optan por proponer como objetos del SD a aquellos que están actualmente siendo dispersados activamente por Neptuno, independientemente de sus orígenes. Así, clasifican un objeto como SDO si durante una integración de $10^{7}$ años su semieje mayor varía en más de 1.5 UA. Similar criterio adoptan Morbidelli et al. (2004). Autores como Gomes et al. (2008) consideran SDO a todo TNO con $q>30 U A$ y $a>50 U A$, pero Gladman sostienen que la población del SD no debe limitarse a los objetos con semiejes mayores a partir de las $50 U A$, sino que debe ampliarse dicha región hasta hacerla comenzar en $30 U A$

Por su parte, Morbidelli et al. (2004) sostienen que parece haber una población extendida que no puede explicarse en el marco del modelo de Duncan y Levison (1997) y especulan que estos objetos serían objetos sobrevivientes de una población original mucho más numerosa y que fue removida por las perturbaciones de Neptuno a lo largo de toda la edad del SS. Al final de su trabajo dejan como interrogantes decidir si los SDOs se formaron en la región planetaria $(a<35 U A)$ y luego fueron transferidos a la región entre 35-50 UA para finalmente ser perturbados hacia regiones más allá de las $50 \mathrm{UA}$; o si en su defecto, existió algún evento que excitó a la mayoría de los objetos primordiales de la TNR, llevándolos a tener altas excentricidades.

d) Los Objetos del Disco Desprendido Extendido

Se consideran como objetos de esta población a todos aquellos TNOs no dispersados, con excentricidades $e>0.24$ y con $a<2 \times 10^{3} U A$, tal que las influencias externas no son importantes en su dinámica (Gladman et al., 2008). También son definidos como aquellos objetos que no estando en MMR con Neptuno, poseen $q>40 U A$ y $a>50 U A$ (Gomes et al., 2008). En las primeras publicaciones que hacían referencia a esta población, se la denominaba indistintamente como Disco Disperso Extendido o Disco Disperso Fosilizado, hasta que Gladman et al. (2008) advirtieron lo inapropiado que era tanto un nombre como el otro, argumentando que no quedaba claro que estos objetos existieran por un fenómeno de dispersión. En su lugar, propusieron el término Detached (Desprendido) -que ya había sido sugerido por Delsanti y Jewitt (2006)- para notar que son objetos lejanos y desacoplados de Neptuno y de esta manera, a partir de entonces muchos autores adoptaron esa denominación, llamando a esta región como Extended Detached Disc (la EDD de la cual hablamos en la sección 1.3). Debe quedar claro que el hecho que sean objetos desacoplados de Neptuno no implica necesariamente que sean objetos que alguna vez estuvieron acoplados a él; de hecho, Emel'yanenko et al. (2003) mediante simulaciones numéricas sobre tiempos comparables con la edad del SS y empleando una muestra compuesta por los EDDOs observados hasta ese momento, hallaron que cinco de ellos nunca se encontraron con Neptuno.

El miembro más emblemático de esta población es sin dudas (90377) Sedna -incluso se discute sino sería un miembro de la Nube de Oort Interna (OCI) (Fernández, 2005), que junto con $2000 C R_{105}$ son dos EDDOs con grandes semiejes que se diferencian claramente de todo SDO en que escapan a toda influencia de Neptuno y cuyo origen 
no se puede explicar por una dinámica de MMR, de resonancias de Kozai o por un mecanismo combinado de ambas. Incluso Gomes et al. (2008) llegan a afirman que ni siquiera hay acuerdo sobre si son objetos escapados del SD o tienen un origen totalmente distinto. En su trabajo, estos autores discuten algunos mecanismos que podrían haber llevado a un SDO a convertirse en un EDDO, luego de sufrir un aumento considerable en su distancia perihélica. Además, especulan que es muy probable que el mismo (90377) Sedna sea el primer objeto descubierto de una población de objetos cuyas masas serían un orden de magnitud mayor a la de cualquier objeto del TNb. Una teoría que explicaría satisfactoriamente el origen de este gran TNO, de un diámetro estimado en $D=995 \pm$ $80 \mathrm{~km}$ (Pál et al., 2012), se basa en considerar la formación del Sol en un cúmulo estelar donde los objetos dispersados por los planetas gigantes en los comienzos del SS pudieron haber aumentado su distancia perihélica debido al efecto sobre ellos de los pasajes de estrellas vecinas cercanas y a los efectos de marea de la misma nube molecular (Fernández y Brunini, 2000; Brasser et al., 2006). Otro mecanismo que generaría objetos con grandes perihelios puede ser el producido por las perturbaciones de una hipotética compañera solar sobre los SDOs (Gomes et al., 2006), efecto que se produciría por resonancias seculares o de Kozai inducidas por la misma. Por su parte, Gladman y Chan (2006) sugieren que un cuerpo del tamaño de la Tierra -o más de uno- pudo ser dispersado por Neptuno en el SS temprano -idea ya antes planteada tanto por Ip (1989) como por Petit et al. (1999)-, y así su interacción con los SDOs habría incrementado los perihelios de algunos de ellos. Incluso se ha sugerido que el origen de los EDDOs puede estar relacionado con algún mecanismo que involucra objetos extrasolares por el cual el Sol podría haber capturado objetos pertenecientes al disco de algún objeto subestelar que se haya formado en el mismo cúmulo, y llevar a esos objetos capturados a órbitas similares a la de (90377) Sedna (Morbidelli y Levison, 2004; Kenyon y Bromley, 2004d). El inconveniente que plantea esta última hipótesis es que no se sabe si estrellas de ese tipo poseen a su alrededor discos de planetesimales conteniendo objetos tan grandes como (90377) Sedna (Gomes et al., 2008).

\subsection{La Nube de Oort}

La energía orbital de un objeto es inversamente proporcional a su semieje mayor, y el análisis de la distribución de dicha energía puede aportar datos de gran utilidad, particularmente en el caso de los cometas de largo período. En la Figura 1.5.1 se muestra un histograma de la distribución de las recíprocas de los semiejes mayores de las órbitas originales de 386 cometas con órbitas cuasi-parabólicas del catálogo de Marsden y Williams (2003). Las órbitas son originales, es decir que las perturbaciones planetarias han sido tenidas en cuenta y por consiguiente hablamos de aquellas que tenían los cometas antes de ingresar a la región planetaria por vez primera. En principio llama la atención que no es una distribución uniforme sino que presenta un pico pronunciado para valores en el intervalo $\left(0,10^{-4}\right]$, valores en $U A^{-1}$. Ello equivale a hablar de semiejes mayores $a_{\text {originales }}>10^{4} U A$. Teniendo en cuenta que una órbita parabólica posee energía cero, estamos hablando, entonces, de órbitas cuasiparabólicas. Otro detalle a destacar es que si bien todos los cometas observados y ligados al Sol tienen órbitas elípticas y por lo tanto sus energías orbitales deberían ser menores que cero -equivalentemente, sus recíprocas de semiejes adoptar valores positivos-, en la muestra 
observamos que hay cantidades $a_{\text {originales }}{ }^{-1}<0$, lo que implicaría, en principio, que la muestra contendría cometas con órbitas hiperbólicas o, lo que es lo mismo, cometas provenientes desde el espacio interestelar. Una posible explicación para este resultado es que tal vez no son tenidas debidamente en cuenta las fuerzas no-gravitacionales y así, una pequeña fracción de cometas se muestra con órbitas hiperbólicas (Fernández, 2005). Otra alternativa más exótica incluye la perturbación de una posible compañera solar masiva, localizada entre la TNR y la OC (Fernández, 2010).

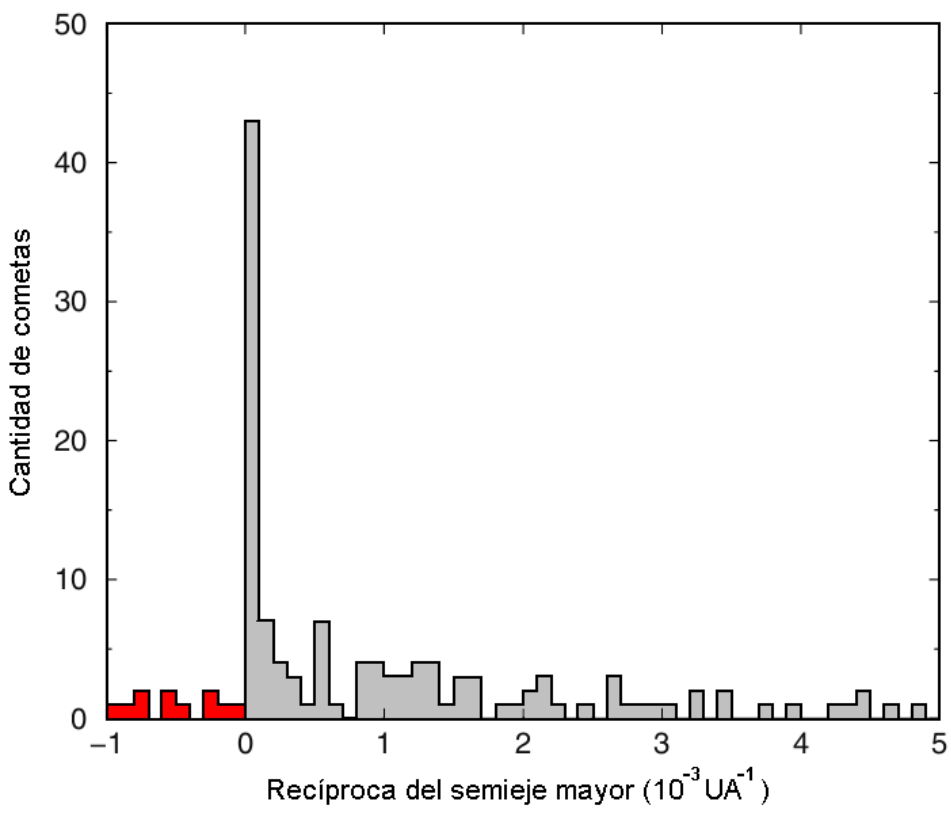

Figura 1.5.1. Distribución de las recíprocas de los semiejes mayores de las órbitas originales de una submuestra de cometas con órbitas cuasi-parabólicas con $a_{\text {originales }}{ }^{-1}<$ $5 \times 10^{-3} U A^{-1}$ y $q<2 U A$ (Adaptado de Fernández, 2005).

Fue precisamente el pico que se observa en la Figura 1.5.1 lo que llevó a Oort a desarrollar su teoría postulando una nube de cometas en órbitas cuasi-parabólicas con energías cercanas a cero, y por lo tanto habitando una región ubicada a grandes distancias heliocéntricas. Dicha nube se habría formado con aquellos cuerpos menores que fueron llevados por perturbaciones planetarias hacia esas órbitas. El razonamiento de Oort se basaba en el hecho que todo cometa que ingresaba a la región planetaria por primera vez debía traer una energía tal que la recíproca del semieje mayor de su órbita debía estar en el intervalo $\left(0,10^{-4} U A^{-1}\right]$. Equivalentemente, todo cometa que era observado con valores mayores era un cuerpo que ya había visitado antes la región planetaria (Oort, 1950). Estudiando la distribución de semiejes $a_{\text {original }}$ de esos cometas, puede concluirse que la máxima concentración se da para cometas con orígenes a varios miles de unidades astronómicas, con órbitas con semiejes en el intervalo $2 \times 10^{4} U A<a_{\text {original }}<3 \times 10^{4} U A$. Esta teoría que hipotetiza sobre la existencia de una nube de cometas en los confines del SS, con ciertas modificaciones, es la que se acepta hoy en día.

Los efectos que sufre la órbita de un cometa proveniente de la OC en su primera incursión en la región planetaria pueden ser muy dramáticos, como puede apreciarse graficando la 
función de distribución de probabilidades de los cambios de energía de un cometa cuando llega a su perihelio (Figura 1.5.2). Esta función expresa el cambio típico de la energía orbital experimentado por revolución, en función de la distancia perihélica. La curva 1 representa a los cometas de menor inclinación, entre $0^{\circ}$ y $30^{\circ}$; la 2 entre $30^{\circ}$ y $60^{\circ}$ y así hasta llegar a la curva 6 , que representa a los cometas más retrógrados, con órbitas cuyas inclinaciones van desde los $150^{\circ}$ hasta los $180^{\circ}$. Observamos que cuando un cometa entra en la región planetaria su órbita experimenta un cambio de energía que puede alcanzar hasta dos órdenes de magnitud.

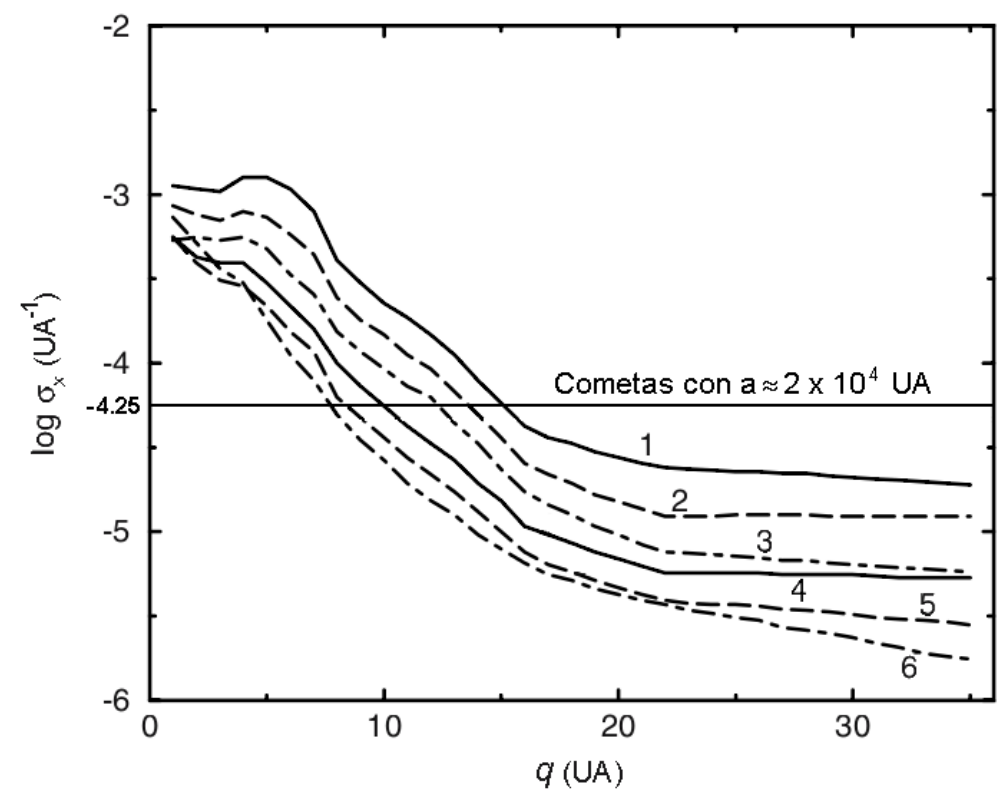

Figura 1.5.2. Gráfico de la función de distribución de probabilidades para distintas inclinaciones del cambio de energía de un cometa por cada pasaje por su perihelio. La curva 1 representa a los cometas de menor inclinación, entre $0^{\circ}$ y $30^{\circ}$; la 2 entre $30^{\circ}$ y $60^{\circ}$ y así hasta llegar a la curva 6 , que representa a los cometas más retrógrados, con órbitas con inclinaciones de $150^{\circ}$ a $180^{\circ}$. (Adaptado de Fernández y Brunini, 2000).

En el gráfico se observa que hay una gran dependencia entre el cambio de energía orbital y la distancia perihélica y que existe cierta dependencia con el ángulo de inclinación orbital. Lo que interesa destacar es la abrupta modificación que sufre la órbita de un cometa proveniente de la OC, para el cual su energía orbital es aproximadamente $10^{-4.25} U A^{-1}(a \simeq 17800 U A)$. Si su perihelio es cercano a la órbita de Júpiter o se encuentra a una distancia menor, su energía orbital, como se mencionó, podrá sufrir un salto de hasta dos órdenes de magnitud y ello implicará un cambio tan drástico que incluso hará que el cometa pueda ser eyectado del SS.

El entorno en el cual se formó nuestro SS definió la estructura de la OC. De hecho, si consideramos que el Sol se formó como una estrella aislada -algo poco verosímil- ello daría una configuración de nube bastante ineficiente en términos de fuente de LPC; pero si éste se formó en un cúmulo estelar abierto como lo hacen la mayoría de las estrellas, es de suponer que en sus comienzos las estrellas vecinas influyeron con sus perturbaciones a desestabilizar 
objetos de la nube, generando así cometas con órbitas cuasi-parabólicas. Ciertamente hoy no podemos saber cuál era la densidad de ese cúmulo donde presuntamente se formó el Sol, pero en un trabajo de Fernández y Brunini de 2000 los autores proponen distintos entornos estelares originales del SS y lo dejan evolucionar hasta la formación de una nube de partículas. Suponen tres escenarios iniciales: un entorno denso (25 estrellas $\left.p c^{-3}\right)$, un entorno diluido (10 estrellas $\left.p c^{-3}\right)$, y un entorno superdenso (100 estrellas $\left.p c^{-3}\right)$. Los respectivos resultados se muestra en la Figura 1.5.3.
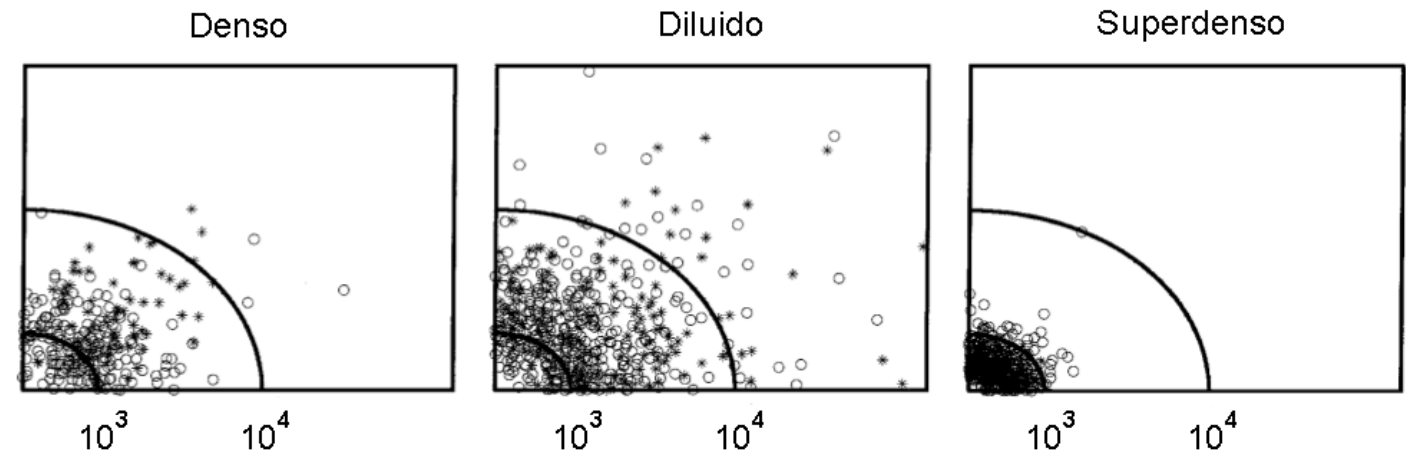

Figura 1.5.3. Gráficos que muestran cómo los cometas atrapados en distintas "nubes de Oort" aparecen distribuidos en el plano ecliptical en un momento dado, para tres casos de cúmulo estelar. Los radios de los círculos están en UA (Adaptado de Fernández y Brunini, 2000).

En las simulaciones la velocidad relativa entre el Sol y las estrellas del cúmulo fue supuesta en $1 \mathrm{~km} \mathrm{seg}^{-1}$, velocidad típica en un cúmulo abierto en equilibrio virial. En los tres casos se integró por un período de $10^{8}$ años, período en el cual se da la completa disolución de un cúmulo abierto típico. En el primer escenario, la nube resultante se extiende algo más allá de las $10^{4} U A$, mientras que en el otro extremo, en el tercer escenario, la nube queda concentrada en una esfera con un radio $\sim 10^{3} U A$. En dicha figura las marcas circulares representan a los cometas que fueron barridos desde la zona comprendida entre las órbitas de Urano y Neptuno $(20-30 U A)$, mientras que los puntos son las partículas que fueron eyectadas desde la zona comprendida entre las órbitas de Júpiter y Saturno $(5-9 U A)$. Una consecuencia importante de estas simulaciones es que dejan en claro que diferentes entornos estelares generan "nubes de Oort" de densidades muy diferentes, algunas más o menos compactas que otras.

En un trabajo de Fernández et al. (2004) los autores sostienen que la OC podría estar actualmente experimentando una notable renovación de su población. Proponen al SD como una de sus fuentes, sosteniendo que la tasa de inyección de objetos podría representar una fracción nada despreciable de las pérdidas totales de cometas, pudiendo superar el $10 \%$. De ser así, si algunos o la mayoría de los cometas -tanto los provenientes de la OC como los JFCstienen su origen en el SD, entonces ambas poblaciones deberían mostrar similitudes químicas entre los dos grupos al menos en su interior profundo, el que aún contendría el componente más primordial y la información sobre la condensación a muy bajas temperaturas del material cometario. Naturalmente, ello no quita que puedan mostrar diferencias en el nivel superficial de sus núcleos debido a las diferentes exposiciones a los rayos cósmicos y a la radiación solar que cada uno pueda haber sufrido. 
La OC se extiende hasta aquella distancia más allá de la cual la atracción gravitatoria solar no tiene intensidad suficiente como para ligar un objeto, el cual será barrido de su posición ante la menor perturbación. Este es un criterio que marca el límite exterior de la nube. Los perturbadores externos que pueden alterar la estabilidad de la OC son, principalmente, los encuentros con una GMC, los encuentros con estrellas cercanas, y el efecto de la fuerza de marea del disco galáctico. El encuentro del SS con una GMC es posible pero altamente improbable, estimándose que desde el origen de nuestro sistema dichos eventos pudieron darse apenas unas decenas de veces (Talbot y Newman, 1977; Scoville y Sanders, 1986; Clube y Napier, 1986; Yeghikyan y Fahr, 2006), con lo cual los mayores efectos serían los provocados por encuentros estelares y principalmente, por la fuerza de marea del disco galáctico (Fernandez, 2005). Oort sostenía que una vez que los cometas eran expulsados de la región planetaria hacia distancias cercanas a las interestelares, el encuentro con estrellas que realizan pasajes cercanos y al azar, reinyectaban a algunos de ellos en el SSI, haciéndolos potencialmente observables. Anteriormente ya Fesenkov (1922) y Öpik (1932) habían realizado, independientemente, estudios sobre los efectos que tenían los pasajes estelares sobre las órbitas cometarias cuasi-parabólicas, pero ninguno de los dos planteó un modelo de nube.

Antonov y Latyshev (1972) proponen un potencial galáctico del cual deducen las dimensiones del elipsoide triaxial centrado en el Sol con superficie de velocidad cero, el cual marcaría el límite de influencia solar. Así, queda establecido un criterio que nos permite estimar el límite exterior de la OC, por el cual un objeto se desligaría del SS si su distancia heliocéntrica en la dirección perpendicular al plano galáctico fuera $R \sim 1.5 \times 10^{5} U A$, o bien si $R \sim 3 \times 10^{5} U A$ en la dirección radial al centro de la Galaxia, o si $R \sim 2 \times 10^{5} U A$, en la dirección ortogonal a las dos primeras. Una distancia crítica se encuentra aproximadamente a $3.4 \times 10^{4} \mathrm{U} A$, donde los cometas de la OC interiores a dicho límite tienen órbitas muy ligadas y difícilmente una interacción exterior pueda perturbarlos e inyectarlos a la zona de visibilidad $(q<2.5 U A$; Everhart, 1972). Los objetos más allá de dicho límite, están en equilibrio con velocidades relativas casi nulas y son los más propensos a ser perturbados por la fuerza de marea del disco galáctico o por encuentros cercanos con estrellas que los pueden inyectar en la región planetaria o directamente eyectarlos del SS (Fernández, 2005). Por su parte, Morbidelli (2005) estima el borde exterior a una distancia de $5 \times 10^{4} U A$, mientras que Levison y Donnes (2007) optan por un límite exterior entre $1-2 \times 10^{5} U A$ y uno interior entre $2-5 \times 10^{3} U A$. 

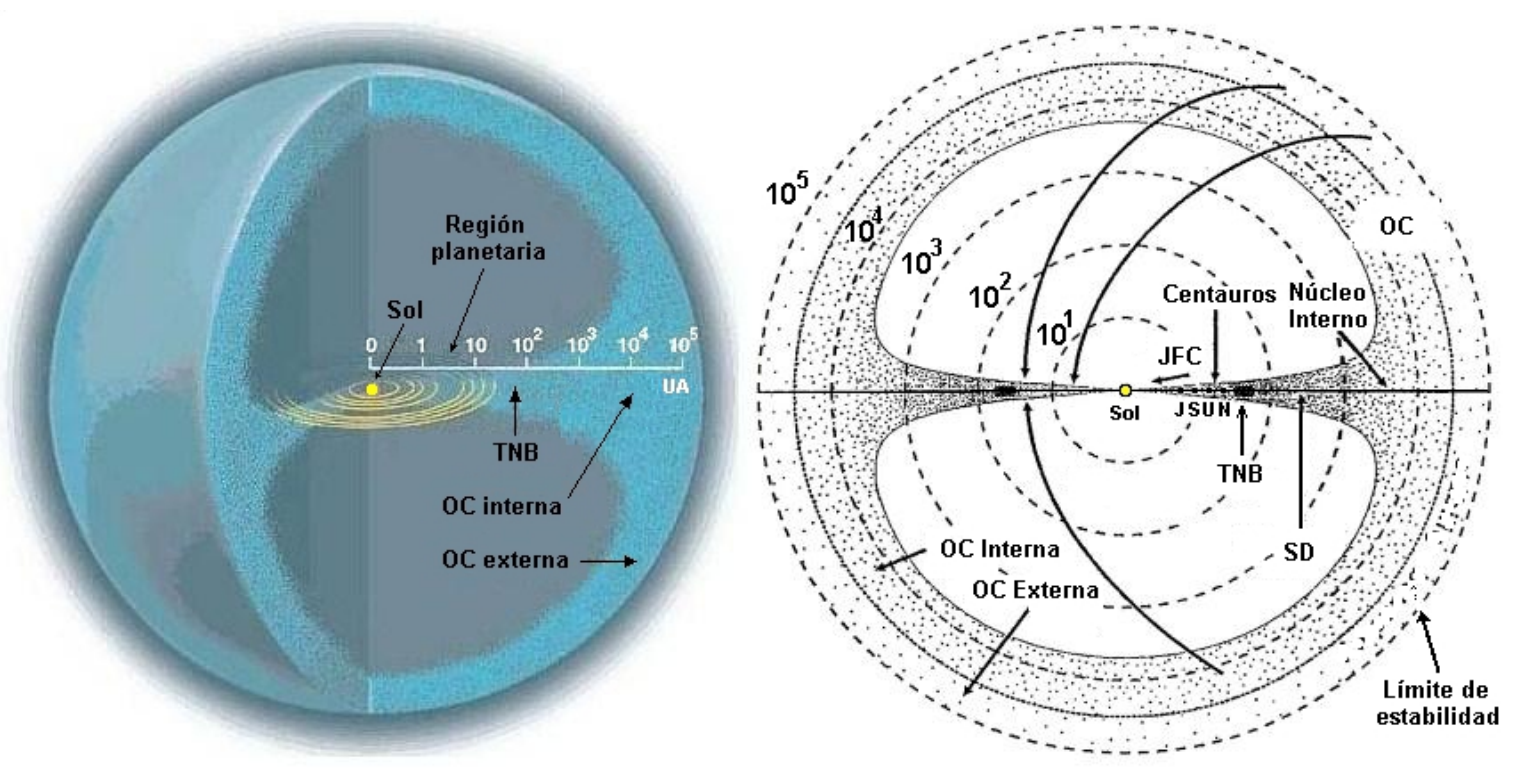

Figura 1.5.4. Esquematizaciones a escala logarítmica del SS y sus distintas poblaciones. Se aprecia la $O C$ con una estructura dual, esférico-toroidal (Adaptados de The Electronic Universe Project y de Fernández (2005)).

Los esquemas de la Figura 1.5.4 nos grafican la idea que hoy se tiene de la morfología del SS, donde se aprecia la OC con una estructura dual que sería la superposición de una estructura esférica con una toroidal. De la región de transición entre ambas aún no conocemos nada y sólo podemos especular que su límite interior estaría entre $10^{2} U A$ y $3 \times 10^{3} U A$ y su borde exterior se localizaría entre $2-3 \times 10^{4} U A$. Actualmente se cree que (90377) Sedna sería un integrante de dicha región de transición (Fernandez, 2005).

A la OC se la puede dividir en Nube de Oort Interna (OCI) y Nube de Oort Externa (OCE). La existencia de la primera fue sugerida por J. G. Hills (Hills, 1981), por lo que muchas veces en la literatura se hace referencia a ella como la Nube de Hills y de existir, según estimaciones numéricas, contendría como mínimo entre 10 y 100 veces más cometas que la OCE (Hills, 1981; Donahue, 1991; Levison et al., 2001), e incluso sería una importante fuente de cometas de la OCE, lo que justificaría la supervivencia de ésta última (Fernández, 1997). De la OCE nos llega información a través de los cometas con órbitas cuasi-parabólicas que podemos observar y en el supuesto que el cometa 1P/Halley sea un prototipo de objetos originados en esta región, se puede estimar su masa en unas $5 M_{\oplus}$ (Weissman, 1983; Morbidelli, 2005). Con los datos con los que se dispone actualmente puede calcularse el volumen de la OC en $4.2 \times 10^{15} U A^{3}$, con una densidad media de $1.3 \times 10^{-4}$ cometas por $U A^{3}$.

\subsection{Evolución de los TNOs hasta objetos de la JFC}

Las ideas de Edgeworth y Kuiper sobre un cinturón formado por cuerpos menores más allá de Neptuno permanecieron ignoradas durante mucho tiempo. Kuiper había tratado de avanzar, incluso, sobre el tema del mecanismo por el cual su hipotético cinturón inyectaba 
objetos en la región planetaria, arriesgando, como mencionamos, que (134340) Plutón dispersaba los planetesimales vecinos hasta que éstos quedaban bajo la influencia de Neptuno, el cual perturbaba aún más sus órbitas haciendo que abandonaran la TNR y se adentraran en el SSI (Kuiper, 1950). Sin embargo, este mecanismo pronto fue desestimado porque se entendió que (134340) Plutón tenía muy poca masa y para peor, dada su alta inclinación, pasaba mucho tiempo alejado del plano medio de la eclíptica donde preferentemente se encuentran los planetesimales. Hasta finales de la década de 1970 no se prestaba atención a la posible existencia de un $\mathrm{TNb}$ e incluso se aceptaba ampliamente que los cometas de corto período eran objetos capturados por Júpiter directamente desde la OC, dando por sentado que esa era la única región capaz de proveerlos (Everhard, 1972; Joss, 1973; etc.).

Ya nos hemos referido al original trabajo de 1980 de J. Fernández, en el que postula que los cometas de corto período no pueden tener como fuente principal a la OC, sino que dicha fuente debe estar en regiones más cercanas (Fernández, 1980). Concretamente en su trabajo propone un escenario donde inicialmente Júpiter y los demás planetas gigantes capturan una población de cometas cuasi-parabólicos provenientes de la OC y calcula que se perderían unos 300 de ellos por cada uno capturado y llevado a una típica órbita de SPC. Luego calcula que el número total de esos cometas eyectados a lo largo de toda la vida del SS ascendería a unos $1.35 \times 10^{12}$ objetos, pero inmediatamente advierte que ese valor es un orden de magnitud más grande que la cantidad de objetos que Oort había estimado para su nube, lo que claramente implicaba que eran eyectados del SS más cometas de los que la OC podía proveer. La conclusión natural a la que llega Fernández es que necesariamente debía existir otra fuente para la población de SPC y propone un cinturón comprendido entre las $35-50 U A$ con una masa inicial de unas $10 M_{\odot}$ y donde se habrían formado cometesimales por inestabilidad gravitatoria con masas de $\approx 10^{18} \mathrm{~g}$. Posteriormente estos objetos habrían evolucionado mediante procesos de acreción-fragmentación que llevó a la población a tener una distribución de masa modelable con una ley de potencias, y finalmente concluyó que como consecuencia de las perturbaciones planetarias, si las masas máximas de estos cuerpos fueron del orden de la de (1) Ceres, la difusión orbital debió ser suficiente como para poder proveer la cantidad necesaria de SPC que hoy observamos.

Otros importantes aportes al estudio moderno de la dinámica cometaria fueron los trabajos numéricos de Harold F. Levison y Martin J. Duncan, particularmente el realizado en 1997 (Levison y Duncan, 1997) en el cual, como se explicó, introducen una nueva clasificación de cometas basándola en el parámetro $T_{J}$. Es pertinente explayarse sobre esta publicación en el contexto de la presente tesis, ya que es un trabajo que ayuda a comprender con claridad los mecanismos que relacionan las poblaciones del TNb con la JFC.

A manera de continuación de un trabajo anterior (Duncan et al., 1995), para el cual integran miles de partículas durante un lapso comparable a la edad del SS para estudiar la estructura actual del TNb y el origen de los SPC, los autores integran 1300 partículas del TNb durante $4 \times 10^{9}$ años con excentricidades en el intervalo $0.01<e<0.3$ y una inclinación única de $i=1^{o}$. Un punto de sumo interés en este trabajo es el estudio que realizan sobre el origen de los JFCs, presentando el gráfico de la Figura 1.6.1, donde llama poderosamente la atención la estrechez del rango de $T_{J}$ para los JFCs y cuyo valor medio es $\bar{T}_{J} \approx 2.8$. Dicha estrechez está relacionada con la chata distribución de inclinaciones mostrada por estos cometas: un cometa visible, cruzador de la órbita joviana con $T_{J}>2.8$ debe tener una inclinación menor que $i \approx 26^{\circ}$. Los autores se preguntan a qué se debe que los JFCs tengan sus $T_{J}$ en un rango 
tan acotado y concluyen que parecería que curiosamente ello se debe a que a medida que los objetos dejan el $\mathrm{TNb}$ sufren un proceso de transferencia dinámica que lleva a un objeto desde el TNb hasta el SSI.

Tanto Kazirnirchak-Polonskaya (1972) como Everhart (1977), especulan que este mecanismo de transferencia es el responsable de la captura de los cometas parabólicos de bajas inclinaciones provenientes de la OC, pero luego Quinn et al. (1990) probaron que dicho mecanismo no es muy eficiente para la mayoría de los cometas con origen en la OC. Pero si se trata de objetos con origen en el TNb, Levison y Duncan muestran en este trabajo que dicho mecanismo es realmente importante. 

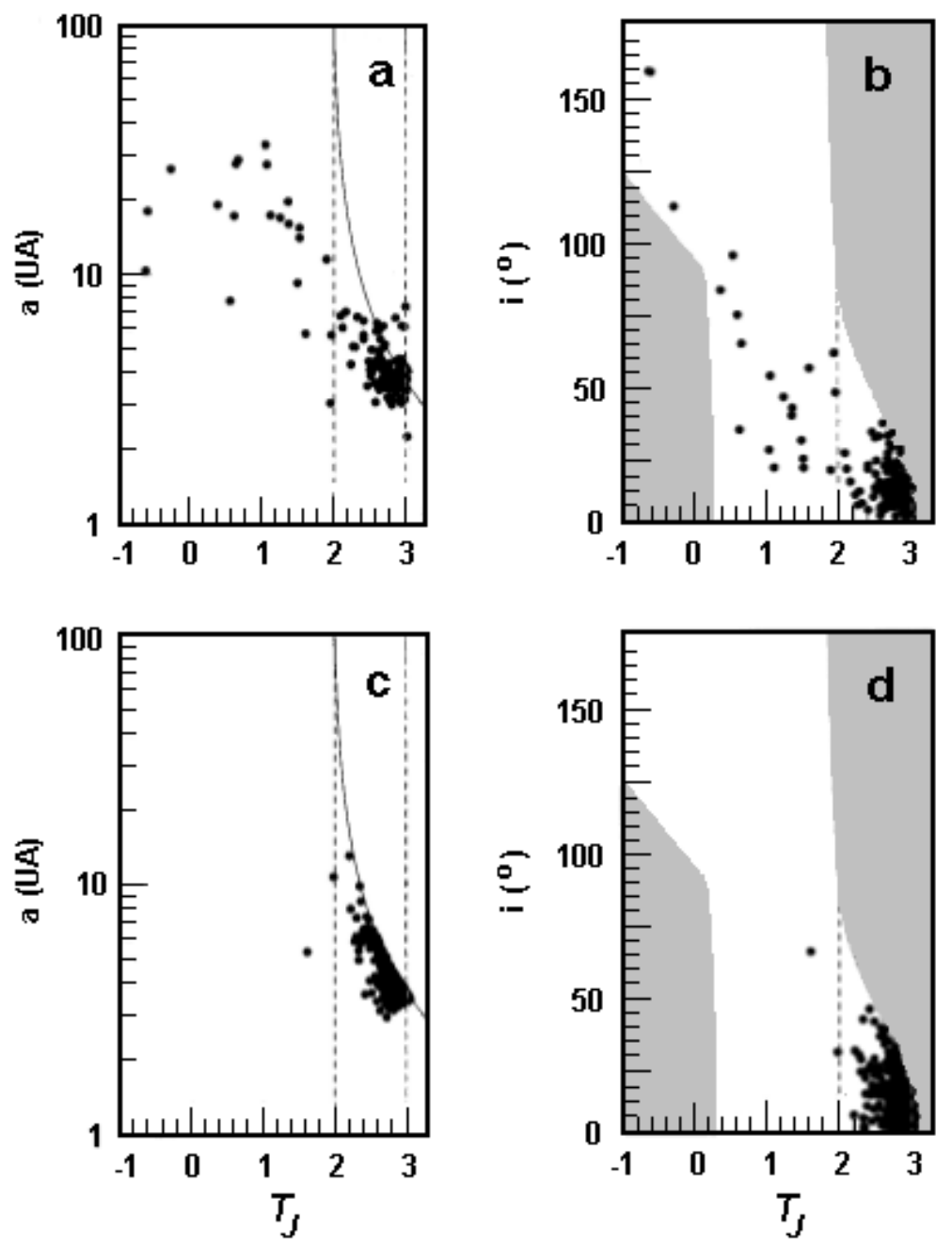

Figura 1.6.1. (a) Semieje mayor de cometas observados con $P<200$ años en función de $T_{J}$. Las líneas punteadas verticales marcan los límites donde se encuentran los JFCs, según la definición de Levison y Duncan (1997). Los objetos por encima de la curva continua deben tener $q>2.5 y$, por lo tanto, no son considerados cometas visibles. Notar que la mayoría de los JFCs poseen $2.5 \leq T_{J} \leq 3$ y $3 U A<a<4.5 U A$. (b) La inclinación en función de $T_{J}$. Las regiones sombreadas son zonas de inaccesibilidad física dada la relación entre $i$ y $T_{J}$, suponiendo $q \leq 2.5 U A$ y $q \geq a_{J}$. (c) y (d) Mismas situaciones que (a) $y$ (b) respectivamente, pero surgidas de simulaciones cuando los cometas se hacen visibles por primera vez (Adaptado de Levison y Duncan, 1997).

La evolución de una partícula representativa de los objetos provenientes del $\mathrm{TNb}$ que se convierten en cometas visibles se muestra en las Figuras 1.6.2 y 1.6.3. En la primera se grafica el parámetro de Tisserand de dicha partícula con respecto a cada planeta gigante en función del tiempo. Un círculo con el color correspondiente a un dado planeta nos indica cuándo la órbita del cometa lo cruza, caso contrario, los autores utilizan una línea punteada. El parámetro de Tisserand con respecto a un planeta siempre supera el valor 2.8 -usualmente, mayor que 3-, condición que indica que la partícula no cruza la órbita del planeta. Llegado 
a este punto es importante notar que cuando la órbita de una partícula es cruzadora de la órbita de un dado planeta, su parámetro de Tisserand respecto a éste es siempre cercano a 3.

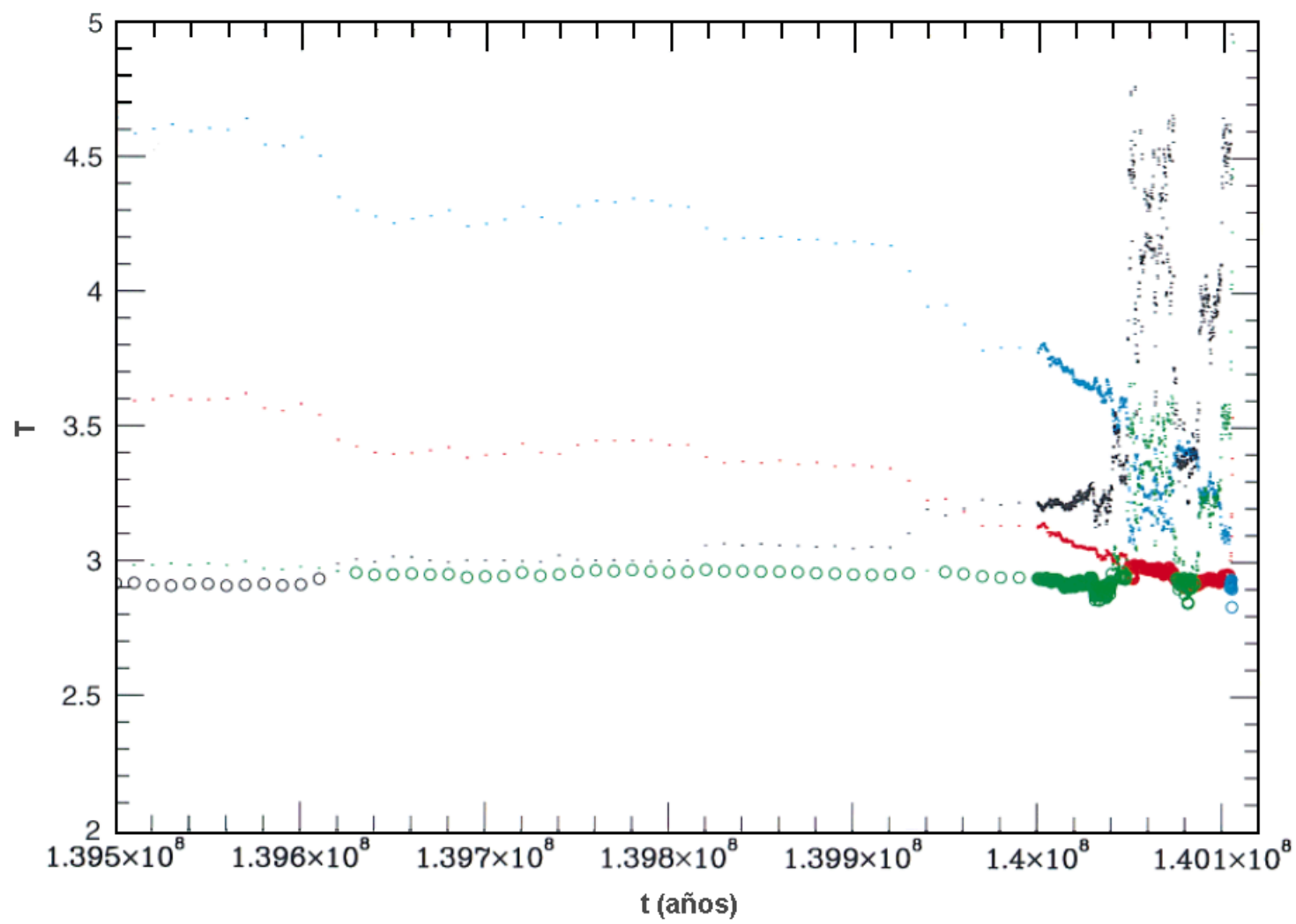

Figura 1.6.2. Evolución de una partícula con origen en el TNb. Se grafica el parámetro de Tisserand de dicha partícula con respecto a cada planeta gigante en función del tiempo - Júpiter (azul); Saturno (rojo); Urano (verde); y Neptuno (negro)-. Se utiliza un círculo del color correspondiente si la órbita del cometa se cruza con el planeta respectivo; caso contrario se utiliza una línea punteada (Adaptado de Levison y Duncan, 1997).

El gráfico de la Figura 1.6.3 muestra la ubicación de la órbita de la partícula en el plano $(Q \times q)$. Las posiciones son unidas por líneas azules hasta que la partícula se hace visible por primera vez $(q<2.5 U A)$, momento a partir del cual quedan unidas con el color rojo. Se observa que en un principio la partícula -que fue elegida al azar- pasa mucho tiempo con su perihelio cerca de la órbita de Neptuno y su afelio más allá de los planetas gigantes; sin embargo, una vez que su perihelio se acerca a la órbita de Urano muestra un claro comportamiento de transferencia dinámica. Luego, la partícula evoluciona con una relativa baja excentricidad hasta hacerse visible -ver las líneas de excentricidad constante, $e=0,0.2, \mathrm{y}$ 0.3- y pasa mucho tiempo con su perihelio cercano a los semiejes mayores de uno de los tres planetas más exteriores y destaca el hecho que su etapa de post-visibilidad es razonablemente típica de los JFCs. 


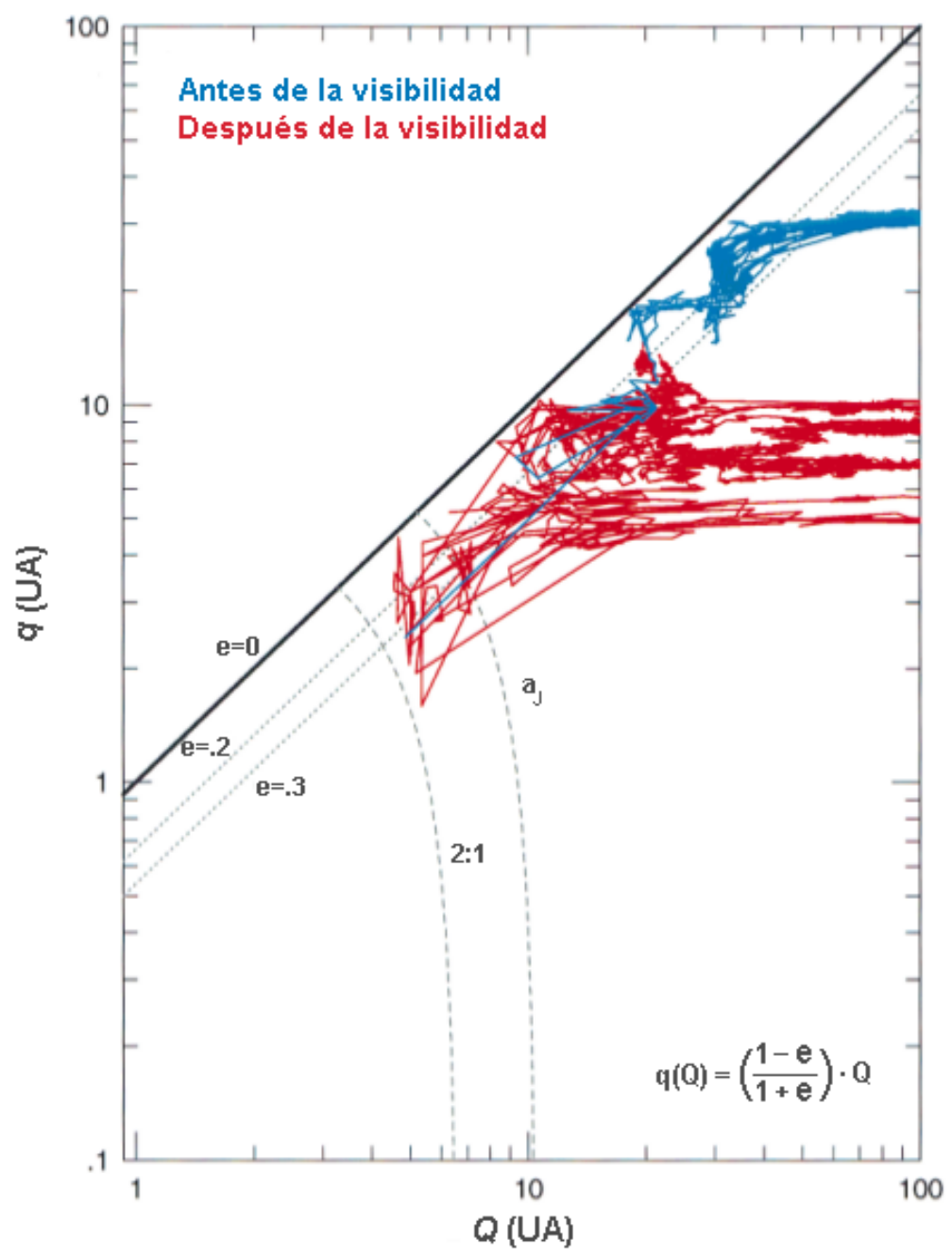

Figura 1.6.3. Órbita de la partícula en el plano $(Q \times q)$. Las posiciones son unidas por líneas azules hasta que la partícula se hace visible por primera vez $(q<2.5 U A)$. A partir de ese momento, están unidas con color rojo. Se utilizaron intervalo cada $10^{4}$ años en la fase de previsibilidad y, posteriormente, cada $10^{3}$ años. Se indican tres líneas de excentricidad constante $e=0,0.2$ y 0.3, y se trazan dos curvas punteadas de semiejes mayores constantes, una a la altura de la órbita de Júpiter y la otra en la MMR 2:1 (3.3UA) con Júpiter (Adaptado de Levison y Duncan, 1997).

El proceso de transferencia dinámica mencionado no sólo predice que todos los JFCs deben tener un $T_{J} \approx 3$, sino que también predice que si una partícula cruza la órbita de un planeta, debe tener un parámetro de Tisserand respecto a dicho planeta cercano a 3 , comportamiento que los autores comprueban en sus múltiples integraciones. El parámetro de Tisserand medio con respecto a un planeta del SSE de todas aquellas partículas que cruzan su órbita, varía entre 2.6 y 2.8, y dado que $T \approx 3$ excluye órbitas con altas inclinaciones, una conclusión importante es que ninguno de los planetas exteriores del SS tiene la capacidad de aumentar las inclinaciones de los objetos del TNb. Este hecho se ilustra en la Figura 1.6.4 que muestra un gráfico del coseno medio de la inclinación en función de la distancia perihélica. 
Notar que las inclinaciones son pequeñas en todas partes y que hay un marcado descenso de la inclinación justo por afuera de la órbita de cada planeta. Gran parte de la estructura que muestra la figura se debe a la mencionada estrechez en el rango de $T$ para cada planeta. Para un valor dado de $T$ cercano a 3 , la relación entre la inclinación máxima que una partícula puede tener y su distancia perihélica, fuerza a la inclinación a ser pequeña siempre que $q$ sea pequeña . Por lo tanto, para que un planeta pueda dispersar a un cometa hacia el interior del mismo, la inclinación del cometa debe ser menor que la inclinación promedio.

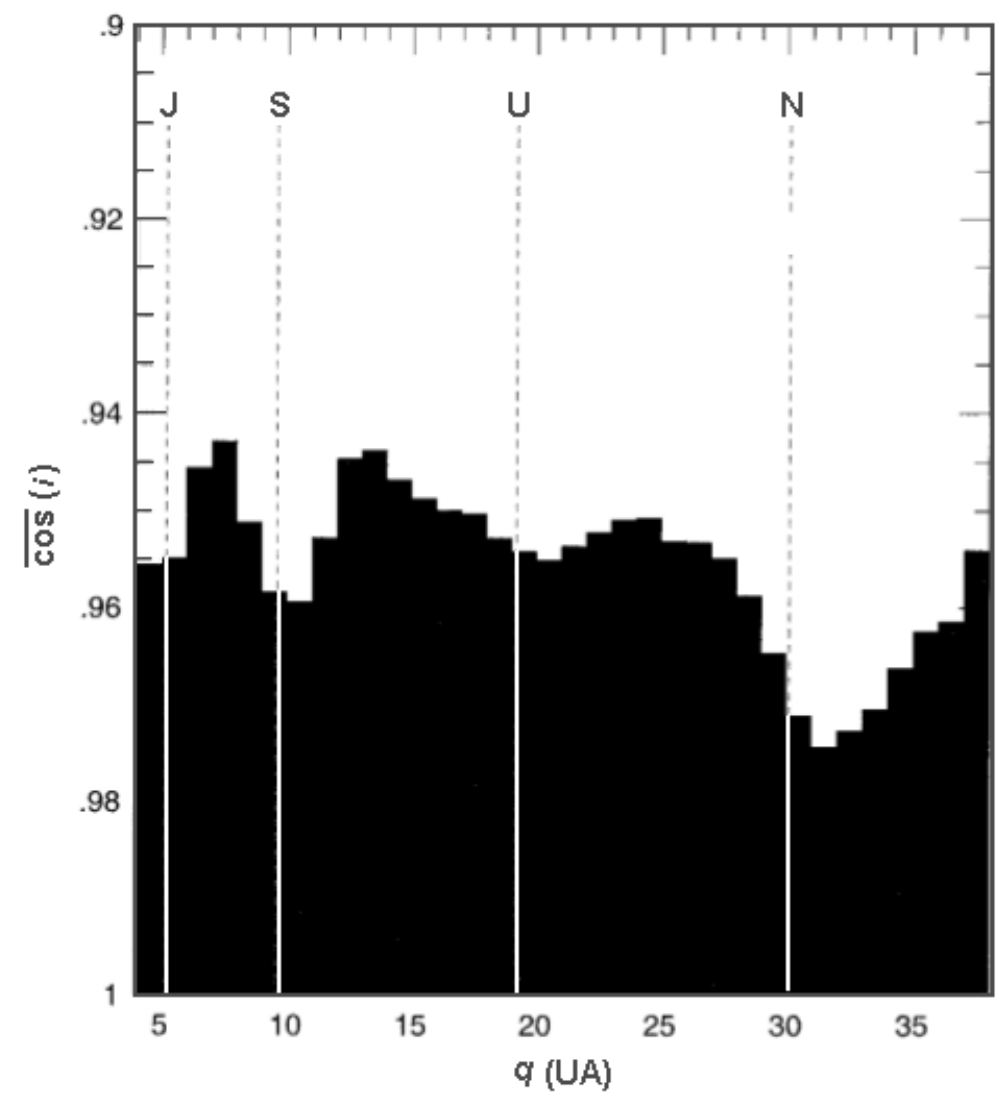

Figura 1.6.4. Relación entre los cosenos de las inclinaciones de los cometas y su perihelio a medida que evolucionan hacia el interior del TNb. Este histograma no incluye los objetos después que se han convertido en cometas visibles. Se dan como referencia las ubicaciones de los cuatro planetas gigantes (Adaptado de Levison y Duncan, 1997).

Otra consecuencia muy importante de los resultados que se desprenden de los párrafos anteriores, es que los objetos del TNb tienden a tener una evolución bastante predecible a medida que migran hacia el interior. De hecho, por lo general se encuentran bajo el control de un sólo planeta, el cual los dispersa al azar y, eventualmente, se lo transfiere al planeta que se encuentra más cercano, ya sea a su vecino inmediato interior o exterior. Por lo tanto, las excentricidades de los cometas que no han llegado a la zona de visibilidad y que se mueven entre los planetas gigantes, se mantendrán relativamente bajas, con valores cercanos a 0.2. Esta misma tendencia también se observa en las simulaciones. 
El escenario recién descripto es sólo una parte -aunque una parte muy importante- de una situación más general, dado que más del $60 \%$ de las partículas de las integraciones no se convierten en cometas visibles y la gran mayoría de esos objetos tienen que evolucionar a órbitas con un $T$ con respecto a uno de los planetas, significativamente menor que 3.

Así, los objetos con $T \ll 3$ juegan un papel muy pequeño en la distribución ecliptical de cometas porque un cometa con un $T$ pequeño respecto de un planeta, es más proclive a ser expulsado por éste del SS. Este hecho queda de manifiesto si consideramos el parámetro de Tisserand de un objeto en órbita parabólica respecto a un planeta $P$ :

$$
T_{P}=2 \sqrt{\frac{2 q}{a_{P}}} \cos (i),
$$

donde $q$ e $i$ son, respectivamente, la distancia perihélica y la inclinación de la órbita del cometa y $a_{P}$ es el semieje mayor de la órbita del planeta. Así, para que se dé una situación de eyección, la distancia perihélica del cometa debe satisfacer la condición $q \leq a_{P}$, lo que implica que $T_{P} \leq 2 \sqrt{2} \approx 2.83$ y naturalmente, si posee un valor mayor el planeta no tendrá ninguna chance de desligarlo del sistema.

El ángulo sólido del cono de pérdida de objetos expulsados del SS por un encuentro con un planeta viene dado por la expresión (Levison y Duncan, 1997),

$$
\Omega=4 \pi\left(\frac{1}{2}-\frac{T_{P}-2}{4 \sqrt{3-T_{P}}}\right) .
$$

Dicho valor para un $T_{N}=2.4$ equivale aproximadamente al $44 \%$ de una esfera, lo que está indicando que un cometa que siga un camino evolutivo tal que su $T_{P}$ disminuya permanentemente, estará cada vez más expuesto a ser expulsado del sistema y tendrá cada vez menos probabilidades de sobrevivir para poder, eventualmente, convertirse en un JFC visible. A priori, ello implica que existiría una correlación entre el $T_{N}$ inicial de un cometa y las posibilidades que éste tiene de convertirse en un JFC visible (en este contexto el término "inicial" hace referencia al estado de la partícula justo antes de abandonar el TNb). Ese hecho parece confirmarse si se observa la Figura 1.6.5a donde se grafica la fracción de objetos que se convierten en JFCs visibles en función de sus $T_{N}$ iniciales. En efecto, los autores incluyen en sus simulaciones al menos 100 partículas por cada partícula individual, y por lo tanto todas ellas tendrán mayoritariamente la misma órbita inicial. Ahora bien, si se tiene en cuenta que cada punto del gráfico representa un grupo de partículas con la misma órbita inicial, se observará que efectivamente la fracción de miembros de los JFCs que se vuelven visibles disminuye a medida que nos movemos hacía los grupos formados por objetos con $T_{N}$ iniciales más pequeños. Por otro lado, en las Figuras $1.6 .5 \mathrm{~b}$ y $1.6 .5 \mathrm{c}$ se observa que no existe correlación alguna entre las cantidades graficadas, lo cual es interesante porque implica que las propiedades orbitales de cada una de las partículas que terminan como JFC, no parecen estar fuertemente correlacionadas con sus órbitas iniciales; en otras palabras, un cometa que termina convirtiéndose en un JFC visible no tiene memoria de la órbita que tenía cuando abandonó el TNb. 

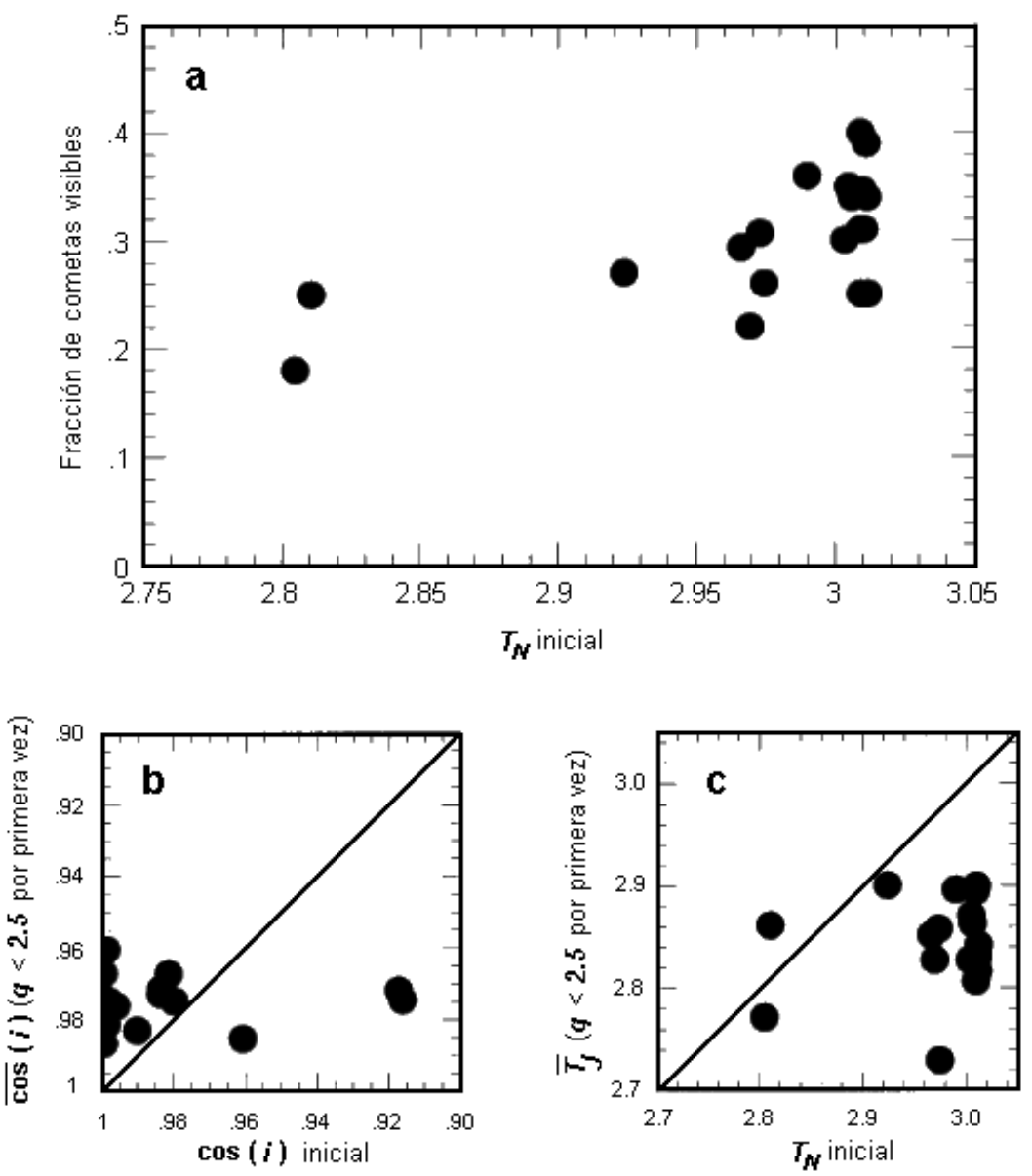

Figura 1.6.5. Relación entre los elementos orbitales de cometas visibles y sus órbitas iniciales. a: Fracción de cometas visibles que se convierten en miembros de la JFC en función de sus $T_{N}$ iniciales. b: Valor medio del coseno de las inclinaciones de los cometas que se hacen visibles por primera vez en función de sus órbitas iniciales. c: Parámetro de Tisserand $T_{J}$ al momento en que el cometa entra por primera vez a la zona de visibilidad en función de su $T_{N}$ inicial (Adaptado de Levison y Duncan, 1997).

Finalmente, otros importantes resultados que surgen de este trabajo pueden resumirse en los siguientes puntos: (a) la vida dinámica media de los cometas eclípticos resulta ser de unos $4.5 \times 10^{7}$ años y cerca del $30 \%$ se convierten en cometas visibles; (b) prácticamente todos los cometas que se convierten en cometas visibles por primera vez, son miembros de la población JFC; (c) la cantidad de cometas eclípticos que tienen su origen en el TNb y magnitudes absolutas integradas $H_{t o t}<9$, ascendería a $1.2 \times 10^{7}$; (d) los JFCs son estadísticamente más propensos a tener tiempos de vida física medios de $\sim 1.2 \times 10^{4}$ años; (e) la proporción entre JFCs extintos y JFCs activos es 3.5 ; (f) se descarta al TNb como fuente principal de cometas Tipo Halley, dada la muy escasa cantidad de objetos que terminan evolucionando en miembros de dicha familia y los autores sugieren en su lugar a la OC como su fuente principal; (g) todas las partículas sobrevivientes terminan con semiejes mayores fuera de la órbita de Neptuno, hecho que a los mismos les hace sospechar sobre la posible existencia de una población de objetos con órbitas muy excéntricas en un disco disperso más allá de la órbita de Neptuno, 
lo que se confirmará años después con el descubrimiento de los SDOs; y (h) las colisiones de un JFC con Júpiter se dan cada $\sim 400$ años y con la Tierra cada $\sim 1.3 \times 10^{7}$ años.

En la actualidad esta ampliamente aceptado que la población de Centauros es una población de transición intermedia en la evolución dinámica de TNOs que partiendo de la TNR, terminan sus días como miembros de la JFC (Fernández, 1980; Duncan et al., 1988; Holman y Wisdom, 1993; Levison y Duncan, 1997; Morbidelli, 1997; Jewitt, 2002; Di Sisto y Brunini, 2007; Volk y Malhotra, 2008; Bailey y Malhotra, 2009; Melita y Licandro, 2012; Perna et al., 2014; Duffard et al., 2014b; etc.).

Dado que los Centauros son objetos con órbitas muy caóticas que cruzan las órbitas de los planetas exteriores teniendo muchos encuentros con los gigantes gaseosos, sus vidas medias dinámicas son cortas (Volk y Malhotra, 2008) no superando los $7.2 \times 10^{7}$ años (Di Sisto y Brunini, 2007).

Si bien los Troyanos de Neptuno (Horner y Lykawka, 2010), los Plutinos (Morbidelli, 1997; Yu y Tremaine, 1999; Kavelaars et al., 2009; Di Sisto et al, 2010), el CTNb (Volk y Malhotra, 2008), el TNb -para TNOs con órbitas inestables y poco excéntricas (Levison y Duncan, 1997) o con inclinaciones de bajas a moderadas (Volk y Malhotra, 2013)- y la OC -para Centauros con altas inclinaciones y grandes perihelios (Brasser et al., 2012) o Centauros con grandes semiejes (Emel'yanenko et al., 2005; Kaib et al., 2009)- constituyen todas fuentes secundarias de Centauros, esta población se alimenta y se renueva principalmente con objetos provenientes del SD (Di Sisto y Brunini, 2007). Volk y Malhotra (2013) sugieren que el estudio de la distribución de inclinaciones de la población de Centauros puede resultar muy útil a la hora de identificar sus diversas fuentes.

En el citado trabajo de Di Sisto y Brunini de 2007, se presentan resultados de un estudio sobre el origen y la distribución de la población de Centauros, basados en integraciones numéricas con partículas que parten del SD e interactúan con el Sol y los planetas gigantes por tiempos del orden de la edad del SS. Solamente la cuarta parte de las partículas sobreviven al tiempo total de la integración, mientras que la mitad es eyectada del sistema y el resto colisiona con alguno de los planetas gigantes o cruza la órbita de Júpiter. Estos autores encuentran una fuerte dependencia con la distancia perihélica $q$ cuando estudian la relación entre la cantidad de objetos eyectados y la cantidad de objetos sobrevivientes. Sostienen que el SD es la fuente principal de la población de Centauros, afirmando que la zona $q<35 U A$ es la más eficiente en proveer de objetos a esa población, mientras que la zona del SD con $q<35 U A$ y $40 U A<a<50 U A$ es la óptima si se trata de convertir un objeto con ese origen en un JFC. Las simulaciones también dan cuenta que las tres cuartas partes de las partículas que sobreviven a la integración ingresan en la zona de Centauros y permanecen en ella entre $10^{7}$ y $10^{8}$ años, con un promedio de tiempo de vida dinámica de $7.2 \times 10^{7}$ años (Figura 1.6.6); y que una tercera parte de estos Centauros termina dentro de la órbita de Júpiter, constituyéndose en posibles JFCs. 


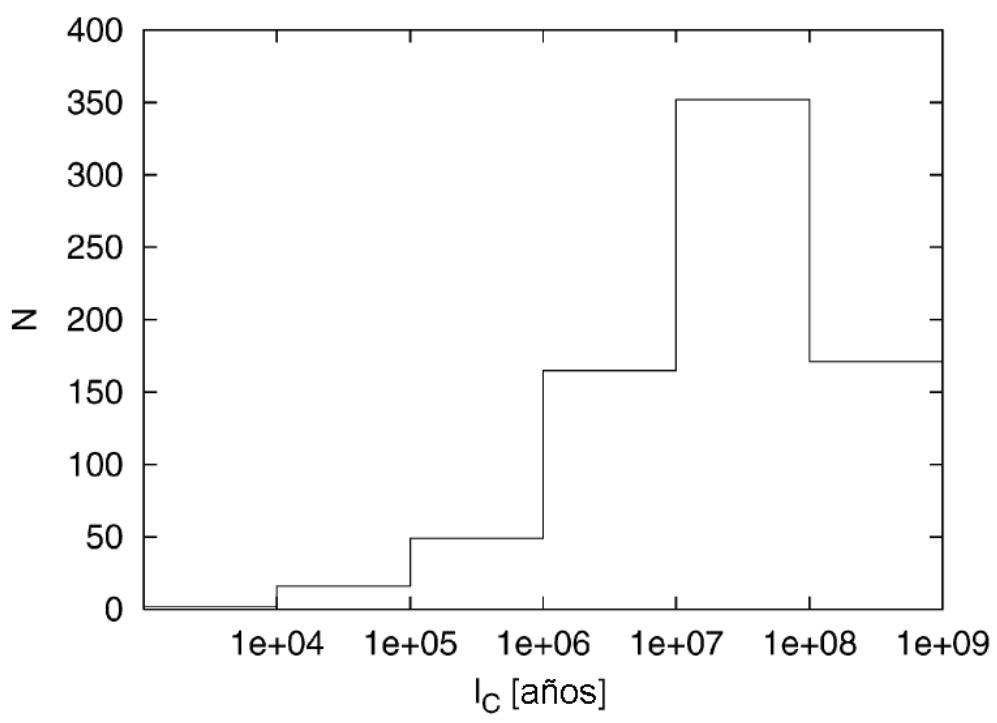

Figura 1.6.6. Distribución de los tiempos de vida dinámica medios en la zona de Centauros de los SDOs de las simulaciones (Adaptado de Di Sisto y Brunini, 2007).

Son varios los autores que también concluyen que los tiempos de vida dinámica medios de esta población es de unas decenas de millones de años (Levison y Duncan, 1997; Dones et al., 1996; Tiscareno y Malhotra, 2003; Horner et al., 2004; Bailey y Malhotra, 2009; etc.). En particular Levison y Duncan (1997), imponiendo a sus integraciones inclinaciones iniciales $i<16^{\circ}$, obtienen para los cometas eclípticos $\left(T_{J}>2\right.$, un grupo que incluye tanto a JFCs como a Centauros), un tiempo de vida dinámica medio de $4.5 \times 10^{7}$ años. Di Sisto y Brunini (2007) restringiéndose al mismo rango de inclinaciones iniciales a fin de establecer condiciones comparables, obtienen un tiempo de vida dinámica medio de $4.2 \times 10^{7}$ años, valor muy concordante.

Otro resultado al que llegan Di Sisto y Brunini (2007) es que el tiempo de vida medio de los miembros de esta población resulta ser altamente dependiente tanto de la inclinación inicial como de la distancia perihélica. Así, la Figura 1.6.7 nos muestra que cuanto mayor es la inclinación inicial de una partícula, mayor será su tiempo de vida dinámica, en consonancia con lo que hallan años después Volk y Malhotra (2013) quienes encuentran que el tiempo de vida dinámica medio aumenta casi linealmente con la inclinación inicial. 


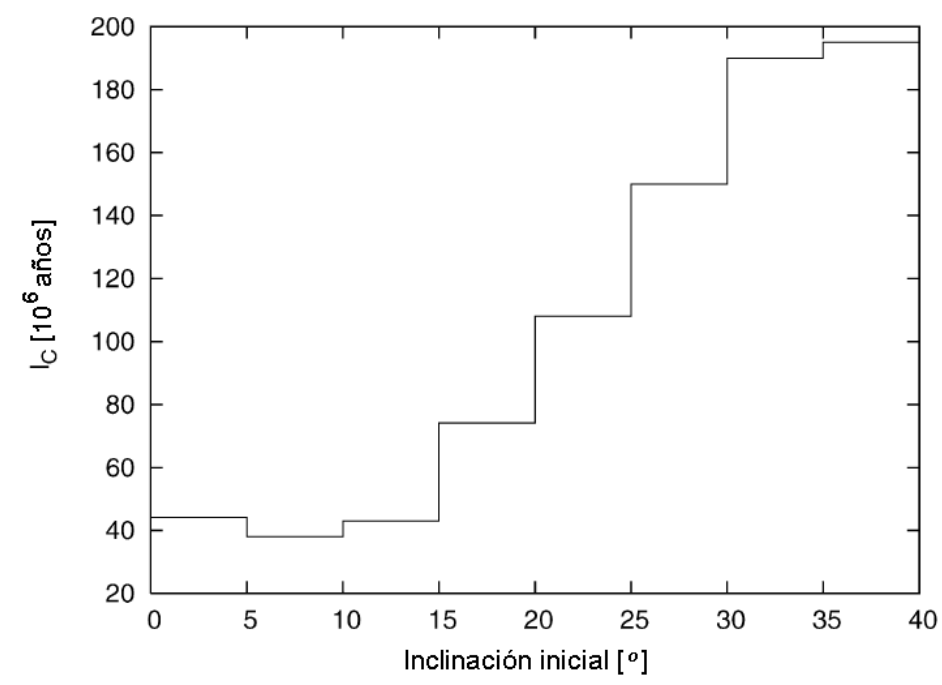

Figura 1.6.7. Inclinación inicial en función del tiempo de vida dinámica medio en la región de Centauros (Adaptado de Di Sisto y Brunini, 2007).

En relación a la distancia perihélica, la fuerte dependencia que encuentran puede observarse en la Figura 1.6.8, mientras que un crecimiento exponencial de la cantidad de Centauros con dicha distancia puede apreciarse en la Figura 1.6.9.

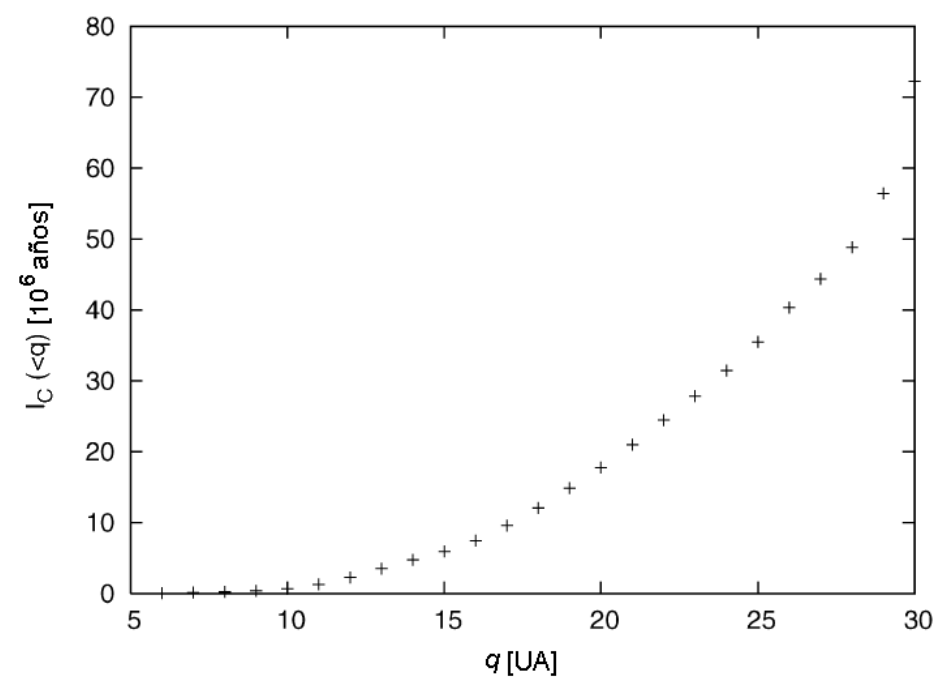

Figura 1.6.8. Tiempo de vida dinámica medio de los SDOs que llegan a la zona de Centauros con $q(U A)$ menor que un valor dado (Adaptado de Di Sisto y Brunini, 2007). 


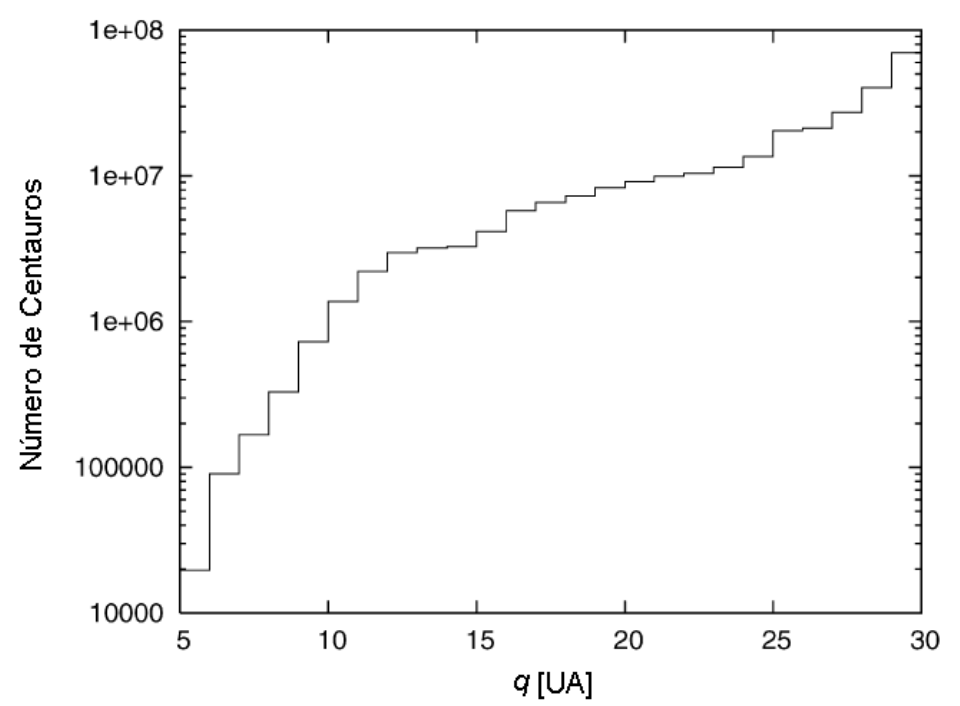

Figura 1.6.9. Histograma que muestra la cantidad de Centauros con $R>1 \mathrm{~km}$ en función de la distancia perihélica $q(U A)$ (Adaptado de Di Sisto y Brunini, 2007).

En relación a la presente tesis, también resulta pertinente mencionar la cantidad de miembros de la población de Centauros con radios $R>1 \mathrm{~km}$ que estos autores calculan basándose en la cantidad de SDOs que Fernández et al. (2004) admiten estimar con gran incerteza, y encuentran que el valor más probable es $2.8 \times 10^{8}$ objetos.

Son también de nuestro interés las conclusiones que pueden obtenerse del modelo que los autores proponen para hallar las zonas más densamente pobladas de la región de Centauros, zonas ocupadas por aquellos Centauros que poseen los tiempos de vida dinámicos más largos. La Figura 1.6.10 muestra que la región con mayor densidad poblacional en el espacio $(a-i)$ (azul) se da para Centauros con $20 U A<a<80 U A$ e inclinaciones nunca mayores que $60^{\circ}$ preferentemente en el rango de $5^{\circ} \leq i \leq 30^{\circ}$-. Por otro lado, en el plano $(Q \times q)$ dicha densidad se observa para objetos con $20 U A<q<30 U A$, por lo que el modelo está prediciendo que la mayor cantidad de Centauros tendría distancias perihélicas $q>20 U A$, hecho que hoy se verifica en raras ocasiones, muy probablemente por un sesgo observacional (Figura 1.6.11). 


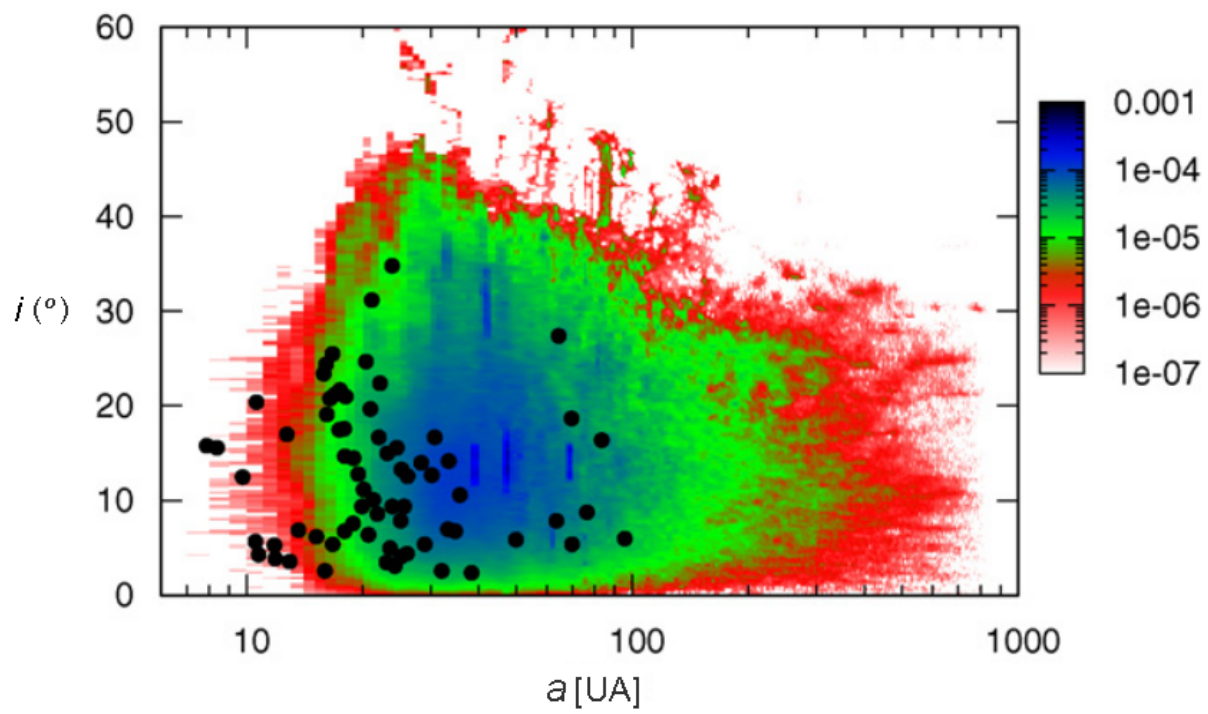

Figura 1.6.10. Tiempo de permanencia de la población de Centauros representado en el plano $(a \times i)$. La mayor densidad de población (azul) se da para Centauros con $20 U A<$ $a<80 U A$ e inclinaciones preferentemente en el rango de $5^{\circ} \leq i \leq 30^{\circ}$. Los puntos son Centauros observados (Adaptado de Di Sisto y Brunini, 2007).

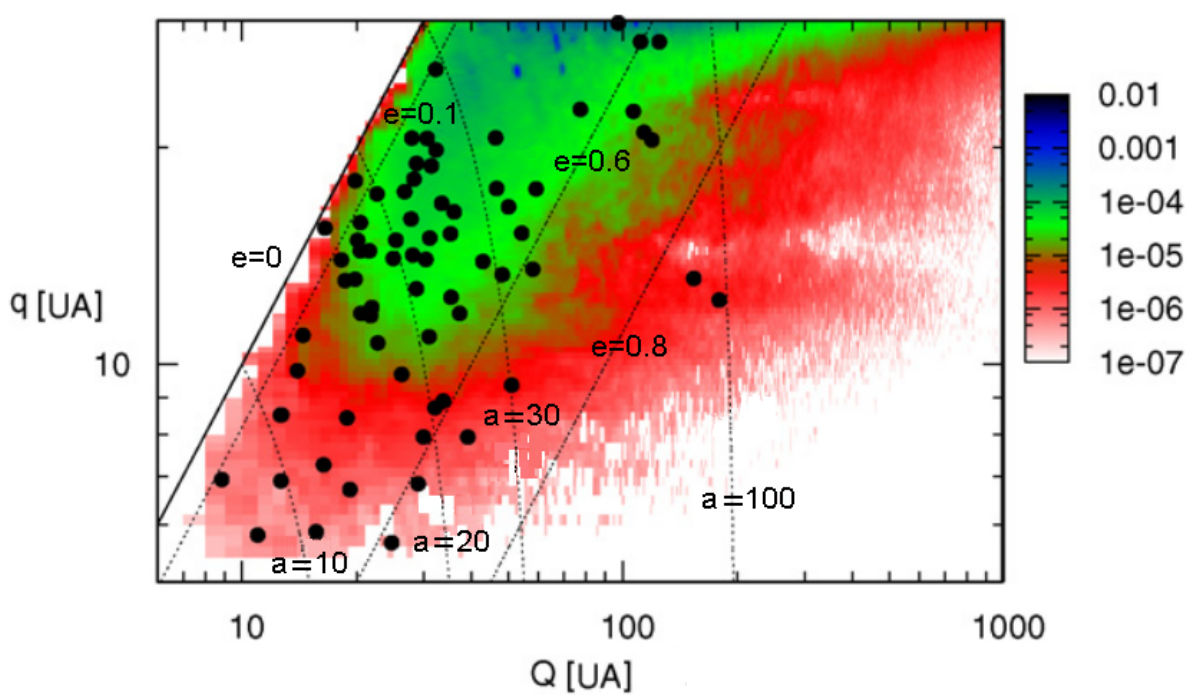

Figura 1.6.11. Tiempo de permanencia de los Centauros generados en la simulación representado en el plano $(Q \times q)$. Los Centauros se concentran en las zonas donde permanecen por más tiempo (azul). Los puntos son Centauros observados -raramente poseen $q>20 U A,-$; las rectas diagonales corresponden a las órbitas de excentricidad constante para $e=0,0.1$, 0.6, y 0.8; las líneas curvadas representan a las órbitas de semieje mayor constante para $a=10,20,30$, y $100 U A$ (Adaptado de Di Sisto y Brunini, 2007). 
Finalmente nos interesa destacar un último resultado de este trabajo y es el relacionado al modelo de distribución de magnitudes aparentes que proponen para la población de Centauros, el cual predice que habría una gran cantidad de esos objetos con radios entre $1-3 \mathrm{~km}$ y magnitudes aparentes y latitudes eclípticas en rangos de observabilidad, visibles principalmente en regiones cercanas a la órbita joviana y aún no descubiertos $(R \operatorname{mag} \approx 22.5)$. Los autores atribuyen ese hecho a la ineficiencia de los programas de búsqueda en la detección de Centauros. Por lo tanto, según el modelo sería de esperar que un programa de búsqueda optimizado para Centauros encuentre evidencias de una mayor densidad de éstos objetos por grado cuadrado de lo que dan cuenta los programas de búsqueda realizados hasta el presente.

\subsection{La Función Acumulativa de Luminosidad}

Como una extensión natural de la larga historia de programas de búsqueda realizados sobre la población del MBA enfocados al estudio de su distribución de tamaños, el descubrimiento de los primeros TNOs llevó a querer conocer también la distribución de tamaños de la TNR y a partir de ella, a tratar de estimar su masa total.

La densidad superficial de luminosidad acumulada a partir de una dada magnitud nos da la cantidad esperable de objetos por grado cuadrado más brillantes que dicha magnitud. Así, a partir de estas mediciones se puede estimar la Función Acumulativa de Luminosidad (CLF) de la región relevada, expresando la densidad superficial $\Sigma(<m)$ por medio de una ley de potencias simple de la forma,

$$
\Sigma(<m)=10^{\alpha\left(m-m_{0}\right)},
$$

donde $m$ es la magnitud aparente, $m_{0}$ es la magnitud aparente para la cual es esperable hallar un objeto por grado cuadrado, y $\alpha>0$ es un parámetro característico de cada población. Es importante mencionar que las magnitudes $m$ involucradas en la definición dada por (1.7.1) hacen referencia implícita a cierta magnitud límite, hecho que aclararemos en lo inmediato.

Considerando que la escala de magnitudes es una escala logarítmica, una manera conveniente de representar una CLF es tomando logaritmos de $\Sigma(<m)$, con lo cual ahora su representación gráfica será una recta de pendiente positiva $\alpha$. La densidad superficial obtenida a partir de un determinado programa de búsqueda se obtiene dividiendo el número de objetos encontrados, por la superficie total relevada, para luego asignar ese valor a la magnitud límite de eficiencia de detección de dicho programa, que no es otra que la mayor magnitud para la cual se detecta al menos el $50 \%$ de los objetos con ese brillo presentes en las imágenes. Por lo tanto, cada punto del gráfico de una CLF representa y resume los resultados obtenidos con un programa de búsqueda específico de magnitud límite conocida. Es importante aclarar que en la literatura solamente unos pocos autores explicitan que las abscisas de sus CLF son efectivamente las magnitudes límites obtenidas (por ejemplo, Luu y Jewitt, 1998; Jewitt et al., 1998; Sheppard et al., 2000; Larsen et al., 2001), mientras que la mayoría hace referencia a dicha magnitud límite simplemente como magnitud $m$-que se definirá a continuación-, lo que puede confundir a un lector que no esté familiarizado con este abuso de notación.

Para un objeto del SS sin actividad cometaria que se encuentra a una distancia heliocéntrica $R$, a una distancia geocéntrica $\Delta$ y es observado con un ángulo de fase $\alpha$, se define su 
magnitud aparente como (Bowell et al., 1989),

$$
m(R, \Delta, \alpha)=H+5 \log (R . \Delta)-2.5 \log (\Phi(\alpha)),
$$

donde $H$ es una constante y $\Phi(\alpha)$ es la función de fase que nos da la fracción de luz dispersada para un ángulo de fase $\alpha$ respecto de la luz que se dispersa para el ángulo de fase cero y está normalizada a 1 cuando $\alpha=0$. Ahora bien, si a un objeto se lo observa con su superficie totalmente iluminada -ángulo de fase $\alpha=0$ - a una distancia de $1 U A$ tanto del Sol como de la Tierra, resulta que $m=H$ y en ese caso se habla de $H$ como la magnitud absoluta del objeto.

Con el fin de analizar la densidad superficial de objetos en función de su magnitud en poblaciones donde sus miembros poseen distancias $R$ y $\Delta$ comparables, pueden emplearse indistintamente magnitudes aparentes $m$ o absolutas $H$.

Pero en poblaciones como la JFC, donde la magnitud aparente de un cometa no sólo es altamente dependientes de sus distancias geocéntrica y heliocéntrica sino que también es dependiente de su actividad cometaria, lo apropiado es utilizar magnitudes absolutas $H$ y en particular, la magnitud absoluta nuclear $H_{N}$.

Los estudios de la CLF son importantes a la hora de diseñar modelos sobre el origen y la evolución del TNb (por ejemplo, Davis y Farinella, 1997) y de estudiar las características físicas de estos objetos (por ejemplo, Luu y Jewitt, 1996b; Tegler y Romanishin, 1998, 2000; Barucci et al., 2000; Jewitt y Luu, 2001; Delsanti et al., 2004; Peixinho et al., 2004, 2012).

La determinación de la pendiente de la distribución de magnitudes aparentes requiere contar con un número de objetos detectados en un programa de búsqueda que cubra una cierta área y posea una sensibilidad conocida. Con el fin de ser de alguna utilidad para su posterior modelización -e inclusive para establecer comparaciones con los resultados de otros trabajos-, Petit et al. (2008) señalan que los programas de búsqueda deben cumplir al menos tres requisitos: (a) especificar el área total relevada; (b) especificar las magnitudes de los objetos descubiertos con sus respectivos errores; y (c) realizar un estudio de la magnitud límite alcanzada por el programa de búsqueda donde debe quedar clara su eficiencia de detección en función de la magnitud.

Los principales trabajos que se enfocan explícitamente en el problema de la determinación de la CLF de la TNR son: Jewitt y Luu (1995), Irwin et al. (1995), Jewitt et al. (1996), Jewitt et al. (1998), Gladman et al. (1998), Luu y Jewitt (1998), Chiang y Brown (1999), Sheppard et al. (2000), Larsen et al. (2001), Trujillo et al. (2001a y 2001b), Gladman et al. (2001), Ferrin et al. (2001), Bernstein et al. (2004), Elliot et al. (2005), Petit et al. (2006), Fraser et al. (2008) y Fuentes y Holman (2008). Se realizaron antes y después muchos otros programas de búsqueda, pero no tenían como finalidad obtener una CLF de TNOs; algunos porque no contaban con una cantidad suficiente de TNOs descubiertos como para realizar un ajuste fiable, y los otros porque tenían como metas estudios principalmente dinámicos. Sin embargo, cabe mencionar que los resultados obtenidos en varios de esos programas de búsqueda (por ejemplo, Tombaugh, 1961; Luu y Jewitt, 1988; Kowal, 1989; Levison y Duncan, 1990; Cochran et al., 1995), fueron empleados para imponer cotas observacionales y/o aportar puntos en las CLF de varios de los trabajos antes mencionados.

En la literatura no todos los programas de búsqueda cumplen con los tres requisitos de los que nos hablan Petit et al. (2008), y se hace indispensable reagruparlos entre los que 
cumplen esas pautas y los que no. Entre los primeros están los programas de Jewitt y Luu (1995), Irwin et al. (1995), Jewitt et al. (1998), Gladman et al. (1998), Chiang y Brown (1999), Trujillo et al (2001a y 2001b), Gladman et al. (2001), Bernstein et al. (2004), Petit et al. (2006), y Fraser et al. (2008), a los que podemos sumar los trabajos de Allen et al. (2002), Trujillo y Brown (2003) y Fuentes y Holman (2008) (Figura 1.7.1).

\begin{tabular}{|c|c|c|c|c|c|c|c|c|}
\hline Referencia & Abreviatura & $\Omega^{*}\left(\operatorname{deg}^{2}\right)$ & $\mathbf{N}^{\dagger}$ & $\eta_{\text {máx }}{ }^{\ddagger}$ & ${ }^{A} R_{m a g} g_{\text {lim }}$ & R.A. (2000) & Lat. ecl. $\left({ }^{\circ}\right)$ & Comentarios \\
\hline \multicolumn{9}{|l|}{ Wide-Area Surveys: } \\
\hline Jewitt and Luu (1995) & JL95 & 1.2 & 7 & 1. & 24.8 & $\begin{array}{l}21: 30-01: 10 \\
10: 00-15: 10\end{array}$ & $\begin{array}{l}0-5 \\
0-5\end{array}$ & $\begin{array}{c}\text { Fall } \\
\text { Spring }\end{array}$ \\
\hline Irwin et al. (1995) & ITZ95 & 0.7 & 2 & 1. & 23.5 & - & $0-10$ & \\
\hline Jewitt et al. (1998) & JLT98 & 51.5 & 13 & 0.91 & 22.5 & $\begin{array}{l}23: 50-02: 10 \\
07: 30-10: 40\end{array}$ & $\begin{array}{l}0-5 \\
0-5\end{array}$ & $\begin{array}{l}\text { Oct. } 1996 \\
\text { Feb. } 1997\end{array}$ \\
\hline Trujillo et al. (2001a) & TJL01 & 73 & 86 & 0.83 & 23.7 & $\begin{array}{l}08: 00-14: 00 \\
21: 20-01: 00\end{array}$ & $\begin{array}{c}-10,0,10 \\
0,20\end{array}$ & $\begin{array}{c}1999 \\
\text { Mar. } 2000\end{array}$ \\
\hline Trujillo et al. (2001b) & T01 & 164 & 4 & 0.85 & 21.1 & $\begin{array}{l}22: 18-01: 25 \\
09: 00-12: 05\end{array}$ & $\begin{array}{c}0-12 \\
0-5\end{array}$ & \\
\hline Allen et al. (2002) & - & 2.3 & 33 & - & 25.2 & - & - & \\
\hline Trujillo and Brown (2003) & - & 5108 & 28 & 0.85 & 20.7 & - & - & \\
\hline Petit et al. (2006) & P06 & $\begin{array}{l}5.97 \\
5.88\end{array}$ & $\begin{array}{l}39 \\
26\end{array}$ & $\begin{array}{l}0.90 \\
0.90\end{array}$ & $\begin{array}{l}24.6 \\
24.2\end{array}$ & $\begin{array}{l}21: 08-21: 17 \\
20: 17-20: 26\end{array}$ & $\begin{array}{l}0-1.9 \\
0-1.7\end{array}$ & $\begin{array}{l}\text { Uranus } \\
\text { Neptune }\end{array}$ \\
\hline Fuentes and Holman (2008) & 8) - & 2.82 & 82 & 0.88 & 25.7 & - & - & \\
\hline \multicolumn{9}{|l|}{ Deep Surveys : } \\
\hline Gladman et al. (1998) & G98 & $\begin{array}{c}0.25 \\
0.175\end{array}$ & $\begin{array}{l}2 \\
3\end{array}$ & $\begin{array}{l}1 . \\
1 .\end{array}$ & $\begin{array}{l}24.6 \\
25.6\end{array}$ & $\begin{array}{c}11: 50 \\
23: 00,00: 10\end{array}$ & $\begin{array}{c}0 \\
0,4.5\end{array}$ & $\begin{array}{l}\text { CFHT/8K } \\
5-\mathrm{m} \mathrm{Hale}\end{array}$ \\
\hline Chiang and Brown (1999) & ) $\mathrm{CB} 99$ & 0.009 & 2 & 1. & 27.0 & $22: 55$ & 0.5 & \\
\hline Gladman ef al. (2001) & G01 & $\begin{array}{c}0.27 \\
0.012\end{array}$ & $\begin{array}{c}17 \\
0\end{array}$ & $\begin{array}{l}1 . \\
1 .\end{array}$ & $\begin{array}{l}25.9 \\
26.7\end{array}$ & $\begin{array}{l}09: 32 \\
19: 24\end{array}$ & $\begin{array}{l}2.6 \\
1.0\end{array}$ & $\begin{array}{l}\text { CFHT/12K } \\
\text { VLT/FORS1 }\end{array}$ \\
\hline Bemstein et al. (2004) & B04 & 0.019 & 3 & 1. & 28.7 & $14: 08$ & 1.5 & \\
\hline Fraser ef al. (2007) & $\Gamma 07$ & $\begin{array}{l}0.64 \\
0.85 \\
0.76\end{array}$ & $\begin{array}{c}6 \\
19 \\
14\end{array}$ & $\begin{array}{l}0.96 \\
0.97 \\
0.92\end{array}$ & $\begin{array}{l}25.4 \\
25.7 \\
25.4\end{array}$ & $\begin{array}{l}21: 40 \\
22: 24 \\
20: 39\end{array}$ & $\begin{array}{c}-0.7 \\
-0.8 \\
1.3\end{array}$ & $\begin{array}{l}\text { CFHT/12K } \\
\text { MEGAPrime } \\
\text { CTIO/Blanco }\end{array}$ \\
\hline
\end{tabular}

* Área relevada.

†Número de TNOs empleados en la determinación de la CLF.

¥Máxima eficiencia de deteccion del programa de búsqueda.

^Límite de eficiencia de deteccíon.

Figura 1.7.1. Listado de los programas de búsqueda que cumplen los requisitos pedidos por Petit et al. (2008) (Adaptado de Petit et al, 2008). Nota: Hemos agregado los trabajos de Allen et al. (2002), Trujillo y Brown (2003) y Fuentes y Holman (2008). El trabajo citado en la tabla como F07 es una comunicación personal a Petit et al. (2008) y en esta tesis esta citado como Fraser et al. (2008).

Por otra parte, Jewitt et al. (1996), Luu y Jewitt (1998), Sheppard et al. (2000), Larsen et al. (2001) y Elliot et al. (2005), si bien ajustaron una CLF con datos propios y ajenos, no explicitan en absoluto una función de eficiencia de sus programas de búsqueda o realizan esa estimación ineficientemente, por lo cual conforman el grupo de los programas de búsqueda que no cumplen estríctamente con las exigencias de Petit et al. (2008) para ser considerados programas bien condicionados (Figura 1.7.2). 


\begin{tabular}{|c|c|c|c|c|c|c|c|c|}
\hline Referencia & Abreviatura & $\Omega^{*}\left(\operatorname{deg}^{2}\right)$ & $\mathbf{N}^{\dagger}$ & $\eta_{\text {máx }}{ }^{\ddagger}$ & ${ }^{\wedge} \operatorname{Rrmag}_{\text {lim }}$ & R.A. (2000) & Lat. ecl. $\left({ }^{\circ}\right)$ & Comentarios \\
\hline \multirow[t]{2}{*}{ Jewitt et al. (1996) } & JLC96 & 4.4 & 3 & - & 23.2 & $12: 15-16: 00$ & $0-20$ & CTIO $1.5-\mathrm{m}$ \\
\hline & & 3.9 & 12 & - & 24.2 & $08: 30-00: 40$ & $0-5$ & UH 2.2-m \\
\hline \multirow[t]{2}{*}{ Jewitt and Luu (1998) } & JL98 & 0.28 & 5 & - & 26.1 & - & - & Keck wide \\
\hline & & 0.028 & 1 & - & 26.6 & - & - & Keck deep \\
\hline Sheppard et al. (2000) & SO0 & 1428 & 0 & 0.92 & 18.8 & $07: 00-12: 00$ & $0-20$ & $0.5-\mathrm{m} \mathrm{APT}$ \\
\hline Larsen et al. (2001) & L01 & 550.1 & 8 & 0.97 & 21.5 & $00: 00-24: 00$ & $0-5$ & SpaceWatch \\
\hline Elliot et al. (2005) & E05 & $\sim 500$ & 512 & 0.96 & 22.0 & 00:00-24:00 & $0-5$ & \\
\hline
\end{tabular}

* Área relevada.

†Número de TNOs empleados en la determinación de la CLF.

¥Máxima eficiencia de deteccion del programa de búsqueda.

A Límite de eficiencia de deteccíon.

Figura 1.7.2. Listado de los programas de búsqueda que no cumplen los requisitos pedidos por Petit et al. (2008) (Adaptado de Petit et al, 2008).

Resulta pertinente detenernos en un trabajo realizado por Bernstein et al. (2004), quienes empleando el HST y cubriendo una pequeña área de 0.019 grados $^{2}$ cercana al plano invariante, descubren tres nuevos TNOs, objetos de magnitud aparente $R m a g>26$ y, considerando un albedo de 0.04 , de diámetros entre $25-44 \mathrm{~km}$. No detectan objetos a más de $43 U A$ y llama particularmente la atención el hecho que no detecten ningún Plutino pese a que las observaciones estaban dirigidas en la dirección de libración de sus perihelios. Teniendo en cuenta distancias e inclinaciones, consideran dentro de la población de TNO dos subpoblaciones, los CTNbOs y los que ellos llaman Excitados que corresponden a TNOs con altas inclinaciones y con una historia de acercamiento a Neptuno u otro objeto masivo. Luego de analizar los resultados encuentran que una ley de potencias simple no ajusta bien los datos dado que las subpoblaciones revelan diferencias en la distribución de magnitudes, lo que implicaría historias de acreción y erosión diferentes entre ambas clases dinámicas.

Teniendo en cuenta que en el trabajo de Trujillo et al. (2001a) se propone una ley de potencias simple con $\alpha=0.63 \pm 0.06$ válida en el rango $19<R$ mag $<27$, el programa de búsqueda de Bernstein et al. (2004) debería detectar unos 85 TNOs, e incluso con un $\alpha=0.51$ deberían haber hallado unos 16 objetos y no sólo los 3 que encuentran. De esta manera, limitando el estudio a la región mejor observada y usando los resultados de Chiang y Brown (1999), Gladman et al. (2001), Allen et al. (2002), Trujillo et al. (2001a), Larsen et al. (2001) y Trujillo y Brown (2003), ajustan una CLF mediante una ley de potencias simple de pendiente $\alpha=0.58 \pm 0.02$, pero encuentran que las observaciones de TNOs no se ajustan correctamente a esta CLF, principalmente en los extremos.

Con el objeto de salvar este obstáculo, ensayan diversos ajustes con otras leyes (Figura 1.7.3). Primeramente intentan ajustar los datos derivados de aquellos programas de búsqueda previamente seleccionados con una ley de potencias envolvente de la forma:

$$
\Sigma(\text { Rmag })=\Sigma_{23} 10^{\alpha(R m a g-23)+\alpha^{\prime}(\text { Rmag }-23)^{2}},
$$

donde $\alpha$ y $\alpha^{\prime}$ son parámetros a determinar y $\Sigma_{23}$ es la densidad superficial para $R$ mag $=23$. Advierten que el mejor ajuste para los TNOs los obtienen con $\alpha \approx 0.66$ y $\alpha^{\prime} \approx-0.05$, pero aclaran que una ley de esa forma tiene el inconveniente que no ajusta bien el número de TNOs brillantes de la población ubicados cerca del plano invariante, y que la probabilidad de hallar a (134340) Plutón en este caso es menor que 0.02. 


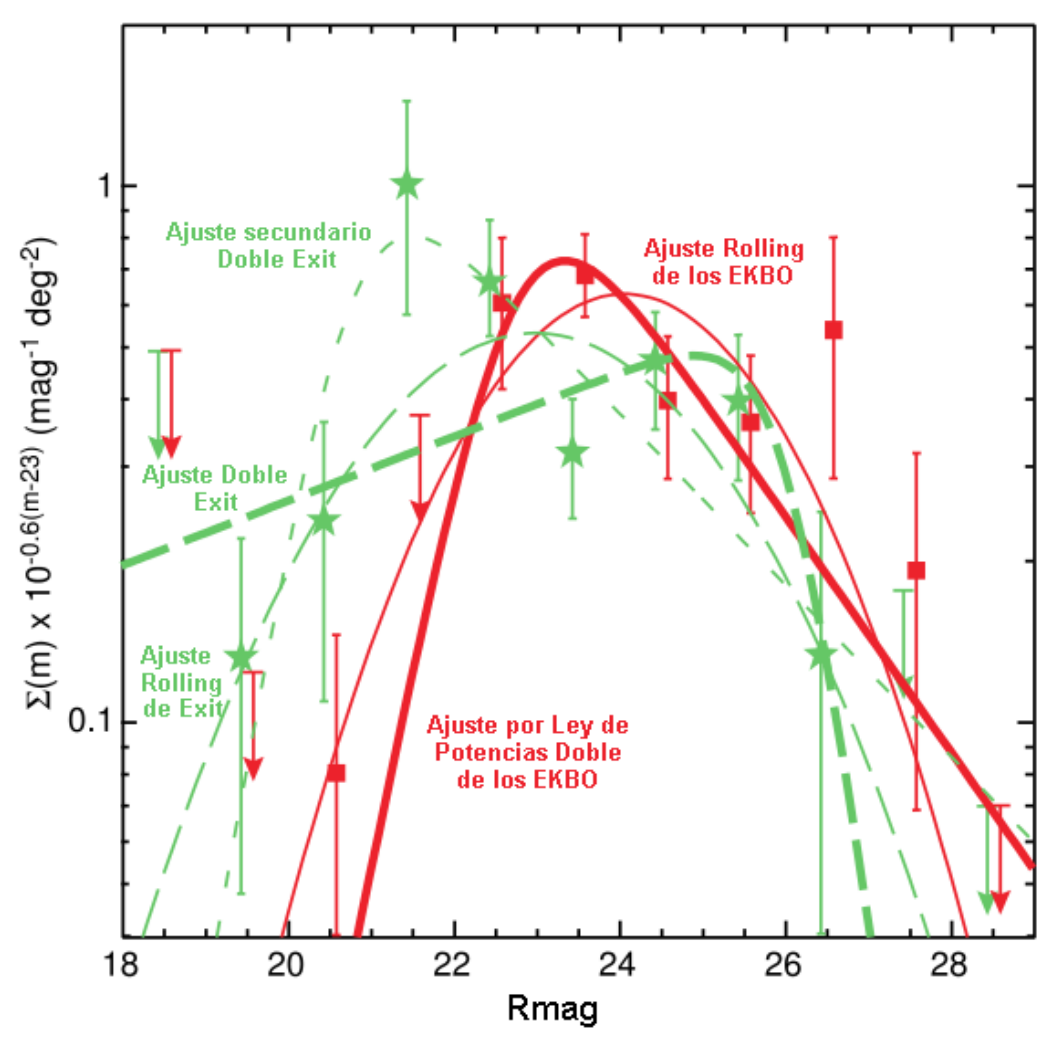

Figura 1.7.3. Diversos ajustes intentados por el grupo de Bernstein (Adaptado de Bernstein et. al, 2004).

Con el fin de lograr mejores ajustes, proponen un ajuste con una ley de potencia doble de la forma,

$$
\Sigma(R m a g)=\frac{(1+c) \Sigma_{23}}{10^{-\alpha_{1}(R m a g-23)}+c 10^{-\alpha_{2}(\text { Rmag }-23)}},
$$

donde $c \equiv 10^{\left(\alpha_{2}-\alpha_{1}\right)\left(\text { Rmag }_{e q}-23\right)}, \alpha_{1}$ y $\alpha_{2}$ son parámetros a determinar con $\alpha_{1}>\alpha_{2}$, y $R \operatorname{mag} g_{e q}$ es la magnitud para la cual ambas leyes contribuyen de forma equitativa.

Utilizando esta ley doble determinan que para los TNOs la pendiente del extremo de objetos brillantes es mayor que las estimadas previamente, mientras que en el extremo de objetos débiles -a partir de Rmag $=24$-, se produce un quiebre en la CLF y la pendiente disminuye notoriamente (Figura 1.7.4). En efecto, para los TNOs hasta Rmag $=24$ ajustan una recta con $\alpha_{1} \approx 0.88$, mientras que más allá de ese límite la recta que mejor ajusta a la CLF de los objetos más débiles se logra con $\alpha_{2} \approx 0.32$. En particular, para el caso especial de los CTNbOs eligen $\alpha_{1} \approx 1.36$ y $\alpha_{2} \approx 0.38$, mientras que para los Excitados, $\alpha_{1} \approx 0.66 \mathrm{y}$ $\alpha_{2} \approx-0.50$. 


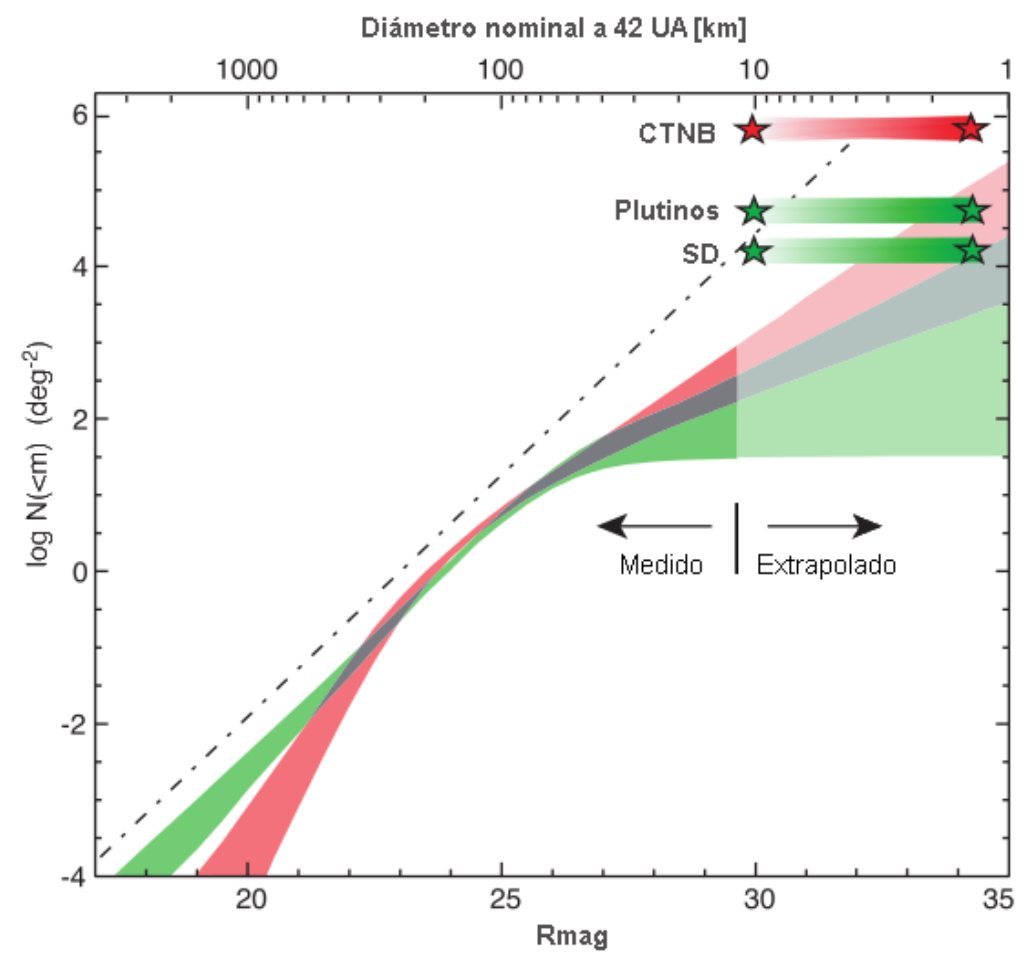

Figura 1.7.4. Ajuste de la CLF con una doble ley de potencias para la población Excitados (verde) y la población CTNb (rojo). La línea punteada es el ajuste obtenido por Trujillo et al. (2001) (Adaptado de Bernstein et al., 2004).

El apartamiento que estos autores observan respecto de una ley de potencias simple implicaría, entre otras cuestiones: (1) que la masa total de la población CTNb sería aproximadamente $0.01 M_{\oplus}$, predominando objetos de diámetros $D \approx 100 \mathrm{~km}$ y que posiblemente la masa de la población de los Excitados sería sólo unas pocas veces mayor; (2) que esta última población presentaría una distribución en la zona brillante con menor pendiente; (3) que los grandes objetos de la misma -que incluye a (134340) Plutón-, constituirían un $10 \%$ mientras que en los de la población CTNb llegarían solamente al $2 \%$; (4) que los grandes objetos de la población Excitados tendrían masas similares a la de (134340) Plutón, por lo que éste podría haber tenido su origen -por algún proceso físico- en dicha población; (5) que los objetos más grandes del CTNb poseerían magnitudes $R m a g \approx 20$; (6) que la deficiencia en la observación de pequeños TNOs sucede en un escenario donde parecería que al día de hoy los procesos de colisión se han interrumpido, sugiriendo una reducción del proceso colisional; (7) que la falta de objetos detectados a distancias de TNOs, implicaría que si cerca del plano invariante mas allá de las $50 U A$ la masa de éstos es comparable con la de la población del CTNb, esa población estaría formada principalmente por pequeños objetos de unos $40 \mathrm{~km}$ de diámetro; y (8) que habría muy pocos objetos pequeños entre los CTNbOs como para que esta población pueda ser la fuente de los JFCs, a menos que hubiera una cantidad significativa de objetos con diámetros menores que $20 \mathrm{~km}$.

Tanto la doble ley de potencias como la ley de potencias envolvente ajustan bien a los grandes objetos brillantes, pero en el último caso el ajuste es aceptable siempre y cuando el 
sistema (134340) Plutón-Caronte se considere una excepción.

Por su parte Petit et al. (2006) presentan los resultados surgidos de un programa de búsqueda que si bien tuvo como principal objetivo el descubrimiento de satélites irregulares de Urano y Neptuno, lo completan con el ajuste de una CLF para TNOs mediante una ley de potencias simple -no considerando necesaria una ley doble en oposición a lo propuesto por Bernstein et al. (2004)-, con una pendiente única $\alpha=0.76 \pm 0.1$ para el rango de magnitudes $22<R \operatorname{mag}<25$, que juntamente con los estimados por Elliot et al. (2005) $(\alpha=0.88 \pm 0.08)$ y Gladman et al. (1998) $(\alpha=0.76 \pm 0.10)$, conforman los valores más altos asignados a ese parámetro para esta población, muy por encima de los valores obtenido por Irwin et al. (1995) $(\alpha=0.32 \pm 0.12)$, Trujillo et al. (2001a) $(\alpha=0.63 \pm 0.06)$ y Gladman et al. (2001) $(\alpha=0.69 \pm 0.07)$. Posteriormente, Fraser et al. (2008) deciden estudiar un rango de magnitudes más amplio $(21<R m a g<26)$ y encuentran que sus datos, junto con los de programas de búsqueda anteriores, pueden ajustarse bien con una ley de potencias simple con $\alpha=0.65 \pm 0.05$, y afirman que para magnitudes $R m a g \gtrsim 24.4$ el ajuste mejora si se opta por una pendiente levemente más plana $(\alpha \approx 0.6)$, confirmando la suposición de Bernstein et al. (2004), pero advierten que la complicación introducida aquí por una ley de naturaleza doble, no garantizaría mejoras sustanciales. En ese mismo año, Fuentes y Holman (2008) realizan un programa de búsqueda sobre un campo de 2.82 grados $^{2}$ centrado en Urano con una magnitud límite de eficiencia de detección de $R m a g=25.69 \pm 0.01$ y modelando una CLF para TNOs con una ley de potencias simple para la región brillante y con una ley de potencias doble para la región débil $\left(\alpha_{1}=0.7, \alpha_{2}=0.3\right)$, afirmando que existiría un quiebre en $R m a g=24.3$, resultados que son consistentes con los obtenidos por Bernstein et al.(2004), y que constituirían una nueva confirmación de su hipótesis de un quiebre en la CLF de TNOs más allá de $R m a g=24$.

En la Figura 1.7.5 se grafican ajustes de la CLF según diversos autores, mientras que en la tabla de la Figura 1.7.6 se resumen los valores de las pendientes de las CLF de TNOs estimados en las publicaciones más destacadas. 


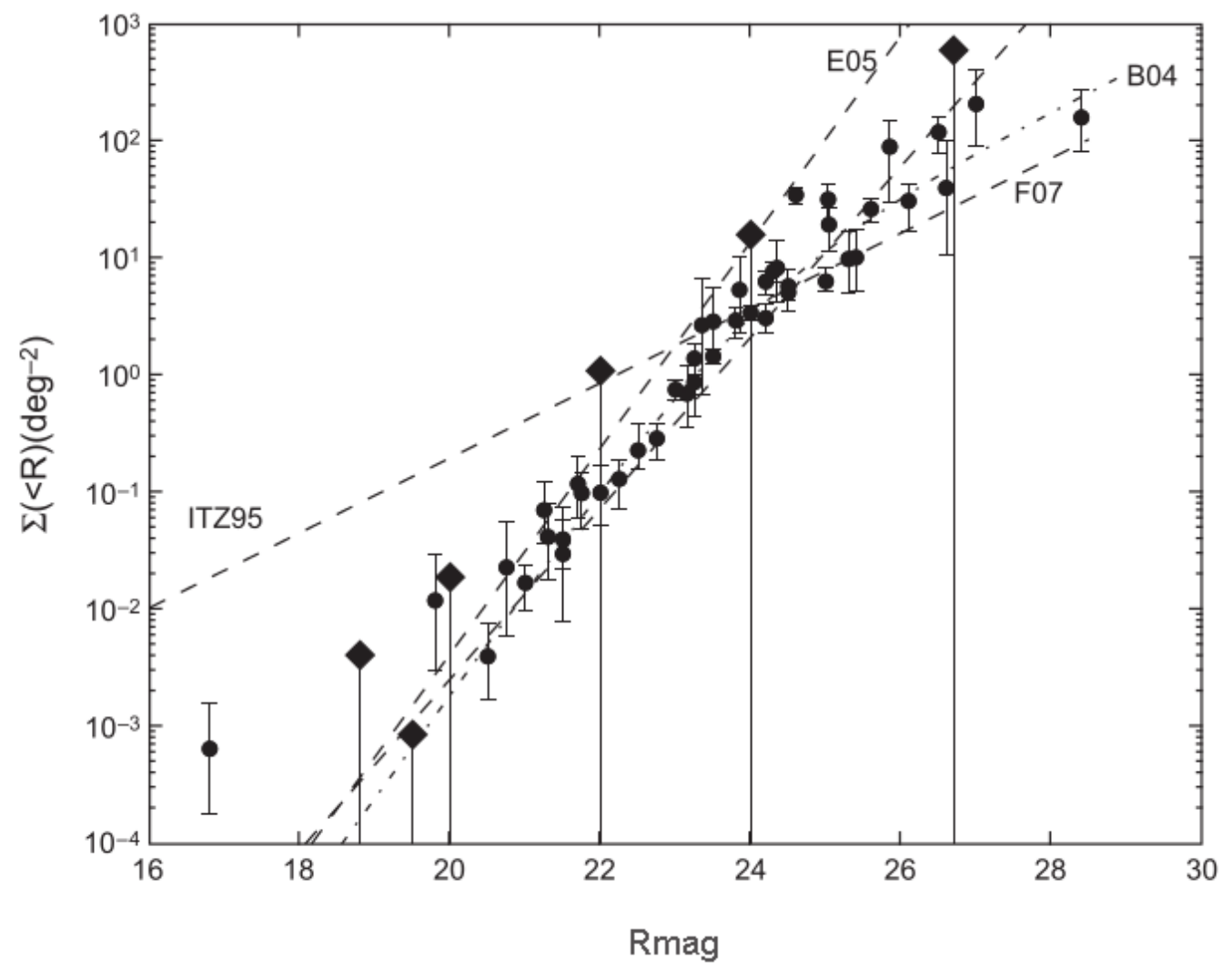

Figura 1.7.5. Diversos ajustes de la CLF realizados por distintos autores. Los círculos sólidos representan los puntos aportados por los trabajos de Tombaugh (1961), JLC96, JL98, L01, JL95, ITZ95, JLT98, G98, CB99, TJL01, G01, T01, B04, P06, y F07 (según las nomenclaturas de las tablas de las Figuras 1.7 .1 y 1.7.2). Las barras de error corresponden a un $68.3 \%$ de probabilidad. Los diamantes sólidos representan el límite superior en un $99.7 \%$ de probabilidad de no detección de K89, Lu y Jewit (1988), Levison y Duncan (1990), S00 y G01. Las líneas de puntos muestran: el ajuste más superficial (ITZ95, $\alpha=0.32$ ); el más reciente entre los aquí graficados (F07, $\alpha=0.65)$, y el más empinado (E05, $\alpha=0.88$ ). La línea de puntos y rayas muestra la CLF de B04, integrado para dar una densidad acumulativa (Adaptado de Petit et al., 2008). 


\begin{tabular}{|l|c|}
\hline \multicolumn{1}{|c|}{ Programas de búsqueda de TNO } & $\alpha$ \\
\hline Jewitt y Luu, 1995 & $<0.4$ \\
\hline Irwin et al., 1995 & $0.32 \pm 0.12$ \\
\hline Jewitt et al., 1998 & $0.58 \pm 0.05$ \\
\hline Gladman et al., 1998 & $0.76 \pm 0.1$ \\
\hline Chiang y Brown, 1999 & $0.52 \pm 0.02 / 0.66 \pm 0.04$ \\
\hline Trujillo et al., 2001a & $0.63 \pm 0.06$ \\
\hline Trujillo et al., 2001b & $0.66 \pm 0.06$ \\
\hline Gladman et al., 2001 & $0.69 \pm 0.07$ \\
\hline Ferrin et al., 2001 & $0.58 \pm 0.05$ \\
\hline Bernstein et al.,2004 (Simple) & $0.61 \pm 0.04 / 0.58 \pm 0.02$ \\
\hline Bernstein et al.,2004 (Doble) & $a_{1}=0.88, \alpha_{2}=0.32$ \\
\hline Eliot et al., 2005 & $0.88 \pm 0.08$ \\
\hline Petit et al., 2006 & $0.76 \pm 0.1$ \\
\hline Fraser et al. 2008 & $0.65 \pm 0.05$ \\
\hline
\end{tabular}

Figura 1.7.6. Sumario de las pendientes estimadas de la CLF para la población de TNOs, según distintos autores.

Finalmente mencionemos que Petit et al. (2008) subrayan que los gráficos de las CLF obtenidos para una determinada población, no deberían manipularse para derivar las distribuciones de luminosidad de otras, como veremos que se ha hecho en el pasado (por ejemplo, Figura 3.2.1).

\subsection{La Distribución Acumulativa de Tamaños}

A lo largo de los años se han utilizado dos formas de determinar la distribución de tamaños de una población dada: por un lado, mediante el modelado directo de la Distribución Acumulativa de Tamaños (CSD) y su comparación con las observaciones disponibles; y por el otro, derivándola directamente desde la CLF con una simple transformación lineal (por ejemplo, Irwin et al., 1995; Gladman et al., 1998; Bernstein et al., 2004; etc.).

Es comúnmente aceptado que para la Distribución Diferencial de Tamaños (DSD) los objetos obedecen una ley de potencias de la forma,

$$
d N(D) \propto D^{-q} d D,
$$

donde $d N(D)$ es el número de objetos con diámetros en el intervalo $(D, D+d D)$ y $q$ es una constante que puede ajustarse por medio de simulaciones de máxima-similitud de un programa de búsqueda, corregida por efectos de distancia heliocéntrica, geocéntrica, por eficiencia de detección del método de búsqueda y por estimación del albedo; o bien puede derivarse a partir de la pendiente $\alpha$ de la CLF de la población, mediante la relación (por ejemplo, Irwin et al., 1995; Gladman et al., 2001; Lowry et al., 2003; Meech et al., 2004; Petit et al., 2006; Fraser, 2008; etc.):

$$
q=5 \alpha+1 .
$$

En otras palabras, dicha relación proporciona el nexo para obtener una DSD a partir de una CLF. Es utilizada ampliamente en la literatura sin mayores cuestionamientos pese a que 
trae implícita la suposición, raras veces aclarada, de que el albedo no varía ni con la distancia ni con el tamaño de los objetos. Si la distribución de albedos de una población variara sólo con la distancia, entonces esto solamente afectaría a la normalización de su CLF (Frasser et al., 2008). Pero ya Jewitt y Luu (1998) advertían que el albedo de un objeto es directamente proporcional a su diámetro, posiblemente como resultado de la retención preferencial de hielos de los objetos más grandes y por el rejuvenecimiento superficial producido por colisiones, aunque advierten que la muestra de la que disponen es demasiado pequeña para sacar conclusiones apresuradas. Profundizando en este tema, Frasser et al. (2008) realizan un interesante trabajo explorando los efectos de utilizar una relación entre los parámetros $q$ y $\alpha$-ya no una simple transformación lineal-, con un albedo $p$ variando con el diámetro $D$, y para ello proponen la siguiente relación más refinada entre ambos parámetros:

$$
q=5 \alpha+1-\frac{5}{2} \beta
$$

donde el parámetro $\beta$ define una ley de la forma,

$$
p \sim D^{-\beta} .
$$

Claramente para una población con albedo constante $(\beta=0)$, recuperamos la clásica relación (1.8.2). Con los datos sobre albedos que hoy se dispone, el parámetro $\beta$ sería negativo, posiblemente $\beta \approx-1$ (Petit et al., 2008). Una estimación de $q$ basada en la suposición de un albedo constante potencialmente subestima el valor de la pendiente de la distribución de tamaños y dado que nuestro conocimiento actual de la relación entre albedo y tamaño es insuficiente para estimar un valor apropiado de $\beta$ (Frasser et al.,2008), debemos estar advertidos que las determinaciones actuales para las CSD de las distintas poblaciones de la TNR y de las poblaciones de Centauros y JFC a partir de sus respectivas CLF, probablemente tengan pendientes subestimadas en valor absoluto.

Actualmente se sabe que para los TNOs el albedo toma valores que van desde 0.06 -con grandes fluctuaciones- para pequeños objetos $(D<200 \mathrm{~km}$ ) (Grundy et al., 2005; Stansberry et al., 2008), hasta 0.6 -(134340) Plutón- (Albrecht et al., 1994; Young et al, 2001; Bertoldi et al., 2006; Brown et al., 2006) para los objetos más grandes $(D \approx 2000 \mathrm{~km})$, y que inclusive pueden alcanzar valores excepcionalmente altos como es el caso de (136199) Eris (0.96 \pm 0.07$)$ (Sicardy et al., 2011).

Equivalentemente, la CSD puede expresarse como:

$$
N(>D)=k D^{1-q},
$$

donde $k$ es una constante de proporcionalidad.

Es habitual representar la CSD en el plano $(\log (D) \times \log (N(>D)))$, lo que da una recta cuya pendiente $1-q$ resulta negativa dado que $\alpha>0$.

Tener una correcta estimación de la distribución de tamaños de la mayor cantidad de poblaciones que conforman las distintas clases dinámicas del SS, proporciona una herramienta fundamental a la hora de comprender los procesos de formación planetaria (Petit et al., 2006), lo que motivó a varios autores a tratar de estimar las CLF de dichas poblaciones y, a partir de ellas, derivar sus respectivas CSD. 
Los TNOs de mayor tamaño conocido son objetos realmente grandes comparados con los diámetros nucleares de los JFCs (estimados entre 1 - $10 \mathrm{~km}$-Meech, 2004; Tancredi et al., 2006-), habida cuenta que asumiendo albedos de 0.04 sus diámetros oscilan entre $30-800 \mathrm{~km}$, exceptuando unos pocos de diámetros mayores (Meech et al., 2004). En el TNb los objetos con diámetros entre $50-100 \mathrm{~km}$ probablemente hayan conservado su distribución de tamaños inicial (Farinella y Davis, 1996; Weidenschilling, 1997) y podrían reflejar las inestabilidades que se dieron en el exterior de la nebulosa solar. De hecho, Weidenschilling (1997) encuentra que inestabilidades gravitatorias pasajeras podrían haber formado nubes de planetesimales con masas suficientes como para formar cuerpos de unos pocos cientos de kilómetros de diámetro, compatibles con un TNO. Por otro lado, objetos con diámetros menores que $20 \mathrm{~km}$ probablemente sean el producto de fragmentos de la actividad colisional con una distribución diferencial de tamaños de la forma expresada por la ecuación (1.8.5), donde $D$ en este caso representaría el diámetro del núcleo cometario, y $q=3.5$ el valor correspondiente a una población aislada, relajada y en equilibrio que evolucionó colisionalmente (Dohnanyi, 1969; Williams y Wetherill, 1994). Incluso Farinella y Davis (1996) llegan a afirmar que quizá el $90 \%$ de los JFCs originados en el TNb son, efectivamente, fragmentos producto de colisiones. Weidenschilling (1997) también afirma que la sugerencia acerca de que cometas de tamaños del orden de los kilómetros sean producto de colisiones entre objetos de mayor tamaño, no es incompatible con los modelos de crecimiento colisional.

Si bien el principal mecanismo que alimenta a la población JFC es la fuga dinámica de los fragmentos productos de colisiones desde la TNR, un mecanismo alternativo es la captura de cometas provenientes de la OC. Ambos procesos podrían generar, respectivamente, una población que evoluciona colisionalmente ( $q=3.5$; Dohnanyi, 1969; Williams y Wetherill, 1994) o una población con una CSD similar a la observada en el TNb. En relación a este mecanismo alternativo debemos mencionar a aquellos objetos que en los primeros tiempos de la formación del SS fueron eyectados directamente a la OC y que estuvieron, por lo tanto, libres de la actividad colisional del TNb. En este sentido, Greenberg et al. (1984) afirman que probablemente los cometas sean remanentes inalterados de la población inicial de planetesimales del SSE y no fragmentos de grandes cuerpos parentales. Stern (1988), en un trabajo sobre colisiones entre miembros de la OC, mostró que la distribución de tamaños de esos objetos habría permanecido prácticamente primordial. Luego, Stern y Weissman (2001) incluyen por primera vez perturbadores externos en un modelo de formación de la OC -como pasajes estelares y las fuerzas de marea galáctica- y muestran que la actividad colisional en el disco antes de las eyecciones fue tan intensa que quizá hasta pudo evitar que la mayoría de los cometas sean lanzados hasta la OC, advirtiendo que ésta posiblemente tenga menos miembros de los se cree. Sin embargo, aclaran que probablemente pudo haber una región del disco donde las colisiones no fueran tan importantes, lo que habría permitió que un subconjunto de esta población escapara hacia la OC, aunque ciertamente su distribución de tamaños pudo haber sido alterada.

A pesar de que la estimación del tamaño de un núcleo cometario siempre ha sido una tarea compleja fundamentalmente porque nunca es fácil advertir la presencia o no de alguna actividad cometaria que enmascare su verdadero tamaño, varios grupos han emprendido el estudio de la distribución de tamaños de los núcleos cometarios. Las primeras estimaciones teóricas de la pendiente de la CLF de la población JFC se basaron en gran medida en el trabajo de Dohnanyi (1969), el cual demostró que la distribución acumulativa de tamaños de una 
población evolucionado colisionalmente debe tener una pendiente $\alpha=0.5$. Si consideramos a la población JFC como una población relajada de objetos de diámetros menores que $20 \mathrm{~km}$ producto de la actividad colisional, una primera aproximación teórica al valor de la pendiente de su CLF, será, como se mencionó, el valor de equilibrio (Dohnanyi, 1969; Williams y Wetherill, 1994). Otro acercamiento desde la teoría es un curioso dato que proveen Kenyon y Windhorst (2001) los cuales, mediante la Paradoja de Olbers, prueban que para objetos con radios entre $1 \mu \mathrm{m}$ y $1 \mathrm{~km}$, la pendiente debe ser $\alpha \leq 0.48$, demostrando que la distribución de tamaños para pequeños TNOs sería sensiblemente más plana que para los de mayor tamaño, evidenciando un cambio de pendiente en la recta. Por último, y antes de analizar los trabajos que se basan en observaciones directas, un tercer acercamiento al problema lo abordan Zahnle et al. (2003) proponiendo una pendiente cercana a $q=3.5$ (equivalentemente, $\alpha=0.5$ ) para cruzadores de Júpiter de diámetros entre $1-20 \mathrm{~km}$, no apoyándose en observaciones directas de cometas sino en un conteo de los cráteres de Europa y Ganímedes.

En cuanto a los trabajos observacionales de miembros de la JFC, Shoemaker y Wolfe (1982) realizando un análisis de núcleos de cometas lejanos, estiman una pendiente $q=3$ ( $\alpha=$ 0.4), mientras que por su parte Cochran et al. (1995), estudiando una muestra de objetos de tamaños comparables con el cometa 1P/Halley observados en el TNb por el HST, estiman que la población JFC podría ajustarse con una pendiente en el rango $3 \leq q \leq 5(0.4 \leq \alpha \leq 0.8)$. Weissman y Lowry (2001) estimaron que la CLF para la población JFC se ajusta con una pendiente $\alpha=0.28 \pm 0.01(q=2.4 \pm 0.05)$, y dos años después los mismos autores realizan otra estimación dando para la pendiente el valor $\alpha=0.32 \pm 0.01(q=2.6 \pm 0.05)$ para núcleos con diámetros entre 2.8 $-12 \mathrm{~km}$ (Weissman y Lowry, 2003) en perfecto acuerdo con $\alpha=0.32 \pm 0.02$ $(q=2.6 \pm 0.1)$, valor que habían obtenido un año antes (Weissman y Lowry, 2002). La muestra de cometas eclípticos que analizan Lamy et al. (2004) quedan bien ajustadas con una pendiente $\alpha=0.32 \pm 0.04(q=2.6 \pm 0.2)$ o $\alpha=0.38 \pm 0.06(q=2.9 \pm 0.3)$, dependiendo de si se consideran o no los NEOs en órbitas cometarias con diámetros $D>3.2 \mathrm{~km}$. Al año siguiente, Lowry et al. (2003) estiman la pendiente para los JFCs en $\alpha=0.32 \pm 0.02(q=2.6 \pm 0.1)$.

Por su parte Meech et al. (2004) encuentran que el uso de una ley como la expresada por la ecuación (1.8.5) con $q=3.5$ es incapaz de reproducir la CSD de los núcleos de los JFCs. Efectivamente, realizan un análisis numérico centrado en dicho valor variándolo entre $q=1.5$ y $q=5$ y en todo el rango no logran mejorar los resultados observacionales, sugiriendo que el problema podría deberse a que cualquier actividad cometaria, inclusive la más leve, aumentaría la cantidad de pequeños objetos y entonces concluyen que la única forma de poder reproducir la distribución observada con una ley de este tipo es quebrando artificialmente la distribución original $D^{-2.5}$ para diámetros pequeños, en cuyo caso la distribución actual estaría fuertemente truncada para los objetos de menor diámetro. Primeramente realizan un ajuste grueso de la CSD de JFC para $2<D<20 \mathrm{~km}$ con $q=2.45 \pm 0.05(\alpha=0.29 \pm 0.01)$, y luego afinan el ajuste para el caso particular de cometas con diámetros en el intervalo $4 \mathrm{~km}<$ $D<10 \mathrm{~km}$, obteniendo el mejor resultado para esta subpoblación con una recta de pendiente algo más abrupta de $q=2.91 \pm 0.06(\alpha=0.38 \pm 0.01)$. Por su parte, Weissman y Levison (1996) sugirieron que los objetos del TNb presentan una distribución de tamaños consistente con una ley de potencias como la de la ecuación (1.8.5) pero quebrada, con pendientes dadas por $q=4.5(\alpha=0.7)$ para diámetros $D>20 \mathrm{~km}$ y $q=3.0(\alpha=0.4)$, compatibles con núcleos cometarios de diámetros $D \leq 20 \mathrm{~km}$. Esto último arroja un valor de pendiente menos profunda que la distribución de tamaños truncada que proponen Meech et al. (2004). La 
idea del truncamiento en la población cometaria también aparece en los trabajo de Weissman (1982), Bailey y Stagg (1988), Weissman (1990), y Fernández et al. (1999) quienes ya lo habían propuesto para núcleos de pequeños tamaños.

Hasta aquí, la mayoría de los autores muestran un aceptable acuerdo entre ellos, estimando para la pendiente $\alpha$ de la CLF de la población JFC valores en el rango $0.29-0.38$, aunque este rango podría ser más amplio. Por ejemplo, Weissman y Lowry (2003) teniendo en cuenta que dado que la pérdida de material por sublimación es un proceso superficial e independiente del tamaño del núcleo (Lowry et al., 2008), estimaron que los de radios más pequeños son los que proporcionalmente tienden a perder a lo largo del tiempo una mayor fracción de su radio inicial en relación con los núcleos más grandes y, debido a este efecto, la pendiente primordial de la CSD podría haber sido $\approx 0.1$ más grande que los valores que arrojaría actualmente, y es por ello que el rango de pendientes $\alpha$ de la CLF del que hablamos, podría variar entre $0.38-0.48$. Una posible confirmación de este hecho podemos encontrarla en el trabajo de O'Brien y Greenberg (2003) que empleando modelos más refinados que Dohnanyi (1969), calculan que para una población que evoluciona bajo un régimen gravitatorio dominado por colisiones, su CLF puede ser ajustada con un parámetro $\alpha=0.41$, valor comprendido en ese último rango y muy similar a la pendiente $\alpha=0.39$ que Stuart (2001) emplea para ajustar la CLF de la población de NEOs.

Sin embargo, valores por afuera de esos rangos, y como se verá posiblemente más propios de la población de Centauros, aparecen en dos trabajos de un mismo grupo de investigadores (Fernández et al., 1999; Tancredi et al., 2006). Los primeros estiman una CLF para magnitudes absolutas en el rango $15.25<H<16$ y afirman que los datos se ajustan bien con una pendiente $\alpha=0.53 \pm 0.05$, es decir $q=3.65 \pm 0.25$, pero Meech et al. (2004) advierten que ese valor por encima del mencionado rango, puede deberse a la inhomogeneidad de los datos que usa el grupo para las distancias heliocéntricas que tenían los cometas en el momento en el que se tomaron las mediciones, donde los más cercanos al Sol muy probablemente presenten datos contaminados por actividades cometarias difíciles de identificar y remover. Por su parte, Lowry et al. (2003) también tienen sus objeciones sobre los resultados del trabajo de Fernandez et al. (1999) advirtiendo sobre la multiplicidad de fuentes usadas -algunas tan antiguas como del año 1950- señalando que la gran mayoría de las estimaciones de magnitudes nucleares derivan de métodos de reducción inconsistentes y de técnicas de sustracción de comas poco confiables. Además, subrayan que no queda claro si las magnitudes son derivadas en base a un sistema fotométrico común. Todo ello conduce a que se vuelva extremadamente difícil realizar comparaciones entre los distintos cometas. De todos modos, años después el mismo grupo obtiene un valor similar para la pendiente de la CLF de la población JFC, estimándola en $\alpha=0.54 \pm 0.05$ para cometas con perihelios menores que 2.5 $U A$ (Tancredi et al., 2006).

Un resumen de las pendientes de las CLF para la población JFC obtenidas por diversos autores se muestra en la tabla de la Figura 1.8.1. 


\begin{tabular}{|l|c|}
\hline Programa de búsqueda de JFCs & $\boldsymbol{\alpha}$ \\
\hline Dohnanyi, 1969 (equilibrio) & 0.5 \\
\hline Shoemaker y Wolfe, 1982 & 0.4 \\
\hline Weissman y Levison, 1997. & 0.4 \\
\hline Fernández et al., 1999 & $0.53 \pm 0.05$ \\
\hline Weissmany Lowry, 2001 & $0.28 \pm 0.01$ \\
\hline Weissman y Lowry, 2002 & $0.32 \pm 0.02$ \\
\hline Weissman y Lowry, 2003 & $0.32 \pm 0.01$ \\
\hline Lowry et al., 2003 & $0.32 \pm 0.02$ \\
\hline Lamy et al., 2004 & $0.32 \pm 0.04 / 0.38 \pm 0.06$ \\
\hline Meech et al., 2004 & $0.29 \pm 0.01 / 0.38 \pm 0.01$ \\
\hline Tancredi et al., 2006 & $0.54 \pm 0.05$ \\
\hline
\end{tabular}

Figura 1.8.1. Sumario de las pendientes de la CLF de la población JFC, estimadas por distintos autores.

Un aspecto que pocas veces se menciona es el hecho que las diversas estimaciones de la CSD de TNOs están realizadas con datos de objetos con diámetros mayores que $100 \mathrm{~km}$ mientras que para el caso de los JFCs los objetos son núcleos cometarios con $D<20 \mathrm{~km}$, y como por el momento no se han observado TNOs tan pequeños, la comparación entre las distribuciones de ambas poblaciones es por lo menos incierta. A este respecto es de notar que si los estudios sobre la distribución de tamaños de los TNOs empleara magnitudes absolutas como se hace en el caso de los JFCs, la comparación entre ambas poblaciones arrojaría resultados más realistas (Lowry et al., 2003).

Si se comparan los valores de las pendientes estimadas para los TNOs (tabla de la Figura 1.7.6) con las estimadas para los cometas de la JFC (tabla de la Figura 1.8.1), se advertirá que las primeras resultan ser siempre mayores que las segundas. Incluso si los valores más altos de $\alpha$ en el caso de la población JFC son correctos, es claro que la curva que representa la distribución de tamaños de esta población resulta más plana que la correspondiente a los TNOs más grandes, y una explicación para este efecto podría ser que haya un cambio en la pendiente de la distribución de tamaños para los TNOs más pequeños (Weissman y Levison, 1996; Bernstein et al., 2004; Fraser et al., 2008; Fuentes y Holman, 2008; etc.). Por otro lado, ignorando cualquier proceso inusual que pudiera cambiar drásticamente la distribución de tamaños para pequeños TNOs a medida que evolucionan hacia el SSI a órbitas cometarias, las CLF que estiman los diversos trabajos sobre los JFCs puedes considerarse como una prueba razonable de que la CSD de los TNOs debería ser mucho más plana para los tamaños más pequeños (Lowry et al., 2004). Además, si damos crédito a la estimación que realiza Larsen et al. (2001) de la pendiente de la CLF de Centauros $(\alpha=0.54 \pm 0.07)$, el quiebre en la CLF de TNOs probablemente ocurra para objetos de diámetros comparables con los de los Centauros más débiles detectados, esto es, aquellos con diámetros inferiores a $20-40 \mathrm{~km}$.

Otra posible explicación podría ser la existencia de un sesgo observacional en relación a que los cometas que observamos son los más grandes de la población, o al menos son los que poseen una mayor área superficial activa. Pero si el valor estimado de la pendiente de la CLF de los JFCs es realmente representativo de esta población, es de suponer que el calor solar provoca la completa desintegración de los núcleos cometarios más pequeños, o al menos reduce rápidamente sus tamaños dejándolos por debajo de toda detección posible, lo que se 
traduce en una mayor disminución en la pendiente de la CLF de esta población (Lowry et al., 2003).

Meech et al. (2004) enfatizan la importancia que tiene el descubrimiento de nuevos Centauros y TNOs para poder obtener buenas estimaciones de sus distribuciones de tamaños, y así poder compararlas con la de los SPC y los LPC y luego aplicar los resultados a modelos dinámicos. Desafortunadamente la tasa de descubrimiento, en particular de Centauros, es relativamente baja, y si a ello le sumamos que no se ha realizado hasta el presente un programa de búsqueda optimizado para hallar la densidad superficial de esta población, indefectiblemente la CSD de la misma no puede estar bien estimada (Jewitt et al., 1996; Levison y Duncan, 1997; Sheppard et al., 2000; Larsen et al., 2001; Di Sisto y Brunini, 2007).

Con el fin de paliar en alguna medida la falta de datos que existe en torno a la confección de una CLF representativa de la población de Centauros y que no se limite su obtención simplemente a desplazar ajustes realizados para otras poblaciones, se consideró que realizar un programa de búsqueda sistemática de Centauros podría conducirnos a la construcción de una CLF más representativa de esta población, lo que se constituyó en el eje de la presente tesis. Un hecho determinante en la viabilidad del proyecto fue la accesibilidad a un instrumento como el Astrograph for the Southern Hemisphere (ASH), con características técnicas -gran campo, luminoso, etc.- y coyunturales -amplia disponibilidad de tiempos de observación, operación remota, etc.- muy propicias a nuestros fines, y además una probada eficiencia tanto en el campo de la Astronomía Estelar como en el estudio de TNOs (Ortiz et al., 2010; Ortiz et al., 2011).

En el siguiente capítulo se expondrá la forma en la que se llevó adelante dicho programa de búsqueda, desarrollando temas como la caracterización y aptitud técnica del telescopio utilizado; la adquisición y procesamiento del material observacional; la descripción del método de búsqueda de objetos del SS de propia autoría; y la estimación de su eficiencia de detección.

Luego, en el capítulo siguiente se detallarán los Centauros descubiertos que permitieron mediante la estimación de una nueva CLF de la población, derivar la CSD de la misma.

En el siguiente, se presentará un estudio de los efectos que produce la interacción de partículas de alta energía con las superficies de los objetos del SSE debido a las variaciones de la heliosfera. Esto resulta relevante en este trabajo, ya que la variación de los albedos afecta la relación entre la CLF y CSD de una población. Así, se presentará un modelo numérico en el que se simulan los efectos del medio interestelar en el SSE y se describen los modelos utilizados, los diferentes medios interestelares con los que interactúa el SS, y los efectos de la radiación recibida por los objetos. Finalmente se discutirán los resultados de las simulaciones.

En un último capítulo, se presentan las conclusiones de la tesis y las perspectivas futuras. 



\section{Capítulo 2}

\section{Programa de búsqueda de Centauros}

\subsection{Caracterización del instrumento}

El programa de búsqueda que se presenta en esta tesis fue realizado con el ASH, telescopio instalado en el Cerro Burek $\left(290^{\circ} 41^{\prime} 35.5^{\prime \prime} \mathrm{E}, 31^{\circ} 47^{\prime} 12.4^{\prime \prime} \mathrm{S}\right.$, a.s.n.m. $=2664.8 \mathrm{~m}$; código del observatorio = I08), Complejo Astronómico El Leoncito (CASLEO), provincia de San Juan, Argentina, operado gracias a un acuerdo entre el Instituto de Astrofísica de Andalucía (IAA), España, y el CASLEO.

El ASH (Figura 2.1.1) es un reflector tipo newtoniano, fabricado por Astro Works Corporation, con montura tipo horquilla, un diámetro del espejo primario de $D=450 \mathrm{~mm}$ y una longitud focal efectiva de $F=1260 \mathrm{~mm}$, con lo que estamos en presencia de un telescopio muy luminoso, con una relación focal $F / D=2.8$. En el foco primario posee una cámara $S B I G$ $11000 M$, fabricada por Santa Barbara Instruments Group que emplea un detector CCD Kodak KAI-11000M de 4008 pixeles $\times 2672$ pixeles enfriado por Efecto Peltier de dos etapas. Las especificaciones de fábrica del detector se detallan en la Figura 2.1.2 y su curva de eficiencia cuántica en la Figura 2.1.3. Es importante mencionar que esta cámara permite usar parte del detector para hacer autoguiado, lo que mejora considerablemente las característica del seguimiento del instrumento. Mediante una conexión a internet puede operarse en forma remota desde cualquier parte del mundo.

De las características del telescopio y del CCD, se desprende que este instrumento ofrece un campo de $1.77 \operatorname{grados}^{2}(97.8 \mathrm{arcmin} \times 65.2 \mathrm{arcmin})$-superficie equivalente a unas nueve lunas llenas- con una escala PIXSCALE $=1.47$ arcsec pixel $^{-1}$. Este gran campo es una propiedad relevante en la implementación del programa de búsqueda propuesto porque permite utilizar siempre las mismas estrellas de referencia para la fotometría y la astrometría, pudiéndose obtener así una alta precisión. 


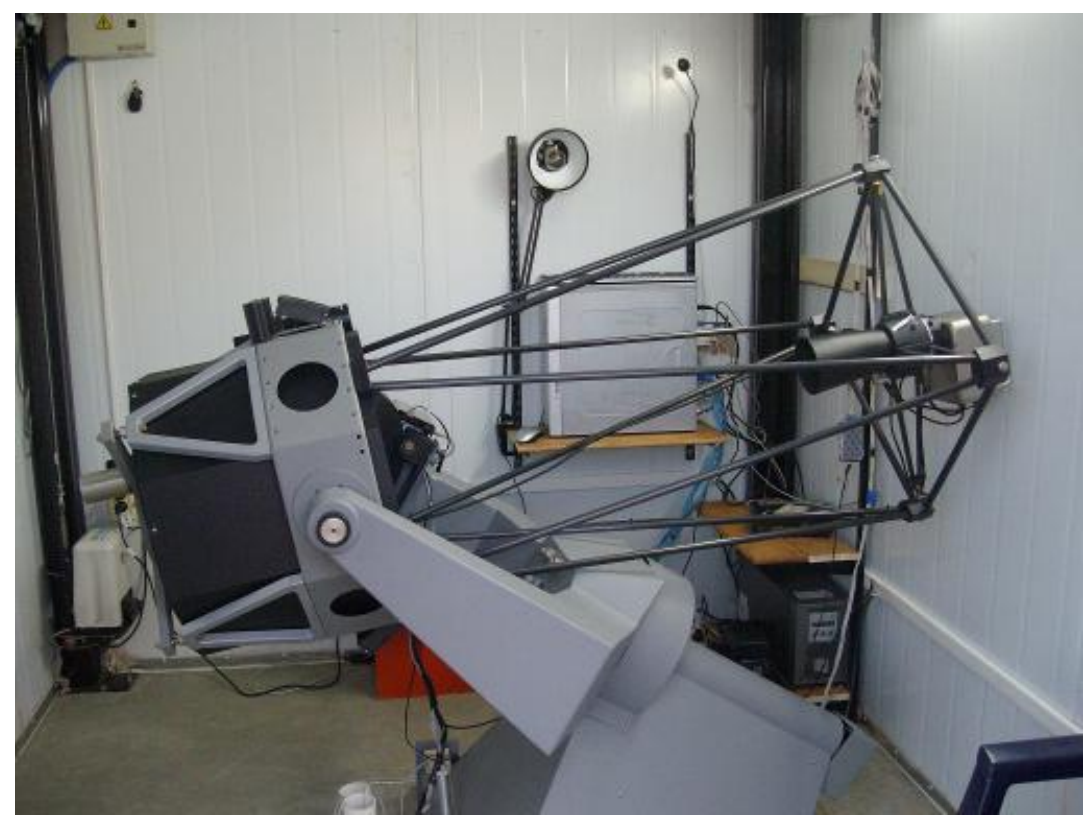

Figura 2.1.1. Telescopio ASH emplazado en el Cerro Burek (CASLEO, San Juan, Argentina) con el que se llevó adelante el programa de búsqueda de Centauros.

\begin{tabular}{|l|c|}
\hline Chip & Kodak Enhanced KAl-11000M \\
\hline Dimensiones del chip & $36 \mathrm{~mm} \times 24.7 \mathrm{~mm}$ \\
\hline Filas $\times$ columnas & 4008 pixeles $\times 2745$ pixeles (incluye pixeles para autoguiado) \\
\hline Tamaño de cada pixel & $9 \mu \times 9 \mu$ \\
\hline Capacidad completa & $50000 \mathrm{e}^{-}$ \\
\hline Corriente de oscuridad & $<1.5 \mathrm{e}^{-/} / \mathrm{pixel} / \mathrm{seg} \mathrm{a}^{\circ} \mathrm{C}$ \\
\hline Tiempo de exposición & $0.01 \mathrm{a} 3600 \mathrm{seg}$ \\
\hline Conversor A/C & $16 \mathrm{bits}$ \\
\hline Ganancia & $0.8 \mathrm{e}^{-} / \mathrm{ADU}$ \\
\hline Ruido de lectura & $<11 \mathrm{e}^{-}$ \\
\hline Enfriamiento & Por efecto Peltier de 2 etapas a $-50^{\circ} \mathrm{C}$ del ambiente \\
\hline Tiempo de lectura & $26 \mathrm{seg}$ \\
\hline
\end{tabular}

Figura 2.1.2. Características de la cámara SBIG 11000M del ASH-especificaciones de fábrica- que permiten hacer un autoguiado. 


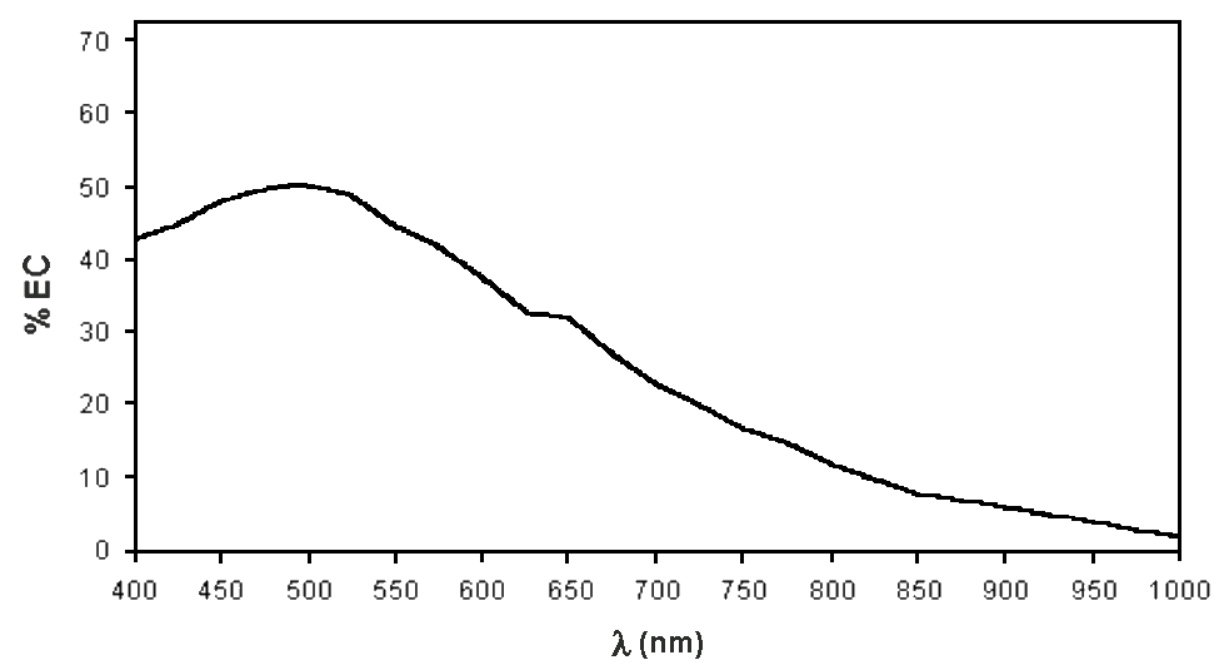

Figura 2.1.3. Curva de eficiencia cuántica del detector Kodak KAI-11000M (Adaptado del manual de especificaciones de fábrica).

Por el momento el ASH trabaja solamente con un filtro denominado de Luminancia (L), centrado en $550 \mathrm{~nm}$ y con un ancho de banda de $300 \mathrm{~nm}$ (Figura 2.1.4). Dado que el ancho de banda del filtro $\mathrm{R}$ del sistema estándar es apenas un tercio del ancho de banda del filtro L y está centrado cerca del límite superior del rango que abarca este último (Bessell, 2005), naturalmente el filtro $\mathrm{L}$ dejará pasar más energía que el $\mathrm{R}$ y los valores de las magnitudes que se obtienen con él son diferentes a las obtenidas con este último. Por lo tanto, si se quiere obtener una equivalencia entre las magnitudes en ambos filtros se deberá hallar una relación que los vincule. El ajuste se realiza teniendo en cuenta las diferencias de las Anchuras a Media Altura (FWHM) para el perfil de transmisión de ambos filtros. Como las FWHM de los filtros L y $\mathrm{R}$ son, respectivamente $300 \mathrm{~nm}$ y $138 \mathrm{~nm}$, la ganancia en magnitud del filtro L ( $\mathrm{mmag}$ ) con relación a la obtenida con el filtro $\mathrm{R}$ (Rmag) será aproximadamente,

$$
\Delta m \approx 2.5 \log \left(\frac{300}{138}\right) \approx 2.5 \log (2.17) \approx 0.84 .
$$




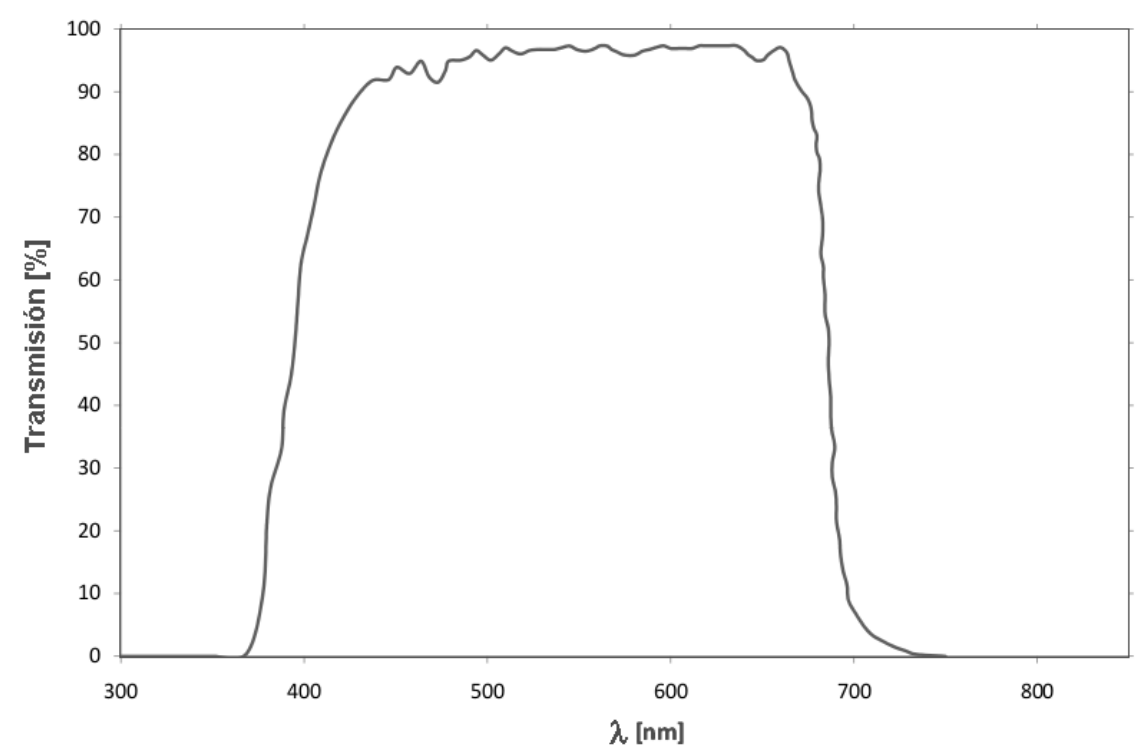

Figura 2.1.4. Curva de transmisión del filtro de Luminancia, utilizado en este trabajo (Adaptado de Ortiz et al., 2013).

Por lo tanto, la corrección que se debe aplicar a las magnitudes obtenidas en el filtro L para convertirlas a magnitudes en el filtro R, estará dada por,

$$
R m a g \simeq \operatorname{Lmag}+0.84
$$

Debido a los fuertes vientos tan frecuentes en el Cerro Burek y a la liviana estructura de carbono propia del instrumento, el ASH está alojado en una caseta protegida cuyo tamaño permite maniobrar el telescopio de manera tal que sólo se puedan barrer campos entre $+2 \mathrm{hs}$ y $-2 h s$ desde el meridiano local y llegar a lo sumo a $-60^{\circ}$ de declinación. Por este motivo el área de cielo disponible corresponde a unos $30^{\circ}-35^{\circ}$ de distancia cenital máxima.

Con el objeto de hallar la magnitud límite alcanzable por el ASH en diferentes condiciones de observación, se realizó un estudio para caracterizar el sistema telescopio+detector+filtro.

\subsubsection{Las observaciones para la caracterización del instrumento}

Las imágenes obtenidas para esta etapa fueron adquiridas en la noche del 14 al 15 de Febrero de 2008, operando el instrumento en forma remota desde las instalaciones de la sala de control del telescopio "Jorge Sahade" (JS) en CASLEO. Las condiciones climáticas durante este período no fueron las ideales pero se pudieron adquirir suficientes imágenes de calidad como para poder cumplir con los objetivos fijados en esta parte del trabajo.

Para facilitar el proceso se eligieron para trabajar dos campos con estrellas estándar. Así, se tomó una serie de seis imágenes por cada uno de los campos SA101 y SA104-SA104E de las áreas seleccionadas de Landolt (1992), utilizando para tres imágenes de la serie un tiempo de exposición de 180 segundos y para las restantes tres, 240 segundos. Dadas las condiciones 
de observación en las primeras horas de la noche, se decidió adquirir las imágenes en modo binning $3 \times 3$ lo que además redujo considerablemente los tiempos de exposición máximos sin saturar la imagen.

Para efectuar la reducción de las imágenes se tomaron una serie de flats con exposiciones de 5 segundos y darks con tiempos de exposición de 5, 180 y 240 segundos. La reducción y procesamiento de las imágenes fue realizado con el paquete IRAF V2.15.1a (Tody, 1986).

Con el objeto de no perder exactitud, todas las imágenes adquiridas se convirtieron a tipo real y se completaron en las cabeceras de las mismas los campos faltantes que son necesarios para realizar la reducción. La reducción básica de las imágenes fue realizada de manera estándar.

Para obtener un dark final a fin de corregir las imágenes, se combinaron los darks obtenidos con el mismo tiempo de exposición utilizando la tarea darkcombine, obteniéndose así un dark final para el procesamiento de las imágenes de 5, 180 y 240 segundos. Es importante hacer notar que no fue necesario obtener bias para realizar las reducciones dado que al ser los darks del mismo tiempo de exposición que las imágenes científicas y las imágenes flats, contienen información sobre el bias y al restarlos a las imágenes corrigen automáticamente los efectos de esta contribución aditiva.

Los parámetros de la tarea darkcombine se setearon de tal modo para que en la combinación de imágenes se obtenga un promedio, utilizando el algoritmo minmax y que siempre desprecie el máximo valor en cada pixel evitando así considerar los valores afectados por rayos cósmicos. Los darks finales obtenidos fueron restados a las imágenes científicas y a los flats, utilizando un proceso por lotes y la tarea $c c d p r o c$. Luego se combinaron los flats ya corregidos para obtener un flat final utilizando la tarea flatcombine, y por último se corrigió por flat las imágenes científicas utilizando nuevamente un proceso por lotes y la tarea $c c d p r o c$.

De esta manera se obtienen las imágenes finales, las cuales fueron llamadas: 101a.fit a 101f.fit, y 104a.fit a 104f.fit para las áreas SA101 y SA104-SA104E, respectivamente. Las imágenes identificadas con las letras $a, b$ y $c$ corresponden a exposiciones de 180 segundos, mientras que las identificadas con $d$, e y $f$ fueron adquiridas con tiempos de exposiciones de 240 segundos.

Con el fin de obtener imágenes con diferentes tiempos totales de exposición para poder luego estimar cuál será el tiempo de exposición más conveniente, se procedió a alinear imágenes de un mismo campo calculando para ello los correspondientes corrimientos $\Delta x$ y $\Delta y$ para cada imagen, y utilizando luego la tarea imshift. Una vez alineadas, se realizaron una serie de combinaciones obteniéndose un total de dieciséis imágenes cuyos nombres, la combinación que las origina, y el tiempo total de exposición equivalente, se listan en la Figura 2.1.5. 


\begin{tabular}{|c|c|c|c|}
\hline & $\mathrm{COI}$ & INACIONES & \\
\hline & Promediadas & Resultado & EXPTIME \\
\hline 1 & 101a.fit con 101c.fit & 101ac.fit & $180=0$ \\
\hline 2 & 104a.fit con 104c.fit & 104ac.fit & 100 \\
\hline 3 & 101d.fit con 101e.fit & 101de.fit & \\
\hline 4 & 101d. fit con 101f.fit & 101df.fit & \\
\hline 5 & 101e.fit con 101f.fit & 101ef.fit & 240 car \\
\hline 6 & 104d.fit con 104e.fit & 104de.fit & $240 \mathrm{seg}$ \\
\hline 7 & 104d.fit con 104f.fit & 104df.fit & \\
\hline 8 & 104e.fit con 104f.fit & 104ef.fit & \\
\hline & Sumadas & Resultado & EXPTIME \\
\hline 9 & 101a.fit + 101c.fit & suma101ac.fit & 360 sea \\
\hline 10 & 104a.fit +104 c.fit & suma104ac.fit & \\
\hline 11 & 101d.fit + 101e.fit & suma101de.fit & \\
\hline 12 & 101d.fit + 101f.fit & suma101df.fit & \\
\hline 13 & 101e.fit + 101f.fit & suma101ef.fit & $480 \mathrm{~s}$ \\
\hline 14 & 104e.fit +104 e.fit & suma104de.fit & \\
\hline 15 & 104d.fit + 104f.fit & suma104df.fit & \\
\hline 16 & 104e.fit $+104 f$ fit & suma104ef.fit & \\
\hline
\end{tabular}

Figura 2.1.5. Imágenes combinadas en base a las imágenes adquiridas para la caracterización del ASH.

Con el fin de realizar las combinaciones de las imágenes se utilizó la tarea imcombine seteando el parámetro combine como sum o average, según lo que se deseaba obtener.

Debido a problemas de foco, las imágenes 101b.fit y 104b.fit resultaron de mala calidad mostrando imágenes estelares deformadas, por lo que fueron descartadas. En un posterior análisis se eliminaron también las combinaciones 6 y 7 dado que arrojaban resultados que distaban mucho de los valores teóricos esperados, indicando algún tipo de problema en su procesamiento.

Los paquetes de tareas de IRAF empleados para realizar la reducción fotométrica fueron noao.digiphot.apphot y noao.digiphot.daophot, mientras que con el paquete noao.digiphot.photcal se obtuvieron las soluciones fotométricas y se realizaron las transformaciones fotométricas correspondientes.

Como primer paso, y como ya se había hecho con las imágenes originales no combinadas, con la tarea hedit se corrigieron las cabeceras de las imágenes modificando o agregando, si hiciera falta, los campos AIRMASS, EXPTIME, EGAIN, RDNOISE, FILTERS.

Las masas de aire se calcularon con la tarea setairmass, completando los campos ra, dec, st, epoch, dateobs, y observatory. Una vez obtenidas las masas de aire para las imágenes individuales consideradas en cada combinación, éstas fueron promediadas para obtener un valor final, que siempre se mantuvo en el rango $1.17 \leq X \leq 1.36$. Por otra parte, si se quiere hacer fotometría en imágenes que son el resultado de combinaciones, deben corregirse los parámetros RDNOISE y EGAIN de la cabecera de las imágenes, los cuales corresponden al ruido de lectura y la ganancia del detector, respectivamente. De esta manera, por un lado los valores que resultan de combinar mediante sumas $N$ imágenes con ruido de lectura y ganancia 
constantes son:

$$
R D N O I S E_{\text {sum }}=R D N O I S E \cdot \sqrt{N}
$$

$\mathrm{y}$

$$
G A I N_{\text {sum }}=G A I N . N
$$

mientras que si la combinación resultante es el promedio de las imágenes, los valores serán,

$$
R D N O I S E_{\text {average }}=\frac{R D N O I S E}{\sqrt{N}},
$$

$\mathrm{y}$

$$
G A I N_{\text {average }}=G A I N
$$

Cabe mencionar que tanto el ruido de lectura como la ganancia no se verán afectados por el hecho de adquirir las imágenes en modo binning. En efecto, al hacer binning se procede a leer una serie de pixeles de una vez, lo que implica que si, por ejemplo, hacemos un binning de $3 \times 3$ el CCD leerá los 9 pixeles en un solo acto y no cada uno por separado para luego combinarlos, y por lo tanto el ruido de lectura es el mismo que si no se binneara. Esa es una de las ventajas que presenta binnear. Por otro lado, como la conversión de unidades analógicasdigitales (ADUs) a electrones es posterior al proceso de lectura, la ganancia tampoco se ve afectada.

Previamente a ejecutar la tarea daofind que identifica las fuentes presentes en una imagen, se setearon una serie de parámetros que se requieren para que la tarea se ejecute correctamente, como la FWHM, la desviación estándar del fondo de cielo, los valores máximo y mínimo que fijan la región de respuesta lineal del detector, y la escala de la imagen. En este caso, la FWHM medida sobre las imágenes binneadas resultó ser de 1.3 pixeles y si consideramos la escala del instrumento con el binning correspondiente, encontramos que el seeing esa noche resultó de unos 5.7 arcsec, lo que habla de la mala calidad de la noche en la que se obtuvieron las imágenes. A pesar del mal seeing, las imágenes aun resultaron útiles para estimar la magnitud límite que se puede alcanzar con el ASH. La desviación estándar del ruido del cielo fue de aproximadamente $70 \mathrm{ADU}$ s para las imágenes con tiempos de exposición de 180 segundos o 240 segundos, y de 90 ADUs para las imágenes con tiempos de exposición igual a 360 segundos o 480 segundos.

Mediante la tarea daofind se obtuvo un archivo de salida con las coordenadas en la imagen de las estrellas detectadas, las cuales sumaron $\sim 2500$ objetos para el campo $S A 101$ y $\sim 3600$ para el campo $S A 104-S A 104 E$, lo que habla de regiones poco densas teniendo en cuenta el tamaño del campo del ASH.

Finalmente, se realizó la fotometría con la tarea phot del paquete noao.digiphot.apphot, utilizando como archivo de entrada el generado previamente por daofind y donde figuran todas las fuentes identificadas en la imagen. Dado el importante brillo de las estrellas estándar en las imágenes, la apertura para todas ellas se eligió con un radio de 8 pixeles, aunque lo más correcto hubiera sido estudiar cómo varían las magnitudes en una serie de aperturas de diferentes tamaños y a partir de allí realizar la elección, pero en nuestro caso dicho procedimiento no se juzgó necesario. Para estimar el brillo del cielo se definió un anillo alrededor de cada estrella con un radio de 10 pixeles y un grosor de 4 pixeles, obteniéndose de allí la moda de los pixeles del anillo con la cual fue posible corregir por la contribución del cielo el valor 
de flujo obtenido para los objetos. Se genera así el archivo de salida de la tarea phot, y con la tarea pdump se extraen a un archivo las magnitudes instrumentales y sus respectivos errores para cada una de las fuentes identificadas.

Como se pretende hallar la magnitud límite alcanzada con el telescopio ASH para un tiempo de exposición dado, en una primera aproximación se asumió que un objeto es detectable si su relación señal/ruido $(S / N)$ es mayor o igual que 5 , con lo que definimos así, en principio, el límite de detección del instrumento. Ahora, como la magnitud viene dada por

$$
m=k-2.5 \log (S)
$$

para un valor de punto cero $k$ y flujo total $S$, resultará que el error en magnitud en función de la relación $S / N$ será:

$$
\begin{aligned}
|(m+\Delta m)-m| & =\mid c-2.5 \log (S+N)-c+2.5 \log (S)) \mid \\
& =2.5 \log \left(\frac{S+N}{S}\right) \\
& =2.5 \log \left(1+\frac{N}{S}\right) \\
& =2.5 \log \left(1+\frac{1}{(S / N)}\right),
\end{aligned}
$$

y como se asumió que $S / N=5$, entonces $\Delta m=0.198$.

Por lo tanto, las estrellas que estarán en el límite de detección serán aquellas para las cuales su error fotométrico es del orden de 0.2. Éste es sólo un valor teórico de referencia ya que en un caso más realista habría que considerar también la propagación de errores introducidos por el ruido poissoniano $(\sqrt{S})$ y los que resultan del procesamiento mismo de las imágenes, como la resta de darks y correcciones por flats.

Entonces, para todas las imágenes con un mismo tiempo de exposición se seleccionaron las estrellas con magnitudes instrumentales cuyos errores eran exactamente iguales a $0.20 \mathrm{y}$ se tomó un valor medio de esas magnitudes para cada imagen. Los valores medios obtenidos para cada una de ellas se promediaron nuevamente para obtener un valor final representativo de la magnitud instrumental máxima alcanzada por el ASH para $S / N=5$, y dicho tiempo de exposición.

En una segunda aproximación, y dado que generalmente se considera que un objeto puede separarse del fondo del cielo recién cuando su relación $S / N$ supera el valor 3, se realizó el mismo análisis considerando dicho límite. En este caso, las magnitudes límites serán aquellas cuyos errores son del orden de las $\Delta m=0.36$ magnitudes.

Ahora bien, partiendo de la magnitud instrumental límite para tiempos de exposición $t_{0}$, podemos estimar la ganancia en magnitud al aumentar los tiempos de exposición en un factor $\Theta$, mediante la expresión

$$
\Delta m=2.5 \log (\Theta),
$$

siendo $\Theta=\frac{t_{\text {exp }}[\operatorname{seg}]}{t_{0}}$ y $t_{0}$ el tiempo de exposición total.

Es decir, si para 180 segundos y una relación $S / N$ dada somos capaces de detectar objetos de magnitud $m_{180}$, entonces en una imagen adquirida con un tiempo de exposición 
$t_{\text {exp }}[s e g]$ teóricamente estaremos en condiciones de detectar objetos de magnitud instrumental

$$
m_{l i m}\left(t_{\text {exp }}\right)=m_{180}+2.5 \log \left(\frac{t_{\text {exp }}}{180}\right)=m_{180}+2.5 \log \left(t_{\text {exp }}\right)-5.64 .
$$

En la Figura 2.1.6 se listan las magnitudes instrumentales límite para diferentes tiempos totales de exposición referidas a la magnitud instrumental límite $m_{180}$ alcanzada luego de integrar durante $t_{0}=180$ segundos.

\begin{tabular}{|c|c|}
\hline$t_{\text {exp }}(\mathrm{seg})$ & $m_{\text {lim }}$ \\
\hline 240 & $\mathrm{~m}_{180}+0.31$ \\
\hline 360 & $\mathrm{~m}_{180}+0.75$ \\
\hline 480 & $\mathrm{~m}_{180}+1.06$ \\
\hline
\end{tabular}

Figura 2.1.6. Incrementos en las magnitudes en relación a la magnitud máxima $m_{180}$, alcanzada luego de integrar durante 180 segundos.

Una vez que hemos estimado la magnitud instrumental máxima alcanzada por el ASH para una cierta relación $S / N$ luego de integrar un tiempo $t_{\text {exp }}$, debemos resolver las ecuaciones de transformación fotométrica, las que son particulares del sistema telescopio+detector+filtro, y que nos permitirán obtener para un objeto cualquiera su magnitud en un sistema estándar, partiendo de su magnitud instrumental.

Las ecuaciones de transformación fotométrica a primer orden tienen la forma,

$$
m=M+k_{1}+k_{2} \cdot X+k_{3} \cdot(I C),
$$

donde,

$m$ : Magnitud instrumental.

M: Magnitud estándar de catálogo en un cierto sistema fotométrico.

$k_{1}$ : Coeficiente de punto cero.

$k_{2}$ : Coeficiente de extinción.

$X$ : Masa de aire correspondiente al momento de la observación.

$k_{3}$ : Coeficiente de transformación.

$(I C)$ : Índice de Color.

Los parámetros $k_{1}, k_{2}, \mathrm{y} k_{3}$ son los que definirán la transformación.

Una vez seleccionadas $N \geq 3$ estrellas estándares en una imagen, puede armarse el siguiente sistema de ecuaciones

$$
m_{\star j}=M_{\star j}+k_{1}+k_{2} \cdot X+k_{3} \cdot(I C)_{j}, \quad(j=1, \ldots, N),
$$

que resolviéndolo por mínimos cuadrados permitirá estimar los coeficientes $k_{1}, k_{2}$, y $k_{3}$. Como en nuestro caso sólo contamos con un solo filtro naturalmente no se midieron los índices 
de color, pero como el término en $k_{3}$ es casi constante para objetos de colores solares, su contribución se puede minimizar eligiendo estrellas estándares de color similar. Por otra parte, como el término en $k_{2}$ es constante para todos los objetos en una misma imagen, los tres últimos términos del miembro de la derecha de la ecuación (2.1.12) pueden considerarse como un valor de punto cero global y, por lo tanto, la ecuación de transformación se reduce a,

$$
M_{\star}=m_{\star}-\hat{k_{1}}
$$

donde $\hat{k_{1}}$ es efectivamente el nuevo coeficiente de punto cero que se obtendrá de promediar las diferencias de cada una de las $N$ estrellas estándares elegidas.

Es importante mencionar que el valor $\hat{k_{1}}$ tendrá una cierta dispersión afectada por la dispersión en los índices de color de las estrellas observadas, pero dado que $k_{3}$ en CASLEO tiene un valor en el V que varía entre -0.04 y -0.08 (Gil-Hutton, 2012), y considerando que en general $(I C)<1$, los efectos de esta dispersión serán despreciables.

Además, dado que la relación entre las FWHM de las bandas pasantes de trasmisión del filtro L $(300 \mathrm{~nm})$ y del filtro V $(87 \mathrm{~nm})$ es de 3.4 , procediendo en forma análoga a como desarrollamos la ecuación (2.1.1), resultará que la ganancia respecto de un filtro $\mathrm{V}$ estándar es del orden de $2.5 \log (3.4)=1.34$ magnitudes, y por lo tanto, las magnitudes en el filtro L y las magnitudes estándares en la banda V del Sistema Fotométrico UBVRI de Johnson-Cousins $(V m a g)$, podrán relacionarse mediante la aproximación,

$$
V m a g \simeq \operatorname{Lmag}+1.34
$$

De las ecuaciones (2.1.2) y (2.1.14) puede obtenerse una relación explícita entre las magnitudes $V$ mag y Rmag mediante la expresión,

$$
V m a g-R m a g \simeq 0.5,
$$

que es justamente la relación empleada por Luu y Jewitt (1998) y Sheppard et al. (2000) en sus respectivos programas de búsqueda.

\subsubsection{Resultados}

Las magnitudes límites obtenidas también se vieron afectadas por las malas condiciones de seeing durante las noches de observación, así que si en lugar de un tamaño de imagen de unos 6 arcsec se hubiera trabajado con uno de 3 arcsec -valor éste más representativo de las condiciones habituales del sitio-, la magnitud límite obtenida para los diferentes tiempos de exposición se habría incrementado en un valor que depende de la relación entre las distribuciones de energía teórica de dos imágenes con esas FWHM y brillo constante. En este caso ese incremento es de $0.2-0.3$ magnitudes.

Teniendo en cuenta esas correcciones, en la Figura 2.1.7 se listan los resultados obtenidos para valores de seeing medido (6 arcsec) y estimado ( 3 arcsec), de las magnitudes $V$ mag lím alcanzadas por el ASH en función de los tiempos de exposición y de la relación $S / N$ considerada. 


\begin{tabular}{|c|c|c|c|c|}
\cline { 2 - 5 } \multicolumn{1}{c|}{} & \multicolumn{2}{c|}{ seeing $=6$ arcsec } & \multicolumn{2}{c|}{ seeing = 3 arcsec } \\
\hline $\mathbf{t}_{\text {exp }}$ (sec) & $\mathbf{S} / \mathbf{N}=\mathbf{5}$ & $\mathbf{S} / \mathbf{N}=\mathbf{3}$ & $\mathbf{S} / \mathbf{N}=\mathbf{5}$ & $\mathbf{S} / \mathbf{N}=\mathbf{3}$ \\
\hline 180 & 20.0 & 20.7 & 20.3 & $\mathbf{2 1 . 0}$ \\
\hline 240 & 20.3 & 21.0 & 20.6 & $\mathbf{2 1 . 2}$ \\
\hline 360 & 20.7 & 21.1 & 21.0 & $\mathbf{2 1 . 4}$ \\
\hline 480 & 21.0 & 21.5 & 21.3 & $\mathbf{2 1 . 8}$ \\
\hline
\end{tabular}

Figura 2.1.7. Resultados finales para $V m a g_{l i ́ m}$ en distintas condiciones.

En la Figura 2.1.8 se grafica la evolución de la $V_{m a g} g_{\text {lím }}$ en función de los tiempos de exposición, para una relación $S / N=3$ y asumiendo un tamaño de imagen representativo del sitio de 3 arcsec.

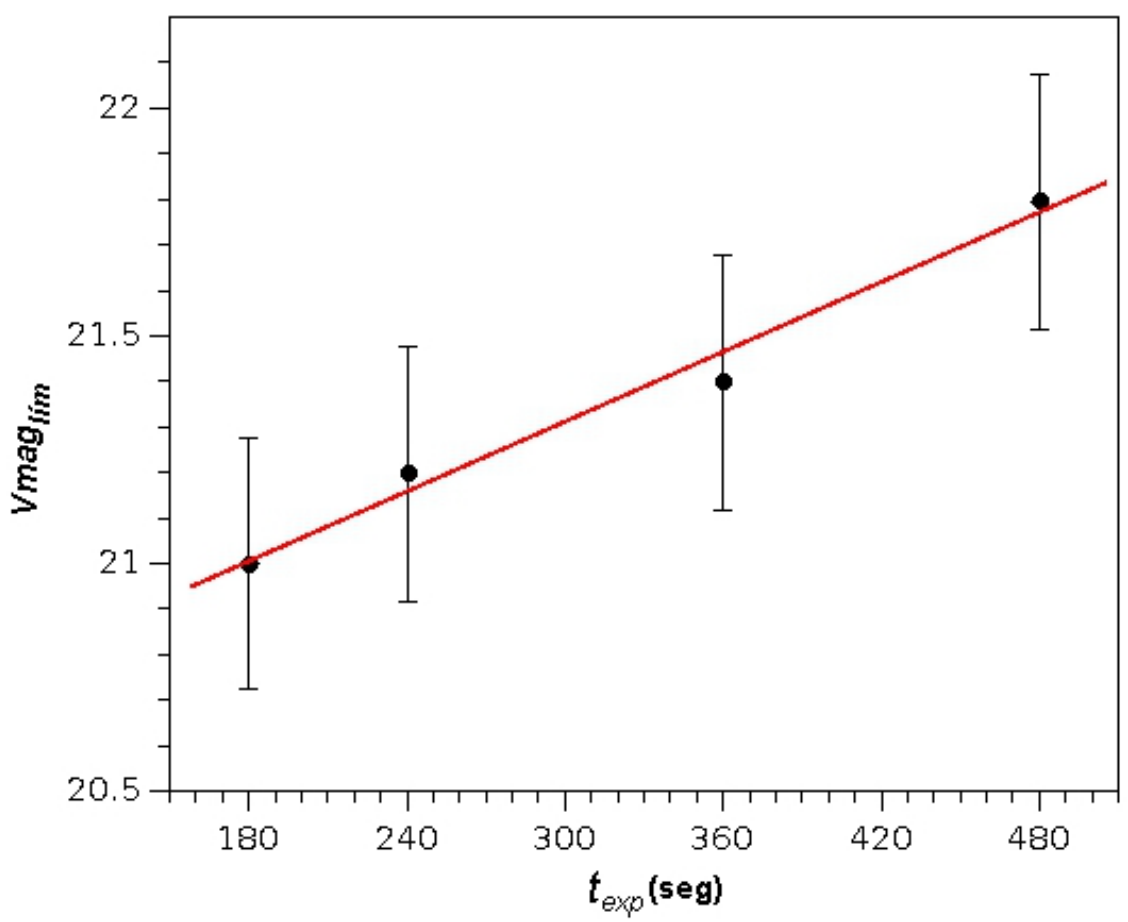

Figura 2.1.8. Evolución de la magnitud límite del ASH en la banda $V$ del Sistema de Johnson en función de los tiempos de exposición, para una relación $S / N=3$ y un seeing de 3 arcsec, representativo del sitio.

Finalmente, estimamos que la magnitud límite en el filtro V del Sistema Fotométrico UBVRI de Johnson-Cousins alcanzada por este instrumento para una relación $S / N=3$ y exponiendo durante 180 segundos es $\operatorname{Vmag}_{\text {lím }} \simeq 21.0($ Rmag $\simeq 20.5)$.

Dada la relación focal del ASH, es de esperar que para exposiciones de algunos minutos la mayoría de las estrellas brillantes del campo aparezcan saturadas. Esta condición se alcanza para estrellas con magnitudes $V m a g \simeq 15.0$ en integraciones de 180 segundos y de $V$ mag $\simeq$ 15.2 para exposiciones de 240 segundos. Estos resultados que caracterizan al telescopio ASH de CASLEO, fueron presentados en Mammana y Gil-Hutton (2008). 
Dado que lo que se pretende es llevar adelante un programa de búsqueda de objetos con magnitudes muy débiles, la coadición de imágenes es el camino indicado para lograr incrementar la relación $S / N$. Ahora bien, como para tiempos de integración de 180 segundos el ASH posee una magnitud límite de $V \operatorname{mag}_{\text {lím }} \simeq 21.0$, entonces si sumamos $N$ imágenes adquiridas cada una de ellas exponiendo 180 segundos, la magnitud máxima teórica alcanzable será,

$$
\operatorname{Vmag}_{\lim (}\left(t_{\text {exp }}=180 \mathrm{seg}\right) \simeq 21.0+2.5 \log (N) \text {. }
$$

Esto indica que si, por ejemplo, se coadicionan $N=20$ imágenes adquiridas con tiempos de 180 segundos, es teóricamente posible detectar en la imagen coadicionada objetos con $V m a g \simeq 24.3(R m a g \simeq 23.8)$, lo que nos permite concluir que el telescopio ASH es un instrumento apto para los fines de búsqueda que nos proponemos.

\subsection{Las observaciones para el programa de búsqueda}

Las observaciones se adquirieron durante quince noches centradas alrededor de la luna nueva, en los meses de mayo y agosto de 2008, época en la que en el hemisferio sur la eclíptica está elevada. Se trabajó sobre ocho campos independientes de aproximadamente $1.63^{\circ} \times 1.09^{\circ}$ cada uno, cubriéndose un área total de $14.17 \operatorname{grados}^{2}$ de cielo. En la Figura 2.2.1 se lista la cantidad de imágenes adquirida por campo relevado, donde los centros de placa, la fecha y la hora en TU, son los correspondientes a la primera imagen tomada en la primera de las dos noches que se dedico a cada uno.

\begin{tabular}{|c|c|c|c|c|c|}
\cline { 2 - 6 } \multicolumn{2}{c|}{ Centro del campo (J2000.0) } \\
\hline 00 & 45 & 150041.00 & -154727.0 & $2008-05-02$ & $05: 32: 40$ \\
\hline 02 & 40 & 144028.00 & -150209.0 & $2008-05-10$ & $02: 07: 34$ \\
\hline 01 & 20 & 150528.00 & -171656.0 & $2008-05-12$ & $04: 19: 40$ \\
\hline 03 & 40 & 195230.00 & -213335.0 & $2008-08-06$ & $03: 32: 38$ \\
\hline 09 & 40 & 213428.00 & -151238.0 & $2008-08-06$ & $05: 09: 06$ \\
\hline 04 & 40 & 202630.00 & -201314.0 & $2008-08-08$ & $03: 49: 46$ \\
\hline 05 & 40 & 200430.00 & -195827.0 & $2008-08-08$ & $02: 18: 54$ \\
\hline 06 & 40 & 203529.00 & -182808.0 & $2008-08-27$ & $02: 17: 39$ \\
\hline 07 & 40 & 211528.00 & -162747.0 & $2008-08-30$ & $02: 20: 46$ \\
\hline
\end{tabular}

Figura 2.2.1. Cantidad de imágenes por campo, donde los centros de placa, la fecha y la hora en $T U$, son los correspondientes a la primera imagen adquirida en la primera de las dos noches que se dedico a cada uno.

Los campos fueron elegidos de tal manera que los centros de los mismos no estuvieran más allá de los $5^{\circ}$ de la eclíptica y dentro de los $\pm 45^{\circ}$ de la oposición, evitando la zona de confusión que se encuentra entre $125^{\circ}$ y $155^{\circ}$ de elongación solar, y que corresponde a la región en donde asteroides del MBA, Centauros y TNOs pueden presentar velocidades angulares similares en el plano del cielo (Kavelaars et al., 2009). Las imágenes fueron adquiridas en general cerca del meridiano local donde los objetos alcanzan su altura máxima, lo que a su vez maximiza la relación $S / N$ que se puede lograr y, al mismo tiempo, minimiza la refracción diferencial. 
Dado que ciertos Troyanos de Júpiter no se pueden diferenciar de Centauros moviéndose en regiones próximas a la órbita de este planeta, es conveniente no realizar observaciones cuando los Puntos Lagrangianos $L_{4}$ y $L_{5}$ están en dirección a la oposición, que como se dijo es nuestra dirección de observación elegida. Así, si se considera que los Troyanos de Júpiter se encuentran distribuidos a lo largo de la órbita de éste subtendiendo un arco de libración $\delta L$ centrado para cada caso en dichos puntos, entonces es de esperar que no habrá Troyanos en la oposición si se realizan las observaciones en la época del año cuando la configuración con Júpiter satisface una de las siguientes inecuaciones:

$$
\left|\varphi_{J} \pm S O T_{J}-120^{\circ}\right|>\frac{\delta L}{2},
$$

donde $S O T_{J}$ es la elongación solar de Júpiter y $\varphi_{J}$ su ángulo de fase. Con la condición surgida de considerar (+) se evitan los Troyanos que orbitan $L_{4}$ y con $(-)$ los que orbitan $L_{5}$.

Si bien el ángulo medio de libración de esta población es $\delta L \sim 14^{\circ}$, los casos extremos pueden duplicar esa amplitud (Murray y Dermott, 1999), con lo cual eligiendo $\delta L \sim 30^{\circ}$ para las condiciones (2.2.1), se tendrá fijada la condición limitante que esta situación impone.

De las regiones que cumplían los mencionados requisitos se eligieron los campos menos poblados, algo de vital importancia en una búsqueda de las características que aquí se presenta, pero pese a una exhaustiva selección, dado el amplio y luminoso campo del ASH, nunca fue posible evitar un número de objetos menor a 20000 estrellas en cada uno. Todos los campos fueron observados con masas de aire menores a 1.4.

A excepción de los campos 00 y 01, para cada uno de los restantes se adquirieron cuarenta imágenes de 180 segundos de exposición en dos noches consecutivas, veinte en cada una de ellas. Al conjunto formado por las veinte imágenes adquiridas en una misma noche de un campo dado, le llamaremos serie. En el caso del campo 00 se tomaron cuarenta y cinco imágenes, mientras que para el campo 01 solamente veinte. El número total de imágenes científicas que se adquirieron a lo largo de las quince noches es de trescientos cuarenta y cinco y en ningún caso fue necesario utilizar un modo de binning porque las condiciones de observación fueron aceptables. Cada serie fue tomada mediante un script que permite automatizar la operación del telescopio y cámara. En este caso, el script le ordena al ASH que adquiera las diez primeras imágenes de una serie en forma consecutiva moviendo cada imagen unos 10 arcsec entre ellas y que, luego de un salto de reposicionamiento, adquiera las diez restantes repitiendo el mecanismo empleado para las primeras. Dicho salto se observa justo en mitad de los trazos dejados, por ejemplo, por los asteroides más brillantes en toda imagen que resulta de sumar imágenes alineadas (por ejemplo, ver el trazo dejado por el asteroide $1993 T W_{1}$ en la Figura 2.4.15). Este desfasaje entre las imágenes favorece la remoción de rayos cósmicos si se realiza un proceso de coadición, y constituye un procedimiento estándar en el ASH.

Dada la variedad de definiciones que existe para los Centauros, es necesario fijar a priori cuál de todas ellas se considerará en este trabajo y es así que, por una cuestión de simplicidad en la implementación de este programa de búsqueda, se opta por aquella que se basa en la velocidad de los objetos en el fondo del cielo en dirección a la oposición (Sheppard et al., 2000), para lo cual previamente debe elegirse el modelo que mejor reproduzca dicha velocidad en la oposición en los rangos involucrados en dicha definición. 
El movimiento angular aparente en el plano del cielo $\dot{\theta}$ en unidades de segundos de arco por hora de un objeto del SS cerca de la oposición y en función de su distancia heliocéntrica $(R>1 U A)$, puede aproximarse mediante la expresión (Luu y Jewitt, 1988; Hainaut et al., 1994),

$$
\dot{\theta}\left(\operatorname{arcsechs}^{-1}\right) \approx 148 \frac{1-R[U A]^{-\frac{1}{2}}}{R[U A]-1} .
$$

Sheppard et al. (2000) trabajan con una identidad de esa misma expresión, pero bajo una forma algebraicamente más amigable:

$$
\dot{\theta}\left(\operatorname{arcsech}^{-1}\right) \approx \frac{148}{R[U A]+R[U A]^{\frac{1}{2}}} .
$$

De la misma se puede inferir que un objeto cuya distancia heliocéntrica varíe en el rango $5 U A \lesssim R \lesssim 30 U A$, tendrá una velocidad

$$
4 \operatorname{arcsechs}^{-1} \lesssim \dot{\theta} \lesssim 20 \operatorname{arcsechs}^{-1},
$$

mientras que un objeto con $R>30 U A$, poseerá velocidades en el intervalo

$$
\dot{\theta}<4 \operatorname{arcsech} s^{-1} \text {. }
$$

De la ecuación (2.2.3) se puede demostrar que la distancia heliocéntrica $R[U A]$ en función de la velocidad $\dot{\theta}\left[\operatorname{arcsec} h s^{-1}\right]$ es la solución

$$
R_{1 ; 2} \approx \frac{\dot{\theta}+296 \pm \sqrt{(\dot{\theta}+296)^{2}-87616}}{2 \dot{\theta}},
$$

de la aproximación

$$
R^{2}+\left(-1-\frac{296}{\dot{\theta}}\right) R+\left(\frac{148}{\dot{\theta}}\right)^{2} \approx 0
$$

que satisface la condición de contorno

$$
R<\frac{148}{\dot{\theta}}
$$

Es posible comprobar que para objetos con $R<5 U A$-equivalentemente $\dot{\theta}>20$ arcsec hs $^{-1}$ la expresión (2.2.3) rápidamente pierde precisión a medida que disminuye $R$.

Por su parte, Frasser et al. (2008) optan por la aproximación

$$
\dot{\theta}\left(\operatorname{arcsechs}^{-1}\right) \approx 148\left(\Delta[U A]^{-1}-R[U A]^{-\frac{3}{2}}\right),
$$

donde $\Delta$ es el módulo del vector geocéntrico del objeto en la oposición, con lo cual

$$
\dot{\theta}\left(\operatorname{arcsechs}^{-1}\right) \approx 148\left((R[U A]-1)^{-1}-R[U A]^{-\frac{3}{2}}\right) .
$$


Por último, Roques et al. (2008) se valen de la relación

$$
v\left(k m s e g^{-1}\right)=v_{\oplus}\left[k m s e g^{-1}\right]\left(\cos (\omega)-\frac{1}{R[U A]^{\frac{1}{2}}}\right),
$$

para expresar la velocidad en el plano del cielo de un objeto con $R>1 U A$ que se desplaza en órbita circular sobre la eclíptica alrededor del Sol, donde $v_{\oplus} \approx 30 \mathrm{~km} \mathrm{seg}^{-1}$ representa la velocidad orbital de la Tierra y $\omega$ es el ángulo de la dirección al objeto medido desde la oposición (Figura 2.2.2). A partir de dicha expresión se puede aproximar la velocidad angular del objeto en el plano del cielo en la oposición $(\omega=0)$ en unidades de segundos de arco por hora, y arribar a

$$
\dot{\theta}\left(\operatorname{arcsech}^{-1}\right) \approx 147.8\left(R[U A]^{-1}-R[U A]^{-\frac{3}{2}}\right) .
$$

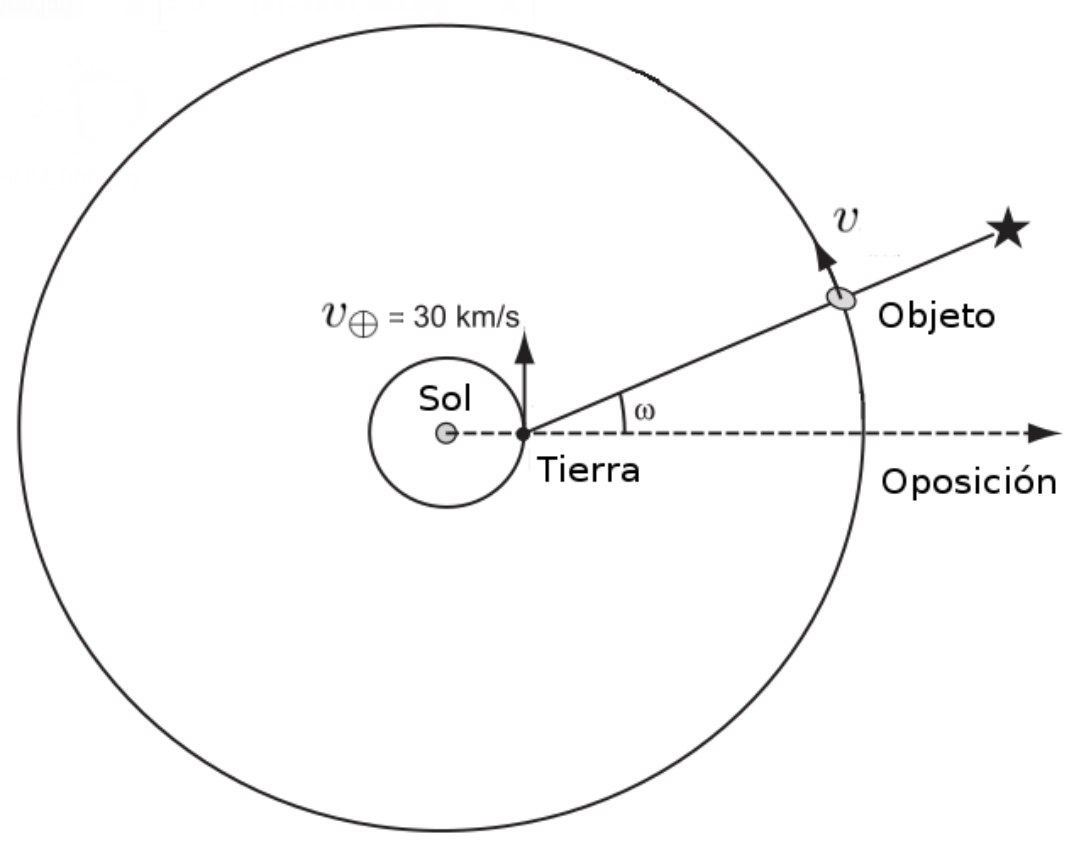

Figura 2.2.2. Esquema Sol-Tierra-objeto, con el ángulo $\omega$ al que hace referencia la ecuación (2.2.11). (Adaptado de Roques et al., 2008).

Las aproximaciones empleadas en las cinco publicaciones mencionadas y que se resumen en las ecuaciones $(2.2 .2),(2.2 .3),(2.2 .10)$ y $(2.2 .12)$, arrojan resultados muy similares en el rango de velocidades involucrado en la definición propuesta por Sheppard et al. (2000) (Figura 2.2.3), pero luego de varias pruebas contrastadas con datos observacionales de Centauros en la oposición, se eligió trabajar con la estimación de la que nos hablan Luu y Jewitt (1988), Hainaut et al. (1994) y Sheppard et al. (2000), bajo la forma en que la expresan estos últimos. 


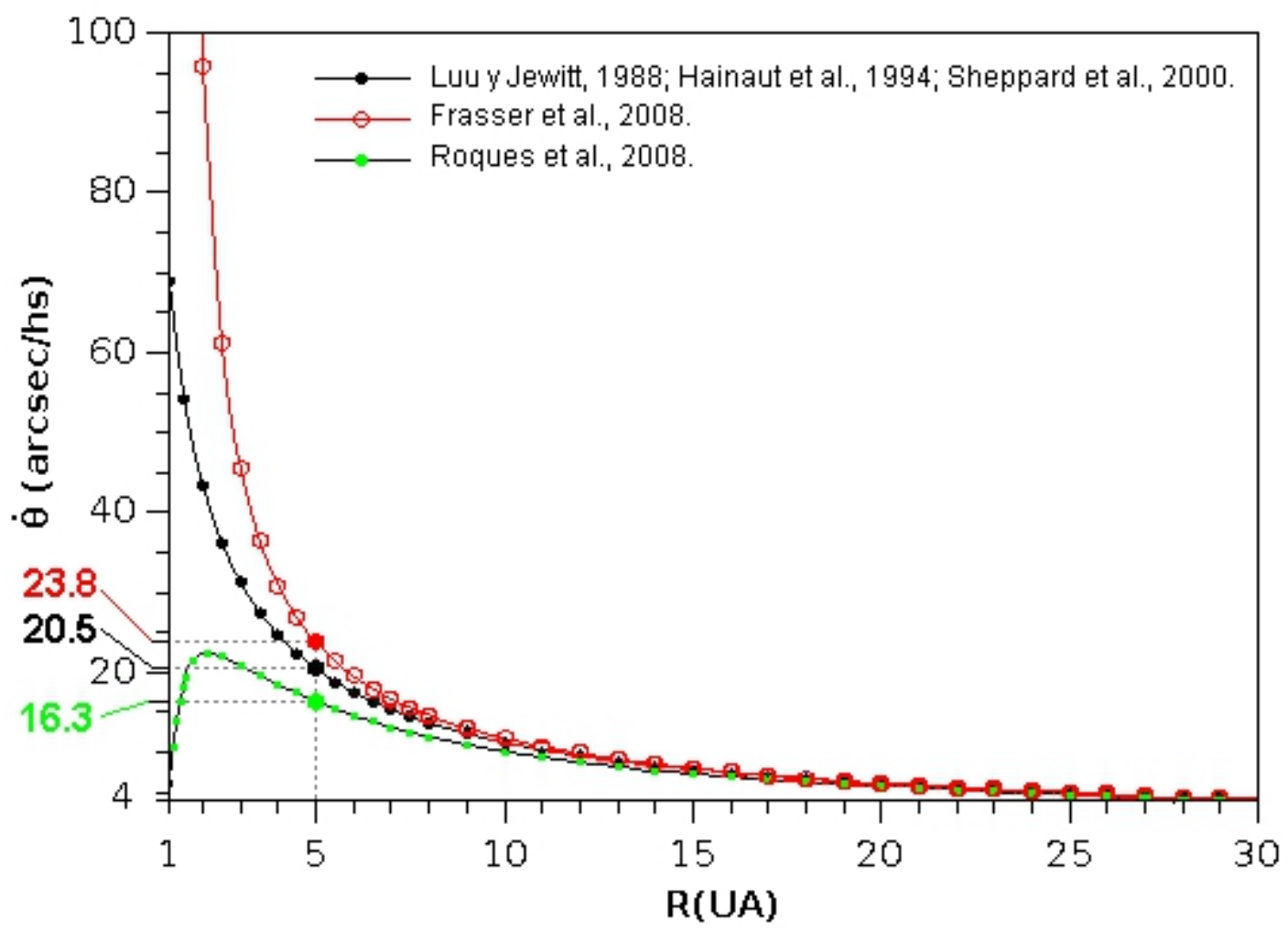

Figura 2.2.3. Velocidad angular aparente en el plano del cielo en dirección a la oposición en función de la distancia heliocéntrica.

De esta forma, en la implementación de nuestro programa de búsqueda se considerará como Centauro a todo objeto que se desplace sobre el plano del cielo en la oposición con velocidades angulares en el rango definido por las inecuaciones (2.2.4), donde la velocidad angular $\dot{\theta}$ responde a la aproximación expresada por la ecuación (2.2.3), optando así no sólo por la definición de Centauro dada por Sheppard et al. (2000), sino también por la expresión que éstos autores proponen para modelar dicha velocidad.

Dado que los objetos que nos interesan detectar deben estar más allá de las $5 U A$ (equivalentemente, $\dot{\theta} \lesssim 20$ arcsec $^{-1} s^{-1}$, se necesitó definir un tiempo de exposición máximo para el cual un objeto con esa velocidad límite no se desplazara más allá de un pixel. Si consideramos un objeto cuya velocidad angular $\dot{\theta}$ es constante durante el tiempo de integración de la imagen, el tiempo máximo en el que permanecerá en $n$ pixeles de una imagen adquirida con binning $B \times B$, estará dado por

$$
t_{m a ́ x}(\operatorname{seg})=\frac{3600\left[\operatorname{seg~h}^{-1}\right] \cdot n[\text { pixel }] . B . P I X S C A L E\left[\operatorname{arcsec}_{\text {pixel }}{ }^{-1}\right]}{\dot{\theta}\left[\operatorname{arcsech}^{-1}\right]} .
$$

Como en nuestro caso $n=1, B=1, P I X S C A L E\left[\right.$ arcsec pixel $\left.^{-1}\right]=1.47$ y la velocidad angular $\dot{\theta}\left[\operatorname{arcsech} \mathrm{s}^{-1}\right]=20$, resulta que $t_{\text {máx }} \simeq 264.6 \mathrm{seg} \simeq 4.41 \mathrm{~min}$. Es decir que exponiendo menos de 4 minutos nos aseguramos que cualquier Centauro en la oposición permanecerá en un pixel y de esta manera no se perderá señal debido a la pérdida de flujo por desplaza- 
miento del objeto (efecto de Trailing Loss). Dicho efecto es directamente proporcional tanto a la velocidad del objeto en el fondo del cielo $(\dot{\theta})$ como al tiempo de expesición $\left(t_{\text {exp }}\right)$, e inversamente proporcional al seeing del sitio $\left(\theta_{F W H M}\right)$ :

$$
\Delta m \propto \frac{\dot{\theta} \cdot t_{\exp }}{\theta_{F W H M}}
$$

Por lo tanto, y para estar a resguardo de este tipo de pérdidas, se toma 180 segundos como tiempo de exposición para todas las imágenes científicas del programa de búsqueda, ya que incrementar el tiempo de exposición, por ejemplo a 240 segundos, no representaría una ganancia significativa en magnitud para el tiempo de exposición total empleado. Esa es la razón por la cual en el estudio previo donde se caracterizó el ASH y se estimó su magnitud límite alcanzable, se eligió ese valor para el tiempo de exposición testigo.

Teniendo en cuenta el tiempo de exposición de cada imagen (180 segundos), más el tiempo muerto del instrumento entre dos imágenes consecutivas y los 243 segundos que insume la mencionada maniobra de reposicionamiento en mitad de la serie, el tiempo total en la adquisición de una serie es de aproximadamente 81 minutos. Considerando que la escala del ASH es de 1.47 arcsec pixel $^{-1}$, un objeto en la oposición a $R=30 U A$ se desplazará entre la primera y la última imagen de la serie unos 3.7 pixeles. En el otro extremo, un objeto en la oposición a $R=5 U A$, se habrá desplazado 18.3 pixeles.

En la Figura 2.2.4 se detalla una lista de las principales características del programa de búsqueda que se realizó para esta tesis.

\begin{tabular}{|l|c|}
\hline \multicolumn{2}{|c|}{ Características del programa de búsqueda } \\
\hline \multicolumn{1}{|c|}{ Características } & ASH 0.45 m \\
\hline Razón focal & f / 2.8 \\
\hline CCD (pixel x pixel) (campo útil) & $4008 \times 2672$ \\
\hline Escala de placa (arcsec/pixel) & 1.47 \\
\hline Extensión EO (deg) & 1.63 \\
\hline Extensión NS (deg) & 1.09 \\
\hline Dimensión del campo (deg ${ }^{2}$ ) & 1.77 \\
\hline Tiempo de lectura (seg) & 26 \\
\hline Filtro & Luminance \\
\hline Vlimite (Sistema Johnson) (180 seg) & 20.96 \\
\hline Area total relevada (deg ${ }^{2}$ ) & 14.17 \\
\hline Binning (pixel x pixel) & $1 \times 1$ \\
\hline Tiempo de integración por imagen (seg) & 180 \\
\hline Tiempo de integración de las series (hs) & $1.35-1.47$ \\
\hline Límite de eficiencia (Rmag) & 22.3 \\
\hline Seeing (arcsec) & $2.1-3.2$ \\
\hline SP (Survey Power) & 0.33 \\
\hline
\end{tabular}

Figura 2.2.4. Parámetros y características del programa de búsqueda realizado para esta tesis.

El parámetro SP (Survey Power) que figura en el último renglón de la tabla es un intento de cuantificar la potencialidad para realizar un programa de búsqueda que tienen en conjunto 
un telescopio y el sitio donde está emplazado, y considera no sólo características propias del telescopio como un instrumento aislado, sino que trata de incluir la calidad del cielo del lugar. Está descripto en Jewitt (2003) y ha sido tenido en cuenta por varios autores como por ejemplo Trujillo (2008), quien realiza una serie de comparaciones entre las potencialidades de varios telescopios y sitios en la búsqueda de TNOs. Su expresión está dada por,

$$
S P \equiv \pi\left(\frac{D / 2}{m}\right)^{2}\left(\frac{\Omega}{\text { grados }^{2}}\right)\left(\frac{\operatorname{arcsec}}{\theta}\right)^{2}
$$

donde $D$ es la apertura del telescopio en metros, $\Omega$ es el campo del instrumento en grados cuadrados y $\theta$ es el seeing medio del sitio medido en segundos de arco.

\subsubsection{El procesamiento de las imágenes}

Para este programa de búsqueda, como se mencionó, se adquirieron en total trescientos cuarenta y cinco imágenes científicas de las zonas seleccionadas y suficientes darks y flats en cada noche de observación. Los flats se obtuvieron con un tiempo de exposición de 2 segundos, y los darks con tiempos de 180 segundos y 2 segundos para poder aplicarlos directamente en la corrección de las imágenes de programa y en los flats, sin procesar por bias. Antes de cualquier procesamiento se agregó en las cabeceras los campos necesarios y todas las imágenes fueron convertidas a reales.

A fin de comenzar con la pre-reducción de las observaciones, se procedió a combinar los darks para imágenes de programa y flats, utilizando tareas del paquete IRAF. En el primer caso, y dado que el detector se enfría mediante Efecto Peltier, se procedió a adquirir darks tanto al principio como al final de cada noche, que luego fueron combinados independientemente y comparados entre sí. En ningún caso estos darks finales presentaron diferencias sensibles entre uno y otro. En el caso de los darks para flats, los mismos fueron adquiridos inmediatamente antes o después de la serie de flats, para asegurar que el dark final permita una corrección de excelente calidad.

Luego de corregir todas las imágenes de programa y los flats por la contribución de dark y bias correspondiente a cada noche, se procedió a combinar los flats individuales para obtener flats finales. Para cada noche se combinó un número de no menos de cinco flats individuales para lograr el flat final. Por último, las imágenes científicas de programa fueron corregidas por los correspondientes flats finales renormalizados con su valor medio.

El siguiente paso consistió en un minucioso análisis individual de cada una de las imágenes de programa a fin de descartar las defectuosas, las que sumaron un total de 17 . En las Figuras 2.2.5 y 2.2.6 se muestran los dos tipos de defectos por los que fueron eliminadas prácticamente todas las imágenes con problemas. El efecto ilustrado por la primera de las imágenes es muy posiblemente la consecuencia de un salto durante la adquisición de la imagen, mientras que el mostrado en la segunda es muy probable que sea producto de las vibraciones de la estructura del telescopio debido al viento cuando el instrumento se encuentra apuntando a una posición cercana al cenit.

El campo 00 fue relevado durante tres noches consecutivas en las cuales se tomaron un total de cuarenta y cinco imágenes repartidas en cinco, veinte y veinte imágenes. Se 
descartaron las únicas cinco imágenes tomadas en la primera noche como prueba, porque no resultaban útiles para el programa. Para el campo 01 se obtuvieron sólo veinte imágenes, dado que por mal tiempo no se pudo completar el relevamiento de ese mismo campo la noche siguiente y por lo tanto la serie completa fue descartada. Por lo tanto, luego de esta depuración el material observacional consistió en trescientas tres imágenes, repartidas en ocho campos relevados cada uno durante dos noches consecutivas mediante conjuntos de unas veinte imágenes por noche. El análisis y las estrategias de búsqueda fueron implementadas individualmente por campos, comparando grupos de imágenes dentro de una misma noche o entre noches consecutivas. Por la depuración de imágenes sólo una minoría de tales conjuntos no posee estrictamente veinte imágenes, pero para mayor comodidad en las explicaciones que se darán a continuación sobre procedimientos y métodos, seguiremos llamando serie a todo conjunto de imágenes de una misma noche, independientemente de si consta de veinte imágenes o de un número menor.

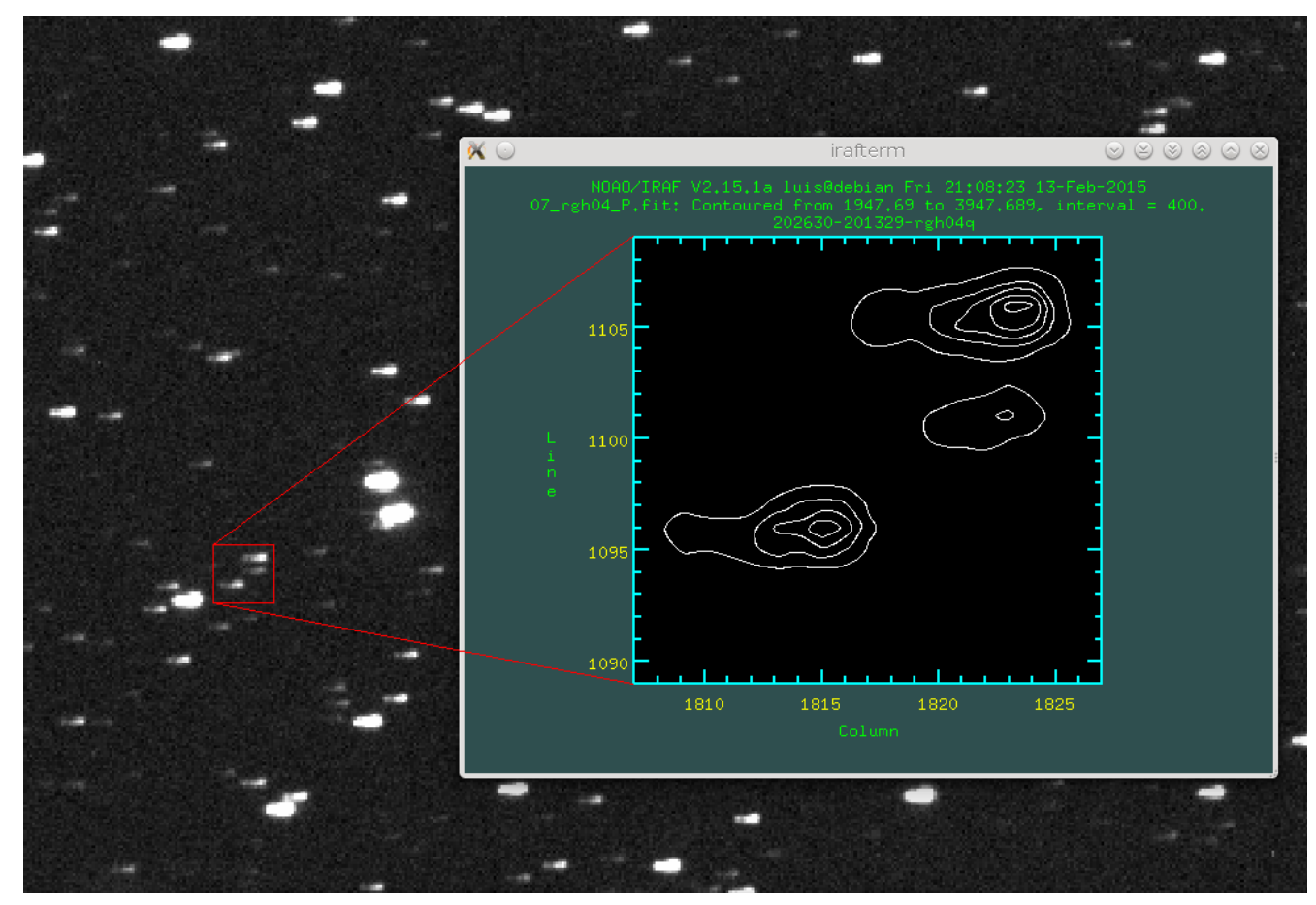

Figura 2.2.5. Imagen descartada: Algunas de las imágenes como la que aquí se muestra, fueron descartadas porque mostraban cierto exceso en dirección $E$ - $W$, posiblemente por un salto durante la adquisición de las mismas. 


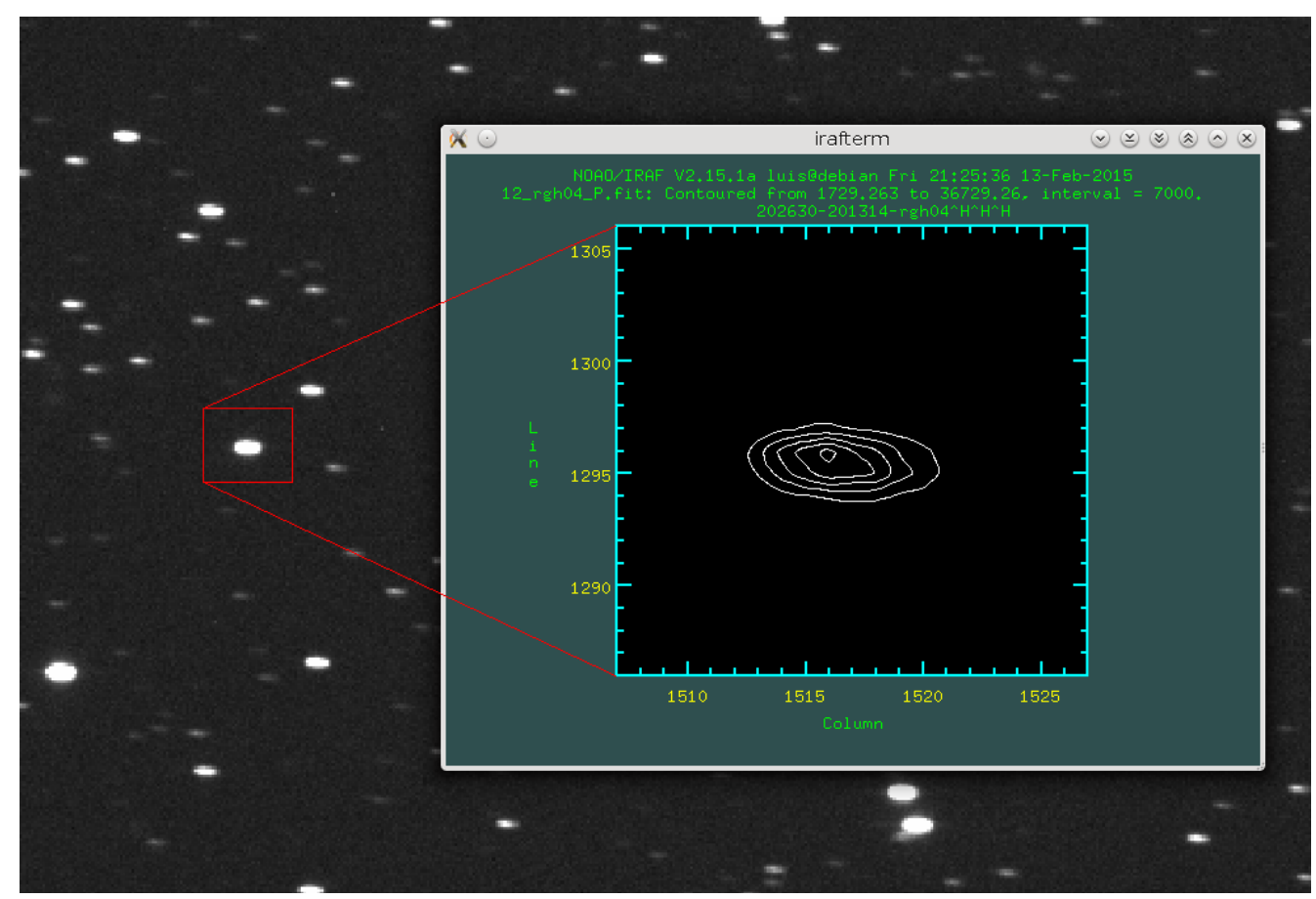

Figura 2.2.6. Imagen descartada: Otra causa de descarte se dio con imágenes que mostraban elongaciones en todas las estrellas del campo, sin preferencia de zona alguna, posiblemente por el efecto del viento sobre la estructura del telescopio.

Como se vio anteriormente, coadicionando veinte imágenes de una serie con tiempos de integración de 180 segundos, es teóricamente posible detectar objetos bastante débiles. Ahora bien, si se desea adicionar imágenes a fin de mejorar la relación $S / N$ de cada fuente presente en ellas, previamente será necesario registrarlas. En instrumentos donde el campo útil es de pocos minutos es usualmente suficiente determinar la posición de algunas estrellas mediante la tarea daofind del paquete noao.digiphot.apphot de IRAF, para luego aplicar los corrimientos necesarios utilizando la tarea imshift. Lamentablemente este procedimiento no es suficiente en un instrumento de gran campo como es el ASH y en estos casos se requiere aplicar otro tipo de procedimientos para lograr el máximo campo útil. Así, para poder coadicionar imágenes adquiridas con un instrumento de gran campo es necesario corregir en todas ellas los efectos producidos por distorsión debida a leves variaciones del foco durante la noche, por rotación de campo, y por la curvatura de campo residual producto de una insuficiente corrección de la aplanadora de campo que se encuentra delante del detector, efectos que resultan muy notorios en los bordes de las imágenes. Para realizar esta corrección se determinaron las coordenadas $(\mathrm{x}, \mathrm{y})$ de los centros geométricos de doce estrellas uniformemente distribuidas. Luego, mediante la tarea de IRAF geomap se realizó un mapeo de la distorsión de cada imagen y finalmente con la tarea geotran se aplicó la corrección. Todas las correcciones de todas las imágenes se realizaron simultáneamente mediante un script de desarrollo propio sólo con el dato inicial de dichas coordenadas. El modelo numérico utilizado corrigió las imágenes por desplazamiento, rotación y escala, obteniéndose un buen resultado y por lo tanto no siendo necesario aplicar correcciones más allá del segundo orden.

De esta forma, finalmente se obtienen las imágenes reducidas, corregidas por defectos 
geométricos y alineadas por noche y por campo, condición inicial necesaria para implementar cualquier estrategia de búsqueda.

\subsection{Estrategias de búsqueda}

Los Centauros son en general objetos extremadamente débiles y si se desea implementar un programa de búsqueda exitoso sobre esta población habrá que tener la capacidad de detectar objetos más débiles que $V m a g=21$. Dada la magnitud límite que se alcanza con el ASH para los tiempos de exposición utilizados, en las imágenes individuales sólo se detectarán Centauros brillantes. Si se aumentan los tiempos de exposición, existe el agravante del movimiento propio sobre el fondo de las estrellas que desplaza al objeto en la imagen y distribuye la energía recibida en un área mucho mayor del detector, lo que resulta en una peor relación $S / N$. Por otra parte, si se desea detectar un objeto que por su debilidad no es visible en ninguna de las imágenes de una serie, realizar una adición de todas las imágenes alineadas no sumará para estos objetos sus señales individuales porque éstas se irán desplazando de imagen a imagen, la relación $S / N$ no mejorará y será imposible detectarlo. Pero si se conoce la dirección del movimiento y su velocidad angular entre las estrellas fijas, tendremos la posibilidad de detectarlo si desplazamos las imágenes ya alineadas en sentido inverso a su movimiento de manera tal de llevar cada señal individual del objeto en cada imagen a la posición de origen de su trayecto, para recién ahí realizar la suma. La imagen final resultante de este proceso es una imagen formada, por un lado, por trazos estelares producidos por el desplazamiento de las imágenes individuales y, por el otro, por objetos puntuales ubicados en la posición que tenían los objetos en la primera imagen y que se mueven a esa velocidad y dirección. Así, el desplazamiento $\left(\Delta \mathrm{x}_{k}, \Delta \mathrm{y}_{k}\right)$ que debe aplicárse a la $k$-ésima imagen para que la posición que ocupa un cuerpo en un tiempo $t_{k}$ quede superpuesta a la posición que ocupaba en la primera imagen en el instante $t_{1}$, vendrá dado por las expresiones,

$$
\begin{aligned}
& \Delta x_{k}(\text { pixel })=\frac{-\dot{\theta}\left[\operatorname{arcsech}^{-1}\right] \cdot\left(t_{k}-t_{1}\right)[h s]}{\text { PIXSCALE }\left[\operatorname{arcsec}^{\left.-1 x e l^{-1}\right]} \cos \alpha,\right.} \\
& \Delta y_{k}(\text { pixel })=\frac{-\dot{\theta}\left[\operatorname{arcsech}^{-1}\right] \cdot\left(t_{k}-t_{1}\right)[h s]}{\text { PIXSCALE }\left[\text { arcsec pixel }^{-1}\right]} \operatorname{sen} \alpha,
\end{aligned}
$$

donde $\alpha$ es el ángulo entre el vector desplazamiento del objeto en las imágenes y el eje X, medido en sentido directo (ver Figura 2.4.11).

El movimiento de los objetos en las imágenes siempre tiene una orientación EW y ello se debe a que todos los campos relevados por el presente programa de búsqueda están dirigidos en dirección a la oposición, y alrededor de esta región todos los objetos con $R>1 U A$ retrogradan porque la proyección sobre el fondo del cielo del vector $\overrightarrow{v_{\oplus}}-\overrightarrow{v_{o}}$, donde $\overrightarrow{v_{\oplus}}$ y $\overrightarrow{v_{o}}$ son los vectores velocidad angular de la Tierra y del objeto respectivamente, tendrá un sentido retrógrado (En la imagen de la Figura 2.3.1 se indica la orientación que tienen todas las imágenes del programa).

Ahora bien, como a priori no conocemos ni la dirección de movimiento ni la velocidad angular de los objetos que buscamos dado que no son visibles en ninguna imagen, la única alternativa es desplazar las imágenes de $\mathrm{W}$ a $\mathrm{E}$ asumiendo una determinada dirección 
de movimiento y una velocidad angular que asociamos con su correspondiente distancia heliocéntrica a partir de la relación (2.2.3), para luego sumarlas. Un minucioso análisis de la imagen suma permitirá detectar todos los objetos que se encuentran a esa distancia y que se desplazan en la imagen en la dirección y sentido elegidos, mostrándolos concentrados en objetos puntuales, mientras que las estrellas se verán como trazos que imitan en longitud y dirección los trazos que dejarían esos mismos objetos moviéndose en una imagen coadicionada si fueran visibles en todas las imágenes de la serie (ver esquemas de la Figura 2.4.13 y un caso real en la Figura 2.4.14). Por otro lado, un objeto que se moviera en una dirección cercana a la que elegimos y/o estuviera a una distancia heliocéntrica levemente diferente, formará una débil figura apenas elongada -cuasi puntual- como producto de las superposiciones parciales de las veinte señales individuales, lo que permitirá incluso detectar objetos que se mueven aproximadamente en aquella profundidad y dirección elegidas. En ese caso, habrá que realizar un ajuste fino de los desplazamientos de las imágenes y realizar nuevamente la suma hasta dar con la velocidad y dirección de movimiento correctas para luego determinar su distancia heliocéntrica real y así poder clasificarlo o no como un Centauro. Por lo tanto, la idea no es solamente concentrarse en los objetos puntuales bien formados en las imágenes suma -hecho que se dará en casos muy excepcionales-, sino también prestar atención a la aparición de toda figura elongada de dirección y/o longitud diferente a los trazos estelares que se forman en las imágenes generadas. Esto último es un punto importante y constituye una idea que estuvo presente en todas las estrategias de búsqueda que se exploraron.

Para la coadición de imágenes se utilizó la tarea imcombine de IRAF, donde se decidió no aplicar el procedimiento usual de descarte de pixeles altos y bajos que se utiliza para eliminar de la combinación los rayos cósmicos y los pixeles defectuosos. El objetivo de no realizar dicho procedimiento es fundamentalmente mantener series del máximo número de imágenes individuales para obtener la mejor relación $S / N$ que sea posible y mejorar las probabilidades de detección de objetos débiles. Esta decisión complica un poco el proceso de análisis de las imágenes dada el área abarcada por cada una de ellas, pero con un poco de práctica no es muy problemático diferenciar entre rayos cósmicos y pixeles defectuosos -encendidos o apagadosdel resto de la imagen, aunque a veces ciertas estructuras que se forman al azar pueden llevar a confusión. 


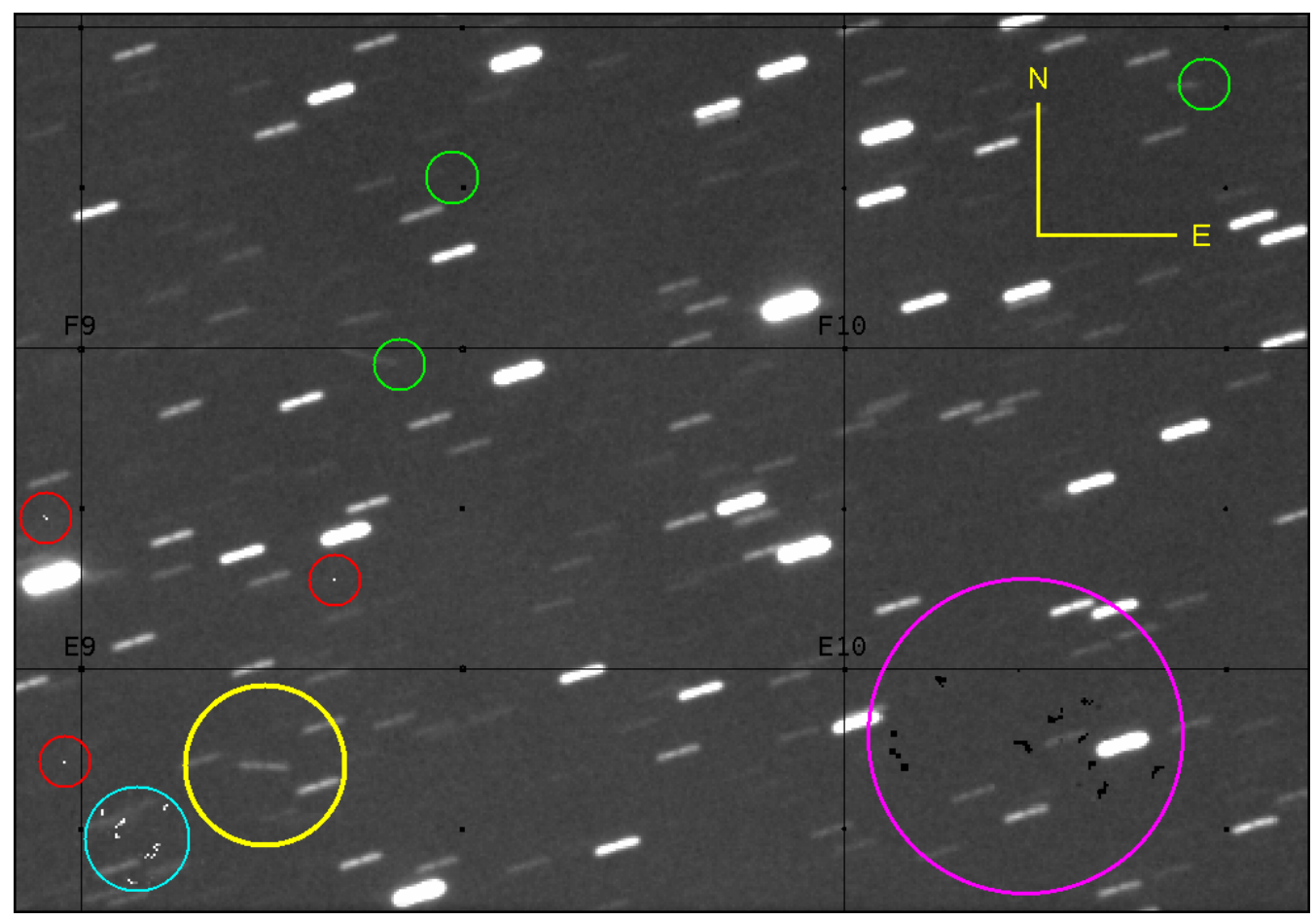

Figura 2.3.1. Diferentes detalles en una imagen a analizar luego de una coadición. verde: Objetos catalogados y que un soft astrométrico de desarrollo propio marca automáticamente en la imagen con un círculo verde. Dichos círculos son centrados en la posición que tenía el objeto en la primera imagen de la serie. Se observa que uno de los objetos catalogados posee una magnitud muy débil como para ser detectado en esta imagen y por ello el círculo verde correspondiente aparece vacío; amarillo: Un asteroide del MBA sin marca de círculo verde, indicativo de que es un objeto que no figura en la base de datos del MPC: es uno de los muchos asteroides descubiertos por nuestro programa de búsqueda; rojo: Rayos cósmicos; celeste: Pixeles encendidos; magenta: Zona de pixeles apagados (negro). Todas las imágenes del programa de búsqueda tienen la orientación que aquí se indica.

En las Figuras 2.3.1 y 2.4.6 pueden verse algunos ejemplos de estructuras y situaciones frecuentes con las que uno puede enfrentarse y que a veces pueden generar confusión.

Fueron varios los intentos por hallar el mejor algoritmo de identificación. Naturalmente el primer esfuerzo se enfocó en idear un método automático de detección, pero todo intento resultó de poca utilidad. Debemos resaltar que si bien existen códigos disponibles que detectan objetos en movimiento, lo hacen operando exclusivamente en los casos en que los objetos son detectables al menos en dos imágenes, conforme van cambiando de posición en todas ellas. En nuestro caso es necesario analizar imágenes en las cuales, en principio, el objeto a encontrar no es detectable en ninguna imagen individual y se requiere coadicionarlas para poder, de alguna manera, dejarlo al descubierto.

En cuanto a los diversos métodos que se intentaron para lograr una detección automática de los objetos, todos los casos se vieron frustrados por un sin número de inconvenientes, como por ejemplo el fondo de cielo desparejo que posee toda imagen que ocupa un amplio campo y las variaciones del tamaño de la imagen durante la noche de adquisición o en noches sucesivas. Si bien se cuenta con métodos para corregir las imágenes por estos problemas, 
resultan computacionalmente muy costosos y no se justifican. Por ejemplo, un método posible para eliminar los problemas producidos por las variaciones de seeing en la combinación de imágenes es el de descomponer cada imagen individual en una pirámide de múltiple resolución (Adelson et al., 1984; Sunkavalli et al., 2010) para luego proceder a la coadición de las mismas. Otra posibilidad para lograr una detección automática es aplicar análisis de diferencia de imágenes (Bramich, 2008; Snodgrass et al., 2013), pero tanto este proceso como el anterior implicarían un enorme trabajo que no justificaría la mejora lograda.

De todos modos, como se intentaron algunas opciones con el fin de desarrollar un algoritmo que diferenciara en forma automática en las imágenes coadicionadas y desplazadas, los trazos dejados por las estrellas de las figuras puntuales formadas por los objetos, se comentarán a continuación algunos de los obstáculos que se presentan a la hora de diseñar un tal algoritmo.

En teoría, la imagen a analizar debería ser una imagen formada por trazos y objetos puntuales -o cuasi puntuales- sobre un fondo más o menos uniforme y lo que se busca es separar dichas formas sin mucha dificultad. Pero el proceso de desplazar y sumar imágenes adquiridas en condiciones de observación variables da como resultado una imagen con trazos de sección irregular rodeados de un fondo con cierta estructura que muchas veces presenta la apariencia de los objetos que se desean encontrar. Precisamente, la cantidad de estructuras puntuales o cuasi puntuales que se forman es tal, que ni siquiera puede considerarse seriamente identificarlas automáticamente, para luego realizar un proceso de descarte visual, caso por caso.

Por ejemplo, si se releva un campo durante dos noches consecutivas con veinte imágenes por noche, se desplaza y coadiciona cada serie (Figuras 2.3.2 y 2.3.3) y finalmente se las resta una vez alineadas, en los lugares donde los trazos estelares deberían haberse cancelado aparecen figuras extrañas con las cuales no es fácil trabajar, debido a los cambios del seeing entre ambas noches (Figura 2.3.4). Lo mismo sucede si se intentan eliminar mediante una resta los trazos estelares dejados en dos imágenes obtenidas coadicionando las mismas imágenes de una misma noche realizando los mismos desplazamientos de las imágenes individuales pero en sentidos opuestos. Por lo tanto, en ambas coadiciones las estrellas dejarán trazos idénticos, pero en una los objetos a detectar aparecerán en forma de puntos brillantes mientras que en la otra -donde las imágenes son desplazadas en la dirección y sentido de movimiento de los objetos-, los mismos distribuyen su brillo en un segmento de recta mucho más largo por lo cual sus señales individuales no se superpondrán, y por lo tanto no serán visibles. De esta manera se habrán obtenido dos imágenes finales para restar una vez que las hayamos alineado, donde sería de esperar que los trazos estelares se anulen entre sí y que la aparición de los objetos como puntos en sólo una de ellas fuera suficiente para por comparación, ponerlos al descubierto. Pero lo cierto es que nuevamente las variaciones de seeing, en este último caso dentro de una misma noche, impiden que los trazos estelares sean idénticos en ambas coadiciones y que la resta sea completa. 

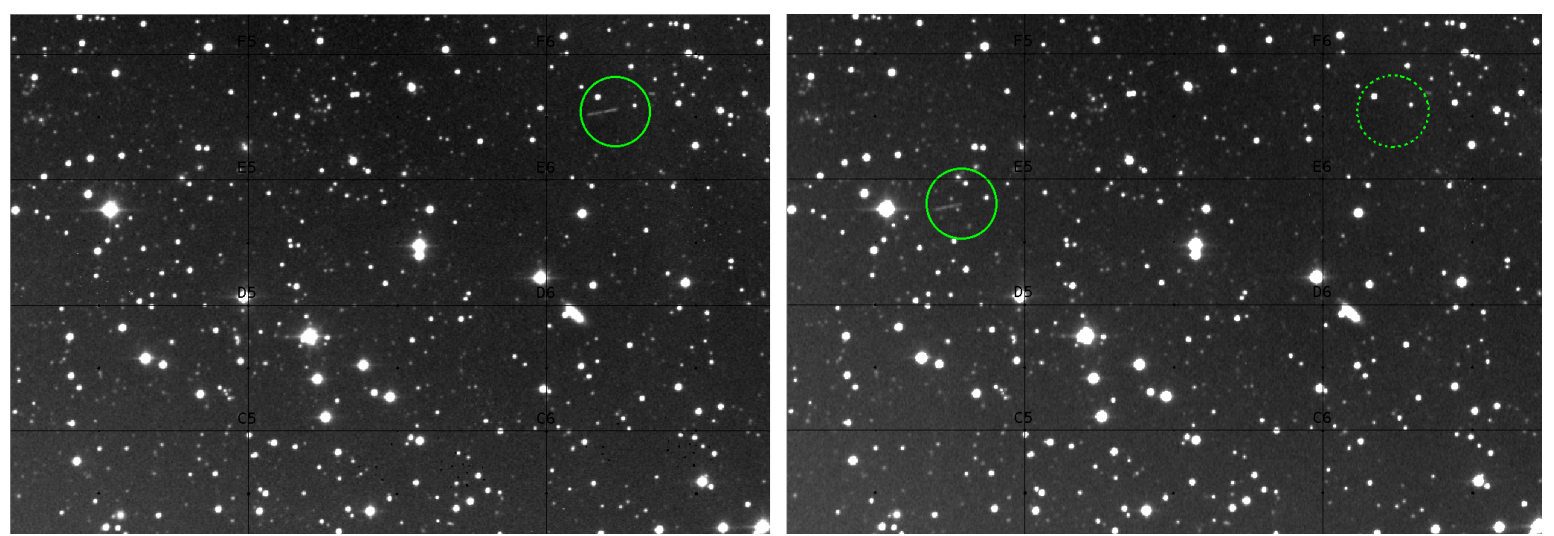

Figura 2.3.2. Imágenes coadicionadas de las series obtenidas para el campo 07 en las noches del 30 y 31 de agosto de 2008. Se observan los trazos dejados por el asteroide 2000 GC4, en una y otra noche, durante la hora y veinte que llevó aproximadamente adquirir cada serie. Los círculos están centrados en la primera posición que ocupaba el asteroide en cada serie.
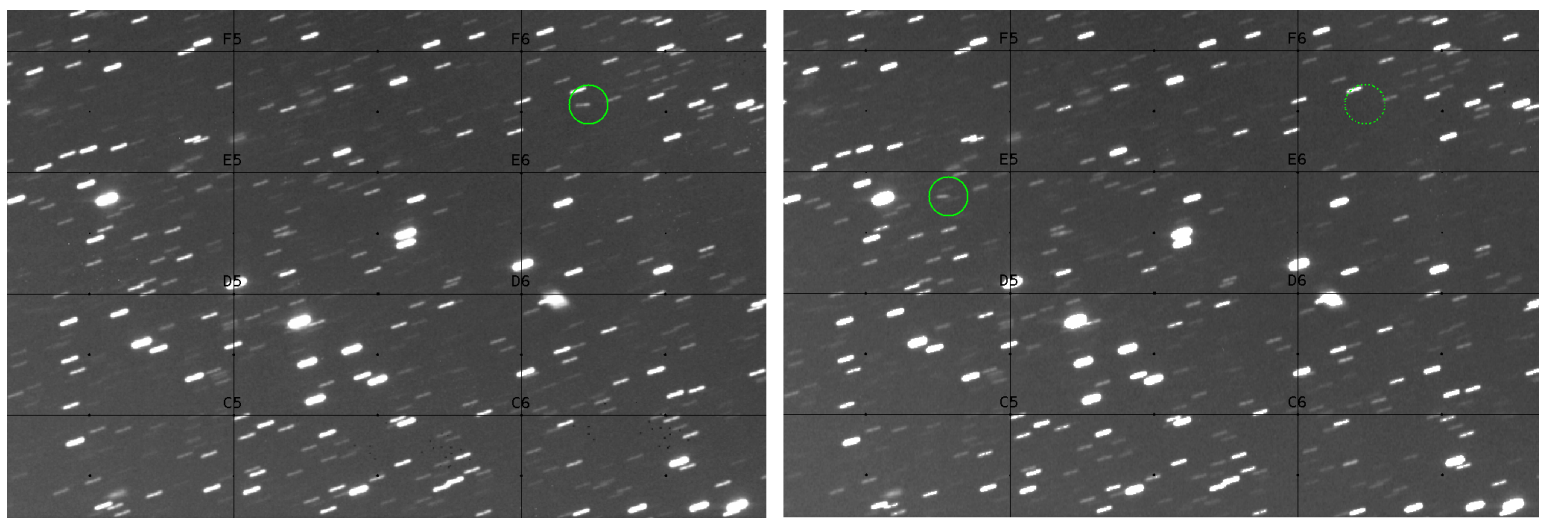

Figura 2.3.3. Imágenes coadicionadas de las mismas series que las combinadas para formar las resultantes de la Figura 2.3.2, pero ya desplazadas para la búsqueda de objetos a $6.7 U A$, moviéndose en un ángulo $\alpha=197^{\circ}$ medido en sentido directo desde el eje X. Se observan en ambas noches los trazos de 2000 GC4 arrastrados por el desplazamiento de las imágenes. 


\section{Programa de búsqueda de Centauros}

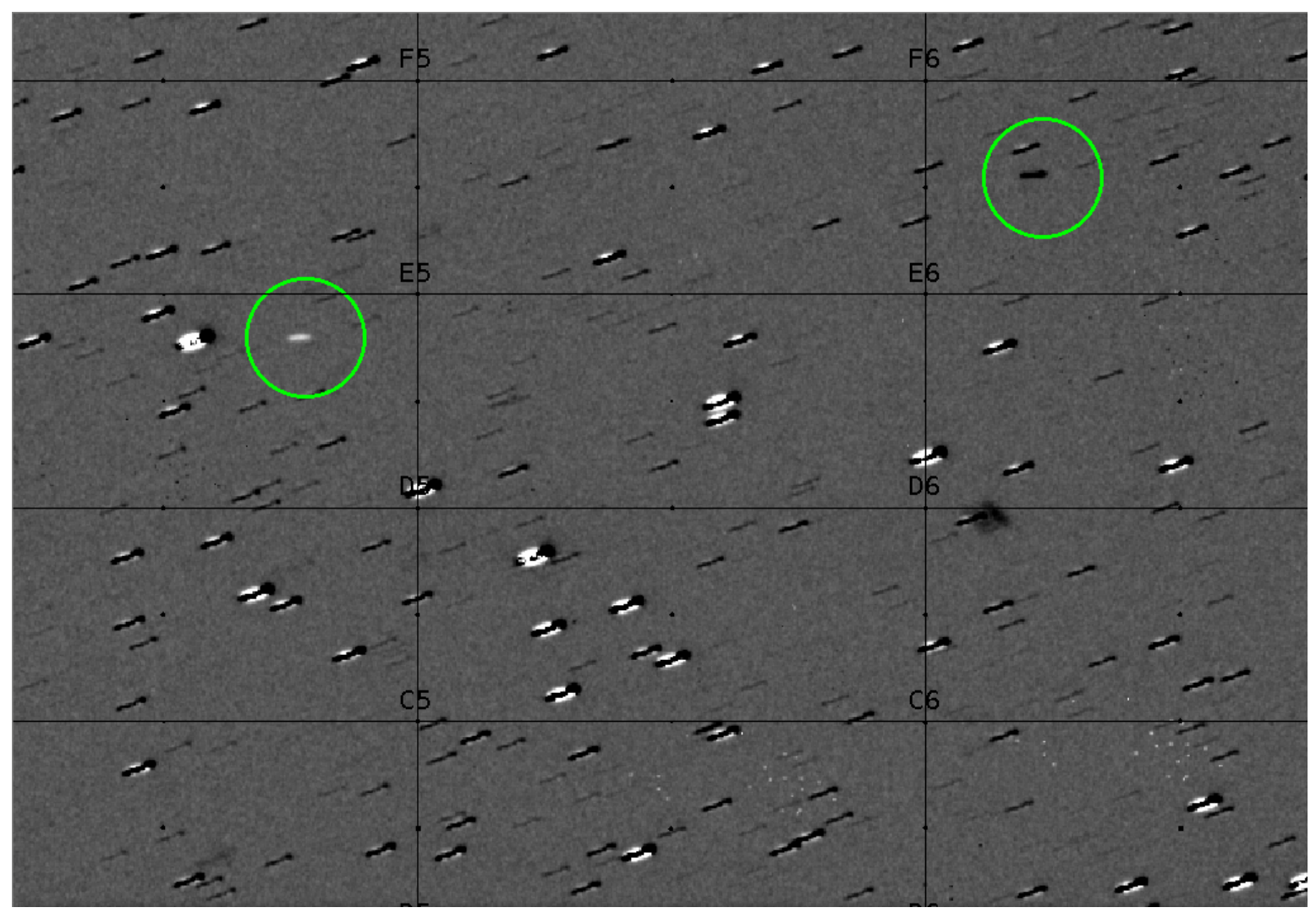

Figura 2.3.4. Resultado de restar las imágenes de la figura anterior luego de alinearlas. Lejos de quedar una imagen clara y pareja donde los trazos estelares se anulan entre sí, la imagen-resta aparece salpicada de imperfecciones que dificultan la detección de alguna imagen puntual dejada por algún objeto real. Se observan los rastros dejados por $2000 G C_{4}$ según la resta sea un número de cuentas de signo positivo (brillante) o negativo (oscuro).

Otro intento consistió en utilizar la tarea daofind de IRAF con la esperanza que la misma sólo detectara y reportara como fuentes los objetos puntuales en la imagen coadicionada haciendo caso omiso de las fuentes estelares enmascaradas en los trazos estelares, pero lamentablemente la tarea no sólo identifica las fuentes puntuales aisladas sino que también logra resolver, identificar y reportar como fuente puntual cada una de las estrellas individuales que forman cada trazo por más compacto que éste sea, por lo que su aplicación resulta de poca utilidad.

Por último, tampoco resultaron útiles el uso de convoluciones con kernels que reproducían la forma de un trazo estelar individual, o programas tradicionales como SExtractor (Sourse Extractor; Bertin y Arnouts, 1996) e ISIS (Image Subtraction; Alard, 2000), por lo cual no quedó más alternativa que aplicar técnicas de detección imagen por imagen. 


\subsection{El método de búsqueda}

Finalmente el método de búsqueda que se implementó consistió en comparar la imagen coadicionada luego de desplazar en cierta dirección y cierta distancia heliocéntrica la serie de una noche, con la imagen obtenida de la misma manera a partir de la serie de la noche siguiente. Como no tiene mucho sentido considerar trazos cuya longitud varían pixel a pixel, y la longitud del trazo depende de la distancia heliocéntrica a la que se encuentra un objeto (ver Figura 2.4.18), para la región del SS que resulta de interés para buscar Centauros es suficiente considerar sólo cinco distancias o profundidades base (Figura 2.4.1). Si bien la detección es visual, se estableció una estrategia mecanizada y ágil de pasos bien determinados que permite, luego de adquirida cierta práctica, realizar la búsqueda con mucha eficiencia. Básicamente lo que se hace es comparar dos imágenes coadicionadas de un campo adquiridas en noches sucesivas en función de una profundidad y dirección preestablecidas, y tratar de detectar en ellas objetos puntuales que cambien de posición entre una y otra, sin dejar de prestar atención a formas levemente elongadas que puedan corresponder a objetos que se desplazan a profundidades y direcciones cercanas a las elegidas previamente, y que posteriormente, luego de un análisis individual, se tratarán de transformar en formas puntuales luego de realizar las correspondientes correcciones diferenciales en profundidad y dirección.

\begin{tabular}{|c|c|c|}
\hline $\mathrm{R}(\mathrm{UA})$ & $\dot{\theta}($ arcsec/hs $)$ & $\mathrm{d}$ (pixel) \\
\hline 6.7 & 16 & 14.6 \\
\hline 8.5 & 13 & 11.9 \\
\hline 11.4 & 10 & 9.1 \\
\hline 17.0 & 7 & 6.4 \\
\hline 31.4 & 4 & 3.7 \\
\hline
\end{tabular}

Figura 2.4.1. Las cinco profundidades base, las correspondientes velocidades esperables para un objeto en la oposición y su distancia recorrida durante la integración de la serie.

Se establecieron cinco criterios para definir como positivo un determinado hallazgo:

1. El objeto debe formar una imagen puntual en las dos noches consecutivas que cubren un campo, en alguna profundidad y dirección específicas.

2. Dicha profundidad debe corresponder a una velocidad compatible con la de un objeto en la oposición en la región de Centauros.

3. La distancia entre las posiciones del objeto en una y otra imagen coadicionada de cada noche, debe ser compatible con un movimiento rectilíneo uniforme a la velocidad angular correspondiente.

4. La imagen puntual formada en una imagen a la profundidad y dirección de desplazamiento correctas, debe tener una evolución en su morfología tal que a medida que se varían los valores de profundidad y dirección su forma cambie sin límite de continuidad desde figuras alargadas hasta formas cuasi puntuales que nuevamente se vuelven a alargar (ver secuencia en la Figura 2.4.2).

5. El objeto en ambas imágenes coadicionadas de cada noche debe tener magnitudes similares. 


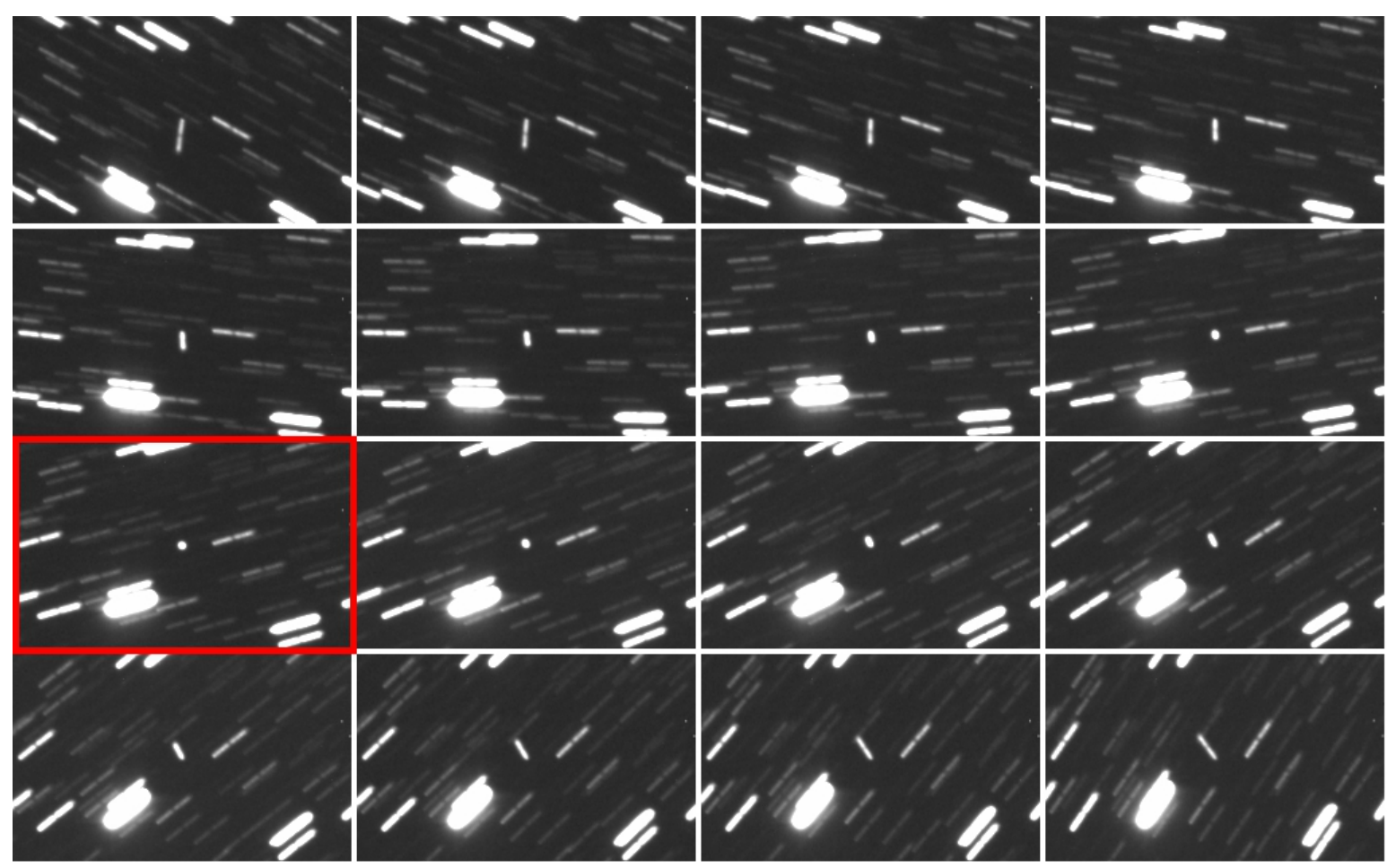

Figura 2.4.2. Secuencia de imágenes generadas por el script y código de desarrollo propio para concentrar en la primera posición de la noche todas las señales aportadas por el asteroide (2085) Henan en cada imagen de la serie. La secuencia muestra una clara evolución morfológica continua de los trazos dejados por el asteroide. La forma puntual perfecta sólo se da en aquella imagen coadicionada cuya profundidad y dirección corresponden con los desplazamientos correctos de cada imagen de la serie -recuadro rojo-.

Para poder analizar las imágenes y realizar la búsqueda de objetos, desarrollé un script de IRAF que permite automatizar el proceso y correr un código (al que llamé puntual.f) que realiza todos los cálculos. El script automáticamente genera y despliega imágenes coadicionadas desplazando las diecinueve imágenes individuales de una serie en una dirección a elección hacia la primera posición de la noche, según la profundidad donde se desee buscar. El script también ofrece la opción de desplazar las imágenes hacia la última posición de la noche, permitiendo elegir formar la imagen puntual en cualquiera de los dos extremos de la serie, lo que posibilita obtener rápidamente dos imágenes puntuales del objeto y optar, por ejemplo, cuál de ellas es la que se forma más lejos de una estrella brillante que pudiera alterar el fondo de cielo en la vecindad del objeto afectando la relación $S / N$ final. Además, no sólo permite elegir desplazar las imágenes en una dirección en particular, sino que se puede optar por que el código decida y calcule la cantidad necesaria de direcciones que deben barrerse para finalmente generar las imágenes suma correspondientes para cada una de dichas direcciones. Incluso puede optarse por un paso angular en particular. Por ejemplo, en la Figura 2.4.2 se muestra una secuencia de dieciséis imágenes creadas por el script, que automáticamente las despliega en pantalla. En esa secuencia se puede ver al asteroide (2085) Henan del MBA -a una distancia heliocéntrica $R=2.76 U A$ y magnitud $V m a g=15.63-$, cuyo trazo varía de tal manera que logra formar una imagen puntual y nítida en el momento en el que la velocidad angular y dirección de movimiento coinciden con las reales del objeto (también puede verse 
la secuencia de la Figura 2.4.16).

\subsubsection{Búsqueda a distintas profundidades para una dirección dada}

Para realizar una búsqueda en una dirección en particular, por cada noche el script crea seis imágenes conformadas por las correspondientes cinco profundidades bases, más una imagen coadicionada directamente sobre las estrellas (o sea, velocidad angular cero). Para que las seis imágenes correspondiente a las seis profundidades construidas con la serie de la segunda noche queden alineadas con sus correspondientes de la primera, se las desplaza hacia éstas adecuadamente mediante la tarea imshift de IRAF. Una vez que todas estén registradas se las renombra de modo tal que cuando sean desplegadas todas juntas, queden ubicadas de a pares -una por cada noche- y por profundidad. De este modo las dos primeras imágenes en ser comparadas entre sí serán las correspondientes a la velocidad angular $\dot{\theta}=16$ arcsec hs $^{-1}$ de cada noche (objetos a 6.7 $U A$ ) (Figura 2.4.3).

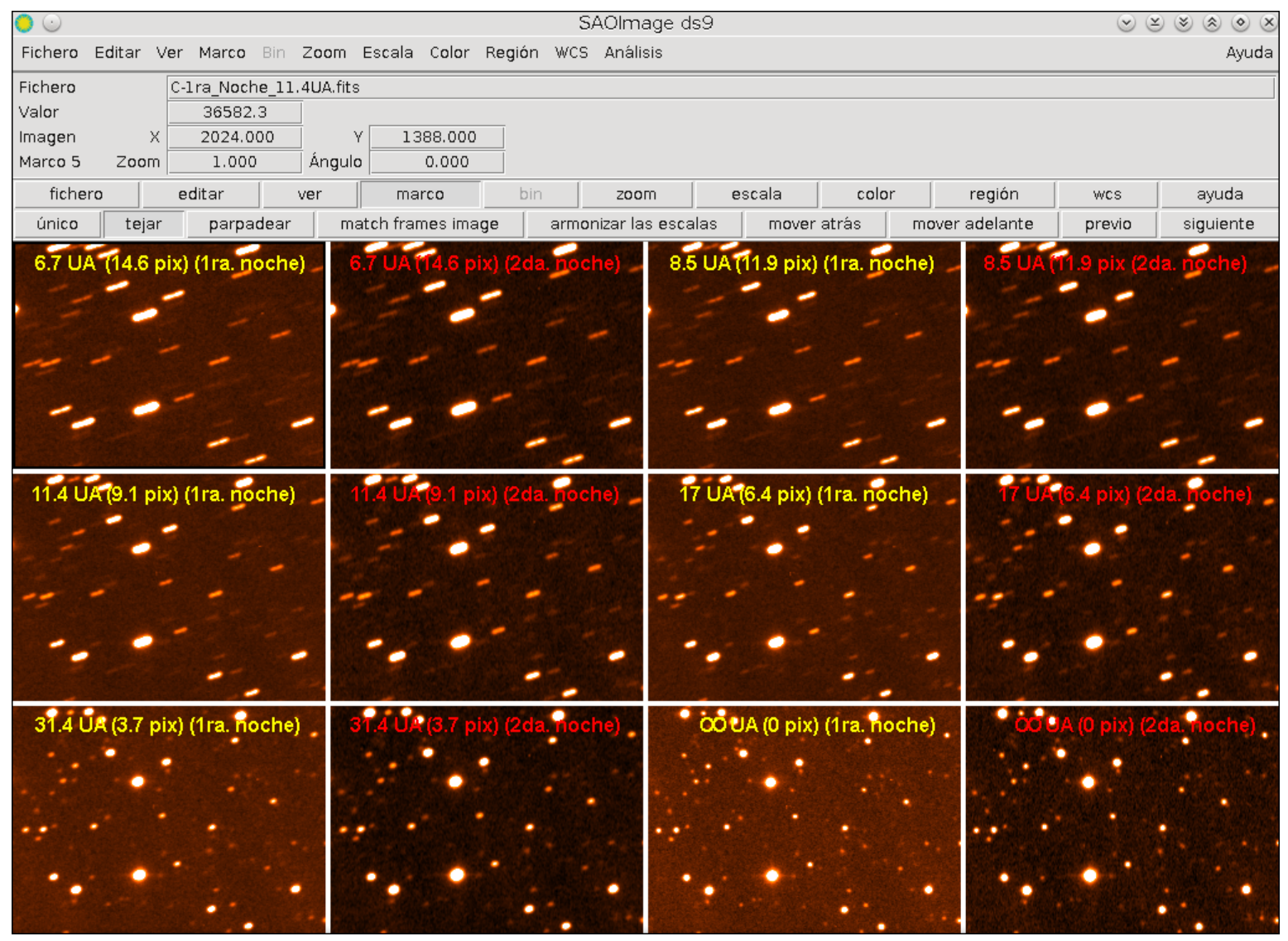

Figura 2.4.3. Para una dirección fija, despliegue de a pares -una por cada noche- de las doce imágenes a comparar para las cinco profundidades base diferentes, más la profundidad correspondiente a una velocidad angular cero. Las que están en un orden impar corresponden a la primera noche. Las últimas dos, son las imágenes coadicionadas sin desplazamientos previos sobre las estrellas. Obsérvese las diferencias de contraste en las imágenes de una misma noche a distintas profundidades y principalmente, las diferencias entre las imágenes entre una noche y la siguiente. 
De esta manera, consecutivamente se compara cada profundidad de a pares de una noche a la siguiente, con lo cual es posible ver simultáneamente cómo evoluciona un trazo a medida que nos internamos cada vez más en la región de Centauros (en el SAOImage ds9: Frame $\rightarrow$ Blinking/0.125 segundos). En la secuencia de la Figura 2.4.3 se aprecia que a una profundidad cercana al límite exterior de la región, correspondiente a velocidades angulares cercanas a los $4 \operatorname{arcsec} \mathrm{s}^{-1}$ (órdenes 9 y 10 de la secuencia), es muy difícil diferenciar entre trazos estelares y objetos puntuales.

A fin de realizar una búsqueda detallada y ordenada de un campo en particular, se construyó una malla-guía reglada y numerada que divide a las imágenes en 273 celdas de 300 pixeles $\times 130$ pixeles $\left(A_{1}, \ldots, U_{13}\right)$, subdivididas en 4 subceldas de 150 pixeles $\times 65$ pixeles cada una (Figura 2.4.4).

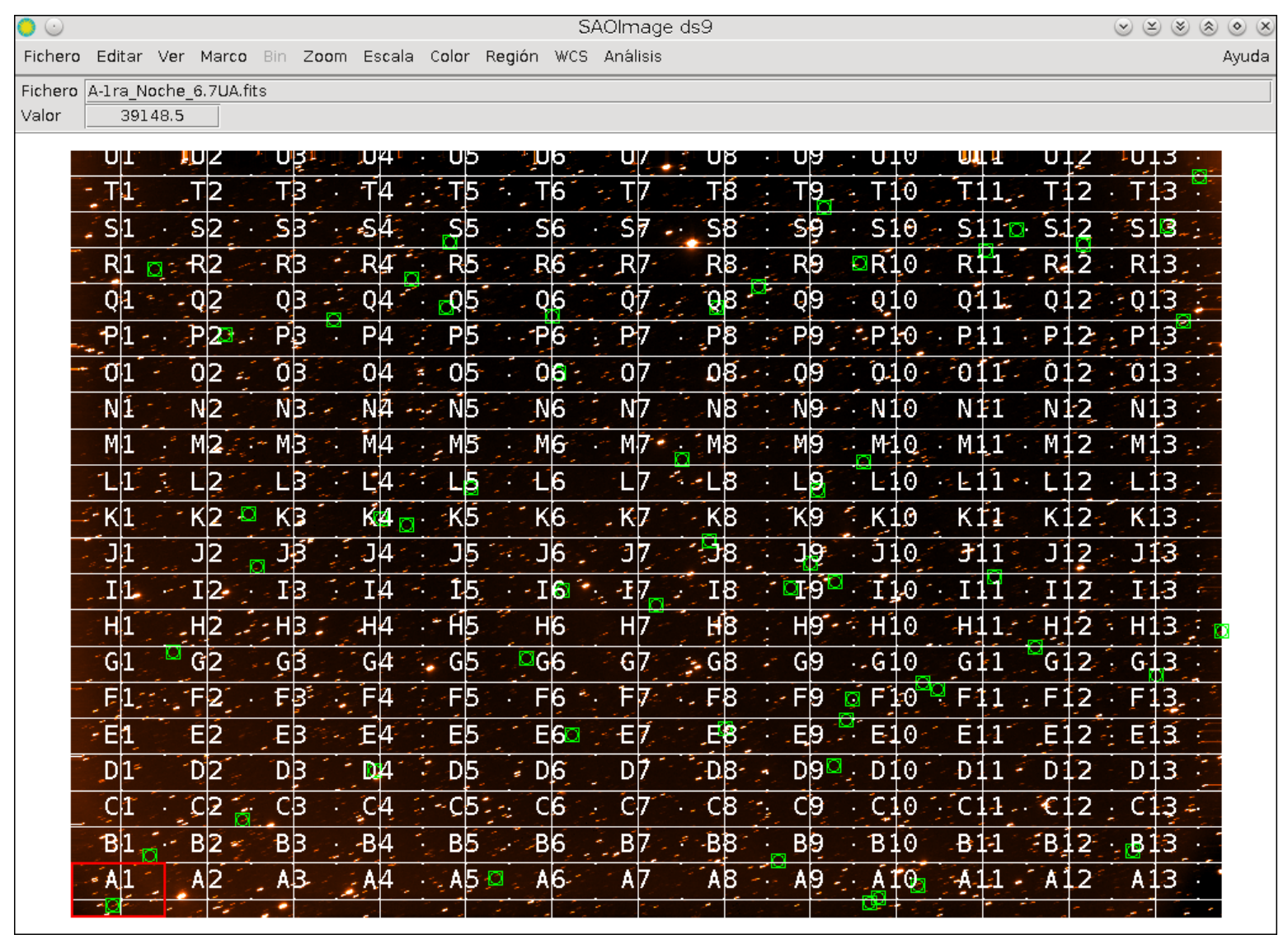

Figura 2.4.4. Una de las imágenes a comparar con la malla-guía y la plantilla de objetos catalogados por el MPC para esa noche (círculos verdes), ya montadas sobre la imagen. Nótese lo despareja que es la imagen en términos de brillo y contraste. Se resalta la celda $A_{1}$, en el centro de coordenadas de la imagen.

Una vez desplegadas las doce imágenes, en la primera de ellas realizamos un zoom en la celda $A_{1}$ hasta que quede centrada ocupando toda la pantalla (Figura 2.4.5). Ésta será la primera celda que se comparará con las otras once celdas $A_{1}$, y constituye el punto de partida del proceso de búsqueda. 


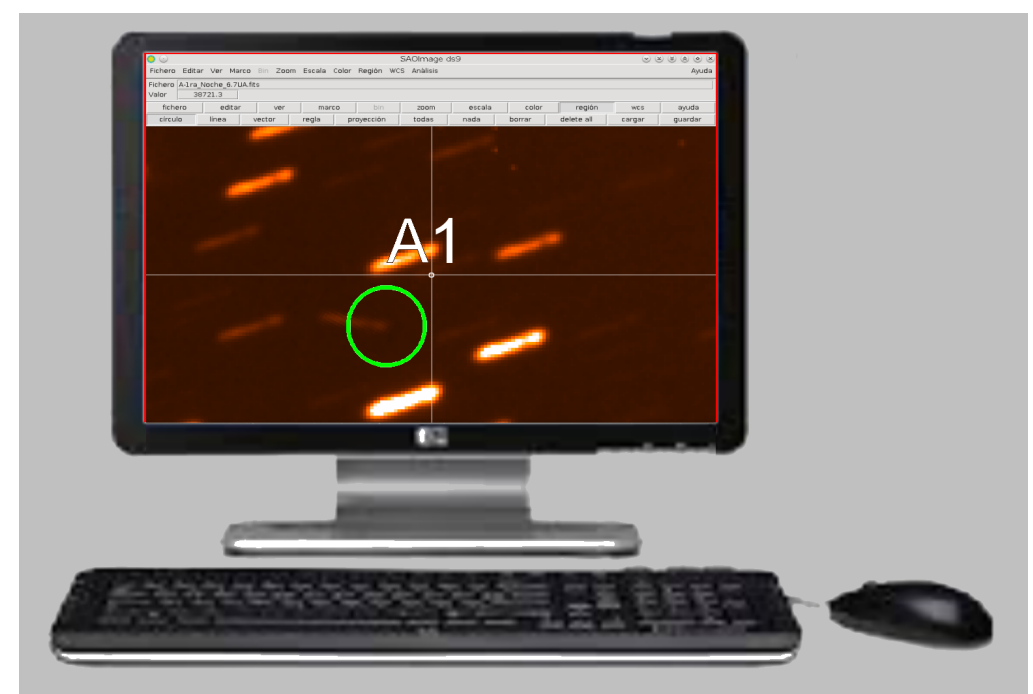

Figura 2.4.5. Celda $A_{1}$ centrada y desplegada ocupando toda la pantalla en la primera imagen a comparar y punto de partida del proceso de comparación y búsqueda.

Ese mismo proceso de centrado debe realizarse manualmente sobre cada una de las 273 celdas de la primera imagen a medida que avanzamos en la búsqueda en nuestro campo $\left(A_{1} \rightarrow\right.$ $\left.A_{2} \rightarrow A_{3} \rightarrow \ldots\right)$, barriendo todas las celdas. Una vez que una celda de la imagen de partida haya quedado centrada, es posible centrar automáticamente todas las restantes imágenes en esa misma celda. Antes de proseguir, deberán emparejarse todas las celdas en contrastes/brillos y escalas, pudiéndose hacer esto de forma automática, pero desafortunadamente siempre con algunos inevitables reajustes individuales de forma manual. En el caso del SAOImage ds 9 estas opciones de ajustes automáticos se encuentran disponibles con los comandos Frame $\rightarrow$ Match Frame Image, Frame $\rightarrow$ Match Color Bar y Frame $\rightarrow$ Match Scale, respectivamente.

Por otra parte, como las imágenes adquiridas para este programa de búsqueda abarcan un área en el cielo considerablemente grande y cercanas a la eclíptica, irremediablemente aparecerán objetos que no necesariamente serán Centauros, como NEOs, MBAs, cometas, TNOs, etc. Para poder identificar dichos objetos en las imágenes desarrollé un código (que llamé identify.f) que además de hallar la solución astrométrica de las imágenes, genera una plantilla de círculos (círculos verdes de la Figura 2.4.4) lista para ser cargada en el SAOImage $d s 9$ con la cual quedan identificados sobre las imágenes todos los objetos conocidos que se encuentran en la base de datos del Minor Planet Center (MPC). Por otro lado, este código genera un archivo que lista las efemérides completas de dichos objetos y otras características como, nombre (y/o designación provisoria), coordenadas ecuatoriales celestes a J2000.0, coordenadas (x,y) en la imagen, ángulo de fase, $V m a g$-cuya precisión puede evaluarse conociendo dicho ángulo-, velocidad proyectada en el cielo $(\dot{\alpha} \cos \delta ; \dot{\delta})$, distancia heliocéntrica, distancia perihélica, y finalmente, una estimación provisoria de la población a la que pudiera pertenecer realizada por el código en base a la zona en la que se encuentra, su perihelio, su velocidad proyectada en la imagen, etc., pero teniendo siempre presente que la región donde se detecta un objeto no define su familia de pertenencia (por ejemplo, puede detectarse un objeto a 39.5 UA y no ser necesariamente un Plutino). Si entre los objetos catalogados del campo hubiera un Centauro, éste naturalmente deberá ser tenido en cuenta entre los objetos detectados 
por el programa de búsqueda, aunque no fuera un Centauro descubierto por el mismo. Así, antes de comenzar a analizar un campo es posible identificar fácilmente los puntos o trazos correspondientes a objetos catalogados y que no son Centauros, lo que por un lado permite pasarlos por alto como objetos de interés en el proceso de búsqueda, y por el otro facilita la generación de reportes de sus posiciones, y reportes de los objetos que no están identificados con las marcas circulares como nuevos descubrimientos. Como agregado, el código permite también ingresar con una lista de coordenadas $(\mathrm{x}, \mathrm{y})$ de objetos sospechosos que percibimos en las imágenes, e inmediatamente nos dice si es un objeto que figura en la base de datos del MPC o si se trata de un objeto nuevo, en cuyo caso se genera automáticamente una salida con sus coordenadas ecuatoriales celestes a J2000.0, listo para ser reportado.

Algo muy importante que es oportuno mencionar es que el paquete observacional fue adquirido más de seis meses antes de que se comenzara su análisis, con lo que fue necesario hacer correr el código identify.f, que identifica los objetos presentes en las imágenes, con las efemérides calculadas por el servicio prestado por el Jet Propulsion Laboratory Horizons Ephemeris System (JPL), en lugar de las efemérides de uso habitual disponibles en la base del MPC. El motivo es que ésta última está confeccionada sin tener en cuenta los elementos osculadores de los objetos al momento de integrar sus órbitas, mientras que el servicio de Horizons JPL tiene en cuenta la época en la que fue adquirida cada imagen, hace las pertinentes correcciones por perturbaciones planetarias y recién ahí calcula las posiciones. Como se pudo comprobar, considerar elementos orbitales constantes en el cálculo de efemérides para posiciones de apenas unos pocos meses de antigüedad, puede conducir a errores muy groseros.

Entonces es así que junto con las doce imágenes con sus mallas-guías listas para ser comparadas, también se cargan las dos plantillas de círculos de objetos catalogados de cada noche, lo que permite que durante el análisis de las celdas solamente nos concentremos en objetos nuevos, máxime considerando el hecho que como se mencionó, todos los campos están centrados próximos a la eclíptica, lo que ocasiona que en las imágenes aparezcan poco menos de un centenar de MBAs por cada una (Figura 2.4.4). Como un apoyo adicional al proceso de comparación, pero absolutamente necesario, se despliegan en dos nuevas terminales cada una de las dos series completas de imágenes individuales del campo de cada noche, con sus mallas-guías y sus plantillas de círculos correspondientes, a fin de consultarlas para descartar, en el análisis primario de la comparación de las doce imágenes, cualquier estructura formada al azar por motivos muy variados y que podría confundirse con el débil trazo de un Centauro, dando un falso positivo en la búsqueda.

Estos falsos positivos pueden originarse por la presencia en una imagen individual de grupos de pixeles encendidos o apagados alineados que persistirán en la suma coadicionada; o algún defecto alargado en particular, que cuando se desplazan y suman las imágenes en la dirección de esas alineaciones o elongaciones formarán, eventualmente, una imagen cuasi puntual. También, y por el mismo motivo, estructuras naturales propias del campo pueden generar falsos positivos como es el caso de una seguidilla de varias estrellas muy cercanas y alineadas -un hecho nada infrecuente en campos poblados con más de 20000 estrellas- o estructuras alargadas como ciertas galaxias de perfil. Cualquiera de esos casos muy probablemente quedará al descubierto cuando se inspeccione la región motivo de duda en cada una de las veinte imágenes de una u otra noche. Algunas de estas anomalías se muestran en la Figura 2.4.6. 


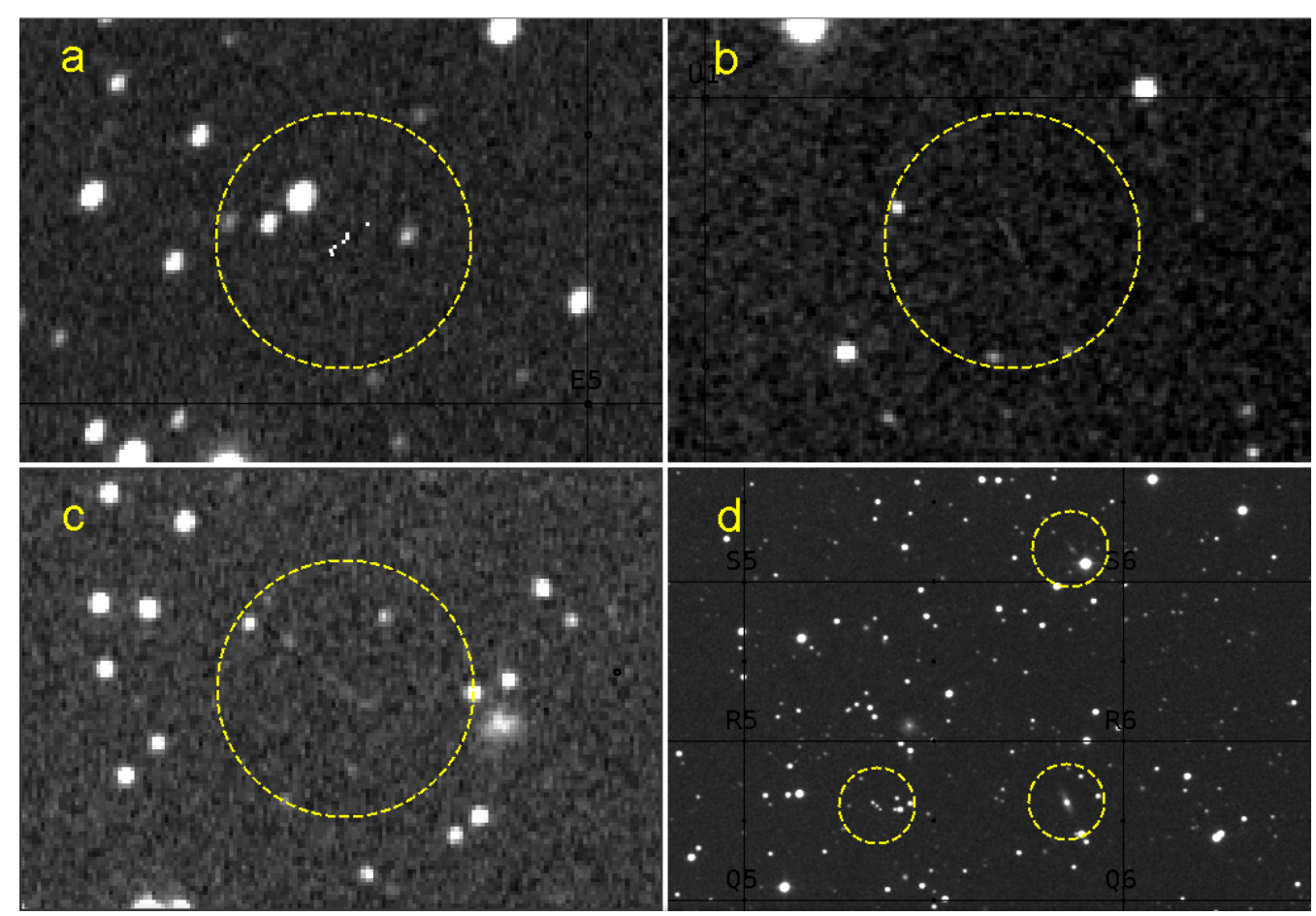

Figura 2.4.6. Anomalías en imágenes individuales y que se propagan en las imágenes-suma a comparar: (a) Pixeles encendidos alineados; (b) Estructura alineada de origen desconocido; (c) Cuatro estrellas débiles alineadas, que sólo quedan resueltas con la tarea daofind; (d) Estructuras naturales alargadas, como galaxias, conjunto de estrellas muy cercanas y alineadas, etc.

Otra fuente frecuente de falsos positivos es la superposición de extremos de trazos estelares débiles, que aunque incluso imperceptibles individualmente se hacen visibles como perfectos puntos en la intersección de los mismos. Es una anomalía generada de manera más sutil que la provocada, por ejemplo, por un simple desperfecto en una imagen y requiere, por lo tanto, que se le preste un especial cuidado. En la Figura 2.4.7 se muestra una secuencia de imágenes donde dos trazos débiles se intersecan en sus extremos formando un falso punto. Con el fin de seguir la evolución de ambos trazos a lo largo de toda la secuencia, se los resaltó artificialmente con líneas amarillas en la primera y en la última imagen. En los casos donde los trazos no son visibles, estos falsos positivos sólo pueden descartarse luego de un laborioso trabajo comprobando que es imposible reconstruir el punto, desplazando y sumando las imágenes a la profundidad y dirección que se deducen de los trazos estelares al momento de formarse el punto falso; o en el mejor de los casos directamente porque el mismo no resiste ningún análisis sobre cómo evoluciona morfológicamente en la comparación de las doce imágenes, apareciendo y desapareciendo abruptamente. 


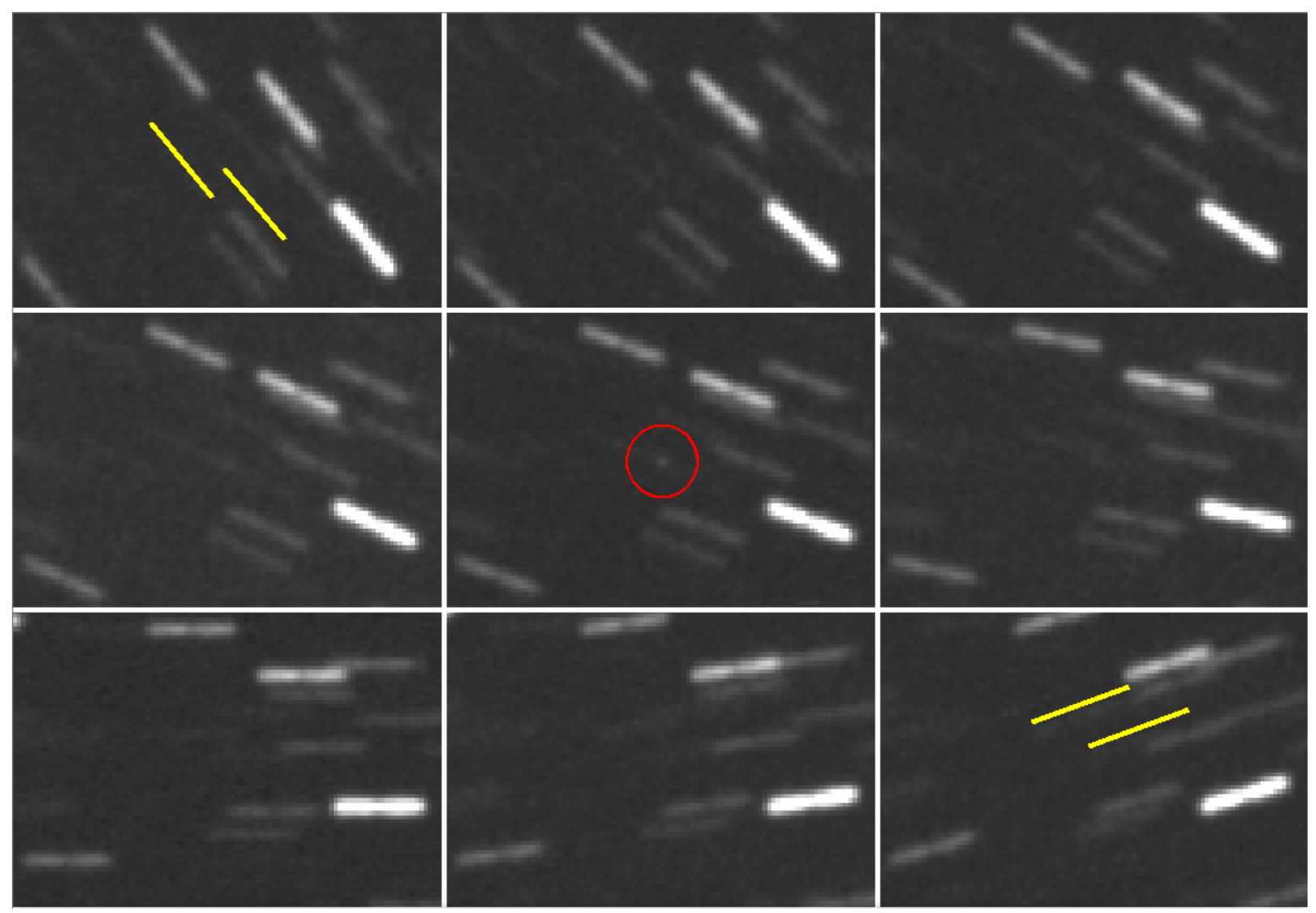

Figura 2.4.7. Secuencia de la formación de una imagen puntual por superposición de extremos de trazos débiles. Para mayor claridad, se da un ejemplo donde los trazos, si bien débiles, son visibles. En la primera y la última imagen se remarcaron con líneas amarillas los trazos causantes del falso positivo.

Si bien objetos con distancias heliocéntricas mayores que $30 U A$ no son de particular interés en esta búsqueda, a dichas distancias los objetos con órbitas retrógradas pueden ser motivo de problemas. En efecto, si se comparan las velocidades relativas a la velocidad orbital de la Tierra de dos cuerpos a la misma distancia heliocéntrica pero uno con órbita directa y el otro con órbita retrógrada, ambos tendrán en las imágenes trayectorias en la dirección EW, pero el objeto que se mueve en órbita retrógrada parecerá desplazarse a mayor velocidad, moviéndose a una velocidad típica de distancias heliocéntricas menores, y de ser ésta compatible con la de un Centauro no habrá manera de saber que en realidad no es un objeto desplazándose en zona de Centauros.

Otra situación indeseable, pero a la vez inevitable, se origina cuando un Centauro eclipsa a una estrella en algún punto de su trayectoria durante el tiempo de integración de la serie. En este caso en la imagen que se construye sumando las imágenes desplazadas en la dirección de movimiento del objeto, la estrella eclipsada formará su trazo pasando por arriba de la imagen puntual formada por el objeto en algún punto de dicho trazo, lo que hará imposible su detección (Figura 2.4.8). Para imágenes coadicionadas en direcciones cercanas, se podrá advertir la inminente formación de la imagen puntual del objeto y, si bien de esta manera podremos afirmar que el objeto formará efectivamente una imagen puntual sobre el trazo estelar, a nuestros fines es un caso perdido dado que no basta con contabilizar un Centauro más 
en nuestro programa de búsqueda, sino que como vimos, según el criterio que nos impusimos debemos además ser capaces de estimar su magnitud. Quizá, llegado el caso, su magnitud podría ser estimada considerando el flujo total de la figura cuasi puntual que forma el objeto justo antes de desaparecer bajo el trazo estelar, pero seguramente estaríamos frente a un proceso delicado.
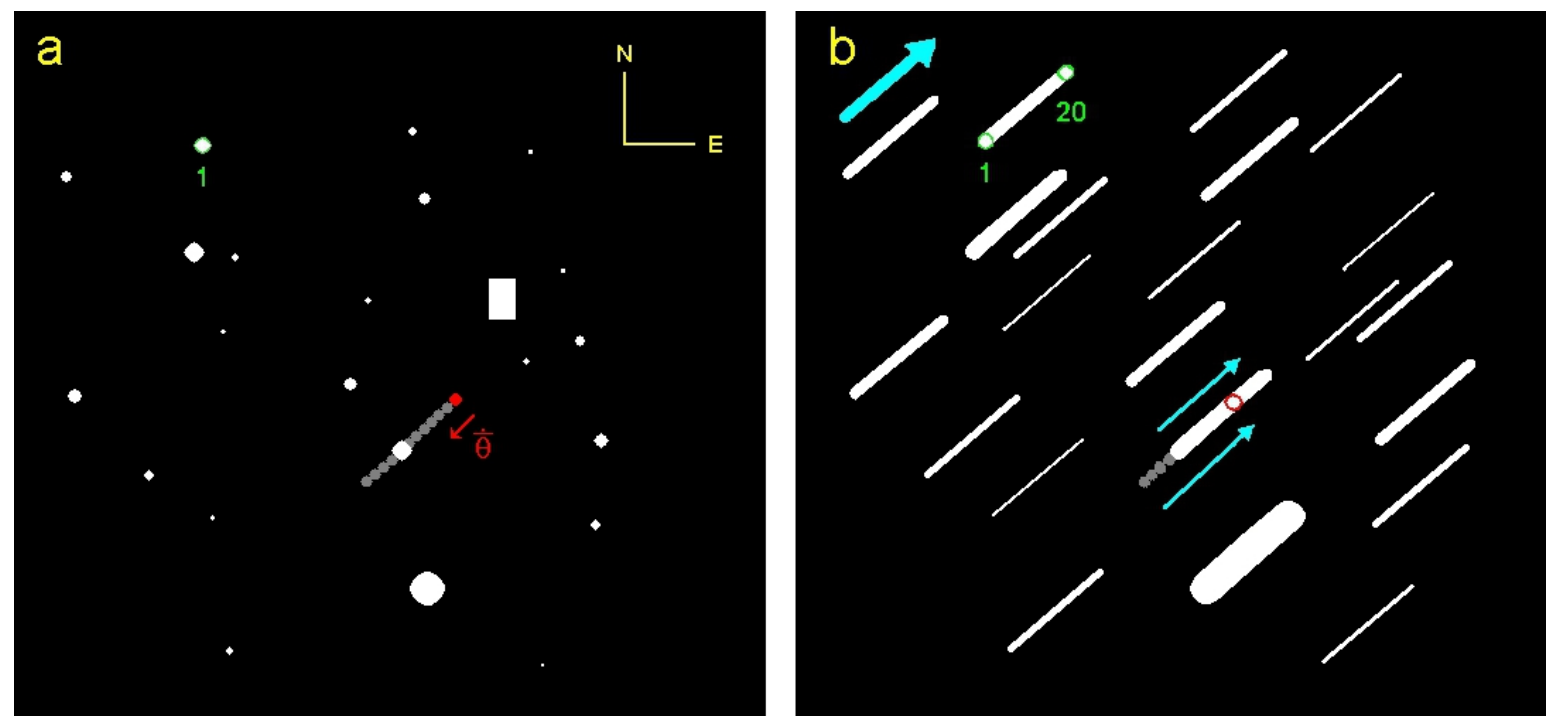

Figura 2.4.8. Ejemplo ficticio demostrativo de un trazo que oculta un objeto. a) Primera imagen de una serie, donde se ve a un objeto que eclipsará una estrella antes que termine la adquisición total de la misma. b) Coadición luego de desplazar las diecinueve imágenes de la serie hacia la primera justo en la dirección del movimiento propio del objeto, el cual forma su imagen puntual en el trazo dejado por la estrella -círculo rojo-. Para imágenes coadicionadas en direcciones vecinas, se advertirá la inminente formación de la imagen puntual del objeto sobre dicho trazo.

Por último, mencionemos el caso extraño pero posible de un objeto que por características propias de su órbita posea una velocidad cuya componente proyectada en el plano del cielo de nuestro campo sea compatible con la velocidad orbital de un Centauro en la oposición. En ese caso, cometeremos irremediablemente el error de confundirlo con uno de tales objetos. Ese puede ser el caso de un cometa con una órbita muy excéntrica y línea de las ápsides en dirección cercana a la oposición.

A continuación detallaremos el proceso empleado para estimar la distancia a la que se desplaza un objeto, partiendo de la débil anomalía que deja en una imagen coadicionada. Para ejemplificar nuestro desarrollo nos ayudaremos de una serie de imágenes ficticias (Figuras 2.4.9 a 2.4.13).

Las imágenes a analizar en busca de objetos móviles en un campo dado se construyen coadicionando las imágenes de una serie luego de realizar los corrimientos individuales $(\Delta \mathrm{x}, \Delta \mathrm{y})$ hacia la primera de ellas, según las ecuaciones (2.3.1) y (2.3.2) y en una dirección $\alpha$ preestablecida (Figura 2.4.9 flecha celeste). Si bien los trazos estelares poseerán todos igual longitud y dirección, es posible que aparezca un trazo de diferente longitud y dirección, una anomalía (Figura 2.4.9b). 

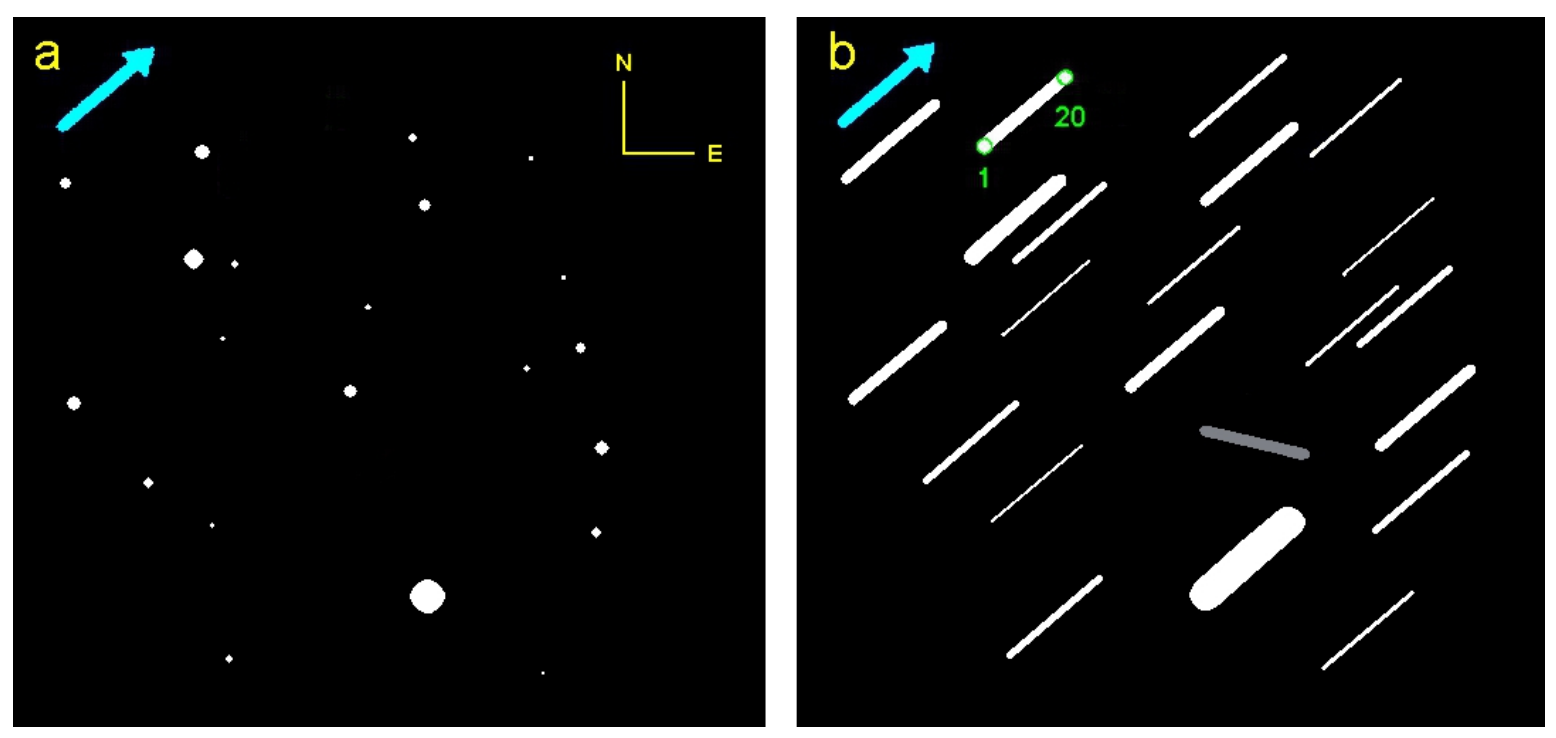

Figura 2.4.9. (a) Pila de imágenes alineadas y listas a desplazar según las ecuaciones (2.3.1) y (2.3.2), en una dirección preestablecida (flecha celeste); (b) Trazos estelares de igual longitud dejados por cada estrella del campo en la imagen coadicionada, luego de haber desplazado en una dirección dada a las diecinueve imágenes de la serie hacia la primera según las ecuaciones (2.3.1) y (2.3.2). Se destaca un trazo particular que no es paralelo a los trazos estelares y que constituye una anomalía en la imagen coadicion(elongación gris).

Consideremos un objeto que no posee suficiente $S / N$ como para ser detectado en ninguna de las veinte imágenes de la serie. Ahora bien, puede ocurrir que como producto de cierto desplazamiento y posterior coadición de las mismas, las Point Spread Function (PSF) del objeto en cada imagen no se superpongan en absoluto y por lo tanto, el mismo tampoco será visible en dicha coadición. En el otro extremo, puede suceder que las veinte PSF del objeto se superpongan de forma total en un solo punto, alcanzando así su máxima $S / N$ posible y sus mayores posibilidades de ser detectado. Naturalmente existirán casos intermedios: si esa anomalía que ha aparecido en la coadición de la Figura 2.4.9b es la huella de un objeto moviéndose entre las estrellas, su aparición se explica como el producto de las superposiciones parciales de las PSF de dicho objeto en cada imagen.

En la Figura 2.4.10 se representan los dos únicos caminos posibles que pueden originar aquella anomalía, y vemos cómo el desplazamiento de las diecinueve imágenes arrastra el aporte de cada una de ellas a su posición final en la imagen coadicionada. 

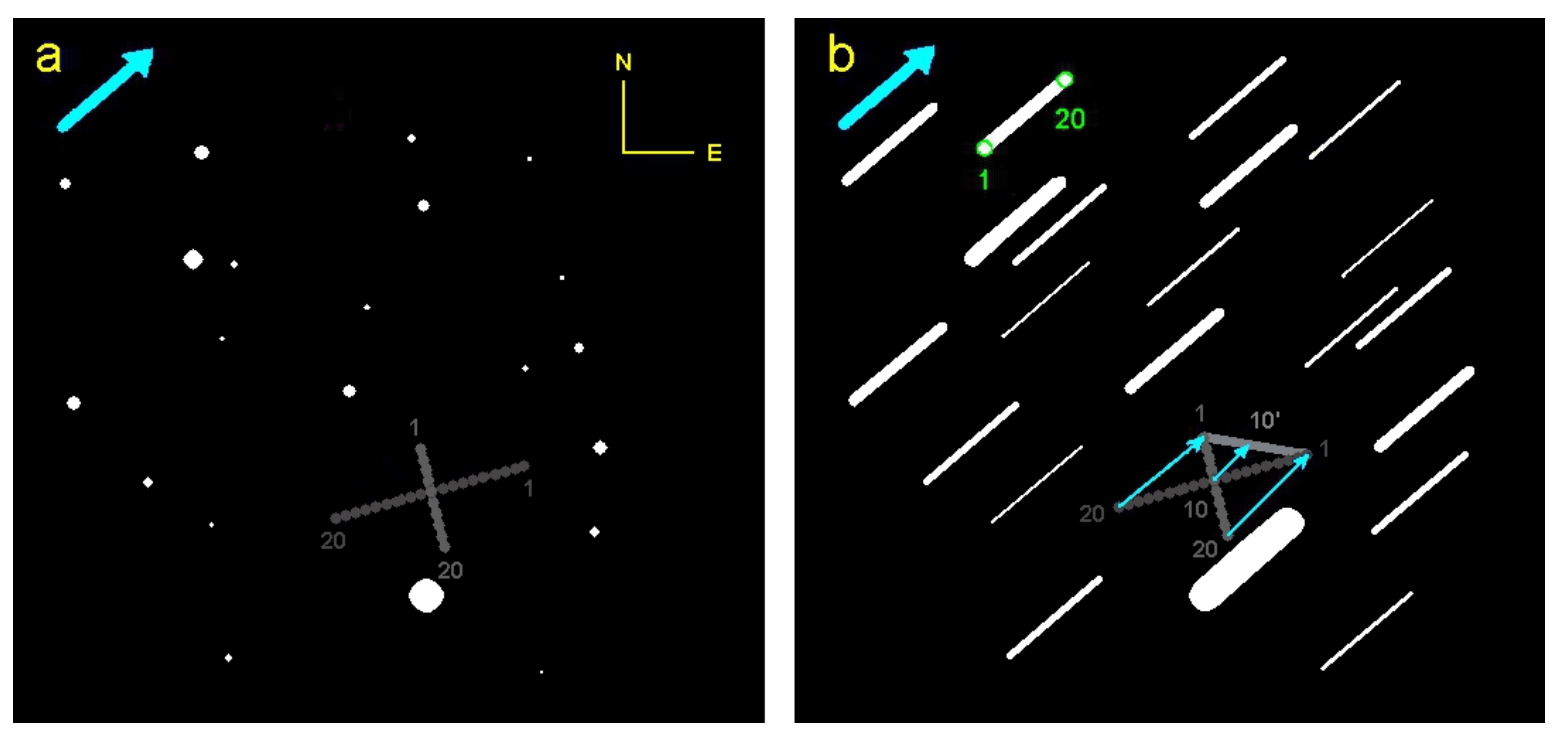

Figura 2.4.10. Causa de la aparición del particular trazo en la imagen coadicionada (anomalía): un objeto se está desplazando invisiblemente con movimiento propio entre las estrellas fijas y debido al solapamiento parcial de sus veinte señales, su desplazamiento imperceptible en la imagen (a), es ahora apenas visible en la imagen (b).

Para saber cuál de las dos es la trayectoria verdadera que siguió el objeto, bastará con identificar cuál de los dos extremos de la anomalía es el que corresponde a la primera imagen. Una vez identificado dicho extremo, aunque no seamos capaces de ver moviéndose al objeto entre las imágenes, podremos estimar su vector desplazamiento con sólo trasladar un trazo estelar cualquiera $\Delta$, hacia el otro extremo de la anomalía -el que corresponde al aporte de la veinteava imagen de la serie-, tal como se muestra en la Figura 2.4.11a.
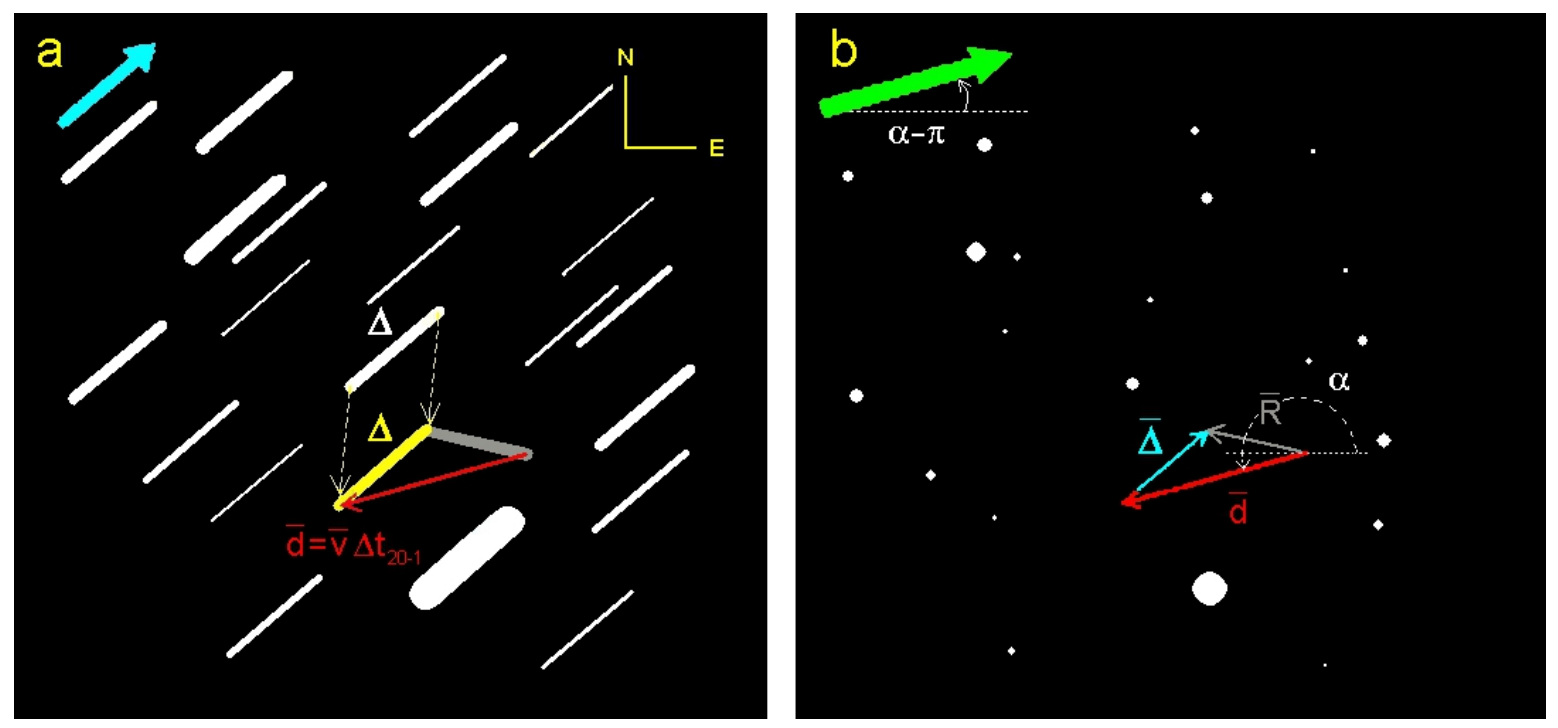

Figura 2.4.11. Aunque no veamos moverse al objeto entre las imágenes, podemos deducir su vector desplazamiento simplemente transportando uno de los trazos estelares al extremo de la anomalía que corresponde al aporte de la veinteava imagen de la serie. 
Como se esquematiza en la Figura 2.4.11b, la relación vectorial entre el desplazamiento real de un objeto debido a su movimiento propio sobre el fondo del cielo $(\vec{d})$, el vector desplazamiento de la última imagen respecto a la primera $(\vec{\Delta})$ y el vector que representa a la anomalía $(\vec{R})$, viene dada por

$$
\vec{R}=\vec{d}+\vec{\Delta}
$$

La medición precisa sobre la imagen tanto de la longitud de la anomalía, como la de la longitud del trazo dejado por las estrellas o la medida de ángulos, puede tornarse crítica en algunos casos a la hora de decidir si un objeto es o no un Centauro, teniendo en cuenta que los que tienen mayores probabilidades de ser descubiertos son los que se encuentran en el límite interno de su región, lindando con el MBA. Afortunadamente programas como SAOImage $d s 9$ ofrecen una serie de herramientas para trabajar geométricamente sobre las imagen con una precisión más que aceptable para los fines que aquí perseguimos. Entonces valiéndonos de dichas herramientas, por un lado promediamos varias mediciones de la longitud de la anomalía y por el otro promediamos las mediciones de varios trazos estelares. Una manera que se probó eficiente de medir la longitud de un trazo o de una anomalía, se ejemplifica en la Figura 2.4.12, donde se observa que realizar una medición longitudinalmente desde el primer pixel de un extremo hasta el último del otro, puede diferir en varios pixeles de su valor real $\Delta=a-b$.

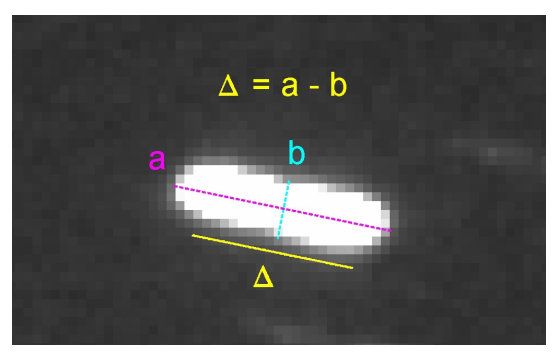

Figura 2.4.12. Se muestra una forma práctica de obtener la longitud de un trazo $(\Delta)$. Las mediciones sobre las imágenes en algunos casos pueden tornarse decisivas a la hora de clasificar un objeto como Centauro.

De esta manera, si la figura alargada anómala es efectivamente una consecuencia del movimiento de un objeto real desplazándose sobre el fondo del cielo, deberemos ser capaces de reconstruir su trayectoria; y si queremos obtener la imagen coadicionada en la cual ese objeto invisible que dejó su huella en la anomalía que despertó nuestra atención se materialice en un objeto puntual justo en la posición que ocupaba a la época $t_{1}$, no tendremos más que darle a nuestro código de generación puntual.f, la velocidad del objeto y su dirección de desplazamiento para que obtenga y despliegue por pantalla la imagen deseada (Figura 2.4.13). Para estimar ambas cantidades debemos medir sobre la imagen la dirección y el módulo del vector $\vec{d}$ en pixeles. Con éste último valor podremos obtener con bastante precisión su velocidad angular proyectada en el plano del cielo mediante la expresión,

$$
\dot{\theta}\left(\text { arcsechs }^{-1}\right)=\frac{d[\text { pixel }] . P I X S C A L E\left[\text { arcsecpixel }^{-1}\right]}{\Delta t_{20-1}[h s]},
$$

donde $\Delta t_{20-1}$ es la diferencia entre los tiempos de adquisición de la última imagen y de la primera. Entonces, una vez estimada la velocidad en segundos de arco por hora, ya sabremos 
si estamos en presencia de un objeto en zona de Centauros o no, según la misma satisfaga respectivamente (2.2.4) o (2.2.5), ya que todos los campos, como se dijo, fueron elegidos en dirección a la oposición. Además, mediante la ecuación (2.2.6) y ayudados con la condición de contorno (2.2.8), podremos estimar su distancia heliocéntrica $R(U A)$.
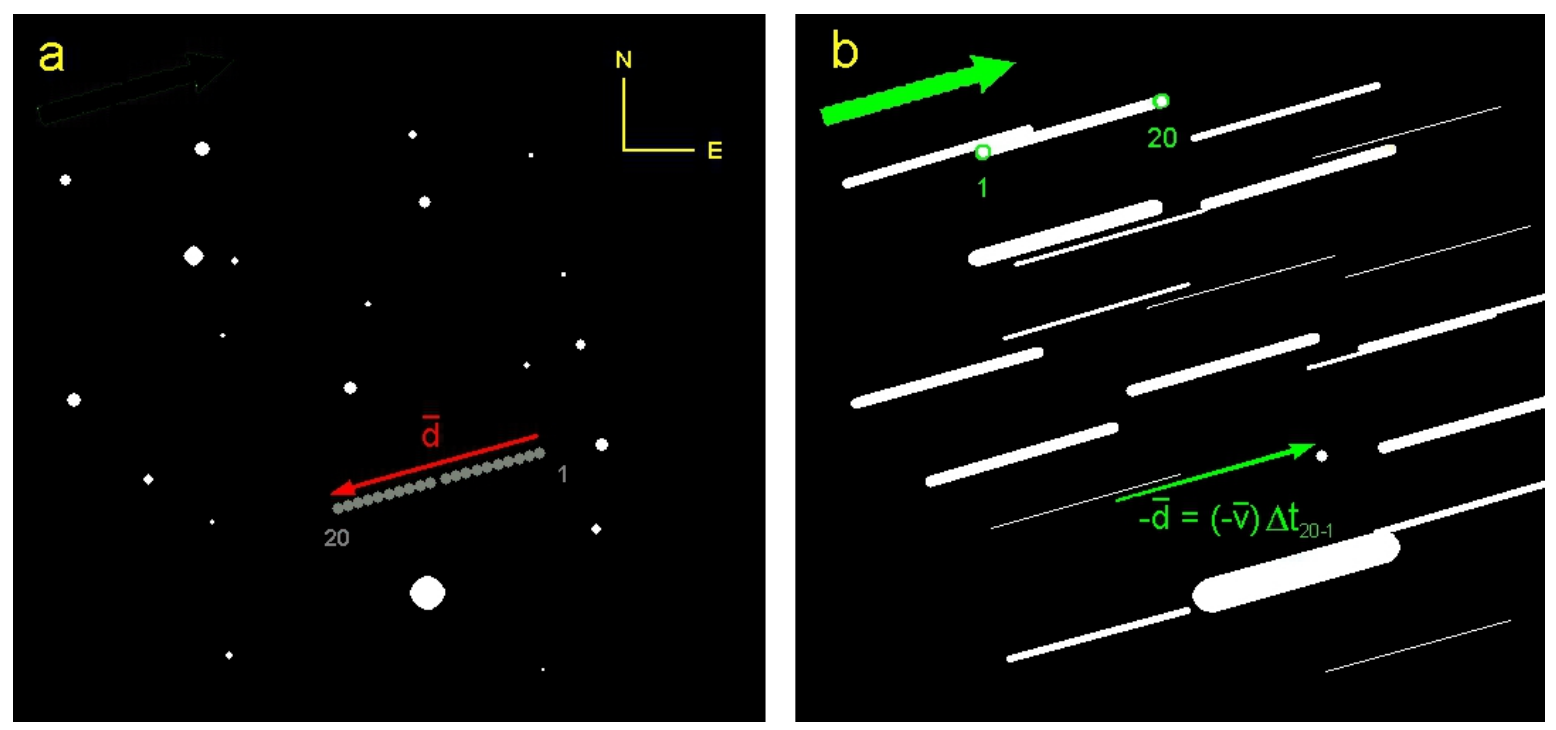

Figura 2.4.13. Una vez conocido el módulo, la dirección y el sentido del vector $\vec{d}$, ya estamos en condiciones de obtener una imagen que concentre en un punto todas las señales del objeto.

Naturalmente, como éstas estimaciones iniciales están muy afectadas por errores en la medida de un vector sobre la imagen, será necesario realizar un ajuste fino típico de todo programa de búsqueda y hacer correr nuestro script las veces que sean necesarias hasta que por aproximaciones sucesivas, realizando pequeñas modificaciones en velocidad y dirección, demos con la imagen final en la cual el objeto se verá como un punto claro y definido.

En la Figura 2.4.14 se muestra un caso real de una situación como la esquematiza en la Figura 2.4.13, donde el asteroide $1981 \mathrm{EH}_{2}$ por un lado deja su trazo en la coadidión de las veinte imágenes alineadas, y por el otro se muestra como un punto luminoso y claro en la imagen coadicionada de la serie cuyas imágenes han sido previamente desplazadas según las ecuaciones (2.3.1) y (2.3.2), hasta concentrar todas sus señales en un punto, en la posición que tenía a la época de la primera imagen (b).

Aprovechando la gran cantidad de asteroides que aparecían en nuestras imágenes y que nos proveían de una gran variedad de ejemplos de trazos (con diferentes longitudes, direcciones, brillos, contrastes, etc.), lo natural era testear el método con ellos. Los resultados fueron todos positivos y sirvieron para ajustar las diferentes técnicas que se deben aprender para hacer del método algo práctico y dinámico. 


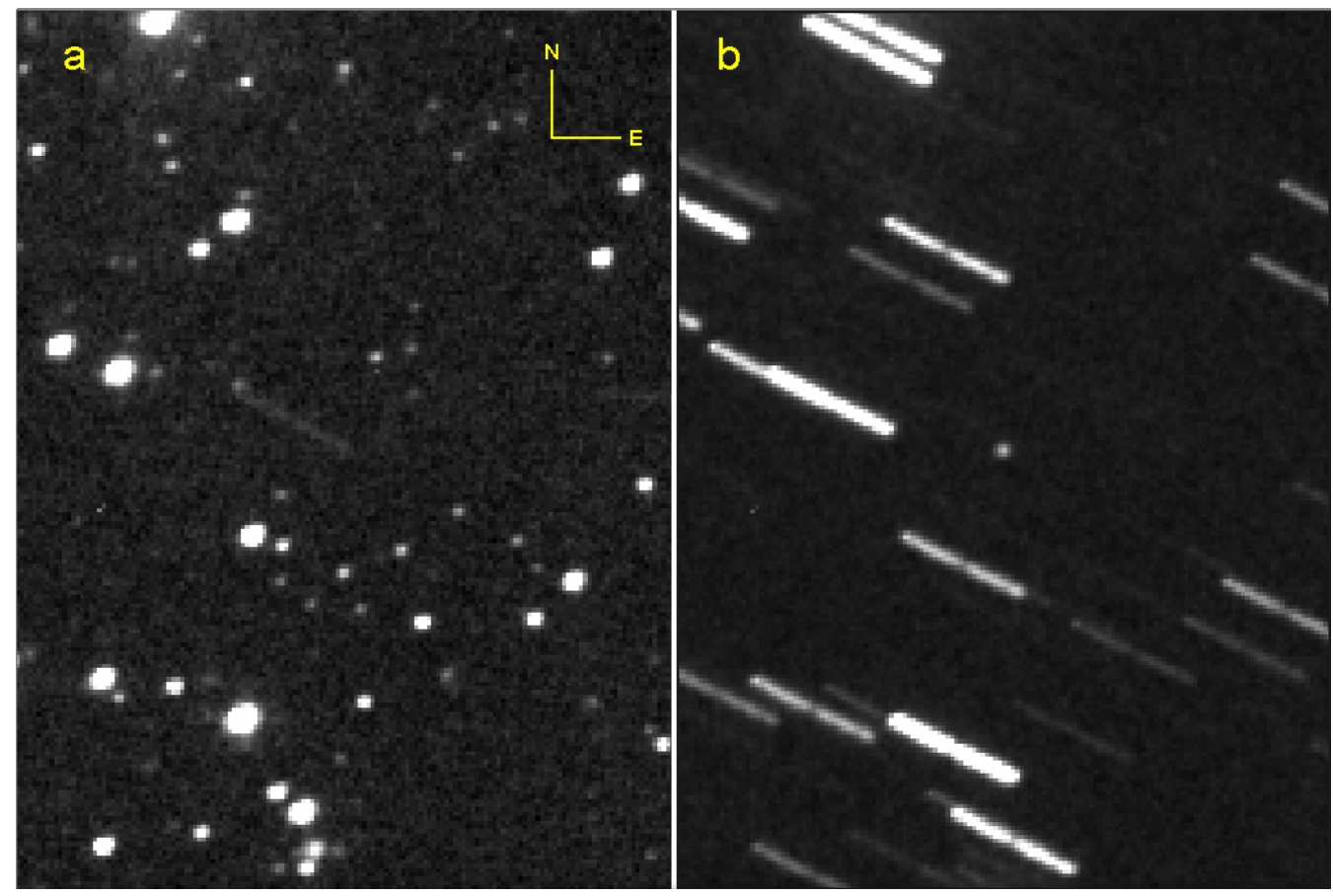

Figura 2.4.14. Una situación real como la que se esquematizó en la Figura 2.4.13. A la izquierda, rastro dejado en el campo por un asteroide $\left(1981 \mathrm{EH}_{2}\right)$ durante el tiempo total en el que se tardo en completar la serie. A la derecha, su posición en la primera imagen luego de concentrar en un solo punto todas las señales aportadas por cada imagen.

En la imagen de la Figura 2.4.15 se observan claramente los trazos dejados por dos asteroides del MBA. Los dos círculos verdes están centrados en las posiciones en la primera imagen de la noche que tenían los asteroides $1981 E H_{2}$ (izquierda) y $1993 T W_{1}$ (derecha), estimadas en la imagen por el código astrométrico desarrollado utilizando las efemérides calculadas por Horizons JPL, mientras que los círculos rojos son sus posiciones observadas.

El corto trazo dejado por $1981 E H_{2}$ en relación al de $1993 T W_{1}$, nos está indicando que el primero está a mayor distancia de la Tierra. Sus magnitudes, distancias heliocéntricas y diferencias entre posiciones observadas y calculadas al momento de la observación fueron para $1981 E H_{2}: V m a g=19.3, R=3.06 U A, 10.3$ arcsec; y para $1993 T W_{1}: V m a g=17.1$, $R=2.66 U A, 6.9$ arcsec. El trazo que se observa débilmente en el centro de la figura es el rastro dejado por un tercer asteroide del MBA no catalogado, uno de los tantos descubiertos en este programa de búsqueda. 


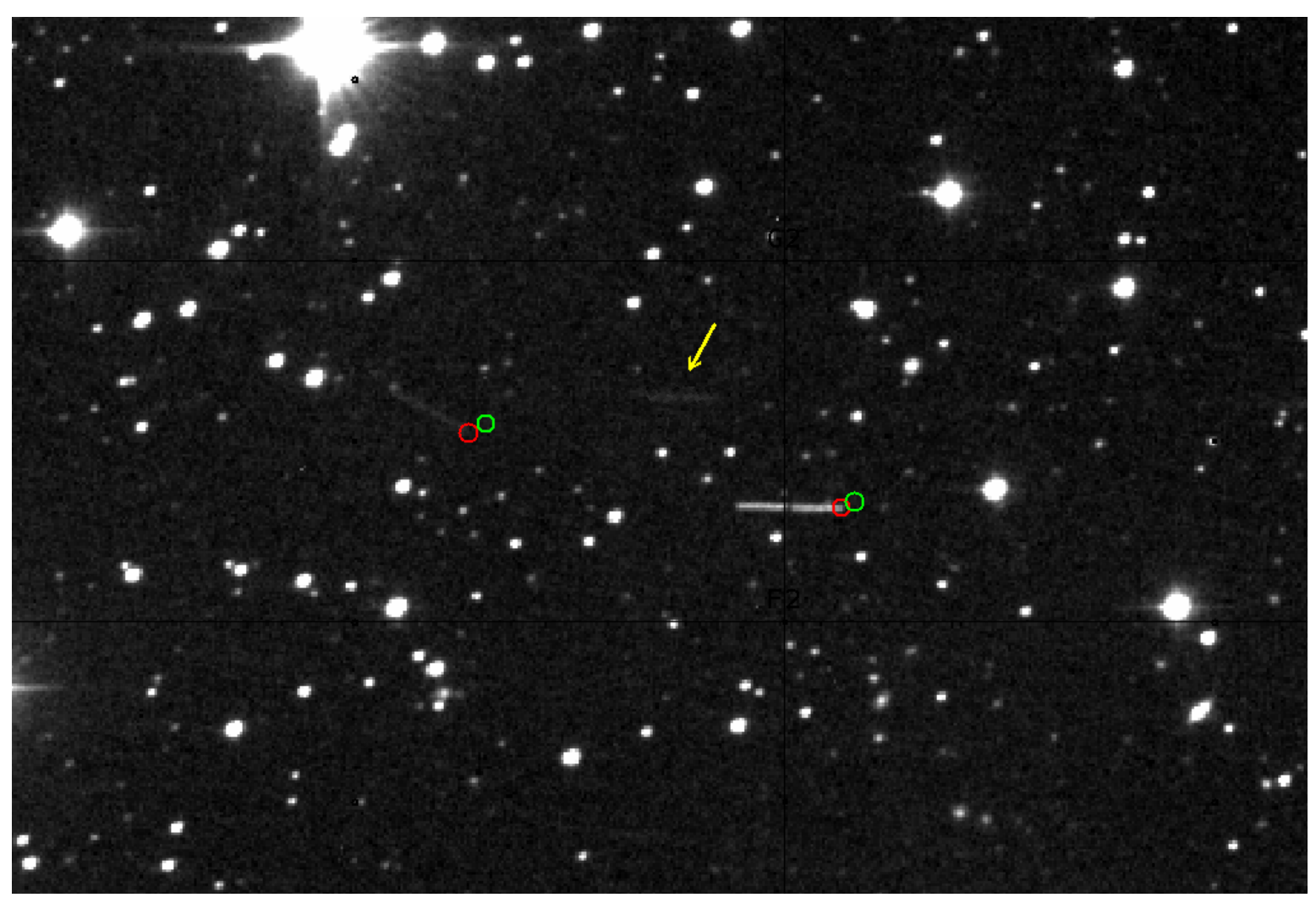

Figura 2.4.15. Trazo dejado por el desplazamiento sobre el plano del cielo de tres asteroides del MBA en una imagen coadicionada: En círculos rojos, $1981 \mathrm{EH}_{2}$ (izquierda) y $1993 \mathrm{TW}_{1}$ (derecha). El tercero que se aprecia débilmente en el centro de la imagen dejando un trazo horizontal (flecha amarilla), es un asteroide del MBA no catalogado y descubierto por este programa de búsqueda.

A partir de las imágenes coadicionadas que dieron como resultado la imagen de la Figura 2.4.15, en la Figura 2.4.16 se muestra una secuencia de imágenes generadas automáticamente por el código desarrollado, desplazadas en dieciséis direcciones diferentes con el objetivo de formar la imagen puntual de $1981 \mathrm{EH}_{2}$ en la posición que tenía en el instante de la adquisición de la primera imagen de la serie. Notemos que mientras ésta se forma en la novena imagen, en la decimotercera el asteroide sin catalogar adopta una forma cuasi puntual, dando la pauta que la distancia heliocéntrica a la que se encuentra es muy similar a la de aquel $(\sim 3 U A)$. Por otro lado, notemos también que dado lo paralelo de los trazos dejados por el objeto nuevo en comparación con los dejados por $1993 T W_{1}$, era de esperar que ambos asteroides formaran su imagen más puntual en la misma imagen de la secuencia. 


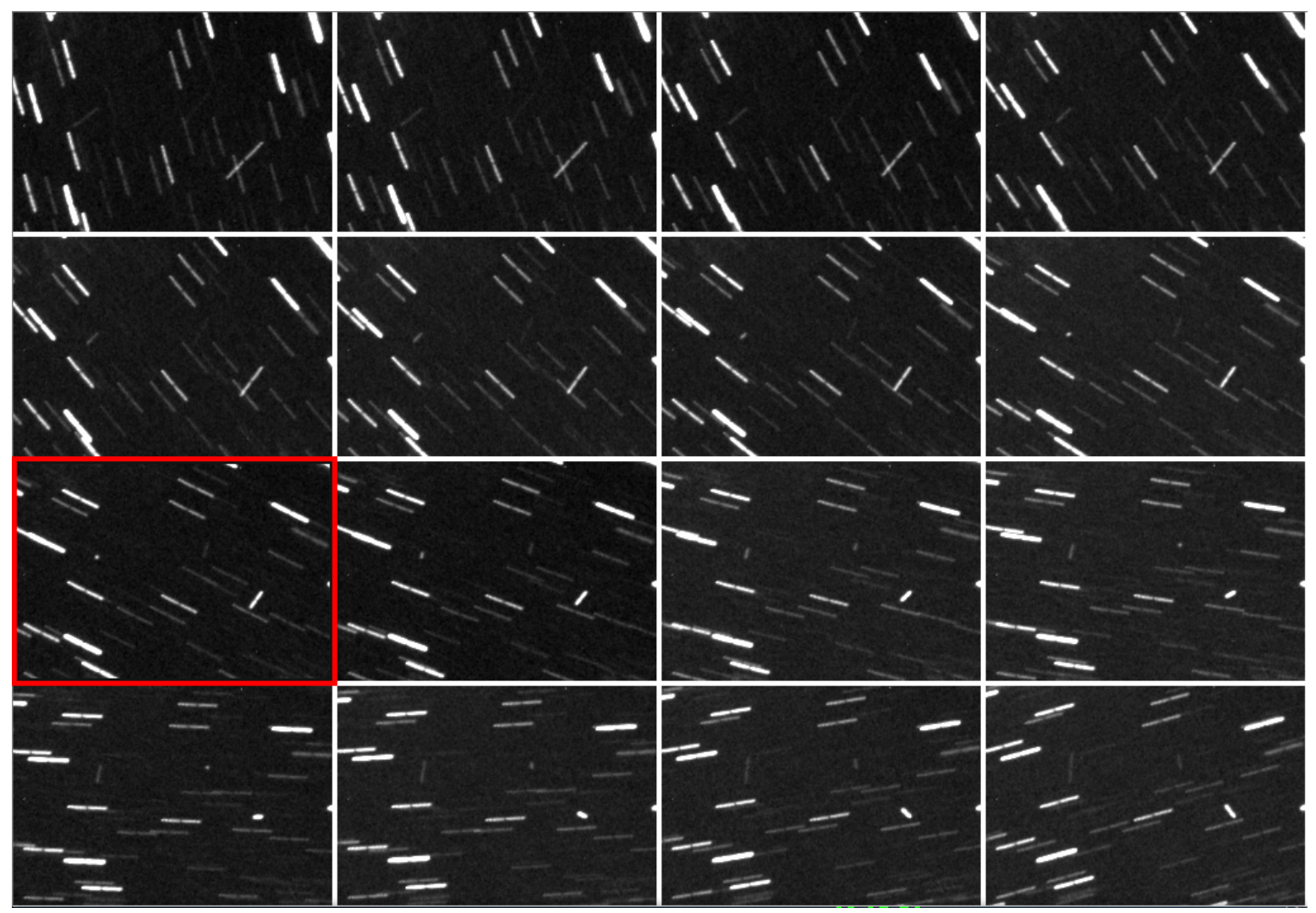

Figura 2.4.16. Secuencia de dieciséis imágenes generadas por el código para concentrar en la primera posición de la noche todo el flujo que $1981 \mathrm{EH}_{2}$ imprime en cada imagen de la serie. En la novena posición -recuadro rojo- se observa que el asteroide adquiere una forma puntual brillante. En la decimotercera, con las imágenes desplazadas prácticamente en la dirección de movimiento del nuevo asteroide en el plano del cielo, éste forma una imagen cuasi puntual. La secuencia muestra una evolución morfológica continua en los tres asteroides.

Es importante destacar que a lo largo de toda la secuencia los tres asteroides muestran sin límites de continuidad una evolución en la morfología de sus imágenes, desde antes de la formación de las formas cuasi puntuales hasta sus paulatinas disoluciones. También se puede observar claramente cómo va aumentando el brillo de sus trazos a medida que nos acercamos a las formas puntuales y cómo luego sus huellas se desvanecen a medida que nos alejamos de ellas. En cuanto a los trazos dejados por las estrellas, en algunos podemos resolver parte de las veinte estrellas que los forman; en otros, el mencionado salto a mitad de trazo por reposicionamiento del telescopio en la integración de la serie; y en todos, una continuidad de brillo de cuadro a cuadro, característica ésta que no comparten con los trazos dejados por los objetos móviles.

En la Figura 2.4.17 se magnifican cuatro cuadros de la Figura 2.4.16, representativos de toda la secuencia previa a la formación puntual de $1981 \mathrm{EH}_{2}$ y en el momento mismo en el que se forma la imagen puntual -órdenes 3, 5, 7 y 9-. Claramente se observa en cada cuadro que por una progresiva superposición de las PSF del aporte de cada una de las veinte imágenes, el trazo se va haciendo cada vez más brillante, lo cual ayuda en su identificación. 


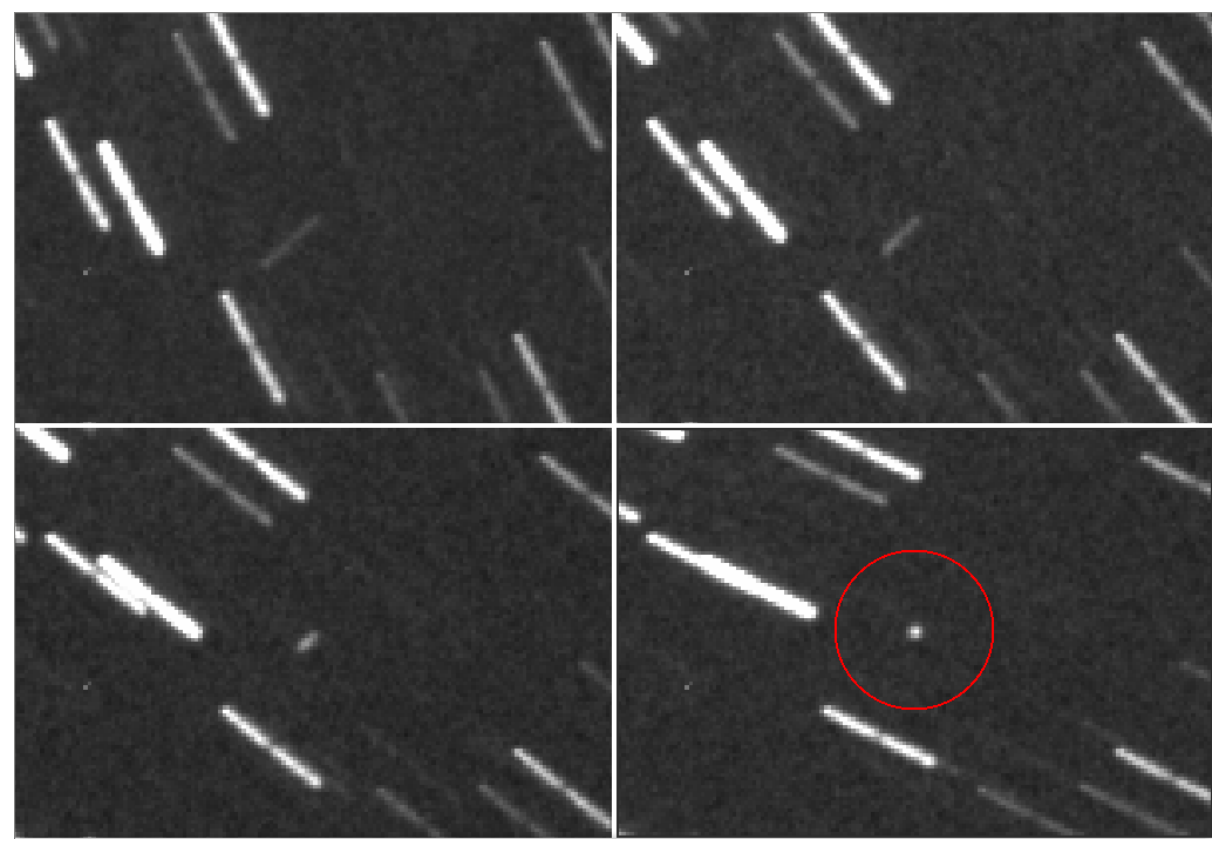

Figura 2.4.17. Detalle de la secuencia anterior centrado en $1981 \mathrm{EH}_{2}$ : cuadros 3, 5, 7, y finalmente 9 donde se termina formando la imagen puntual del mismo.

\subsubsection{Variando las direcciones de desplazamiento de las imágenes}

Fijada una profundidad de búsqueda para cierta distancia heliocéntrica queda automáticamente determinada la velocidad angular del objeto. Hasta aquí hemos detallado todo el proceso de nuestra estrategia de búsqueda aplicado a las cinco profundidades base definidas, pero siempre para una dirección fija predeterminada, como si supiéramos a priori cuál es la dirección de movimiento entre las estrellas del objeto invisible buscado. Ahora, para completar todo el proceso de búsqueda debemos repetir dicho proceso para cada campo y en todas las direcciones en las cuales los objetos pudieran estar moviéndose.

La cantidad de direcciones a considerar está definida por la longitud de los trazos o, lo que es lo mismo, por la distancia a la que se encuentra el objeto. De la Figura 2.4.18 queda claro que la cantidad de direcciones a barrer para cubrir un mismo arco $\alpha$ dependerá, efectivamente, de la profundidad a la que se observe: para objetos más lejanos, será necesario considerar menos direcciones.

Entonces, el procedimiento aplicado por el código puntual.f para determinar cuántas y cuáles son las direcciones a considerar se basa en que éstas dependerán de la distancia heliocéntrica previamente considerada. En efecto, si se asume que la mínima unidad para resolver una imagen es un pixel, para barrer un mismo ángulo $\alpha$ el número de direcciones a considerar variará en función de la longitud del trazo correspondiente a esa distancia heliocéntrica. Ahora, si consideramos el trazo de longitud $r$ pixeles dejado por un objeto con una FWHM de $s$ pixeles y lo hacemos rotar sobre uno de sus extremos, describirá, naturalmente, una circunferencia de longitud $2 \pi r$ pixeles, y la cantidad total de direcciones que debemos 
considerar será,

$$
n=\frac{\pi r[\text { pixeles }]}{s[\text { pixeles }]}+1 \text {. }
$$

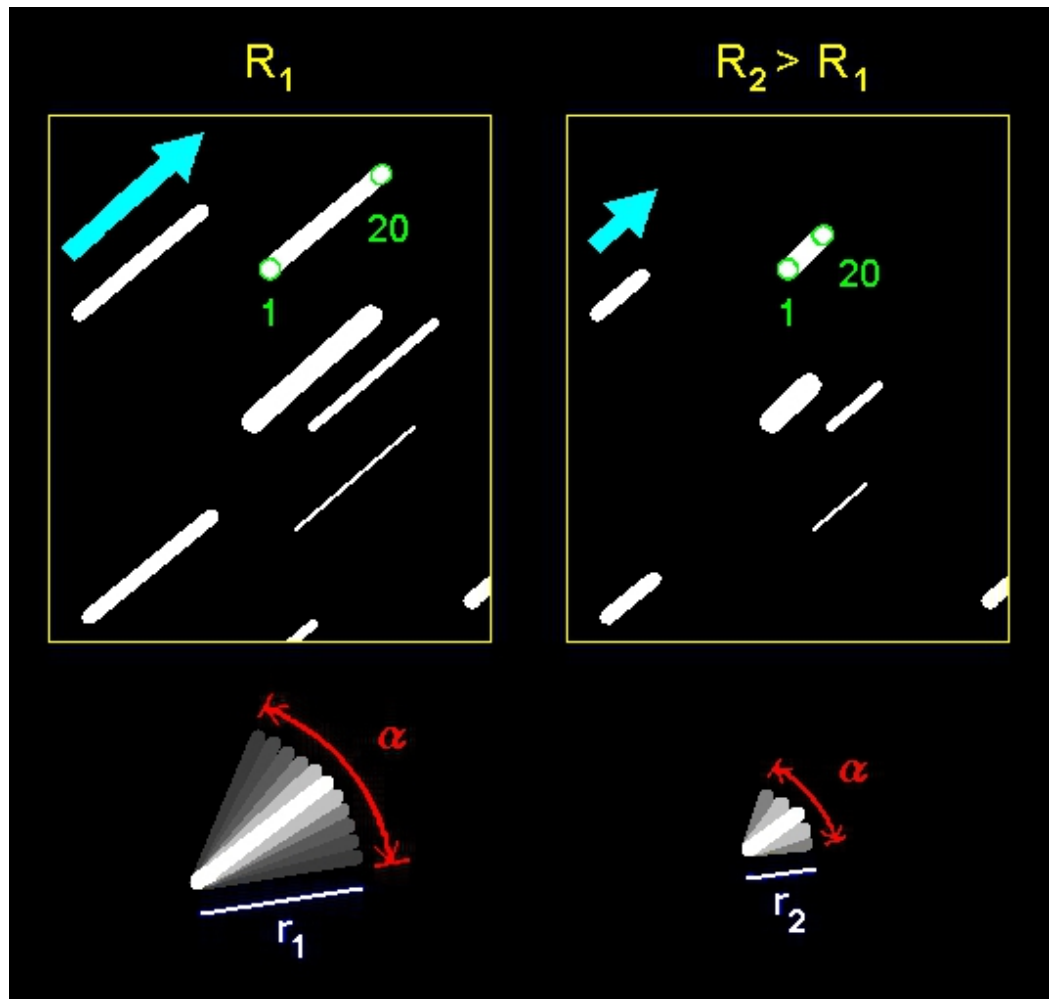

Figura 2.4.18. La cantidad de direcciones a considerar para barrer un mismo ángulo $\alpha$, es dependiente de la longitud del trazo. Comparación a dos distancias heliocéntricas $R$ distintas

El abanico de posibles direcciones que incluiría, por ejemplo, trayectorias altamente improbables de objetos cruzando la imagen en dirección NS, debe acotarse criteriosamente. Así, y dado que las imágenes están orientadas de manera tal que en todos los campos la eclíptica los cruza prácticamente en forma horizontal, es razonable restringir arbitrariamente dicho abanico de posibles direcciones a un arco de $90^{\circ}$, centrado en la eclíptica de cada campo.

Con esas condiciones de contorno, y considerando una FWHM de 2 pixeles, el número total de direcciones a considerar se reduce a

$$
n=\frac{1}{4} \pi r[\text { pixeles }]+1 .
$$

De esta manera, la cantidad total de direcciones necesarias para barrer un ángulo $\alpha$-que en un principio uno puede pensar que eran infinitas-, se reducen, por ejemplo, a quince para una distancia heliocéntrica igual a $5 U A$, bajando a nueve para $9 U A$ y a sólo cuatro para objetos a una distancia de $30 U A$, límite de la región de nuestro interés.

La cantidad de direcciones que el código puntual.f calcula en función de la profundidad puede consultarse en la tabla de la Figura 2.4.19, donde vemos que si realizamos la suma 
bruta de todas ellas, con analizar cuarenta direcciones cubrimos todos los casos necesarios. Pero lo cierto es que analizando el problema detenidamente y comparando las diferentes direcciones que el código definió para cada profundidad, podemos reducir el número total a sólo doce, descartando aquellas que difieren entre sí en menos de $5^{\circ}$ y tomando en esos casos el valor medio, lo que es suficiente para no perder ninguna generalidad. Esto significa que si se consideran primero las cuatro direcciones que se requieren para una velocidad angular de $4 \operatorname{arcsec}_{h} s^{-1}$, para la velocidad siguiente de $7 \operatorname{arcsechs}^{-1}$ será suficiente analizar sólo las dos direcciones resaltadas en su columna correspondiente para cubrir todas las posibilidades para esta velocidad, para luego continuar análogamente el análisis con las restantes tres velocidades.

\begin{tabular}{|c|c|c|c|c|}
\hline \multicolumn{5}{|c|}{$\dot{\theta}\left(\operatorname{arcsec}^{-1}\right)$} \\
\hline 4 & 7 & 10 & 13 & 17 \\
\hline $15^{\circ}$ & $9^{\circ}$ & $6^{\circ}$ & $5^{\circ}$ & $4^{\circ}$ \\
\hline $45^{\circ}$ & $27^{\circ}$ & $19^{\circ}$ & $15^{\circ}$ & $12^{\circ}$ \\
\hline $315^{\circ}$ & $45^{\circ}$ & $32^{\circ}$ & $25^{\circ}$ & $20^{\circ}$ \\
\hline $345^{\circ}$ & $315^{\circ}$ & $45^{\circ}$ & $35^{\circ}$ & $29^{\circ}$ \\
\hline \multirow{4}{*}{$333^{\circ}$} & $315^{\circ}$ & $45^{\circ}$ & $37^{\circ}$ \\
\cline { 2 - 4 } & $351^{\circ}$ & $328^{\circ}$ & $315^{\circ}$ & $45^{\circ}$ \\
\cline { 2 - 4 } & $341^{\circ}$ & $325^{\circ}$ & $315^{\circ}$ \\
\cline { 3 - 4 } & $354^{\circ}$ & $335^{\circ}$ & $323^{\circ}$ \\
\cline { 3 - 4 } & & $345^{\circ}$ & $331^{\circ}$ \\
\cline { 3 - 4 } & & $355^{\circ}$ & $340^{\circ}$ \\
\cline { 4 - 4 } & & & $348^{\circ}$ \\
\cline { 4 - 4 } & & $356^{\circ}$ \\
\cline { 3 - 4 }
\end{tabular}

Figura 2.4.19. Las direcciones de búsqueda calculadas por el código para cada distancia heliocéntrica de búsqueda o equivalentemente para cada velocidad en el plano del cielo. Sólo es necesario considerar doce direcciones: las cuatro de la primera columna más las ocho resaltadas en las otras.

Por lo tanto, considerando los ocho campos a analizar, subdivididos en doscientas setenta y tres celdas cada uno, a seis profundidades y doce direcciones diferentes, nuestro programa de búsqueda nos exige realizar más de un millón doscientas cincuenta mil comparaciones entre subceldas a pantalla completa, para dar por concluida la búsqueda. Cabe señalar que con una velocidad típica de parpadeo de 0.125 segundos, escudriñar una celda de un campo determinado para las seis profundidades y una dirección preestablecida, con el método y la práctica desarrollada, no insume en promedio más de 15 segundos, luego de lo cual será posible pasar inmediatamente a analizar la celda siguiente después de centrarla y ajustar brillos/contrastes. Eventualmente, entre el análisis de una celda y la siguiente, habrá que tomarse un tiempo -generalmente considerable- en estudiar meticulosamente una anomalía que pudiera aparecer.

Una vez identificado un objeto de interés en una imagen determinada, es necesario determinar su magnitud Vmag, en el Sistema Fotométrico UBVRI de Johnson-Cousins.

La imagen puntual del objeto estará en una imagen coadicionada donde las estrellas formarán trazos. Por otro lado, también se dispone de la imagen coadicionada directamente 
sobre las estrellas para esa noche, las cuales tendrán su habitual aspecto puntual y el objeto, si fuera perceptible, formará un trazo debido a su desplazamiento sobre el fondo de las estrellas fijas. Ahora bien, a los efectos de hacer fotometría del objeto puntual y de las estrellas, se utilizarán estas dos imágenes que si bien fueron coadicionadas en forma diferente, ambas poseen el mismo tiempo de exposición total.

Si ahora consideramos una estrella de catálogo con un índice de color similar al solar cercana a la posición que ocupa nuestro objeto en la época de la primera imagen y restamos las expresiones para la transformación y extinción fotométricas (2.1.11) correspondiente al objeto y a la estrella, dado que la masa de aire no varía y que el producto del coeficiente de transformación por la diferencia de índices de color $k_{3}(I C)$ es aproximadamente cero para la precisión requerida, obtendremos que

$$
M=M_{\star}+m-m_{\star},
$$

donde, $M$ y $m$ son, respectivamente, la magnitud estándar e instrumental del objeto y $M_{\star} \mathrm{y}$ $m_{\star}$, las mismas cantidades para una estrella de catálogo.

Las aproximaciones realizadas están perfectamente justificadas si tenemos en cuenta que la precisión de las estimaciones de magnitud para los cuerpos menores publicadas tanto por el MPC como por el JPL rondan la décima de magnitud. Por otra parte, es importante mencionar que el efecto de pérdida de flujo por desplazamiento del objeto, que puede afectar la estimación de la magnitud y tiene una influencia moderada en el caso de los Centauros (Jewitt et al., 1996), en nuestro método es compensado por cómo se desplazan y coadicionan las imágenes.

Por lo tanto, para obtener la magnitud estándar $M$ de un objeto, deberemos estimar para él y para unas diez estrellas de catálogo presentes en la imagen y con índices de color similares al solar y cercanas al mismo, sus magnitudes instrumentales $m$, para luego promediar.

Para hallar las coordenadas y magnitudes de catálogo de las estrellas presentes en el campo de la imagen, puede descargarse esa información de uno de los tantos servicios que están disponibles. En nuestro caso particular recurrimos al sitio de VizieR para descargar el catalogo USNO-B1 que correspondía a cada campo. De esta forma, VizieR nos enviará automáticamente el archivo con el listado de las estrellas respetando los parámetros de búsqueda que previamente hayamos definido (centro del campo, dimensiones del mismo, filtro, magnitud limite para las estrellas del envío, etc.). Seguidamente, leeremos el archivo recibido ayudados con el código cat2xy.f90 (Gil-Hutton, 2012) que genera un archivo de salida donde se lista en un formato legible las coordenadas ecuatoriales celestes de las estrellas, una aproximación inicial de las coordenadas ( $\mathrm{x}, \mathrm{y})$ en la imagen estimadas a partir de la escala de placa de la imagen, y la magnitud. Para relacionar estas estrellas de catálogo con los objetos que aparecen en la imagen, se diseñó un script de IRAF, astrocat.cl (Gil-Hutton, 2012), que muestra la imagen con el catálogo superpuesto y permite relacionar objetos en la imagen con objetos de catálogo. En el archivo de salida que produce el script se guardan para cada estrella seleccionada sus coordenadas ecuatoriales, sus coordenadas $(\mathrm{x}, \mathrm{y})$ en la imagen y su magnitud obtenida del catálogo.

Para hallar las magnitudes instrumentales de las estrellas de catálogo y de nuestro objeto, se realiza fotometría de apertura utilizando la tarea phot de IRAF. 
Finalmente, utilizando como comparación cada una de las diez estrellas de catálogo que se seleccionaron y empleando para cada una la ecuación (2.4.5), calculamos la magnitud estándar del objeto en el filtro del catálogo utilizado, luego de promediar los diez resultados parciales. En el caso de trabajar con catálogos de estrellas con magnitudes en el filtro R, para obtener las respectivas magnitudes en el filtro V del Sistema Estándar de Johnson, podemos hacer uso de la relación (2.1.15).

\subsection{Estimación de la eficiencia de detección del programa de búsqueda}

Como se mencionó, una de las sugerencias donde Petit et al. (2008) ponen mayor énfasis para diseñar y desarrollar correctamente un programa de búsqueda de objetos menores del SS, es la estimación de la eficiencia de detección del método de análisis utilizado, en función de la magnitud límite alcanzada. En general, si bien se supone que un objeto es detectable si su señal supera el brillo de fondo de cielo por un cierto valor que se debe determinar, esto es válido para objetos estelares estáticos que no poseen un movimiento propio adicional al sidéreo. En este caso, usualmente se considera que para garantizar una detección fehaciente, la relación $S / N$ debe ser mayor o igual que 5 . Pero lo cierto es que cuando uno trata con imágenes reales de objetos con un cierto movimiento aparente, pueden no ser detectables por muchas razones tales como problemas cosméticos en las imágenes, superposición de la imagen del objeto con la de alguna estrella, el brillo variable del fondo del cielo, malas elecciones de algunos parámetros de búsqueda, etc. Actualmente existe consenso en considerar que la magnitud límite a la que se llega con un cierto método de búsqueda aplicado a objetos del SS viene dada por la mayor magnitud para la cual se detecta al menos el $50 \%$ de los objetos con ese brillo presentes en las imágenes.

Como no se conoce a priori el número total de objetos presentes en la imagen, para hallar la magnitud límite de detección del método, se siguió el proceso usual de implantar en la imagen un número determinado de objetos al azar con magnitudes distribuídas en un cierto rango, a los cuales se los intenta detectar mediante el mismo procedimiento utilizado para analizar las imágenes en busca de objetos (ver por ejemplo, Bernstein et al., 2004; Petit et al., 2006). Los objetos fueron implantados en las imágenes coadicionadas utilizando la tarea mkobject del paquete noao.artdata de IRAF considerando la PSF característica de la imagen a procesar y el rango de magnitudes $20.0<R m a g<24.0$, lo que resulta razonable para los tiempos de exposición empleados y la magnitud límite calculada previamente para el ASH para objetos estáticos. Se eligió sembrar en cada imagen 100 objetos repartidos en cinco grupos de veinte objetos cada uno con magnitudes $R$ mag $=18,20,22,24$ y 26, respectivamente, a los cuales se les asignó una velocidad angular y dirección al azar en el rango de interés del programa (esto es, $4 \operatorname{arcsec}^{-1} \mathrm{~s}^{-} \lesssim \dot{\theta} \lesssim 20 \operatorname{arcsechs}^{-1}$ ). Luego, se realizó el proceso de detección aplicado en el programa de búsqueda y se trató de identificar los objetos implantados.

La eficiencia del método de búsqueda se muestra como una función de la magnitud Rmag en la tabla de la Figura 2.5.1 y en el gráfico de la Figura 2.5.2, donde los puntos fueron 
ajustados mediante la función

$$
E f(R m a g)=A e^{\frac{-(R m a g-\mu)^{2}}{2 \sigma^{2}}}+B
$$

donde $A=-110.03 \pm 0.17, B=100.21 \pm 0.13, \mu=25.109 \pm 0.005$ y $\sigma^{2}=2.061 \pm 0.007$.

\begin{tabular}{|c|c|c|}
\hline Rmag & Detectados & \% de detección \\
\hline 19 & 20 & 100 \\
\hline 20 & 20 & 100 \\
\hline 21 & 19 & 95 \\
\hline 22 & 14 & 70 \\
\hline 23 & 2 & 10 \\
\hline 24 & 0 & 0 \\
\hline
\end{tabular}

Figura 2.5.1. Resultado de la detección de los 100 Centauros artificiales implantados al azar en una imagen que coadiciona las veinte imágenes de una serie.

De dicha función se obtiene que una eficiencia de detección del $50 \%$ se alcanza para $R m a g=22.3(V m a g=22.8)$, magnitud a partir de la cual sólo fue posible hallar menos de la mitad de los objetos implantados y, por lo tanto, se definió a esa magnitud como el límite de detección de nuestro programa de búsqueda.

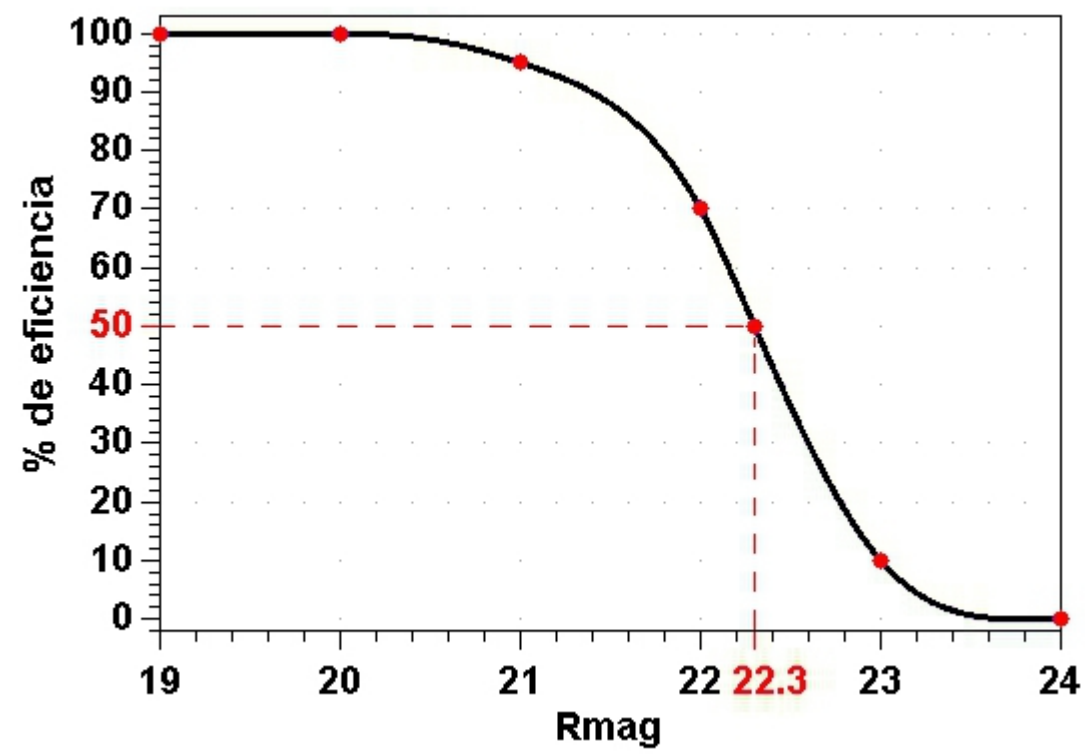

Figura 2.5.2. Interpolación de los datos obtenidos del estudio de la eficiencia de detección del programa de búsqueda. Se destaca su magnitud límite estimada, Rmag=22.3. 


\section{Capítulo 3}

\section{El descubrimiento de nuevos Centauros y una nueva determinación de la CLF de la población}

\subsection{Los Centauros descubiertos y otros objetos menores}

Luego de un exhaustivo análisis de las imágenes mediante la aplicación del método de búsqueda descripto, se lograron descubrir tres nuevos Centauros.

En la Figura 3.1.1 se muestra, a manera de ejemplo, la secuencia de imágenes coadicionadas en distintas direcciones y construidas a partir de la serie adquirida la noche del 2 de mayo de 2008, donde se detecta (séptima coadición) un objeto -C02- con una magnitud $R m a g=20.20 \pm 0.10(V m a g=20.70 \pm 0.10)$ y velocidad angular sobre el plano del cielo estimada en $\dot{\theta}=17.8$ arcsechs $^{-1}$, lo que equivale a un objeto moviéndose en la oposición a una distancia heliocéntrica aproximada de $R=5.89 \mathrm{UA}$. Promediando esos valores con los obtenidos a partir de su recuperación la noche siguiente, resultó finalmente ser un objeto Centauro con velocidad $\dot{\theta}=17.59$ arcsec hs $^{-1}$, a una distancia heliocéntrica $R=5.97 U A$ y magnitud Rmag $=20.25 \pm 0.10($ V mag $=20.75 \pm 0.10)$.

Asumiendo un albedo geométrico visual constante típico de cometas de $p_{v}=0.04$ (Hartmann et al., 1987; Lamy et al., 2005), de las ecuaciones (1.7.2) y (4.2.1) puede inferirse que se trataría de un objeto con un radio $r=6.8 \pm 0.3 \mathrm{~km}(H \simeq 13.4)$. 
3. El descubrimiento de nuevos Centauros y una nueva determinación de la CLF de la población

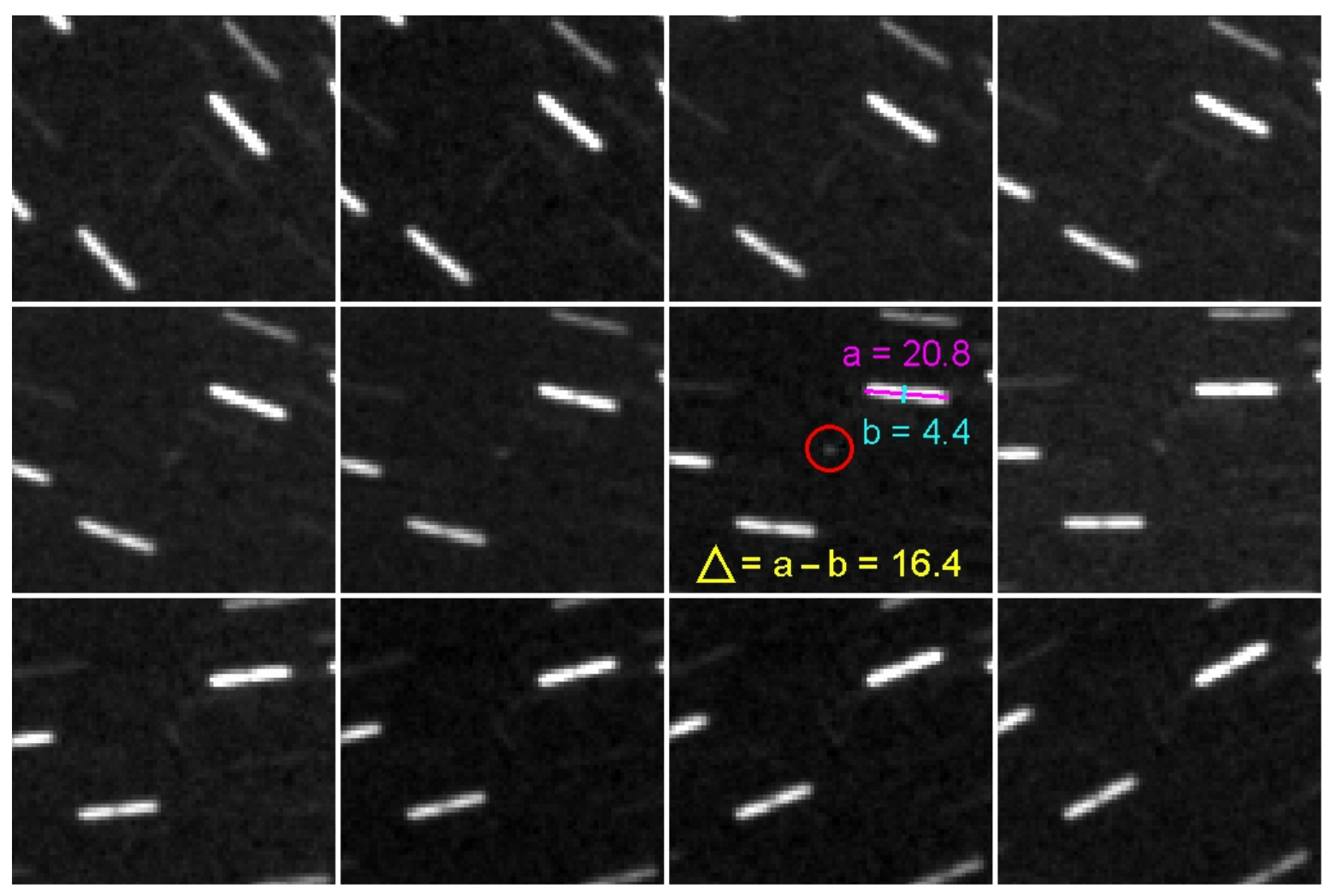

Figura 3.1.1. Secuencia de imágenes coadicionadas en distintas direcciones, construidas a partir de la serie adquirida la noche del 2 de mayo de 2008. En la séptima coadición de la secuencia se aprecia el Centauro que denominamos C02. Con un $|\vec{d}| \simeq 16.6$ pixeles, resulta ser un objeto moviéndose en la oposición con una velocidad angular de $\dot{\theta}=17.8$ arcsec hs $^{-1}$.

De forma similar, en imágenes adquiridas el 27 y 28 de agosto de 2008, se hallaron dos Centauros más -C01 y C03-, a distancias heliocéntricas, magnitudes y tamaños estimados respectivamente en, $R=8.5 U A, R m a g=20.67 \pm 0.85(V \operatorname{mag}=21.17 \pm 0.85), r=13.3 \pm$ $5.2 \mathrm{~km}(H \simeq 12.2)$ y $R=5.86 U A, R m a g=17.69 \pm 0.15(V m a g=18.19 \pm 0.15), r=$ $21.8 \pm 2.0 \mathrm{~km}(H \simeq 10.9)$.

En la tabla de la Figura 3.1.2 se detallan las circunstancias y características de cada uno de estos tres descubrimientos. 


\begin{tabular}{|c|c|c|c|c|c|c|}
\hline & \multicolumn{6}{|c|}{ Circunstancias y características de los descubrimientos por noche } \\
\hline & \multicolumn{2}{|c|}{$\mathrm{C01}$} & \multicolumn{2}{|c|}{$\mathrm{CO2}$} & \multicolumn{2}{|c|}{$\mathrm{CO3}$} \\
\hline & 1ra. Noche & 2da. Noche & 1ra. Noche & 2da. Noche & 1ra. Noche & 2da. Noche \\
\hline & 2008-Aug-27 & 2008-Aug-28 & 2008-May-02 & 2008-May-03 & 2008-Aug-27 & 2008-Aug-28 \\
\hline $\mathrm{RA}(\mathrm{J} 2000.0)$ & $20: 35: 14.161$ & $20: 34: 54.017$ & $15: 03: 01.696$ & $15: 02: 30.875$ & $20: 37: 31.808$ & $20: 36: 31.002$ \\
\hline $\operatorname{Dec}(J 2000.0)$ & $-18: 24: 27.17$ & $-18: 25: 09.08$ & $-15: 38: 51.50$ & $-15: 37: 31.28$ & $-18: 59: 18.26$ & $-18: 54: 36.03$ \\
\hline$\Delta \mathrm{t}(\mathrm{hs})^{*}$ & 1.44111 & 1.47 & 1.35417 & 1.36194 & 1.44111 & 1.47 \\
\hline $\mathrm{d}\left(\right.$ pixel $^{\dagger}$ & 12.9 & 12.7 & 16.4 & 16.1 & 17.5 & 17.9 \\
\hline$\dot{\theta}\left(\operatorname{arcsec} \cdot \mathrm{hs}^{-1}\right)$ & 13.16 & 12.70 & 17.80 & 17.38 & 17.85 & 17.90 \\
\hline $\mathrm{R}$ (UA) & 8.35 & 8.70 & 5.89 & 6.05 & 5.87 & 5.85 \\
\hline \multirow[t]{3}{*}{ Rmag } & $20.7 \pm 0.9$ & $20.7 \pm 0.9$ & $20.2 \pm 0.1$ & $20.3 \pm 0.1$ & $17.4 \pm 0.2$ & $18.0 \pm 0.2$ \\
\hline & \multicolumn{6}{|c|}{ Valores medios } \\
\hline & \multicolumn{2}{|c|}{$\mathrm{C01}$} & \multicolumn{2}{|c|}{$\mathrm{CO} 2$} & \multicolumn{2}{|c|}{$\mathrm{CO3}$} \\
\hline $\mathrm{d}\left(\right.$ pixel $^{\dagger}$ & \multicolumn{2}{|c|}{12.8} & \multicolumn{2}{|c|}{16.3} & \multicolumn{2}{|c|}{17.7} \\
\hline$\dot{\theta}\left(\operatorname{arcsec} \cdot \mathrm{hs}^{-1}\right)$ & \multicolumn{2}{|c|}{12.96} & \multicolumn{2}{|c|}{17.59} & \multicolumn{2}{|c|}{17.88} \\
\hline $\mathrm{R}$ (UA) & \multicolumn{2}{|c|}{8.5} & \multicolumn{2}{|c|}{5.97} & \multicolumn{2}{|c|}{5.86} \\
\hline Rmag & \multicolumn{2}{|c|}{$20.7 \pm 0.9$} & \multicolumn{2}{|c|}{$20.3 \pm 0.1$} & \multicolumn{2}{|c|}{$17.7 \pm 0.2$} \\
\hline$r(\mathrm{~km})\left(\mathrm{p}_{\mathrm{v}}=0.04\right)$ & \multicolumn{2}{|c|}{$13.3 \pm 5.2$} & \multicolumn{2}{|c|}{$6.8 \pm 0.3$} & \multicolumn{2}{|c|}{$21.8 \pm 2.0$} \\
\hline
\end{tabular}

Figura 3.1.2. Circunstancias y características de los tres descubrimientos de Centauros -C01, C02 y C03-, realizados en el marco del presente programa de búsqueda.

* : Tiempo total de integración de la serie.

$\dagger$ : Distancia en pixeles recorrida por el objeto en el tiempo total $\Delta t$ de integración de la serie.

Como un subproducto del programa de búsqueda implementado, también se prestó atención a la aparición en las imágenes de objetos de otras poblaciones. En efecto, las marcas circulares impresas en las imágenes sobre la inmensa cantidad de objetos identificados por uno de los códigos desarrollados (identify.f), como los que se muestran en la Figura 2.4.4, permite reconocer rápidamente NEOs, MBAs, cometas, Centauros, TNOs, etc., ya catalogados, y además nos genera de forma automática una lista con sus características orbitales, lo que permite reorganizarlos con cierta precariedad por grupos dinámicos. De esta manera, aprovechando los recursos y el método de búsqueda desarrollados y sin perder de vista que nuestro interés estaba enfocado exclusivamente en detectar Centauros, conforme se iban analizando todas las imágenes se tomó nota de las posiciones prioritariamente de aquellos objetos que no eran Centauros y que, (a) eran objetos no identificados previamente, y (b) que podían ser recuperados en la noche siguiente de manera tal de poder reportar un arco de al menos un día. La cantidad promedio de asteroides del MBA que aparecen por campo es $\sim 80$ y luego de relevarlos a todos, los objetos hallados y aún no catalogados ascendieron a 63 asteroides, los que están siendo reportados periódicamente al MPC (Mammana et al., 2015a, 2015b, 2015c).

\subsection{Estimaciones previas de las Funciones Acumulativas de Luminosidad de Centauros}

Ya habíamos mencionado que todos los Centauros descubiertos hasta la fecha han sido el subproducto de programas de búsqueda que han tenido como principal objetivo la detección y el estudio de objetos de otras poblaciones (NEOs, MBAs, cometas, TNOs, etc.). Ello tiene el 
serio inconveniente de ser programas pensados para detectar objetos que poseen velocidades angulares en el fondo del cielo muy distintas a las típicas de un Centauro. Así, en el caso de aquellos programas optimizados para TNOs, imponen a sus métodos y estrategias limitaciones en las velocidades de los objetos para poder descartar aquellos con velocidades típicas de MBAs que inevitablemente aparecerán en gran cantidad en las imágenes siempre adquiridas cerca de la eclíptica, lo que los hace insensibles a objetos con velocidades típicas de Centauros. En el otro extremo, los programas de búsqueda dedicados a NEOs son sensibles a objetos con velocidades demasiado elevadas para un Centauro, por lo que sus eficiencias en la detección de miembros de ésta población son muy bajas.

Para suplir esta grave falencia hasta ahora lo que numerosos autores han venido haciendo para obtener la CLF de la población de Centauros, es estimarla con un conveniente y simple desplazamiento horizontal de la recta que ajusta la CLF de TNOs hacia magnitudes más débiles, forzándola a coincidir con los pocos datos de Centauros disponibles. Esas manipulaciones dan por sentado que los ajustes lineales de las funciones de luminosidad de ambas poblaciones poseen la misma pendiente, pero en realidad dicha suposición no tiene mucha justificación más allá de la argumentación de que una población se origina de la otra.

Los principales trabajos que tratan de estimar una CLF de Centauros mediante dicho procedimiento son los de Jewitt et al. (1996), Sheppard et al. (2000), Larsen et al. (2001) y Trujillo et al. (2001b), y agrava la situación el hecho que de los cuatro trabajos, los tres primeros no cumplen las mencionadas condiciones de calidad para programas de búsqueda propuestas por Petit et al. (2008).

Los tres únicos trabajos que estiman un ajuste de la CLF de la población de Centauros son los de Jedicke y Herron (1997), Sheppard et al. (2000) y Larsen et al. (2001).

Jedicke y Herron (1997), cubriendo un área de 3740 grados $^{2}$ logran detectar cuatro Centauros y estiman para la pendiente de la CLF un valor $\alpha=0.61 \pm 0.08$, pero sin dar estimaciones de las magnitudes de los objetos ni una estimación de la magnitud límite de eficiencia de su programa de búsqueda, lo que impide obtener información suficiente como para considerar este trabajo en nuestro objetivo de estimar una nueva CLF para la población de Centauros.

Por su parte, Sheppard et al. (2000) realizan un programa de búsqueda en el que examinan 1428 grados $^{2}$ de cielo, no encontrando ningún Centauro nuevo, pero detectando serendípicamente al Centauro (10199) Chariklo. Encuentran que el mejor ajuste para esa población lo consiguen con un índice $q \approx 4(\alpha \approx 0.6)$. En el gráfico de la Figura 3.2.1 se aprecia cómo los autores estiman la CLF para la población de Centauros (línea continua) desplazando horizontalmente hacia la derecha la CLF de TNOs (línea punteada), tratando de ajustarla a puntos aportados por otros programas de búsqueda y al suyo propio, proceso que como ya se mencionó, Petit et al. (2008) desaconsejan. 


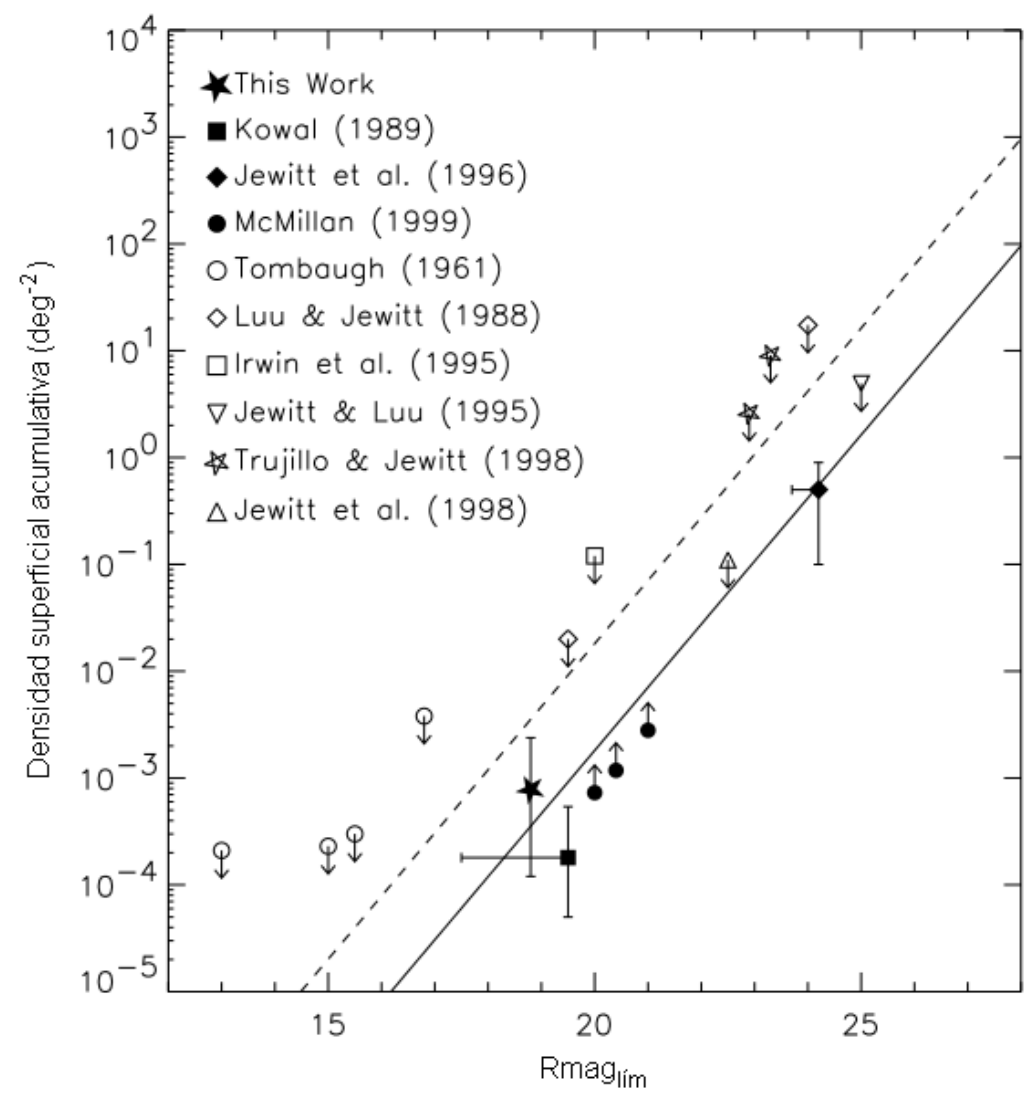

Figura 3.2.1. CLF de Centauros. Los símbolos con flechas que apuntan hacia abajo representan los programas de búsqueda con un límite de confidencia superior a $3 \sigma$ y que obtuvieron resultados nulos. Los símbolos con flechas que apuntan hacia arriba representan programas de búsqueda con límites inferiores. Los demás símbolos representan los programas de búsqueda que tuvieron en cuenta Sheppard et al. (2000) en su trabajo. La línea punteada es el ajuste de los datos para los TNOs y la línea continua es el mismo ajuste desplazado hacia magnitudes más débiles para obtener una CLF de Centauros (Adaptado de Sheppard et al., 2000).

Por último, Larsen et al. (2001) detectan tres Centauros cubriendo un área total de cielo de 1483.8 grados $^{2}$ y extienden el tramo final del extremo brillante de la CLF de TNOs consiguiendo un ajuste estadístico significativo para la CLF de Centauros. Así, le asignan a ésta una pendiente $\alpha=0.54 \pm 0.07$ (Figura 3.2.2). 


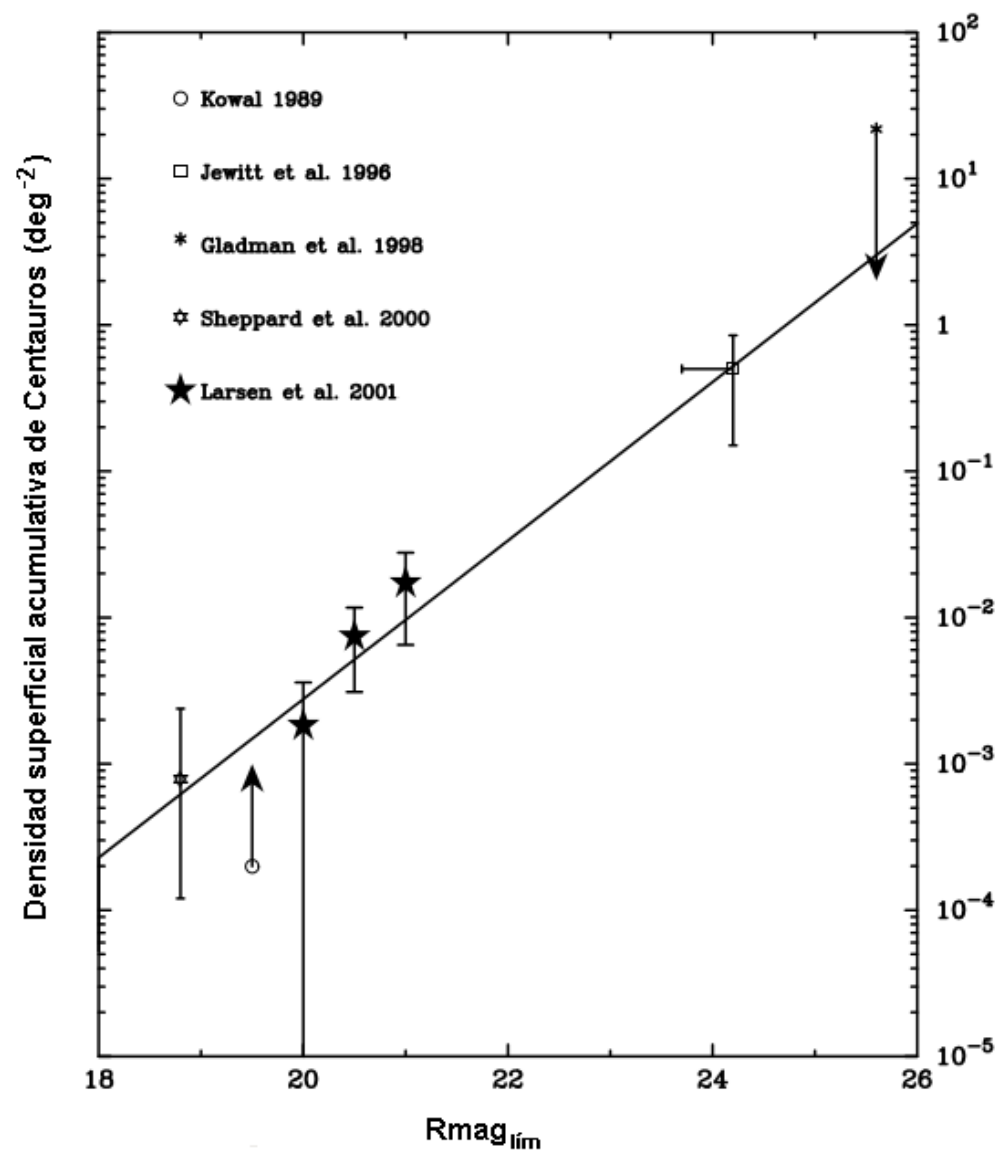

Figura 3.2.2. CLF de Centauros según Larsen et al. (2001). La curva representa el mejor ajuste que los autores realizan con una ley de potencia con $\alpha=0.54 \pm 0.07$. Se valen de la relación $(V-R)=0.5$ para transformar las magnitudes a Rmag (Adaptado de Larsen et al., 2001).

Tanto Sheppard et al. (2000) como Larsen et al. (2001) suman a los datos que les aportan sus propios programas, los aportes de aquellos programas de búsqueda de TNOs en los que se descubre algún Centauro, mejorando así los dos únicos ajustes de CLF existentes al momento, realizados exclusivamente sobre la base de Centauros descubiertos, y sin recurrir a especulaciones teóricas partiendo de ajustes de otras poblaciones. De esta manera ambos autores incluyen en sus estudios los resultados de Kowal (1989) y Jewitt et al. (1996), a los que Larsen et al. (2001) agregan el dato aportado por Gladman et al. (1998). De todos modos, la información que aportan dichas publicaciones deben utilizarse con sumo cuidado y se deben tener en cuenta las peculiaridades de cada trabajo: por ejemplo, en el trabajo de Jewitt et al. (1996) los autores enfatizan que su programa de búsqueda no es sensible a los Centauros con $5 U A<R<10 U A$ debido a la pérdida de flujo por desplazamiento del objeto y por lo tanto, el punto correspondiente en la Figura 3.2.2, debe ser considerado como un límite inferior.

Un ajuste de la CLF de Centauros puede mejorarse sustancialmente con el aporte de trabajos posteriores a los realizados por Sheppard et al. (2000) y Larsen et al. (2001), donde se presentan nuevos descubrimientos de Centauros en el marco de programas de búsqueda 
bien condicionados (con magnitudes estimadas de los Centauros y sus errores, área total relevada, magnitud límite de eficiencia de detección, etc.), como son los de Trujillo et al. (2001b), Allen et al. (2002), Trujillo y Brown (2003) y Fuentes y Holman (2008). En efecto, si bien Trujillo et al. (2001b) no estiman una CLF para Centauros, en su programa de búsqueda descubren un Centauro lo que nos permite añadir un punto más en el plano $\left(\operatorname{Rmag}_{l i ́ m} \times \log \left(\Sigma\left(<\operatorname{Rmag}_{l i ́ m}\right)\right)\right)$. Estos autores estiman para la población de objetos brillantes una densidad superficial de 0.01 Centauros por grado cuadrado, tal como lo habían estimado Larsen et al. (2001) y en consonancia con los $3 \times 10^{-3}$ Centauros por grado cuadrado de la estimación de Sheppard et al. (2000). Por su parte Allen et al. (2002) realizan una búsqueda de TNOs con una magnitud límite de $\operatorname{Rmag}_{\text {lím }}=25.2$ en el período 1998-2001 cubriendo un área total de 2.3 grados $^{2}$, descubriendo 33 TNOs y un Centauro. Trujillo y Brown (2003) llevan adelante su programa de búsqueda con una sensibilidad límite $R_{m a g}$ lím $=20.7$ sobre un área total de 5108 grados $^{2}$, y hallan 28 TNOs y 4 Centauros. También podemos valernos del punto que aporta el trabajo de Fuentes y Holman (2008) con su descubrimiento de 5 Centauros en el marco de un programa de búsqueda que cubre un área de cielo de 2.82 grados $^{2}$ con una magnitud límite de eficiencia de detección de $\operatorname{Rmag}_{\text {lím }}=25.69 \pm 0.01$. Otro programa de búsqueda que cumple con las exigencias de Petit et al. (2008) es el realizado por Gladman et al. (2001), los que cubren un área total de 0.322 grados $^{2}$ con una magnitud límite promedio de $R m a g=26.3$ fijando solamente un límite superior ya que aunque no descubren ningún Centauro, detectan un TNO denominado $1999 D A_{8}$ que posee parámetros orbitales que lo convierten en un caso límite entre ambas poblaciones. Entonces, si bien estrictamente no debe utilizarse este trabajo en una estimación de la CLF de Centauros, merece la pena mencionar que incluir el punto que aporta en las estimaciones de dicha CLF, resultaría perfectamente compatible con los datos aportados por los programas que incluyen Centauros confirmados.

En cuanto a la cantidad de miembros de la población de Centauros con radios mayores que $1 \mathrm{~km}$ estimada por los mencionados únicos tres trabajos que ajustan una CLF de Centauros, todos arriban a valores similares. Utilizando como condición de contorno que el Centauro más grande descubierto a la fecha es un objeto único en la población -(10199) Chariklo, con $D \approx 260 \mathrm{~km}$; Stansberry et al. (2008)-, podemos inferir la cantidad de miembros de la población según cada uno de ellos. Así, según estimaciones de Jedicke y Herron (1997) habría un total de $\approx 2.8 \times 10^{6}$ Centauros con radios $r>1 \mathrm{~km}$, mientras que para Sheppard et al. (2000) dicha cantidad para el mismo rango de radios sería de $\approx 2.2 \times 10^{6}$ miembros. Estos últimos autores son los únicos que además estiman la masa total actual de la población, que para objetos con radios $1 \mathrm{~km}<r<260 \mathrm{~km}$ sería de $\approx 2.3 \times 10^{-5} M_{\oplus}$. Finalmente, según estimaciones de Larsen et al. (2001) habría actualmente $\approx 5.1 \times 10^{5}$ Centauros. Di Sisto y Brunini (2007) estiman la cantidad actual de Centauros con radios $r>1 \mathrm{~km}$ en $2.8 \times 10^{8}$ objetos como valor más probable. Las discrepancias con los resultados de los trabajos recién mencionados puede deberse a que, por un lado y como se mencionó en el capítulo 1, dicha estimación tiene un error de un orden de magnitud; y por el otro, la metodología que emplean -basada en métodos numéricos-, no es comparable con métodos exclusivamente observacionales.

A la hora de realizar comparaciones tampoco se tuvieron en cuenta trabajos donde sus autores por distintos motivos se ven obligados a estimar la cantidad de Centauros que habría en una franja reducida de la región total ocupada por esta población, como es el caso de Jewitt et al. (1996) que restringiéndose al rango $10 U A<R<30 U A$, calculan que para Centauros con radios mayores que $75 \mathrm{~km}$ y albedos $\approx 0.04$, habría 2600 objetos. 


\subsection{Estimación de nuevas CLF y CSD para la población de Centauros}

La CLF de una población puede obtenerse graficando el logaritmo de la densidad superficial de objetos en la población contra la magnitud aparente, donde cada punto corresponde a un programa de búsqueda de objetos de esa misma población. La densidad superficial de objetos $\Sigma\left(<R m a g_{l i ́ m}\right)$ por grado cuadrado se obtiene mediante la expresión,

$$
\Sigma\left(<\operatorname{Rmag}_{l i m}\right)=\frac{N}{A}
$$

donde $N$ es la cantidad de objetos de la población detectados por el programa de búsqueda en el área total $A$ que se relevó.

Dado que como se mencionó en el capítulo 1 existen al menos una decena de definiciones diferentes de lo que se considera un Centauro, se contemplaron tres posibles densidades superficiales por grado cuadrado, suponiendo que sean efectivamente Centauros los tres, dos o sólo uno de ellos, y este hecho nos permite estimar el error del punto que nuestro programa aporta al gráfico de la CLF. Entonces, dado que el área total relevada es $A=14.17$ grados $^{2}$, tendremos: $\Sigma\left(<\operatorname{Rmag}_{l i ́ m}\right)=\frac{N}{A}=0.21,0.14$ y 0.07 , respectivamente (Figura 3.3 .1$)$. Teniendo en cuenta estos valores, se estimó para la ordenada del punto que aporta nuestro programa de búsqueda el valor $\log \left(\Sigma\left(<\operatorname{Rmag}_{\text {lím }}\right)\right)=-0.85_{-0.30}^{+0.18}$, correspondiente a una magnitud límite de detección de $\operatorname{Rmag}_{\text {lím }}=22.3$.

$$
\left\{\begin{array}{l}
\log \left(\frac{3}{\mathrm{~A}}\right)=-0.68 \\
\log \left(\frac{2}{\mathrm{~A}}\right)=-0.85 \\
\log \left(\frac{1}{\mathrm{~A}}\right)=-1.15
\end{array}\right]_{-0.3}^{+0.18}
$$

Figura 3.3.1. Forma de estimar el error para $\log \left(\Sigma\left(<\operatorname{Rmag}_{\text {lim }}\right)\right)$.

Dicho punto permite completar el amplio vacío existente en la ventana $21.2<\operatorname{Rmag}_{\text {lím }}<$ 24.2 que muestran las precedentes estimaciones de las CLF de Centauros. Es probable que esta brecha de más de tres magnitudes sea el resultado del mal condicionamiento en esos rangos de los programas de búsqueda realizados hasta el momento. En efecto, los Centauros detectados con magnitudes mayores que $R m a g=24$ son objetos lejanos con movimientos muy lentos y no sufren el efecto Trailing Loss -altamente dependiente de la velocidad del objeto en el fondo del cielo (ecuación (2.2.14))-, y por lo tanto, pueden ser descubiertos sin mayores problemas por programas de búsqueda optimizados para TNOs.

En el otro extremo de la ventana, los objetos con magnitudes menores que $R \operatorname{mag}=21$, son -salvo contadas excepciones-, objetos brillantes que se desplazan a altas velocidades y pese a perder brillo por estar afectados fuertemente por Trailing Loss, son tan brillantes que pueden ser detectados igualmente por prácticamente cualquier programa de búsqueda. 
Pero dado que nuestro método fue diseñado para la búsqueda de objetos sobre imágenes coadicionadas que concentran todas las señales del objeto en un punto -compensando así el efecto Trailing Loss-, ello le confiere la ventaja de detectar objetos débiles, y además, afectados seriamente por dicho efecto, que es justamente el caso de los objetos que permiten formar puntos en la CLF de la población en dicha ventana.

Por lo tanto, dicha compensación que caracteriza al metodo que se diseñó y desarrollo en esta tesis, es posiblemente la principal causa por la cual se pudo encontrar una mayor densidad de Centauros por grado cuadrado que ningún otro programa de búsqueda y completar la mencionada ventana.

A partir de los datos reunidos de todas las publicaciones donde se presentan descubrimientos de Centauros dentro de un programa de búsqueda bien condicionado, y que se han detallado en la tabla de la Figura 3.3.2, realizamos una nueva estimación de la CLF para dicha población, sumando el aporte del punto obtenido por nuestro programa. El mejor ajuste encontrado viene dado por la ley de potencias simple (ecuación (1.7.1)).

$$
\Sigma(<R m a g)=10^{\alpha\left(R m a g-R m a g_{0}\right)},
$$

con $\alpha=0.57 \pm 0.06$ y $\operatorname{Rmag}_{0}=24.9_{-4.4}^{+5.4}$, cuya representación gráfica se muestra en la Figura 3.3.3.

\begin{tabular}{|r|r|c|r|}
\hline Rmag $_{\text {lim }}$ & Nc/A & $\log (\mathbf{N c / A})$ & \multicolumn{1}{l|}{ Fuente del dato } \\
\hline 18.8 & 0.0007 & -3.15 & Shepard et al., 2000 \\
\hline 19.5 & 0.0002 & -3.70 & Kowal, 1989 \\
\hline 20.0 & 0.002 & -2.70 & Larsen et al., 2001 \\
\hline 20.5 & 0.007 & -2.15 & Larsen et al., 2001 \\
\hline 20.7 & 0.0008 & -3.11 & Trujillo y Brown, 2003 \\
\hline 21.0 & 0.017 & -1.77 & Larsen et al., 2001 \\
\hline 21.1 & 0.0061 & -2.21 & Trujillo et al., 2001b \\
\hline $\mathbf{2 2 . 3}$ & $\mathbf{0 . 1 4 1 1}$ & $-\mathbf{0 . 8 5}$ & Presente trabajo \\
\hline 24.2 & 0.5 & -0.30 & Jewitt et al., 1996 \\
\hline 25.2 & 0.43 & -0.36 & Allen et al., 2002 \\
\hline 25.6 & 23 & 1.36 & Gladman et al., 1998 \\
\hline 25.7 & 1.79 & 0.25 & Fuentes y Holman, 2008 \\
\hline 26.3 & 3.1056 & 0.49 & Gladman et al., 2001 \\
\hline
\end{tabular}

Figura 3.3.2. Sumario de las densidades acumulativas de tamaños de Centauros obtenidas de diferentes publicaciones, donde se incluye el dato aportado por el presente programa de búsqueda. Rmag lím: Magnitud límite de eficiencia de detección alcanzada por el programa de búsqueda; $N_{c}$ : Cantidad de Centauros descubiertos; A: Área total relevada en grados cuadrados. 
3. El descubrimiento de nuevos Centauros y una nueva determinación de la CLF de la población

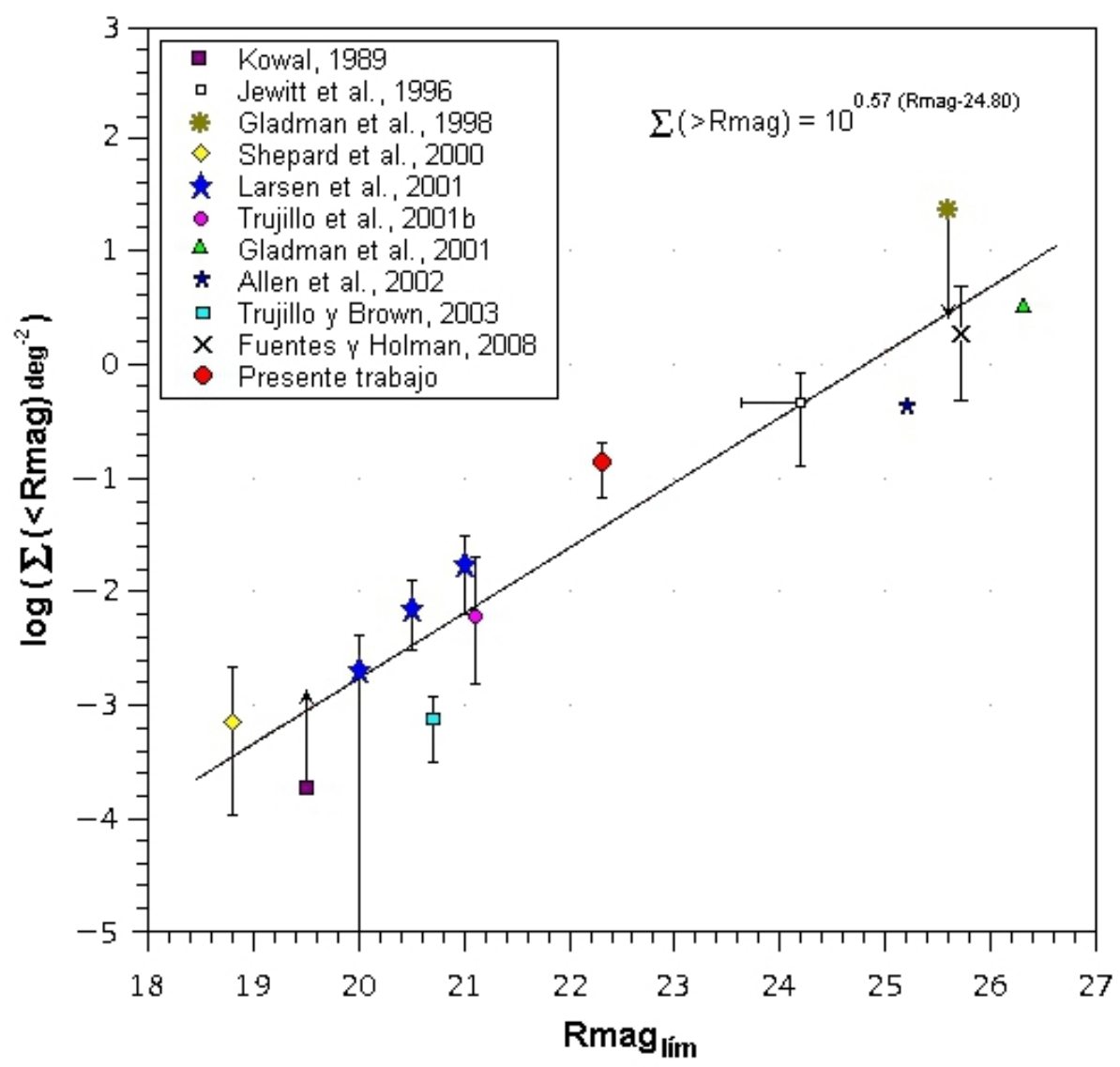

Figura 3.3.3. Nueva función acumulativa de luminosidad para la población de Centauros que incluye los resultados de la presente tesis. La curva representa el mejor ajuste mediante la ley de potencias simple $\Sigma(<$ Rmag $)=10^{0.57(\text { Rmag-24.8) }}$.

Ahora que hemos estimado una pendiente $\alpha$ para la CLF de la población de Centauros, estamos en condiciones de derivar una CSD para la misma. Valiéndonos de la ecuación (1.8.2), de nuestra estimación para $\alpha$ y asumiendo un albedo constante se puede inferir de la ecuación (1.8.5) que,

$$
N(>D) \propto D^{-2.85 \pm 0.30} .
$$

Llegado a este punto es oportuno recordar la reflexión que se hiciera oportunamente en el capítulo 1, en relación a que una estimación de $q$ basada en la suposición de un albedo constante potencialmente subestima las pendientes de las CSD en valor absoluto, con lo cual el valor obtenido sería una cota inferior, y por lo tanto lo más apropiado sería afirmar que $|1-q|>2.85$.

En la Figura 3.3.4 se grafica la nueva CSD estimada para la población de Centauros, cuya expresión teniendo en cuenta el mencionado dato relacionado con el diámetro de (10199) Chariklo, está dada por la ecuación $N(>D)=7.6 \times 10^{6} D^{-2.85 \pm 0.30}$. 


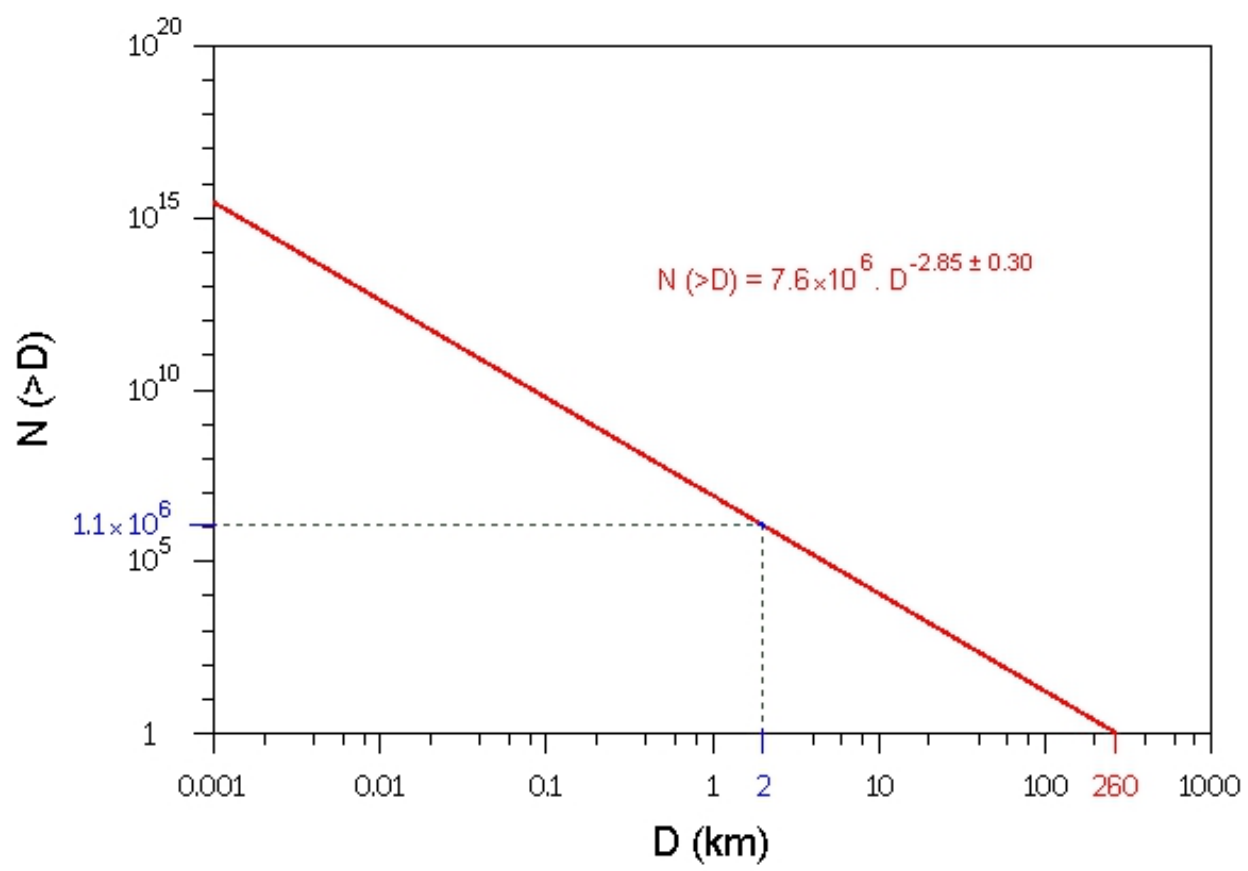

Figura 3.3.4. Nueva distribución acumulativa de tamaños estimada para la población de Centauros. El mejor ajuste está dado mediante la ley de potencias simple $N(>D)=7.6 \times$ $10^{6} D^{-2.85 \pm 0.30}$. Se muestra el valor $N(>2 \mathrm{~km})$ que da la cantidad acumulada esperable de Centauros con radios mayores que $1 \mathrm{~km}$.

Si suponemos que la CSD de la población de Centauros sigue la ley de potencia simple que se acaba de explicitar y consideramos nuevamente como condición de contorno el dato de (10199) Chariklo, los resultados obtenidos permiten estimar que para la población de Centauros habría $\approx 1.1 \times 10^{6}$ objetos con radios mayores que $1 \mathrm{~km}$ y $\approx 1.5 \times 10^{3}$ Centauros con radios superiores a $10 \mathrm{~km}$. Estos valores están en un muy buen acuerdo con las estimaciones ya comentadas que surgen de los trabajos observacionales de Jedicke y Herron (1997), Sheppard et al. (2000) y Larsen et al. (2001). Por otro lado, suponiendo que los Centauros poseen una densidad media de $\approx 1 \mathrm{~g} \mathrm{~cm}^{-3}$, similar a la de los núcleos cometarios, en base a nuestra CSD estimamos que la población actual de Centauros con radios mayores que $1 \mathrm{~km}$ tiene una masa total de $\approx 1.5 \times 10^{-5} M_{\oplus}$, valor que está en buen acuerdo con Sheppard et al. (2000), única estimación que hasta la fecha se ha realizado con datos observacionales sobre esta población.

Una observación importante es que la pendiente de la recta que ajusta nuestra CLF adopta un valor intermedio en relación a los respectivos valores medios de las rectas que ajustan las CLF de las poblaciones de TNOs y JFCs, tal como era de esperar para una población intermedia, y además ese resultado apoyaría la observación de Petit et al. (2008) desaconsejando obtener una CLF de Centauros desplazando horizontalmente la CLF de TNO, suponiéndolas a priori de igual pendiente. Así, observamos que nuestra pendiente $\alpha=0.57$ está entre las pendientes medias estimadas para los TNOs $(\alpha=0.64)$ y los JFCs $(\alpha=$ 0.38) (Figura 3.3.5a). Este hecho tiene naturalmente su contrapartida en las CSD de las tres poblaciones dada la relación lineal entre los parámetros $\alpha$ y $q$, donde vemos que las pendientes de las mismas se hacen cada vez más planas a medida que nos movemos de la 
TNR $(1-q=-3.2)$ a la región de los JFCs $(1-q=-1.9)$, luego de pasar por la zona de Centauros $(1-q=-2.85)$ (Figura 3.3.5b).
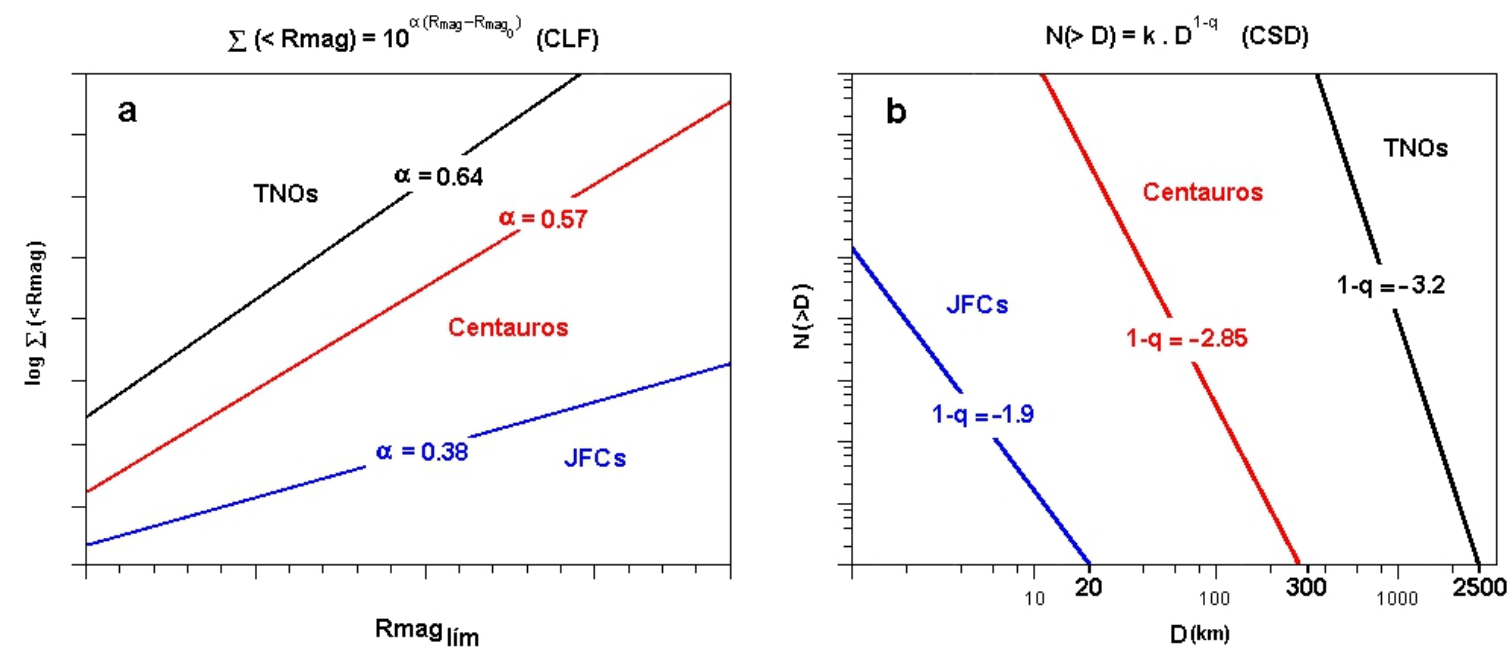

Figura 3.3.5. Gráficos cualitativos de las CLF (a) y las CSD (b) de las poblaciones de TNOs, Centauros y JFCs, donde se ilustran cómo varían las pendientes de las distribuciones.

El resultado obtenido permite realizar algunas interpretaciones físicas. Dohnanyi (1969) indica que para toda población aislada en equilibrio que evoluciona colisionalmente su distribución de tamaños puede ajustarse mediante una ley de potencias con exponente $q=3.5$, pero las distintas poblaciones del SS no conforman en absoluto poblaciones aisladas y su distribución de tamaños estará influenciada también por las interacciones entre ellas. Si además se consideran otros procesos capaces de modificar los tamaños de los objetos de las distintas poblaciones (sublimación, fragmentación no colisional, etc.), naturalmente ello contribuirá a modificar aún más las pendientes de sus CSD.

Weissman y Lowry (2003) encuentran que efectivamente es poco probable que los TNOs que abandonan la TNR preserven su CSD al internarse en el SS y el hecho de que la CSD de la población transneptuniana se ajuste con un valor de pendiente alejado de $q \approx 3.5$, es suficiente para concluir que para TNOs de tamaños mayores a $50 \mathrm{~km}$, una TNR en equilibrio colisional es inconsistente con las observaciones (Fraser et al., 2008). Si bien tales procesos tienen sus efectos en la población de Centauros, sus consecuencias son más evidentes en la de los JFCs, dado que para ésta última los núcleos cometarios son sometidos a rupturas por fuerzas de mareas en los encuentros cercanos con los planetas gigantes (Sekanina, 1997) y los acercamientos al Sol, son fragmentados debido al intenso calor solar (Delahodde et al., 2000; Filippenko y Chornock, 2000), y modificados por la natural disminución de sus tamaños debido a la volatilización de sus componentes. Para un perihelio $\sim 1 U A$ se estima que la pérdida de material en unas pocas miles de órbitas ocasiona una merma en el radio del núcleo del cometa de $\sim 1 m$ (Meech et al., 2004). Estos fenómenos pueden provocar un cambio en la distribución de tamaños primordial de la población de cometas, el cual depende en gran medida de la vida media de los mismos. Por su parte, los Centauros se ven afectados de manera similar, si bien los procesos que actúan sobre ellos tienen un impacto menor sobre sus 
tamaños.

Estos procesos no dinámicos no serían lo suficientemente efectivos para remover las características más notables de la CSD o de la CLF de los TNOs, y por lo tanto si la población de Centauros tiene origen en la TNR, dichas características también deberían observarse en alguna medida en la correspondiente distribución para los Centauros. Particularmente, como se mencionó, varios autores advierten que habría un cambio en la pendiente de la CLF de los TNOs a partir de Rmag $\simeq 24$ (Weissman y Levison, 1996; Bernstein et al., 2004; Fraser et al., 2008; Fuentes y Holman, 2008; etc.) y en la Figura 1.7.5 se puede apreciar que, más allá de la magnitud aparente en la cual efectivamente se produciría dicho cambio, éste se manifiesta más claramente a partir de $R m a g \simeq 27$, donde se puede detectar un apartamiento de una CLF de pendiente única. Entonces, si este quiebre en la CLF de los TNO es real, podría observarse también en la CLF de Centauros.

Si asumimos que en realidad el cambio de pendiente en la CLF se debe a un cambio de pendiente en la CSD, para detectar el mismo cambio en la CLF de los Centauros debemos encontrar cuál es la magnitud aparente de un Centauro del tamaño correcto para que el cambio de pendiente sea observable siendo conocida su magnitud aparente a una distancia correspondiente a la TNR. Entonces, si consideramos ahora la diferencia en magnitud que habría entre dos objetos del mismo tamaño e igual albedo pero a diferentes distancias heliocéntricas $R$ y geocéntricas $\Delta$, digamos uno en la TNR y el otro en la región media ocupada por los Centauros, como $\log D \propto H$, tendremos que,

$$
m_{T N O}-m_{C e n}=5 \log \left(\frac{(R . \Delta)_{T N O}}{(R . \Delta)_{C e n}}\right) .
$$

Si dichos objetos se encuentran uno a $R_{T N O}=40 U A$ y el otro a $R_{C e n}=15 U A$, y asumiendo que $\Delta \simeq R-1 U A$, la diferencia en magnitud entre ambos será $m_{T N O}-m_{\text {cen }}=4.2$ y entonces el cambio de pendiente que en la CLF de TNOs se haría evidente desde $R \operatorname{mag} \simeq 27$, en la CLF de los Centauros se debería notar con claridad a partir de Rmag $~ 23.0$. Un cambio en los valores de $R_{T N O}$ y $R_{C e n}$ no altera significativamente el resultado.

En la Figura 3.3.6 puede observarse que el punto aportado en esta tesis indicaría que los Centauros podrían poseer efectivamente una CLF que deba ajustarse por una doble ley de potencia y que el cambio de pendiente se hace evidente para magnitudes mayores que $R m a g \simeq 23.0$, en acuerdo con el cálculo anterior. 
3. El descubrimiento de nuevos Centauros y una nueva determinación de la CLF de la población

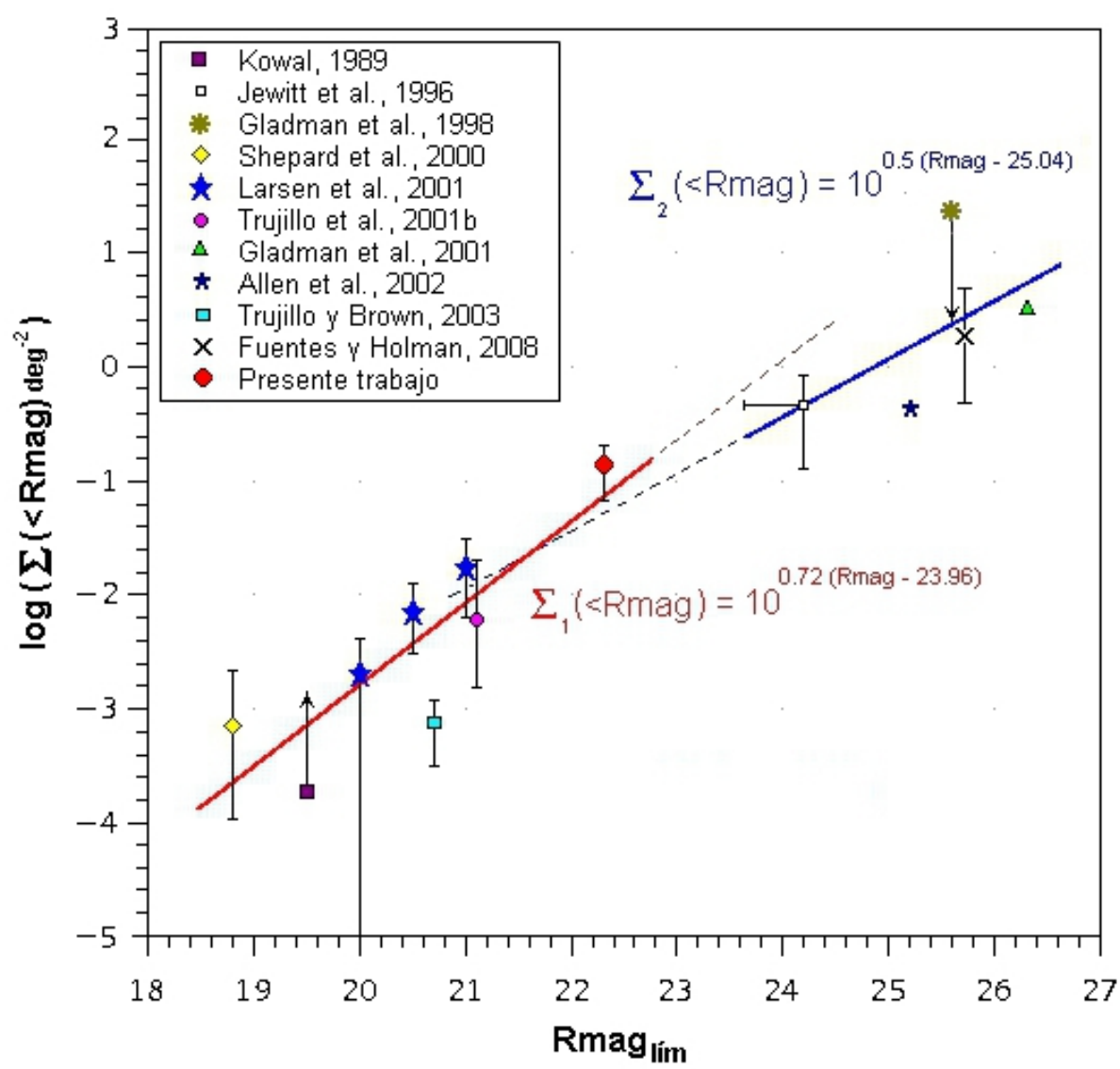

Figura 3.3.6. La nueva función acumulativa de luminosidad para la población de Centauros ajustada con una doble ley de potencia. El cambio de pendiente que se hace evidente para Rmag $\gtrsim 23$, se daría en $R m a g \simeq 21.5$.

Entonces, ajustando los resultados de los diferentes programas de búsqueda con una CLF con una doble ley de potencia, una para el extremo débil y la otra para el brillante, obtenemos,

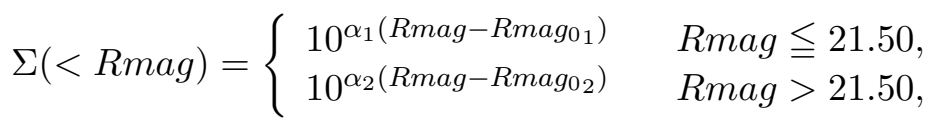

$\operatorname{con} \alpha_{1}=0.72 \pm 0.18$ y $\operatorname{Rmag}_{01}=23.96 \pm 5.00 ; \alpha_{2}=0.50 \pm 0.42$ y $\operatorname{Rmag}_{0_{2}}=25.04 \pm 21.84$.

El resultado obtenido coincide dentro de los errores con los propuestos para TNOs por Bernstein et al. (2004) $\left(\alpha_{1}=0.88\right.$ y $\left.\alpha_{2}=0.32\right)$, Fraser et al. (2008) $\left(\alpha_{1}=0.65\right.$ y $\left.\alpha_{2} \approx 0.6\right)$ y Fuentes y Holman (2008) $\left(\alpha_{1}=0.7\right.$ y $\left.\alpha_{2}=0.3\right)$, pero hay que notar que los puntos correspondientes a la región de brillos más débiles presentan errores importantes que afectan la determinación de $\alpha_{2}$. De todos modos, el ajuste presentaría un cambio de pendiente en $R m a g \simeq 21.5$, unas tres magnitudes más brillante que donde se observa el quiebre de la CLF de TNOs.

Finalmente, con la doble ley de potencias estimada para la CLF de los Centauros puede 
derivarse una ley similar para su CSD asociada (Figura 3.3.7),

$$
N(>D)= \begin{cases}5.9 \times 10^{6} D^{-2.5} & D \leqq 56 \mathrm{~km} \\ 4.9 \times 10^{8} D^{-3.6} & D>56 \mathrm{~km}\end{cases}
$$

donde se asume que la magnitud de cambio de pendiente $R m a g \simeq 21.5$ corresponde a un objeto de radio $28 \mathrm{~km}$, a $15 U A$ y $p_{v}=0.04$. Con esta estimación, la cantidad acumulada de Centauros con radios mayores que $1 \mathrm{~km}$ sería $\approx 10^{6}$.

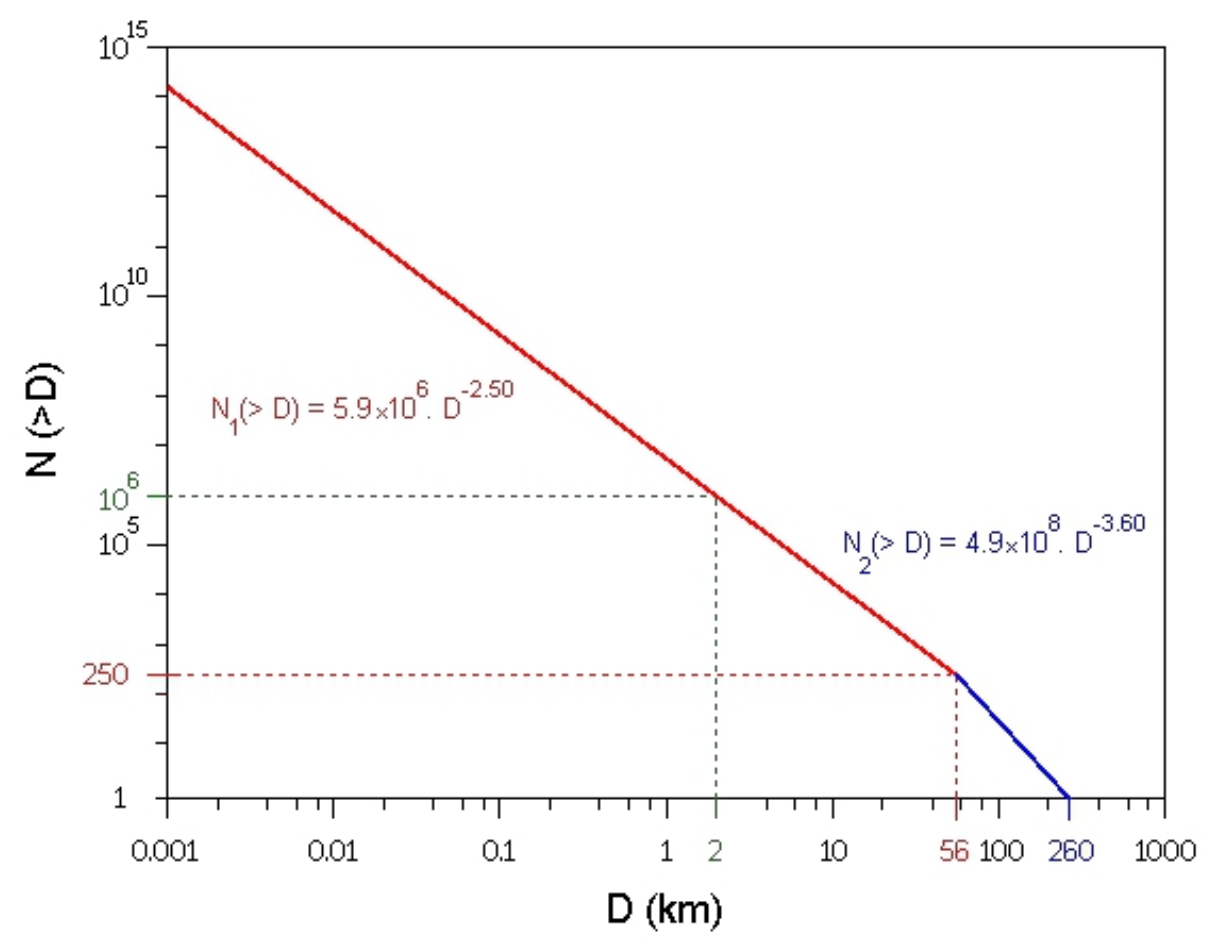

Figura 3.3.7. Nueva distribución acumulativa de tamaños para la población de Centauros ajustada mediante una doble ley de potencias. Se destaca el punto correspondiente al diámetro a partir del cual se produciría el cambio de pendiente, y la cantidad acumulada esperable de Centauros con radios mayores que $1 \mathrm{~km}$. 



\section{Capítulo 4}

\section{La heliosfera y los colores de los Centauros}

Como se mencionó, la expresión (1.8.2) que nos permite relacionar la CLF de una población con su CSD, presupone que el albedo no varía ni con la distancia ni con el tamaño de los objetos, a pesar de que posiblemente exista una retención preferencial de hielos de los objetos más grandes y un rejuvenecimiento superficial producto de colisiones (Jewitt y Luu, 1998). También se mencionó que una estimación de $q$ basada en la suposición de un albedo constante, potencialmente subestima el valor de la pendiente de la distribución de tamaños de una población, lo que llevó a Frasser et al. (2008) a intentar relacionar los parámetros $q$ y $\alpha$ con un albedo $p$ variando con el diámetro $D$-ecuaciones (1.8.3) y (1.8.4)-. En resumen, la variación de los albedos afecta la relación entre la CLF y la CSD de una población, y por lo tanto tendrá una relevancia importante al momento de analizar los resultados obtenidos en cualquier estudio que infiera tamaños a partir de la luz reflejada por los objetos.

Así, teniendo en cuenta que el tema de los albedos es particularmente crítico en la población de Centauros habida cuenta de que es una población que presenta una clara bimodalidad de colores que aún no ha sido debidamente explicada (Doressoundiram et al. 2005; Stansberry et al., 2008; Peixinho et al., 2012; Perna et al., 2014; etc.), consideramos que resulta relevante en el contexto de la presente tesis realizar un acercamiento a este problema, y tratar de aportar una posible explicación que ayude a comprender las peculiaridades de los albedos de esta población.

De esta manera, en este capítulo se desarrollará un estudio teórico mediante simulaciones numéricas, sobre la posible influencia del comportamiento de la heliosfera ante encuentros con medios de distintas densidades, los que la obligan a variar su capacidad de proteger las superficies de los objetos -en particular de los Centauros-, de partículas de alta energía provenientes del ISM, las que modificarán sus albedos (Moroz et al., 2003; Strazzulla et al., 2003). 


\subsection{La heliosfera}

La heliosfera es la cavidad en el ISM causada por la presión del SW, un vasto halo de plasma creado por la corona solar en expansión que se extiende en la dirección del movimiento del Sol a $\sim 150-180 U A$, y a varios miles de unidades astronómicas en la dirección opuesta, regulando el flujo de rayos cósmicos y el material interestelar que ingresa a su interior (Frisch, 2006; Zank et al., 2006). Si la velocidad de una estrella relativa al medio en el que se desplaza es suficientemente elevada, en la dirección de su movimiento se genera en el contacto con su heliosfera un arco de choque (BS) (Figura 4.1.1). Si bien se cree que el Sol genera tal estructura, recientemente McComas et al. (2012) han puesto en duda su existencia debido a las bajas velocidades relativas del Sol respecto al medio interestelar local (LISM). En 2013, McComas et al. (2013) con datos del Interstellar Boundary Explorer (IBEX) postularon la existencia de una extensa cola en dirección al Anti-ápex como un componente más de la heliosfera, definiéndose así una nueva región a la que se llamó Heliotail, componente que ya había sido observado con anterioridad en otras estrellas (Figura 4.1.1 d)).
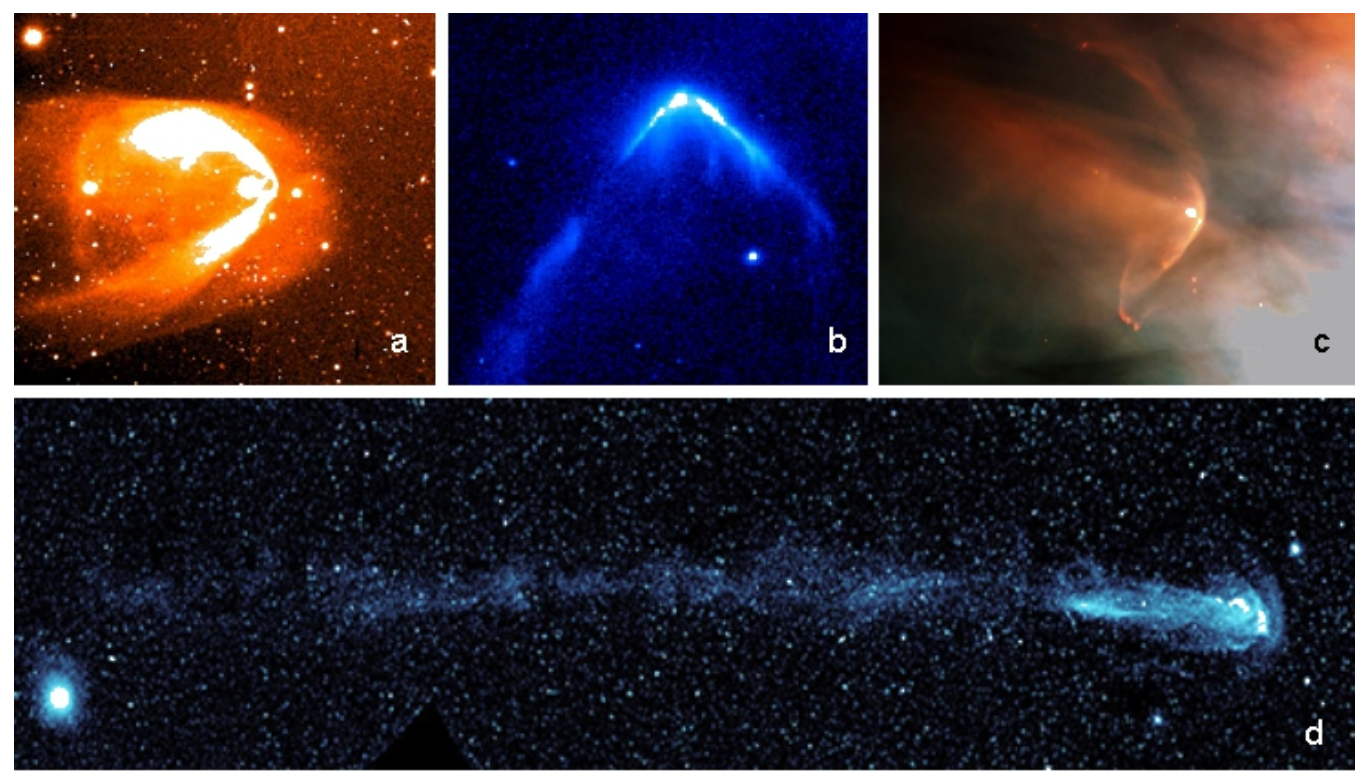

Figura 4.1.1. a) BS alrededor del sistema binario BZ Camelopardalis. b) BS muy pronunciado que evidencia la velocidad de su joven estrella que fue captada por la ACS del HST, y de la que no se da mayor referencia. c) El punto brillante cerca del centro de la imagen es la estrella LL Orionis y frente a ella se despliega todo su BS-NASA and the Hubble Heritage Team (STScI/AURA)-. d) Omicron Ceti (Mira), su BS y su imponente heliotail de más de 13 años luz de longitud (Mosaico confeccionado a partir de imágenes extraídas de NASA/JPL-Caltech/C. Martin (Caltech)/M. Seibert (OCIW)).

Las propiedades del SW, y en particular la presión de radiación, varían con la fase del ciclo de actividad magnética solar y con la latitud eclíptica. Durante el máximo solar el viento de baja velocidad $\left(\sim 300-600 \mathrm{~km} \mathrm{seg}^{-1}\right.$ con una densidad de partículas $\sim 6-10 \mathrm{~cm}^{-3} \mathrm{a}$ $1 U A$ ), se emite sobre la mayor parte del disco solar (Frisch, 2006). El hecho que el joven Sol haya sido mucho más activo en sus comienzos que en la actualidad (Guinan y Ribas, 2002, Yeghikyan y Fahr, 2006) nos permite imaginar una heliosfera unas 10 veces mayor 
que la actual (Parker, 2006). En diciembre de 2004 la nave Voyager 1 cruzó el Termination Shock (TS) -límite a partir del cual el SW pasa a ser subsónico, abandonando su dirección radial- a $94 U A$ (Stone et al., 2005; Burlaga et al., 2005; Gurnett y Kurth, 2005; Decker et al., 2005; Frisch, 2006), internándose en el Inner Heliosheath. Sin embargo las propiedades y dimensiones de la heliosfera no sólo están reguladas por la intensidad del SW sino también por el ISM donde se encuentra inmersa, presentando actualmente una densidad media en el entorno solar de $0.21 \mathrm{~cm}^{-3}$ (Zank et al., 2006, Frisch y Slavin, 2006, Florinski y Zank, 2006).

Los encuentros del Sol con los diferentes escenarios en el medio interestelar necesariamente modifican el tamaño de la heliosfera retrayendo o expandiendo sus límites según sea la densidad del LISM. Así, en encuentros con medios más densos que el LISM, la heliosfera se retraerá hacia el interior del SS (Yeghikyan y Fahr, 2006) pudiendo llegar en algunos casos hasta distancias menores que $1 U A$ (Fahr, 1980, Yeghikyan y Fahr, 2006), lo que provoca que la Tierra quede expuesta a un ISM compuesto sustancialmente de partículas cargadas e H molecular, y que su atmósfera sea barrida por el viento interestelar con importantes implicaciones climatológicas y biológicas (Yeghikyan y Fahr, 2006).

Pero lo cierto es que en la inmensa mayoría de los casos, los encuentros son con medios de densidades menores que $100 \mathrm{~cm}^{-3}$ y si bien la heliosfera no sufre una retracción tan dramática, se contrae lo suficiente como para privar de su protección a los cuerpos más distantes del SS y a objetos no tan lejanos pero con altas excentricidades. Ese último es el caso de muchos Centauros, los que al entrar y salir de la heliosfera dejan así expuestas periódicamente sus superficies a la radiación cósmica, lo que produce diferentes grados de irradiación que puede alterar sus albedos y colores, y es precisamente este escenario el que abordaremos mediante el mencionado estudio teórico.

\section{2. $\quad$ El albedo y el color de las superficies}

Se conoce como albedo geométrico $(p)$ al cociente entre la radiación reflejada por un objeto con un ángulo de fase $\alpha=0$ y la que hubiera reflejado una superficie de iguales dimensiones y reflectancia perfecta ubicada en la misma posición. La mayor parte de los asteroides del MBA tienen albedos geométricos en el intervalo $0.05-0.45$, mientras que el albedo típico de cometas es $\simeq 0.04$. Por su parte, los Centauros poseen albedos entre $0.02-0.18$ y el valor estimado comúnmente para un TNO está entre $0.04-0.06$.

El brillo de un objeto dependerá de las distancias heliocéntrica y geocéntrica y del ángulo de fase $\alpha$. Para un cuerpo que no posea atmósfera como es el caso de la gran mayoría de los cuerpos menores del SS, el brillo también será función de cómo se refleja la luz en la superficie del mismo, de su sección transversal y del brillo del Sol.

Ya se mencionó en el capítulo 1 que para un objeto del SS sin actividad cometaria que se encuentra a una distancia heliocéntrica $R$, a una distancia geocéntrica $\Delta$ y es observado con un ángulo de fase $\alpha$, se define su magnitud aparente mediante la expresión (1.7.2). Ahora, conociendo la magnitud absoluta $H$ de un objeto y su albedo geométrico visual $p_{v}$, puede estimarse su diámetro a partir de la expresión (Chesley et al., 2002),

$$
D[k m]=\frac{1329}{\sqrt{p_{v}}} 10^{-0.2 H} .
$$


La principal fuente de error en la estimación del tamaño de un objeto, en general, surge de la incertidumbre sobre el valor de $H$, ya que puede contener errores significativos en objetos pobremente observados (Bowell et al., 1989; Chesley et al., 2002).

Las variaciones del albedo pueden afectar significativamente la reflectividad en ciertas longitudes de onda y, en consecuencia, modificar el color del objeto. La fotodisociación por radiación UV o por interacción con el SW puede oscurecer las superficies, aunque ciertamente este mecanismo de oscurecimiento es más efectivo por la fotodisociación debida a la radiación de rayos cósmicos altamente energéticos que es la más dominante más allá de las $45 \mathrm{UA}$. Cooper et al. (2003) han sugerido que la separación radial entre las regiones en las cuales esos dos tipos de fuentes de iones tienen más influencia, proporcionaría una posible explicación a los colores predominantemente rojos de los objetos más antiguos de baja inclinación y baja excentricidad que se encuentran más allá de las $40 \mathrm{UA}$.

Los albedos elevados predominan en los objetos de mayor tamaño (Bertoldi et al., 2006) los que a su vez presentan formas que parecen estar en equilibrio hidrostático (Trilling y Bernstein, 2006; Lacerda y Luu, 2006). Particularmente (136199) Eris posee un $p_{v} \simeq 0.96$ (Sicardy et al., 2011). Sin embargo, en la población de Centauros no parecería haber una correlación entre albedos y diámetros (Duffard et al., 2014b).

Desde hace ya varios años se vienen realizado estudios sobre los colores de los Centauros y los miembros de las distintas poblaciones de la TNR, y la distribución de los mismos en el visible ha generado una controversia que ha desatado un debate fecundo sobre el origen de la misma (Luu et al., 2000; Boehnhardt et al., 2001; Tegler et al., 2003; Peixinho et al., 2003; Peixinho et al., 2004; Doressoundiram et al. 2005; Tegler et al., 2008; Stansberry et al., 2008; Melita y Licandro, 2012; Peixinho et al., 2012; Perna et al., 2014; etc.). Esta controversia se ha centrado en desentrañar si los colores son una característica primordial y directamente relacionada con la región de formación de cada población, o son el resultado de procesos de evolución superficial. Una cuestión particularmente desconcertante surge al tratar de explicar por qué los Centauros, que como vimos serían cuerpos escapados de la TNR, exhiben dos grupos de colores bien diferenciados -uno con colores neutros y el otro con colores muy rojos (ver tabla de la Figura 4.5.10)- mientras que la mayoría de las poblaciones de la TNR no, presentando éstas una distribución amplia con una gama continua de colores, desde los solares $\left((V-R)=0.46\right.$ para (32929) $\left.1995 Q Y_{9}\right)$ hasta los muy rojos $\left((V-R)=0.94\right.$ para $\left.1994 E S_{2}\right)$ (Luu y Jewitt, 1996b) y extremadamente rojos ((42301) $2001 U R_{163}$ y (119473) $2001 U O_{18}$, con $(B-V)=2.28$ y 2.06, respectivamente). Particularmente el Centauro (5145) Pholus está entre los objetos más rojos del SS, con un índice de color $(B-R)=2.09$ (Hainaut y Delsanti, 2002), un albedo geométrico estimado en 0.044 (JPL) y un espectro que ha sido asociado con cinco componentes entre los que se observa un $15 \%$ de hielo de agua y un $15 \%$ de metanol -o algún otro hidrocarburo- (Cruikshank et al., 1998; Strazzulla et al., 2003). El desconcierto aumenta si se tiene en cuenta que los JFC, una población con origen en la población de Centauros como ya se discutió, no muestra en absoluto evidencia de una bimodalidad de colores (Lamy y Toth, 2009).

Recientemente en un trabajo de Perna et al. (2014), los autores se preguntan si en realidad la tan discutida bimodalidad de colores de la población de Centauros no es más que un sesgo causado por una subestimada actividad cometaria en toda esta población. Lo cierto es que a la fecha no existe ningún trabajo que proponga un mecanismo para explicar 
dicha bimodalidad, que Peixinho et al. (2004) no dudan en afirmar que solamente existe en la población de Centauros, con la excepción del realizado por Melita y Licandro (2012) quienes hacen un análisis de la evolución orbital de Centauros agrupados según sus colores y explican la bimodaldidad observada como producto de los diferentes procesamientos térmicos sufridos por las superficies como resultado de variaciones significativas en sus distancias perihélicas, hallando que los Centauros que permanecen más cerca del Sol por más tiempo, son los que presentan superficies más neutras/grises.

Se considera que los TNOs son conglomerados de hielo de agua, compuestos de moléculas complejas formadas básicamente por $\mathrm{H}, \mathrm{C}, \mathrm{N}$ y O y polvo, presentando composiciones muy distintas, lo cual se reflejaría en la mencionada diversidad de colores que exhiben. Por ejemplo, se ha detectado en sus superficies hielo de agua, metanol, metano, nitrógeno molecular helado, etc. (Brown et al., 2005; Licandro et al., 2006a; Tegler et al., 2007; Brown et al., 2007; PinillaAlonso et al., 2007; Licandro et al., 2006b; Bauer et al., 2003; Barucci et al., 2002; Merlin et al., 2005). Análisis espectrales en el IR-cercano incluyen otras especies como cianuro, tanto orgánico como inorgánico (Trujillo et al., 2007) e hidrocarburos (Sasaki et al., 2005).

Por otra parte, la actividad colisional también puede alterar las propiedades físicas de sus superficies compitiendo con los procesos de irradiación, aunque se observa que los TNOs más grandes no muestran diferencias importantes en sus colores en el visible e infrarrojo con respecto a los colores observados en los objetos más pequeños $(r<400 \mathrm{~km}$ ) (Gil-Hutton y Licandro, 2001; Doressoundiram et al., 2005).

\subsection{Procesos que modifican las superficies}

Los modelos de migración nos dicen que los TNOs se formaron en diferentes regiones del SS y dadas las diferentes densidades de la nebulosa protoplanetaria y los grandes gradientes de temperatura, sería esperable que en distintas regiones se hayan formado objetos con composiciones muy diferentes. También pudo suceder que todos los TNOs hayan tenido una conformación primordial similar y procesos posteriores hayan actuado modificando las composiciones de sus superficies, pero una combinación de ambas alternativas parece ser el escenario más probable.

Los procesos a los que se hace referencia en la segunda alternativa pueden provocar realmente importantes cambios en las superficies de los objetos, modificando sus colores y albedos, y si bien son numerosos (ver Figura 4.3.1), los tres que se destacan sobre el resto son: el clima espacial (o space weathering), causante del desgaste superficial por efectos físicoquímicos que generan un envejecimiento del material; la renovación superficial por impactos (o collisional resurfacing); y la actividad cometaria. 


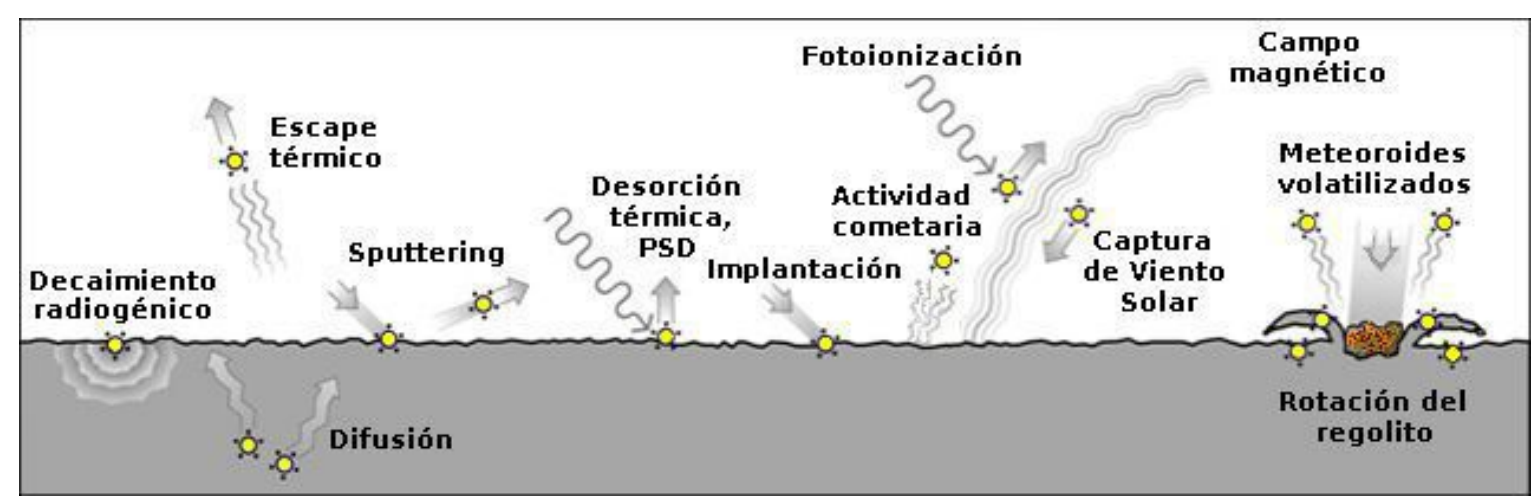

Figura 4.3.1. Distintos procesos que pueden provocar importantes cambios en las superficies de los objetos, modificando sus colores y albedos (Adaptado de MESSENGER Mission, $N A S A$ )

\section{a) Clima espacial (space weathering)}

Es el término general que engloba una serie de procesos físico-químicos que afectan las superficies de los cuerpos sin atmósfera, envejeciéndolas por simple exposición al duro ambiente del espacio exterior. Entre ellos pueden mencionarse: irradiación, decaimiento radiogénico, difusión, escape térmico, sputtering, desorción térmica (Photon Stimulated Desorption o PSD), implantación, y captura de partículas del SW.

Todos los cuerpos del SS son continuamente irradiados por iones energéticos provenientes del SW, de flares solares, de magnetosferas planetarias y diversas micropartículas; sin embargo, los objetos de las regiones más externas son principalmente afectados por rayos cósmicos provenientes del espacio interestelar, los que modifican sus superficies creando un manto sólido de irradiación, refractario, enrojecido y rico en compuestos orgánicos que se mantiene estable luego del calentamiento (Moroz et al., 2003; Strazzulla et al., 2003).

El desarrollo de una corteza orgánica se produce cuando los hidrocarburos de bajo peso molecular se convierten en una red de especies moleculares ligadas. Después de un largo período de exposición a la radiación, el residuo evoluciona hacia un carbono hidrogenado de un color neutro (Moroz et al., 2004). Mediante experimentos de laboratorio es posible estudiar los efectos de la irradiación durante tiempos prolongados sobre diversas superficies y se ha demostrado que los colores de los TNOs observados pueden ser reproducidos por los mismos (Brunetto et al., 2006). Esto sugiere que los TNOs poseen una corteza orgánica refractaria desarrollada después de la irradiación prolongada por iones cósmicos, en analogía con lo que varios autores han sugerido anteriormente para los cometas de la nube de Oort, e incluso para los SDOs y los CTNbOs marginales (por ejemplo, Strazzulla et al., 1991; 2003). Para facilitar las comparaciones entre las diferentes muestras y fuentes de energía -incluso en experimentos de fotodisociación-, la mayoría de los investigadores, como veremos, utilizan como unidad estándar de dosis de radiación el $e V / 16 a m u$.

Muchos TNOs poseen colores rojos que se corresponden a dosis de radiación entre $10-100 \mathrm{eV} / 16 \mathrm{amu}$, pero los objetos de color más neutro podrían haber acumulado dosis mucho más altas (Moroz et al., 2003; 2004). Strazzulla et al. (2003) estiman que 
las capas superficiales $(1-100 \mu \mathrm{m})$ de los objetos a distancias entre las $85 \mathrm{UA}$ (es decir, cercanos al TS) y el LISM, acumulan dosis superiores a los $100 \mathrm{eV} / 16 \mathrm{amu}$ en escalas de tiempo de $10^{6}-10^{9}$ años. Esto sugiere que muchos objetos helados del SSE desarrollan un manto de irradiación en escalas de tiempo de $10^{8}$ años (Hudson et al., 2008). Del trabajo de Cooper et al. (2003) y actualizaciones realizadas por Hudson et al. (2008), se desprende que las dosis recibidas por objetos entre $40-50 U A$ son más bajas, y por lo tanto, materiales volátiles como el nitrógeno molecular, el monóxido de carbono o el metano, pueden conservarse mejor en las superficies de esos TNOs.

La profundidad de penetración en sólidos de hielo de partículas con energías del orden del GeV -típicas de rayos cósmicos- ha sido estimada en $1 \mathrm{~m}$ (Strazzulla y Johnson, 1991). En un trabajo de Shul'Man (1972) el autor sostiene que, como producto de esas irradiaciones se formará un manto superficial en una escala de tiempo de aproximadamente $10^{7}-10^{9}$ años. Por su parte, Strazzula et al. (2003) afirman que una superficie que recibe dosificaciones del orden de los $100 \mathrm{eV} / 16 \mathrm{amu}$ sufrirá cambios radiolíticos en los materiales que la componen y quedará lo suficientemente afectada como para tener un albedo bajo.

Los impactos de micro-meteoritos son eventos que también alteran la superficie de los objetos carentes de atmósferas, pero aún no es claro el peso de tales eventos en el estudio global de los fenómenos de space weathering (Sasaki et al., 2001).

b) Renovación superficial por impactos (collisional resurfacing)

En un trabajo de Luu y Jewitt (1996a) los autores proponen una serie de mecanismos para explicar la diversidad de colores de los objetos de la TNR. Uno de ellos consiste en el cambio de las superficies debido a un proceso denominado collisional resurfacing (Luu y Jewitt, 1996b) por el cual, el proceso colisional remueve el manto de irradiación y la mezcla con el material poco alterado que se encuentra a mayor profundidad, provoca un recambio de material que resulta en un reajuste local de color. Así, según esta hipótesis, los impactos más energéticos excavarían las superficies removiendo material y los restos de esas colisiones que no escaparan a la gravedad, se depositarían sobre la superficie cubriendo la zona con material más brillante. De esta manera, una superficie muy afectada colisionalmente a lo largo del tiempo cambiaría notablemente su albedo y color. Dichas regiones se observan con detalle alrededor de algunos cráteres de impacto en la Luna y en las superficies de los asteroides que han sido visitados por sondas espaciales. La escala de tiempo para el collisional resurfacing es comparable a la escala de tiempo típica para el space weathering del material superficial expuesto. Posteriormente GilHutton (2002) desarrolló más extensamente este mecanismo para explicar la diversidad de colores en el TNb.

\section{c) Actividad cometaria}

Son varias las causas que pueden disparar la actividad cometaria en un objeto pero las principales son: la actividad solar, las fuerzas de marea tanto del Sol como de los planetas gigantes, la transición de fase de hielo amorfo a cristalino, la sublimación de bolsones de materiales muy volátil (por ejemplo, monóxido y dióxido de carbono), las tensiones térmicas que provocan fracturas en la superficie, las altas velocidades de rotación, las colisiones con planetesimales, las colisiones con fragmentos del propio objeto, etc. 
Por lo general, un cometa desarrolla su coma de manera muy nítida a distancias heliocéntricas $R<3 U A$, y dado que la temperatura de equilibrio para un cuerpo a $R \approx 3 U A$ es aproximadamente igual a la temperatura donde comienza a sublimar el hielo de agua, la aparición de una coma bien desarrollada a distancias menores se ha tomado como evidencia de que el principal componente volátil en la mayoría de los cometas es, precisamente, el hielo de agua. Sin embargo, el proceso dinámico que hace que, por ejemplo, algunos Centauros den muestras de actividad cometaria, estaría acompañado de otros fenómenos que modifican sus superficies. Una prueba de ello es que a la fecha se conocen cerca de una decena de objetos en órbitas típicas de Centauros que muestran actividad de algún tipo a pesar de su distancia media al Sol, como es el caso de (2060) Chiron (Jewitt, 2009; Guilbert-Lepoutre, 2012). Incluso a distancias tan lejanas como $15 \mathrm{UA}$ muchos cometas o Centauros pueden mostrar una considerable actividad como producto de la sublimación de otros compuestos, principalmente el monóxido de carbono. Esto pudo observarse en el caso del cometa C/1995 O1 (Hale-Bopp), uno de los cometas más estudiados en las últimas décadas, lo que permitió ajustar una curva teórica de cómo varió la tasa de expulsión de gases respecto a la distancia heliocéntrica tanto para el monóxido de carbono a $R<9 U A$, como para el agua en el caso de distancias heliocéntricas menores (Biver, 2001). Así mismo, no debe dejar de mencionarse que un objeto tan distante como (134340) Plutón ha dado muestras de sublimación de volátiles en su superficie (Stern y Trafton, 2008; Buratti et al., 2015).

La actividad cometaria es considerada por Delsanti et al. (2004) como una de las causas principales del rejuvenecimiento superficial en los TNOs. Los dos escenarios más probables en los que se dan las condiciones para el inicio de una actividad cometaria son, por un lado, cuando el manto superficial es suficientemente fino como para permitir que los volátiles puedan sublimar, y por el otro, cuando las distancias heliocéntricas son tales que las temperaturas son suficientemente altas como para que los volátiles sublimen. Finalmente, mencionemos que existen dos fenómenos espectaculares dentro de las actividades cometarias que pueden desencadenarse abruptamente, llamados outbursts y splittings: el primero es un fenómeno de carácter violento por el cual el objeto sufre un estallido aumentando súbitamente su magnitud; mientras que el segundo -relacionado principalmente con los cometas-, implica una pérdida de masa superior a su media o directamente su fragmentación en dos o más cuerpos de tamaños comparables.

Entonces, ante estos escenarios y dado el peso que tiene el albedo en la determinación de tamaños, es importante estudiar los efectos de la variación de la heliosfera, la interacción con el ISM, y los efectos de la irradiación por partículas cargadas en las superficies de los objetos del SSE, para analizar si la bimodalidad de colores y la variación en los albedos de la población de Centauros, tiene alguna relación con esos eventos.

\subsection{El entorno interestelar del SS}

En su viaje por la Vía Láctea, el SS se va encontrando con diferentes escenarios pero sólo unos pocos poseen una probabilidad de interacción lo suficientemente alta como para que valga la pena considerarlos. A escalas de tiempo de millones de años, varios parámetros que caracterizan nuestro entorno galáctico puede variar considerablemente y entre ellos se 
destacan el flujo de rayos cósmicos, las componentes de presión térmica y no térmica, y la densidad de polvo interestelar y su composición. A escalas más cortas, el entorno galáctico, su dinámica y en particular su estructura espiral, se vuelven muy importantes debido a que dentro de los brazos espirales hay considerablemente mayor actividad que en las regiones que los separan (Shaviv, 2006). A lo largo de su vida, el SS ha atravesado los brazos espirales y las regiones entre los mismos pasando por medios con densidades muy dispares que van desde menos de $0.0025 \mathrm{~cm}^{-3}$ a más de $2500 \mathrm{~cm}^{-3}$ y temperaturas que oscilan en más de 7 órdenes de magnitud, entre $10-10^{7} \mathrm{~K}$. Actualmente el Sol se encuentra en un espacio de baja densidad entre los brazos espirales de Perseo y Sagitario, en el borde interior de lo que se conoce como el Espolón de Orión, en el Brazo Local (Frisch, 2006). Shaviv (2006), sostiene que las causas más importantes de los cambios en el entorno del SS para escalas de tiempo mayores que $10^{7}$ años, pueden resumirse en: (a) la tasa de formación estelar; (b) el paso por los brazos espirales de la Galaxia; y (c) las oscilaciones perpendiculares respecto del plano galáctico; y agrega que a escalas de tiempo menores, dichas oscilaciones adquieren tanta importancia como las heterogeneidades en el LISM.

El ISM en la Galaxia es una mezcla de gas y polvo compuesto por un material denso, neutro y molecular embebido en un medio ambiente cálido y tenue de gran heterogeneidad en términos de densidad y temperatura. Tiende a concentrarse cerca del plano galáctico, preferentemente a lo largo de los brazos espirales donde aproximadamente la mitad de su masa la conforman nubes discretas que ocupan sólo entre el $1-2 \%$ del volumen total del disco. El componente denso está formado por nubes neutras o atómicas frías HI $(T<100 K)$ y por GMC $(T \sim 10-20 K)$. Todas estas estructuras tienen formas irregulares y dimensiones entre $\sim 0.01-50 p c$ con densidades que van desde $\sim 10-100 \mathrm{~cm}^{-3}$ para las nube HI, hasta $\sim 1000 \mathrm{~cm}^{-3}$ para las GMC. En el caso de estas últimas, sus núcleos y las subestructuras que se forman dentro de ellas poseen mayor densidad, superando los $10^{3} \mathrm{~cm}^{-3}$ para los primeros y $10^{5} \mathrm{~cm}^{-3}$ para las segundas, aunque ocupan respectivamente apenas el $\sim 0.1 \%$ y el $\sim 1 \%$ del volumen total de la GMC (Yeghikyan y Fahr, 2006).

Talbot y Newman (1977) estiman que en toda la vida del SS el Sol se ha encontrado con nubes de densidades entre $10-1000 \mathrm{~cm}^{-3}$ unas 135 veces, mientras que los encuentros con nubes de densidades mayores han sido apenas unos 16. Por su parte, Yeghikyan y Fahr (2006) calculan que el tiempo entre dos encuentros con nubes de HI con tamaños $\sim 4 p c$ ha sido de $2.7 \times 10^{7}$ años, mientras que los encuentros con una GMC de $\sim 10 p c$ se dan cada $4.6 \times 10^{8}$ años. Por su parte, Scoville y Sanders (1986) estiman que el tiempo real entre colisiones con una GMC sería dos veces mayor $\left(\sim 10^{9}\right.$ años), mientras que Clube y Napier (1986) se inclinan por períodos más cortos, estimándolos en $7 \times 10^{8}$ años.

Es poco probable que dentro de un período de $\pm 4 \times 10^{6}$ años desde el presente, el Sol haya atravesado o vaya a atravesar una región HII alrededor de una estrella tipo O-B1 dado que no hay tales estrellas o regiones HII dentro de un radio heliocéntrico menor que $80 p c$ (Frisch y Slavin, 2006). Sin embargo, Zank et al. (2006) sostienen que como dentro de un radio de $350 p c$ el ISM presenta características muy dispares, el SS sin dudas tuvo y tendrá encuentros con nubes cuyas densidades pueden estar en el rango $10^{-4}-10^{5} \mathrm{~cm}^{-3}$ y sus temperaturas variar entre $10-10^{6} \mathrm{~K}$. 
La formación estelar modifica permanentemente el ISM y a veces lo hace de manera dramática. Por ejemplo, los núcleos de las estrellas más masivas cercanas tienen una antigüedad de $4-15 \times 10^{6}$ años, por lo que el SS ha sido bombardeado por partículas y fotones de alta energía incluso desde tiempos muy anteriores a $10^{7}$ años. Estas estrellas ionizan sus entornos más allá de los 150 pc dentro del Complejo Sco-Cen, la mayor concentración de estrellas masivas en las cercanía del Sol, formado por las asociaciones Upper Scorpius, Upper Centaurus-Lupus y Lower Centaurus-Crux, a distancias medias de entre 118 - 145 pc (de Zeeuw et al., 1999), y el remanente de supernova Loop I. Por otra parte, recientes eventos de supernovas cercanas incluyen la formación del púlsar Geminga hace aproximadamente unos $2.5 \times 10^{5}$ años, y posiblemente también la liberación de $\zeta O p h$ como una estrella fugitiva hace unos $0.5-1 \times 10^{6}$ años. Es por ello que la misma evolución dinámica del ISM nos limita a la hora de dar una descripción precisa del entorno solar galáctico a escalas de tiempo más allá de unos $1-3 \times 10^{6}$ años y tratar de trazar una trayectoria solar.

La oscilación del SS en el potencial gravitacional galáctico lleva al Sol a atravesar el plano galáctico, según distintas estimaciones, una vez cada $(3.5 \pm 0.8) \times 10^{7}$ años (Matese et al., 1995), $(3.7 \pm 0.4) \times 10^{7}$ años (Stothers, 1998) o $4.2 \times 10^{7}$ (Fernández, 2005), con lo cual éste llegaría a una altura máxima desde dicho plano en $\sim 1.9 \times 10^{7}$ años, aunque otros varios autores la estiman en algo menor, afirmando que llegaría a una altura máxima de $\sim 78 p c$ en unos $1.4 \times 10^{7}$ años (Bash, 1986; Vandervoort y Sather, 1993; Shaviv, 2006; Frisch y Slavin, 2006). Entonces, en un tiempo comparativamente más corto que éstos lapsos las variaciones del entorno galáctico solar serán mucho menores comparadas con las que se darán tanto con las oscilaciones verticales del Sol a través del plano galáctico, como con las disrupciones en el ISM por formación estelar (Frisch y Slavin, 2006).

Teniendo en cuenta todo esto, Zank et al. (2006) sostienen que en tiempos comprendidos entre $\pm 3 \times 10^{6}$ años desde el presente, los cinco escenarios que poseen las mayores probabilidades de protagonizar o de haber protagonizado un encuentro con el Sol, son:

1. Local Bubble (LB): Es una vasta cavidad prácticamente vacía, casi totalmente ionizada y supercaliente que contiene un plasma emisor de rayos X (soft X-ray diffuse backgroung -SXRB-) a temperaturas del orden de $T=10^{6} \mathrm{~K}$ (Zank et al., 2006; Snowden et al., 1998; Pogorelov y Zank, 2006; Kuntz y Snowden, 2000; Frisch y Slavin, 2006; Florinski y Zank, 2006). Su densidad estimada es de unos $n\left(H^{0}\right)<5 \times 10^{-4} \mathrm{~cm}^{-3}$ para el $\mathrm{H}$ neutro y $n\left(H^{+}\right) \sim 1-5 \times 10^{-3} \mathrm{~cm}^{-3}$ para el gas ionizado (Lallement, 2004; Zank et al., 2006), lo que implica una densidad menor que $10^{-26} \mathrm{~g} \mathrm{~cm}^{-3}$. El Sol estuvo al menos en los últimos $3 \times 10^{6}$ años en esta región y si bien la abandonó en algún momento hace $\sim 0.44-1.5 \times 10^{5}$ años para internarse en una región más densa (Frisch, 2006; Frisch y Slavin, 2006), reingresará a ella en el futuro. Esta burbuja posiblemente se formó hace $\sim 1-2 \times 10^{7}$ años como consecuencia de la explosión de varias supernovas cercanas que barrieron el gas y el polvo del ISM, dejando un material caliente y menos denso que el entorno, y desde entonces entre 14 y 20 supernovas han explotado en su interior, contribuyendo a excavar esta vasta región como la observamos hoy (Fuchs et al., 2009; Berghöfer y Breitschwerdt, 2002)(Figura 4.4.1). 

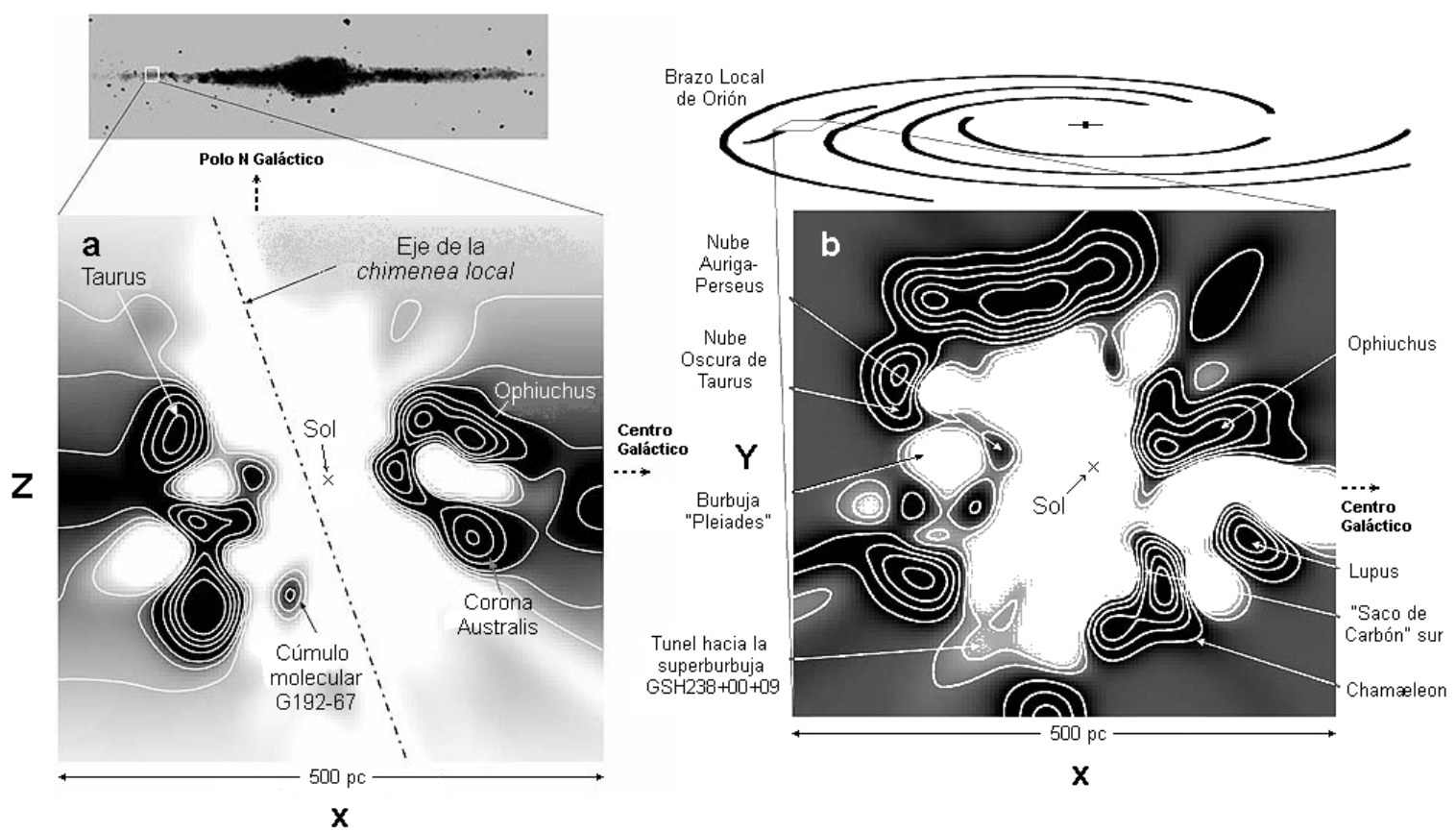

Figura 4.4.1. Corte normal (a) -plano meridional $(X \times Z)$ - y corte tangencial (b) -plano galáctico $(X \times Y)$ - de la LB. En el primer corte se observa la Chimenea Local que se abre hacia el espacio intergaláctico (Adaptado de U.C. Berkeley \& CNRS Press, 2003).

Se estima que sus dimensiones son de unos $100 p c$ en dirección radial en el plano galáctico por unos $300 p c$ en dirección perpendicular a él, que es precisamente el espesor de la Galaxia a $\sim 8 \times 10^{3} p c$, nuestro radio galáctico (Elmegreen, 1998; de Avillez y Breitschwerdt, 2004). Se interconectan con ella otras burbujas de origen similar, como la burbuja Loop I -inmersa en la Asociacion Sco-Cen-, la Loop II y la Loop III. Está ubicada dentro del Cinturón de Gould, un anillo de estrellas jóvenes y regiones de formación estelar originado hace $\sim 3-6 \times 10^{7}$ años (Berghöfer y Breitschwerdt, 2002) que forma un gran círculo que se extiende desde la constelación de Orión a la constelación de Scorpius (Zank et al., 2006).

Según Lallement et al. (2003), aparentemente la LB estaría siendo presionada por las estructuras vecinas en expansión, y sugieren que esta burbuja es mucho más antigua de lo que se creía en un comienzo y que contendría un gas a menor presión que sus vecinas. Por otro lado, estudiando los contornos de la $\mathrm{LB}$ en el plano meridional $(\mathrm{X} \times \mathrm{Z})$ (Figura 4.4.1a), se observa claramente una inclinación de la estructura que coincide con la inclinación del Cinturón de Gould $\left(\sim 20^{\circ}\right)$, lo que podría deberse a que precisamente son las estructuras pertenecientes a dicho cinturón las que estarían presionando a la LB y contribuyendo a modelar un gran túnel al exterior de la Vía Láctea -ver misma figura-, una estructura casi perpendicular al plano galáctico conocida como Chimenea Local. 


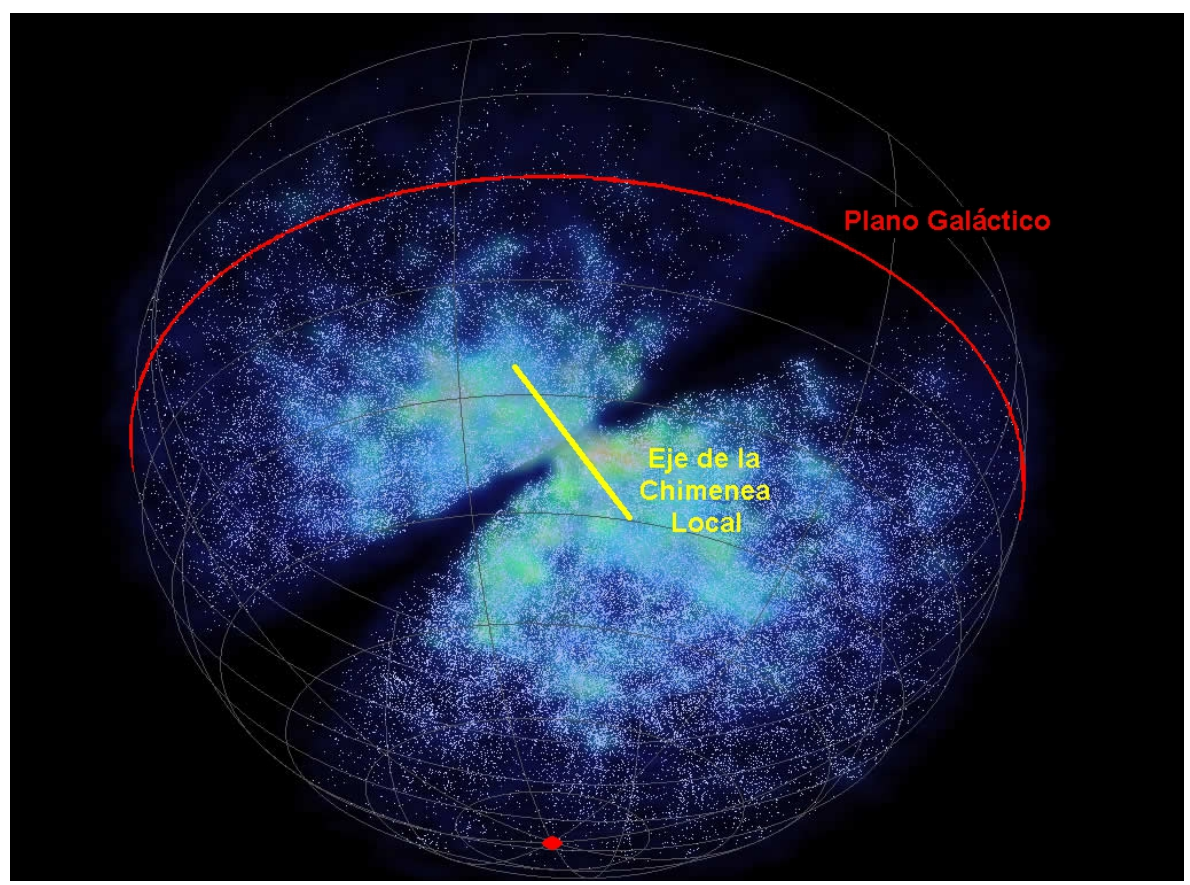

Figura 4.4.2. Ploteo de las $\sim 10^{5}$ galaxias más cercanas al Sol relevadas por el $6 d F$ Galaxy Survey, donde la Vía Láctea se encuentra en el centro de la estructura. Se indica el eje de la Chimenea Local (Adaptado de Fluke C, Centre for Astrophysics and Supercomputing, Swinburne University of Technology, basado en Jones et al., 2009).

Este conducto ya había sido detectada a partir de un estudio sobre la detección en el entorno solar de estrellas emisoras en el UV extremo por Sfeir et al. (1999), y por otros métodos por Welsh et al. (1999). Es gracias a este túnel despejado que se abre ante nosotros permitiéndonos tener dos amplios conos de visión (Figura 4.4.2), que nos fue posible ver más allá de la Vía Láctea y conocer el Universo como lo conocemos hoy, y no quedando limitados a conocerlo solamente en el extremo espectral de las longitudes de onda más largas.

2. Cúmulo de Nubes Interestelares Locales (CLIC) o Local Fluff (LF): Actualmente el ISM cercano, dentro de los $30 p c$ de distancia, es una región formada por un conjunto de tenues y cálidas nubes $(T \sim 7000 \mathrm{~K})$ de densidad promedio $n_{t o t}=n\left(H^{+}\right)+n\left(H^{0}\right)=$ $0.18 \mathrm{~cm}^{-3}$, y por unos filamentos en forma de arcos concéntricos que se generan en la Asociación Sco-Cen y son empujados por presión desde la misma (Frisch y Slavin, 2006). El tamaño típico de esas nubes es $\sim 1 p c$ y el Sol se encuentra actualmente inmerso en una de ellas: la llamada Nube Interestelar Local (LIC) (Ferlet, 1999; Frisch, 2000a; Lallement, 2001; Pogorelov y Zank, 2006). Es una nube molecular parcialmente ionizada a la cual el Sol ingresó hace $\sim 0.44-1.5 \times 10^{5}$ años y de la cual emergerá en $\sim 3.7 \times 10^{3}$ años (Frisch, 2006; Frisch y Slavin, 2006). Nubes de ese tipo constituyen un segundo escenario posible.

En la Figura 4.4.3 se representa el actual entorno solar en un radio de $\sim 460 p c$ (Frisch, 2000b). 


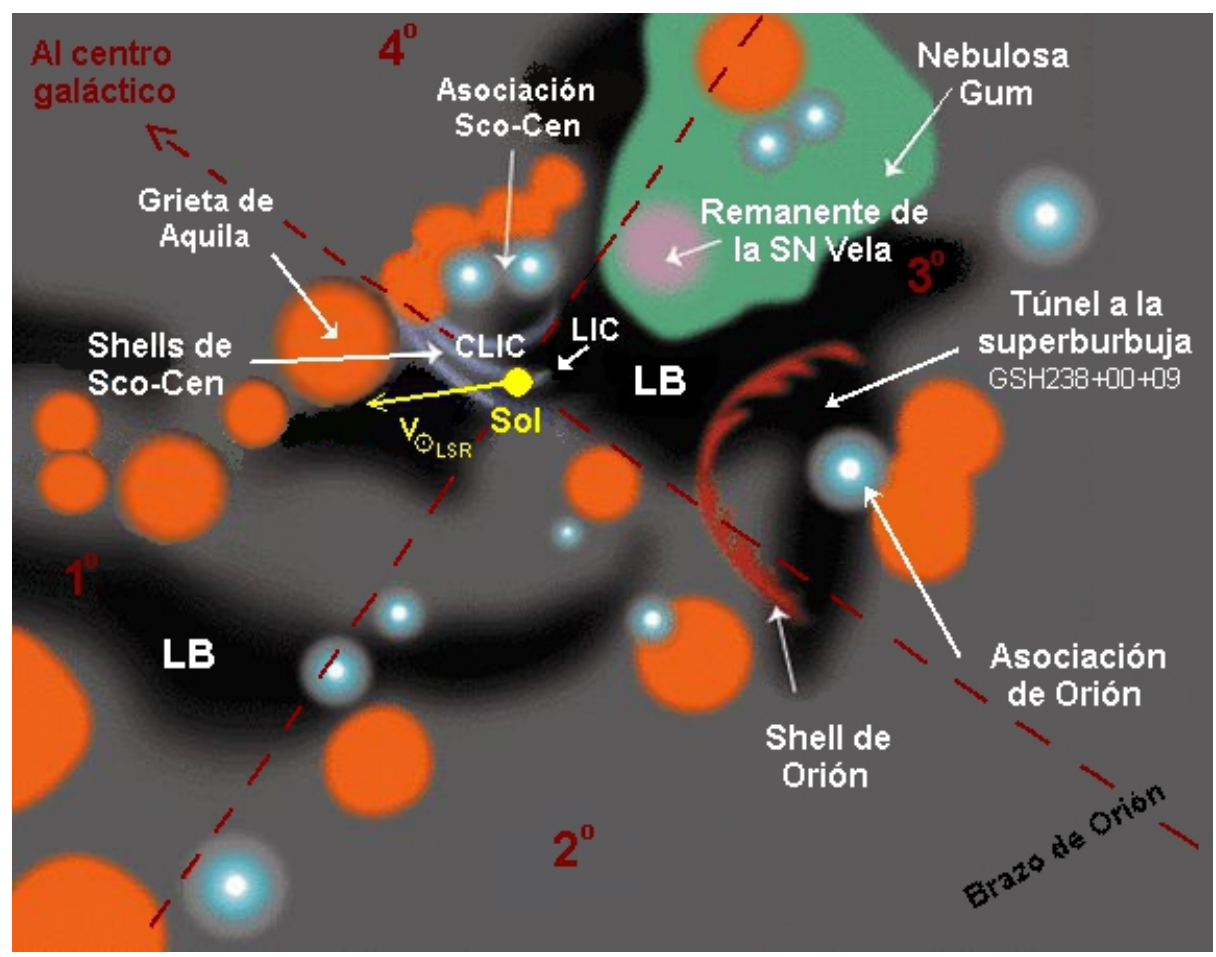

Figura 4.4.3. Entorno local del Sol donde se aprecia la $L B$, los filamentos provenientes de la Asociacion Sco-Cen, la CLIC y la LIC. Las frías nubes moleculares densas, como Aquila Rift, se muestran en naranja (Adaptado de Frisch, 2000b).

En el primer cuadrante se observan las nubes moleculares de alta densidad de la Región de Aquila-Ophiuchus incluyendo la Grieta de Aquila (Aquila Rift), mientras que el segundo cuadrante no muestra estructuras destacables. En el tercero predomina la vasta extensión de la LB, y se distinguen el túnel hacia la superburbuja GSH238+00+09 y la Nebulosa Gum, una región HII que alberga el remanente de supernova de Vela. A grandes distancias, este cuadrante está dominado por la región de formación estelar de Orión, situada a varios centenares de parsecs del Sol. En el cuarto cuadrante galáctico se aprecia el ya comentado Complejo Sco-Cen y sus filamentos asociados.

El ISM con el que la heliosfera tiene contacto directo es el LISM, y en este momento particular el LISM del SS es la LIC. Según los modelos teóricos de transferencia radiativa, el ISM cercano tendría una densidad media de $n\left(H_{t o t}\right)=0.17 \mathrm{~cm}^{-3}\left(n\left(H^{0}\right)=0.2 \mathrm{~cm}^{-3}\right.$ y $\left.n\left(H^{+}\right)=0.1 \mathrm{~cm}^{-3}\right)$ (Frisch y Slavin, 2006).

3. Nubes Difusas (DC): Son pequeñas nubes de densidad media $n_{t o t}=10 \mathrm{~cm}^{-3}$ y diámetros de $\sim 1 p c$. Actualmente el Sol se encuentra en curso de colisión con una de estas nubes: la $G$-Cloud, una nube a una distancia algo menor que $1.3 p c$ y con una densidad unas 15 - 30 veces la densidad de la LIC (Frisch, 2003; Frisch y Slavin, 2006; Florinski y Zank, 2006). En ella se adentrará el SS en unos $4.5 \times 10^{4}$ años (Frisch y Slavin, 2006). La siguiente colisión será contra la Apex Cloud, una nube con una densidad media de $\sim 3 \mathrm{~cm}^{-3}$ a $5 p c$ de distancia y se estima que el encuentro será dentro de unos $1.75 \times 10^{5}$ años (Frisch y Slavin, 2006). 
4. Nubes de Alta Velocidad (HS): Estas nubes están asociadas, por ejemplo, a los shells surgidos de regiones de formación estelar con densidades medias $n_{t o t}=0.24 \mathrm{~cm}^{-3}$.

5. Campos Magnéticos Fuertes (MF): Campos con densidades cercanas a $n_{\text {tot }}=0.3 \mathrm{~cm}^{-3}$ (Zank et al., 2006).

\subsection{Las simulaciones numéricas}

\subsubsection{Condiciones iniciales}

Las condiciones iniciales siguen lineamientos planteados en el trabajo de Di Sisto y Brunini (2007). Partiendo del hecho ya discutido que la principal fuente de la población de Centauros es el SD y que el tiempo de vida dinámica medio de los miembros de dicha población es $\sim 7 \times 10^{7}$ años, se realizaron integraciones con partículas con origen en el SD y que van evolucionando dinámicamente durante un período similar a dicho tiempo de vida dinámica, a medida que el Sol con su heliosfera atraviesa diferentes escenarios con distintas densidades. De esta forma, a partir de 120 SDOs reales extraídos de la base de datos del $\mathrm{MPC}_{3}$ y seleccionados según el criterio seguido por los mencionados autores, se generaron aleatoriamente 1880 clones, obteniéndose un total de 2000 objetos que se integraron empleando el código EVORB (Fernández et al., 2002) con un paso de 0.5 años. Las partículas no poseen masa y están bajo la acción gravitatoria del Sol y los cuatro planetas gigantes, y a la masa solar se le ha sumado la de los planetas terrestres. Las partículas evolucionan a menos que: (a) sean eliminadas por el integrador cuando alcanzan semiejes mayores superiores a las $1000 U A$; (b) colisionen con un planeta; o (c) se internen en la órbita de Júpiter, dado que en este caso las integraciones generarían resultados espurios al no intervenir los planetas terrestres. El integrador considera que una partícula es un Centauro si posee una distancia heliocéntrica más allá de la órbita de Júpiter y si su distancia perihélica es $q<30 U A$. Dados los objetivos perseguidos, no se estimó necesario tener en cuenta sesgos sobre la distribución de inclinaciones, ni sobre el semieje mayor por probabilidad de descubrimientos, como consideran otros autores (por ejemplo, Fernández et al., 2004; Di Sisto y Brunini, 2007; etc.).

\subsubsection{Los modelos incluidos en las simulaciones}

$\mathrm{Al}$ integrador original se le incluyeron un modelo de heliosfera, un modelo de densidad para el medio colisionado, y un modelo de radiación para emular la radiación recibida por las partículas que quedan fuera de la protección heliosférica.

Como modelo de heliosfera se eligió una de las variantes propuestas por Wilkin (1996), que mediante las soluciones analíticas exactas del problema clásico de Baranov, Krasnobaev y Kulikovskii (Baranov et al., 1971), proporciona un modelado estático de la cavidad heliosférica mediante la parametrización en 3D de la superficie (Figura 4.5.1),

$$
R(\theta)=R_{0} \csc \theta \sqrt{3(1-\theta \cot \theta)} .
$$

donde $\theta$ es el ángulo del radiovector heliocéntrico $\vec{R}$ medido desde el eje de simetría de la superficie, valiendo $\theta=0$ en dirección al Ápex y, dado que en esta variante la cavidad 
es abierta en la dirección al Anti-ápex, las condiciones de contorno resultan $R(0)=R_{0} \mathrm{y}$ $R(\pi)=\infty$.

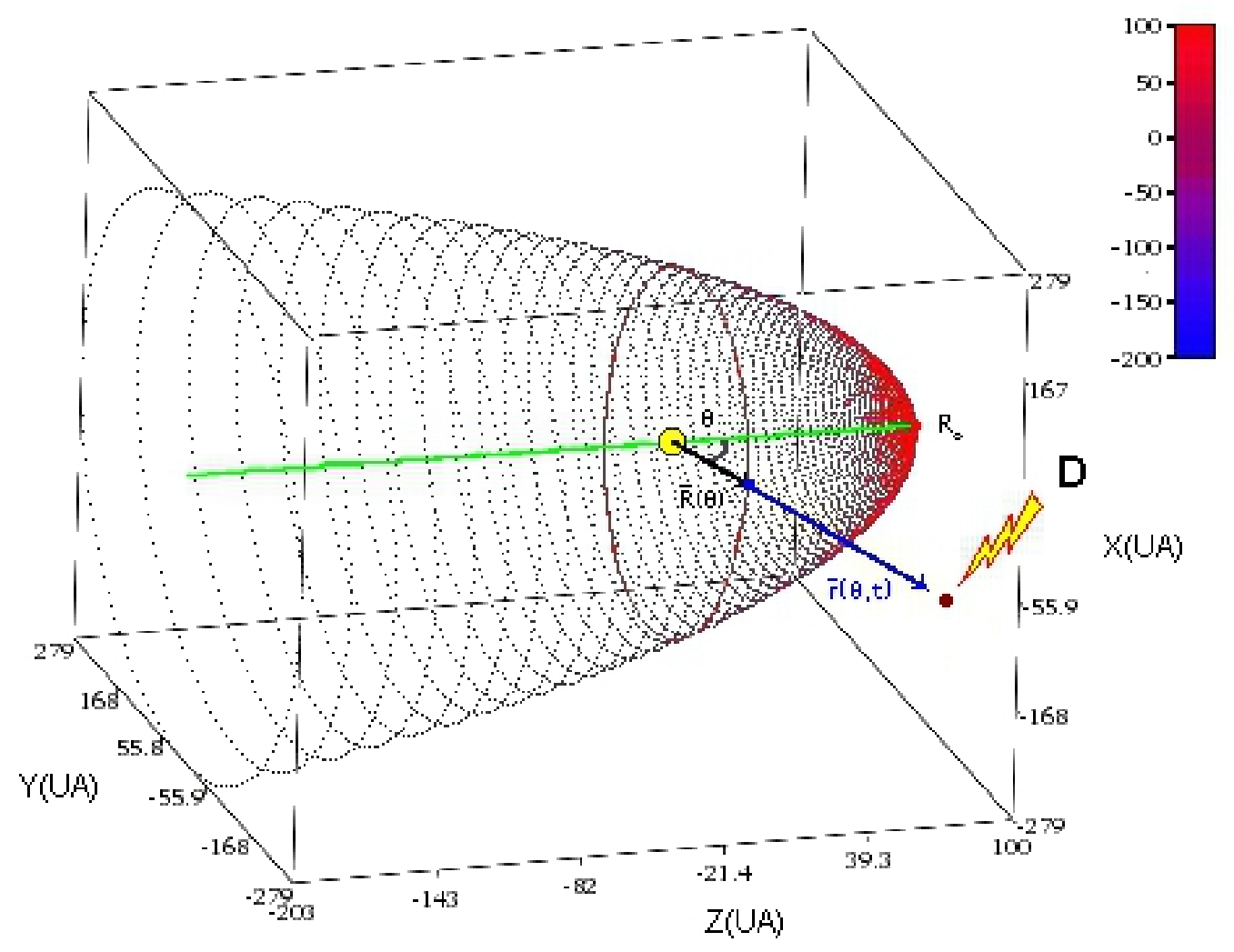

Figura 4.5.1. Ploteo del Modelo Abierto de Heliosfera de Wilkin (1996). Se indica la posición del Sol y una partícula fuera de la protección de la heliosfera siendo afectada por radiación interestelar.

De esta manera, se considerará que a un tiempo $t$ una partícula se encuentra en el interior de la heliosfera si su distancia heliocéntrica $r(\theta, t)$ satisface $r(\theta, t)<R(\theta)$. La singularidad $r(\pi, t)$ por la cual una partícula estaría en la región interna, si bien es una situación ficticia, no altera los resultados debido a que la heliosfera real se cierra en dirección al Anti-ápex recién a varios miles de UA y como se mencionó, el integrador elimina toda partícula con semieje mayor superior a $1000 U A$.

En el modelo que se acaba de describir, $R_{0}$ es la distancia constante a la que se encuentra el vértice de la superficie parametrizada y representa el polo de la heliosfera, punto en dirección al Ápex donde la misma hace contacto con el LISM generando, según Zank et al. (2006), un BS a unas $230 U A$. Gracias a los datos aportados por la sonda Voyager 1 que fue capaz de medir velocidades del SW cercanas a cero, sabemos que el TS está hoy a $\sim 94 U A$ (Stone et al., 2005). Ello nos dice que de existir el BS solar, estará a distancias superiores a las $100 U A$.

Pero, dado que cuando el SS interactúa con el LISM esa distancia $R_{0}$ se retrae o se expande según haga contacto con un medio de mayor o menor densidad que la del medio en el que se encontraba antes del encuentro, se necesita una ley que modele el medio colisionado 
y que gobierne el comportamiento de la ahora variable $R_{0}(t)$. Así, dada la densidad del medio en el que se encuentra el Sol $\left(\rho_{1}\right)$ y la densidad del medio con el que colisiona $\left(\rho_{2}\right)$, el valor al que se retraerá o expandirá el polo de la heliosfera a partir del valor de $R_{0}$ para $\rho_{1}$, está dado por la expresión

$$
R_{0}=R_{0}\left(\rho_{1}\right) \sqrt{\frac{\rho_{1}}{\rho_{2}}}
$$

donde $R_{0}\left(\rho_{1}\right)$ es la distancia heliocéntrica al polo de la heliosfera cuando el SS se mueve en un medio de densidad $\rho_{1}$. La condición de contorno que impone la situación actual del SS es que $\rho_{1}=0.21 \mathrm{~cm}^{-3}$ (densidad de la LIC) y $R_{0}\left(\rho_{1}\right)=94 U A$ (límite del TS), con lo cual si el SS emergiera de la LIC haciendo contacto con el ISM abierto $\left(\rho_{2}=0.17 \mathrm{~cm}^{-3}\right)$, el polo de la heliosfera se expandiría a una distancia heliocéntrica de $\sim 100 U A$. El modelo de densidad que se adopta en las simulaciones para el medio colisionado, propone que la densidad de éste varíe linealmente con el tiempo entre $\rho_{1}$ y $\rho_{2} \equiv \rho_{2}(t)$ hasta llegar en un tiempo $t_{N}$ a un núcleo donde la densidad permanece constante para finalmente, y durante el mismo tiempo $t_{N}$, volver a variar con la misma linealidad pero con una pendiente de signo contrario. De esta manera, la heliosfera será modelada finalmente por la expresión,

$$
R(\theta, t)=R_{0}\left(\rho_{1}\right) \csc \theta \sqrt{\frac{3 \rho_{1}(1-\theta \cot \theta)}{\rho_{2}(t)}} .
$$

Hudson et al. (2008) demostraron que una dosis de $100 \mathrm{eV} / 16 \mathrm{amu}$ es capaz de producir un cambio significativo en la química de los materiales irradiados. Precisamente, una superficie irradiada que interactúa con partículas cargadas del ISM por $\sim 1.5 \times 10^{5}$ años acumula dosificaciones del orden de los $100 \mathrm{eV} / 16 \mathrm{amu}$ y es a partir de esos valores que comienza a desarrollarse la mencionada corteza orgánica, que terminará modificando el color y el albedo del objeto (Strazzulla et al., 2003). De esta manera, y con el fin de estudiar los efectos de la radiación recibida por las partículas que quedan sin la protección heliosférica, incluimos en el integrador un modelo de radiación por el cual a toda partícula cuya distancia heliocéntrica $r(\theta, t)$ está más allá del borde de la heliosfera $R(\theta, t)$ (Figura 4.5.1), se le aplica una dosis de radiación proporcional al tiempo en el que la misma permanece fuera de ésta, según la ecuación

$$
D=\frac{100}{1.5 \times 10^{5}} h
$$

donde $h$ es el paso de integración en años y $D$ tiene unidades de $e V / 16 a m u$.

\subsubsection{Los escenarios de encuentro}

Como se describió anteriormente, sabemos que si se simulan encuentros del SS con medios con densidades aproximadamente iguales a $n_{t o t}=0.17 \mathrm{~cm}^{-3}$ (ISM), $0.003 \mathrm{~cm}^{-3}$ (LB), $0.21 \mathrm{~cm}^{-3}$ (LIC, HS, MF) y $10 \mathrm{~cm}^{-3}$ (DC), se habrán considerado todos los escenarios con mayor probabilidad de ocurrencia. Basados en esa idea se dividió la integración total de $7 \times 10^{7}$ años en siete etapas que constituyen los siete escenarios por los que se hace viajar al SS sin solución de continuidad, con el fin de ir analizando los porcentajes de Centauros que reciben dosis de radiación lo suficientemente altas. Si bien no se pretende en absoluto representar una historia real de la trayectoria seguida por nuestro Sol a través del ISM, se plantean escenarios perfectamente posibles basados en los hechos conocidos de su historia pasada y en 
las predicciones fundadas sobre su historia futura, y que ya fueran discutidos oportunamente en párrafos anteriores.

Para calcular los tiempos de cruce del SS de los diversos medios y así poder estimar tiempos de integración apropiados para cada etapa, se impone conocer la velocidad del Sol. La comparación entre la posición del SS y la de objetos espacialmente definidos requiere la adopción de un marco de referencia de velocidades. De esta forma, el movimiento del Sol respecto a la cinemática de cierto conjunto de estrellas cercanas $(<500 p c)$, conocido como Solar Apex Motion, define una hipotética órbita circular cerrada alrededor del centro galáctico que da un marco inercial instantáneo llamado Local Standard of Rest (LSR). Todos los valores del LSR indican que actualmente el Sol se encuentra a $\sim 8 \times 10^{3} p c$ del centro galáctico, en el tercer cuadrante de la Galaxia $\left(l=180^{\circ} \rightarrow 270^{\circ}\right)$ y se mueve a una velocidad de $13-20 \times 10^{-6}$ pcaño $o^{-1}$. El movimiento orbital medio alrededor del centro de la Vía Láctea de las estrellas cercanas al Sol es $\sim 220 \mathrm{~km} \mathrm{seg}^{-1}$ y la velocidad solar está estimada en $\sim 225 \pm 20 \mathrm{~km} \mathrm{seg}^{-1}$ (Frisch y Slavin, 2006). Es de notar que la definición del LSR es sensible a la selección de las estrellas de comparación, ya que los movimientos medios y la dispersión de poblaciones estelares dependen de las masas estelares. La transformación de la trayectoria solar en el LSR para la comparación con los objetos espacialmente definidos, introduce incertidumbres relacionadas con el mismo.

A continuación se presentan tres experimentos diferentes con sus respectivas simulaciones numéricas.

\subsubsection{Resultados}

\section{Experimento 1}

Los escenarios diseñados para los experimentos numéricos desarrollados en el Experimento 1, se esquematizan en una línea de tiempo en la Figura 4.5.2, y se describen a continuación:

Etapa I: El Sol tiene un encuentro con un medio con la misma densidad del ISM $\left(0.17 \mathrm{~cm}^{-3}\right.$; Frisch y Slavin, 2006) durante los primeros $2.5 \times 10^{7}$ años de integración.

Etapa II: Emergiendo del medio de la primera etapa, el SS hace contacto con un medio con la densidad media de la LB $\left(0.003 \mathrm{~cm}^{-3}\right.$; Lallement, 2004; Zank et al., 2006) y permanece en ella por $10^{7}$ años.

Etapa III: Ya se comentó que hace unos $0.44-1.5 \times 10^{5}$ años el Sol entró en contacto con la LIC, una tenue nube inmersa en la LB y se estima que permanecerá en ella unos $3.7 \times 10^{3}$ años más (Frisch, 2006; Frisch y Slavin, 2006). En esta etapa se propone, entonces, un encuentro con un medio de la densidad estimada para la LIC $\left(0.21 \mathrm{~cm}^{-3}\right.$; Zank et al., 2006; Frisch y Slavin; 2006, Florinski y Zank, 2006) por $10^{5}$ años, una aproximación al tiempo medio total que se estima que el SS habrá realmente permanecido en la LIC.

Etapa IV: Dado que se estima que el SS luego de salir de la LIC reingresará en la LB donde permanecerá $4.5 \times 10^{4}$ años hasta su colisión con la G-Cloud (Frisch y Slavin, 2006), en esta etapa se propone estudiar las consecuencias del encuentro con un medio de densidad $0.003 \mathrm{~cm}^{-3}$ por dicho lapso. 
Etapa $V$ : Resulta natural que el próximo escenario sea la colisión con una nube de densidad igual a $10 \mathrm{~cm}^{-3}$, compatible a la estimada para la G-Cloud $\left(6-10 \mathrm{~cm}^{-3}\right)$. Teniendo en cuenta que dentro de un radio de distancia heliocéntrica de $10 p c$ las nubes poseen diámetros $\sim 1 p c$ y que en estos casos el tiempo medio de cruce para el Sol está estimado en $\sim 6.8 \times 10^{4}$ años (Frisch y Slavin, 2006), se elige integrar en esta etapa por $7 \times 10^{4}$ años.

Etapa VI: Una vez atravesada dicha nube, nuestro sistema ingresa nuevamente a un medio que nos vuelve a remitir a la LB y permanece en él por $3.47 \times 10^{7}$ años.

Etapa VII: En el tramo final de la simulación se propone estudiar las consecuencias de la travesía durante $5 \times 10^{4}$ años por un medio de densidad igual a $3 \mathrm{~cm}^{-3}$, densidad similar a la estimada para la Apex Cloud con quien se espera un encuentro del SS en $\sim 1.75 \times 10^{5}$ años (Frisch y Slavin, 2006), y de esta manera se completa el tiempo total de integración de $7 \times 10^{7}$ años.

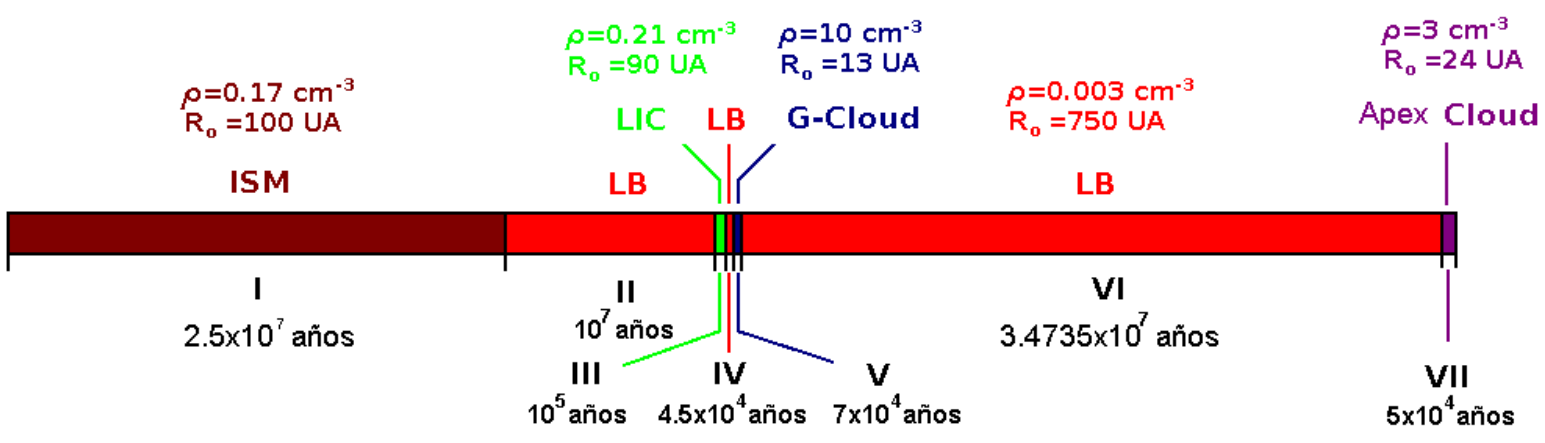

Figura 4.5.2. Línea de tiempo de la integración en siete etapas. $\rho$ : Densidad del medio que el SS atraviesa en la etapa correspondiente. $R_{0}$ : Distancia heliocéntrica extrema a la que llega el polo de la heliosfera en la etapa correspondiente.

Dado que el tiempo de encuentro con nubes HI de densidades del orden de $\sim 10 \mathrm{~cm}^{-3}$ es de unos $2.7 \times 10^{7}$ años (Yeghikyan y Fahr, 2006), en los $7 \times 10^{7}$ años que duran los experimentos es esperable el encuentro con a lo sumo dos medios de esas densidades. Ello justifica nuestra elección de medios de esas características en sólo dos etapas, la V y la VII.

Todas las partículas comienzan cada simulación con dosis de radiación nula y la radiación con la que cada partícula comienza una nueva etapa es la radiación con la que finalizó la etapa anterior. Se llamará "partícula sobredosificada" (PS) a toda partícula que recibe una dosis de radiación superior a $100 \mathrm{eV} / 16 \mathrm{amu}$.

Se realizaron cinco integraciones que repetían el Experimemnto 1, obteniéndose siempre el mismo resultado estadístico. El $93.3 \%$ de las partículas sobrevivieron al tiempo total de integración. El $5 \%$ se interna en la órbita de Júpiter constituyéndose algunos de ellos en posibles JFCs, mientras que el $1.7 \%$ restante es eyectado del sistema o colisiona con uno de los planetas. Dado el corto tiempo de integración, sólo el $6.5 \%$ termina en la región de Centauros. En la tabla de la Figura 4.5.3 se resumen los resultados al final de cada etapa. 
La Etapa I termina a los $2.5 \times 10^{7}$ años de comenzado el experimento y se observa que de las 2000 partículas iniciales terminan en la región de Centauros un $24.4 \%$ de partículas PS, mientras que los SDOs sobredosificados constituyen el $16.3 \%$ de los objetos sobrevivientes de esta población. Es importante notar que ese último porcentaje permanece prácticamente constante en todas las etapas.

Finalizada la Etapa II, cuya duración es de $10^{7}$ años, el $19.5 \%$ de los Centauros resultan ser partículas PS, mientras que entre los SDOs un $16.4 \%$ termina en tal condición.

En las Etapas III, IV y V, notoriamente más cortas que las dos primeras, los Centauros PS con los que termina cada una arrojan resultados similares en términos porcentuales entre sí y en relación a los obtenidos al final de la Etapa II, lo que resulta un claro indicio de que el paso del SS por esos tres últimos escenarios no altera significativamente las superficies de la población, pese a que el SS atraviesa en dichas etapas escenarios de muy diferentes densidades.

Este es un resultado parcial muy relevante ya que parece quedar claro que si la heliosfera al atravesar un medio dado sufre variaciones muy grandes pero por períodos relativamente cortos (por ejemplo, del orden de los tiempos empleados para cruzar las nubes HI), éstas variaciones resultan insuficientes para que una vez atravesado dicho medio, se haya generado un número significativo de partículas PS, ya sea o bien porque no se llegue a los tiempos dinámicos necesarios para que una partícula con origen en el SD -sobredosificada o no- sea inyectada en la región de Centauros, o porque en esos breves lapsos una partícula con una órbita excéntrica -como es el caso de la mayoría de los de Centauros-, entrando y saliendo de la heliosfera, no llegue a acumular suficientes dosis de radiación como para enrojecer su superficie.

Todo ello nos conduce a una primera conclusión y es que por sí sola una reducción de tamaño experimentada por la heliosfera en el cruce de un medio dado, no es suficiente para que se genere una bimodalidad de colores en la población de Centauros.

De la tabla de la Figura 4.5.3 parece quedar claro que luego de $7 \times 10^{7}$ años de integración aproximadamente el $23 \%$ de las partículas que terminan como Centauros han recibido radiación suficiente como para que sus superficies queden enrojecidas u oscurecidas, mientras que el resto no alcanza a recibir suficiente dosis de irradiación. Esos porcentajes se mantienen relativamente constantes para todas las etapas pero tiene sus picos máximos en las etapas de mayores tiempos de integración, es decir, en la I y en la VI, etapas que involucran medios de densidades muy dispares. Por otro lado, el porcentaje de las PS que finalizan como SDOs es prácticamente siempre el mismo y no tiene saltos de una etapa a la siguiente. 


\begin{tabular}{|l|c|c|c|c|c|}
\cline { 2 - 6 } \multicolumn{1}{c|}{} & $\rho\left(\mathrm{cm}^{-1}\right)$ & $\mathrm{R}_{0}(\mathrm{UA})$ & $\mathrm{t}\left(10^{6}\right.$ años $)$ & $\sim \% \mathrm{PSC}_{\mathrm{C}}$ & $\sim \% \mathrm{PSSDO}_{\mathrm{SD}}$ \\
\hline Etapa I & 0.17 & 100 & 25 & 24.4 & 16.3 \\
\hline Etapa II & 0.003 & 752.71 & 10 & 19.5 & 16.4 \\
\hline Etapa III & 0.21 & 89.97 & 0.1 & 18.8 & 16.8 \\
\hline Etapa IV & 0.003 & 752.71 & 0.046 & 18.8 & 17 \\
\hline Etapa V & 10 & 13.04 & 0.07 & 19.2 & 17.4 \\
\hline Etapa VI & 0.003 & 752.71 & 34.735 & 24.1 & 17.5 \\
\hline Etapa VII & 3 & 23.8 & 0.05 & 23.1 & 18.1 \\
\hline
\end{tabular}

Figura 4.5.3. Experimento 1: $\rho_{1}$ : Densidad del medio que el SS atraviesa en la etapa correspondiente; $R_{0}$ : Distancia heliocéntrica extrema a la que llega el polo de la heliosfera; $t$ : Tiempo que tarda el SS en atravesar el medio; $\% P S_{C}$ : Porcentaje de Centauros PS con el que termina cada etapa; \%PS $S_{S D O}$ : Porcentaje de SDOs al final de cada etapa.

El histograma de la Figura 4.5.4 muestra la cantidad de Centauros que han recibido radiaciones en los rangos 0-100 eV/16amu, 100-1000 eV/16amu y mayores que $1000 \mathrm{eV} / 16 \mathrm{amu}$, al final de cada etapa.
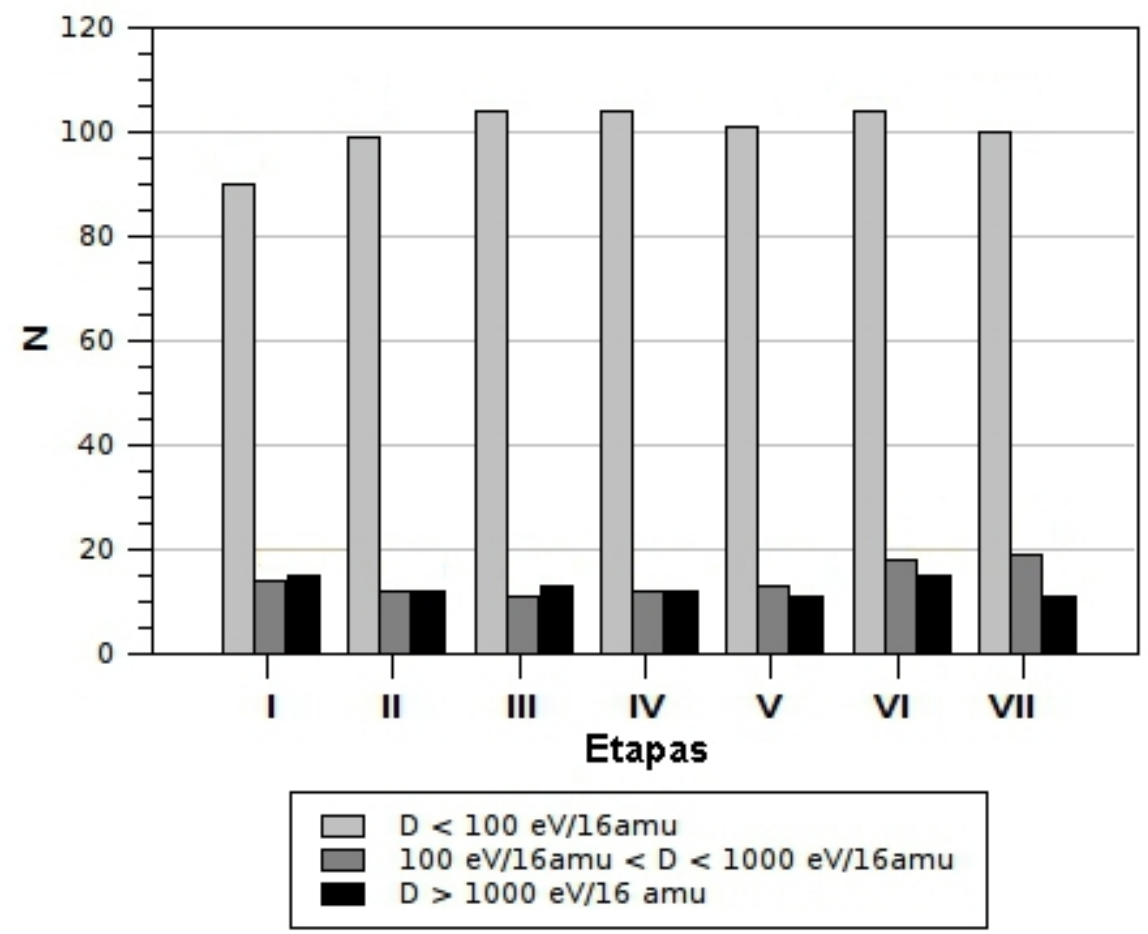

Figura 4.5.4. Experimento 1: Histograma de la cantidad de Centauros que sobrevive en cada etapa, según el rango de dosis recibidas.

En el caso de las PS que terminan como Centauros, prácticamente la mitad ha recibido una dosis entre $100-1000 \mathrm{eV} / 16 \mathrm{amu}$ y la otra mitad una dosis superior a $1000 \mathrm{eV} / 16 \mathrm{amu}$ (Figura 4.5.5). Ello no se observa en el caso de las partículas PS que terminan como SDOs, donde el porcentaje de partículas con dosis superiores a $1000 \mathrm{eV} / 16 \mathrm{amu}$ es tres veces mayor que la cantidad de esas partículas con dosis entre $100-1000 \mathrm{eV} / 16 a m u$ (Figura 4.5.6). 


\begin{tabular}{|l|c|c|c|}
\cline { 2 - 4 } \multicolumn{1}{c|}{} & \multicolumn{3}{c|}{ PS } \\
\cline { 2 - 4 } \multicolumn{1}{c|}{} & $\%$ Dc $<100$ & $100<\sim \% \mathrm{Dc}<1000$ & $\sim \% \mathrm{Dc}>1000$ \\
\hline Etapa I & 75.6 & 11.8 & 12.6 \\
\hline Etapa II & 80.5 & 9.75 & 9.75 \\
\hline Etapa III & 81.2 & 8.6 & 10.2 \\
\hline Etapa VV & 81.2 & 9.4 & 9.4 \\
\hline Etapa V & 80.8 & 10.4 & 8.8 \\
\hline Etapa VI & 75.9 & 13.1 & 11 \\
\hline Etapa VII & 76.9 & 14.6 & 8.5 \\
\hline
\end{tabular}

Figura 4.5.5. Experimento 1: Porcentaje de Centauros que sobreviven al final de cada etapa y el rango de dosis recibida en eV/16amu.

\begin{tabular}{|l|c|c|c|}
\cline { 3 - 4 } \multicolumn{1}{c|}{} & \multicolumn{3}{c|}{ PS } \\
\cline { 2 - 4 } \multicolumn{1}{c|}{} & $\sim \%$ DsDo $<100$ & $100<\sim \%$ DsDo $<1000$ & $\sim \%$ Dsdo $>1000$ \\
\hline Etapa I & 83.7 & 3.9 & 12.4 \\
\hline Etapa II & 83.58 & 3.9 & 12.5 \\
\hline Etapa III & 83.15 & 4.1 & 12.8 \\
\hline Etapa IV & 83.03 & 4 & 13 \\
\hline Etapa V & 82.56 & 4.5 & 12.9 \\
\hline Etapa VI & 82.45 & 4.5 & 13.07 \\
\hline Etapa VII & 81.86 & 4.9 & 13.23 \\
\hline
\end{tabular}

Figura 4.5.6. Experimento 1: Porcentaje de SDOs al final de cada etapa y el rango de dosis recibida en eV/16amu.

Finalizadas las etapas de cortos tiempos de integración se observan poblaciones de Centauros PS muy similares incluso en aquellas donde la heliosfera sufre las mayores retracciones y sólo hay incrementos en la cantidad de miembros sobredosificados al final de las etapas donde el SS permanece por más tiempo. En cuanto a los SDOs sobredosificados, todas las etapas terminan con un promedio cercano al $17 \%$, con lo cual de evolucionar alguna de ellas hacia la región de Centauros, lo hará con su superficie ya afectada.

\section{Experimento 2}

Dado que los resultados del Experimento 1 parecen mostrar que la variación del tamaño de la heliosfera no tiene una influencia de peso en la generación de PS, se decidió llevar adelante un segundo experimento con el fin de analizar más profundamente ese hecho. Así, se integró nuevamente a lo largo de $7 \times 10^{7}$ años, pero esta vez con el SS atravesando un único medio con una densidad de $0.17 \mathrm{~cm}^{-3}$, comparable a la densidad media del ISM. Ello implica una heliosfera estática con un polo constante en $R_{0}=100 \mathrm{U} A$ durante todo el tiempo de integración. El resultado fue que el $51.5 \%$ de las partículas que terminaron en la región de Centauros lo hicieron como PS, mientras que de aquellas que finalizaron como SDOs, el $22.8 \%$ terminaron en tal condición. Los resultados se resumen en la tabla de la Figura 4.5.7 y se grafican en el histograma de la Figura 4.5.8. 


\begin{tabular}{|l|c|c|c|}
\cline { 3 - 4 } \multicolumn{1}{c|}{} & $\sim \% \mathrm{D}<100$ & $100<\sim \% \mathrm{D}<1000$ & $\sim \% \mathrm{D}>1000$ \\
\hline Centauros & $\mathbf{4 8 . 5}$ & $\mathbf{1 4 . 6}$ & $\mathbf{3 6 . 9}$ \\
\hline SDOs & $\mathbf{7 7 . 2}$ & 3.7 & $\mathbf{1 9 . 1}$ \\
\hline
\end{tabular}

Figura 4.5.7. Experimento 2: Porcentaje de Centauros y SDOs, luego de integrar por $7 \times 10^{7}$ años con una heliosfera estática con polo en $R_{0}=100 U A$.

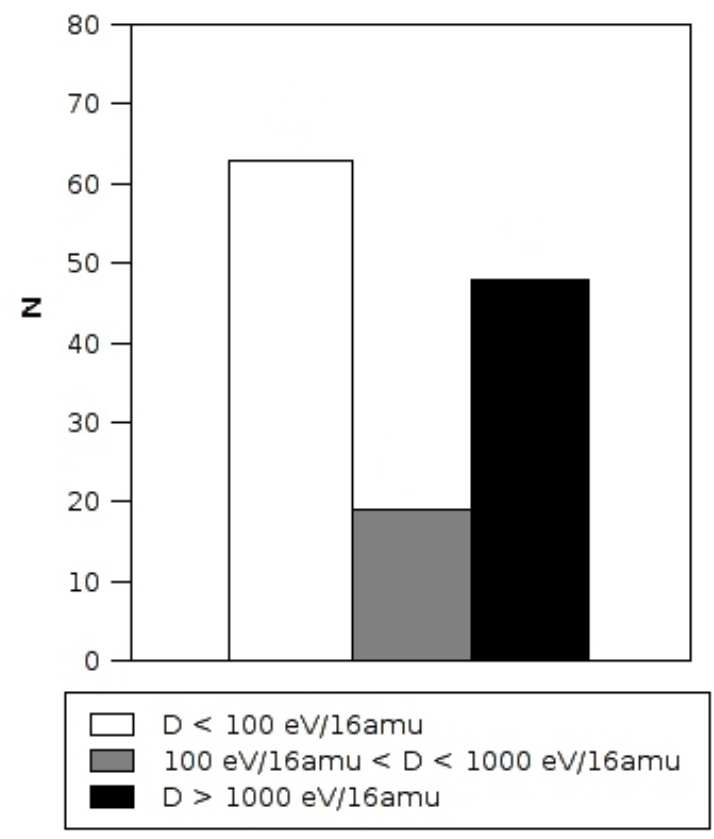

Figura 4.5.8. Experimento 2: Histograma que muestra la cantidad de partículas que terminan en la región de Centauros luego de integrar por $7 \times 10^{7}$ años con una heliosfera estática con polo en $R_{0}=100 U A$, según el rango de dosis recibidas.

En el Experimento 1 veíamos que se hizo atravesar al SS durante casi el $\sim 60 \%$ del tiempo total de integración por un medio de densidad muy baja -Etapas II y VI- que expandió la heliosfera llevando su polo más allá de las $700 U A$, lo que propició la protección de la casi totalidad de las partículas a la radiación exterior, y en particular a prácticamente todos los Centauros. Ello explicaría por qué al final de aquella integración sólo el $23 \%$ de los Centauros resultó PS pese a que durante ciertos momentos -aunque breves- la heliosfera llegó a contraerse fuertemente, mientras que al final de este Experimento 2, donde durante todo el tiempo de integración la heliosfera permaneció expandida hasta muy entrada la región del SD, la cantidad de Centauros sobredosificados llegó a más del $50 \%$. Es importante notar que en términos de colores superficiales, en ambas simulaciones se observan dos poblaciones de Centauros bien definidas. 


\section{Experimento 3}

Finalmente, un tercer experimento tuvo la finalidad de disipar la duda que se generó acerca de la posibilidad de que luego de integrar durante suficiente tiempo todas las partículas terminen con dosis mayores que $100 \mathrm{eV} / 16 \mathrm{amu}$, por simple acumulación. Entonces, se realizó una nueva integración a lo largo de $10^{9}$ años, un tiempo del orden de la edad del SS, con las mismas condiciones iniciales de siempre y en este caso como en el experimento anterior, con una heliosfera estática con su polo en $R_{0}=100 \mathrm{UA}$. Los resultados para la población de Centauros pueden verse en la Figura 4.5.9, donde se grafican los porcentajes de PS a medida que evoluciona el sistema.

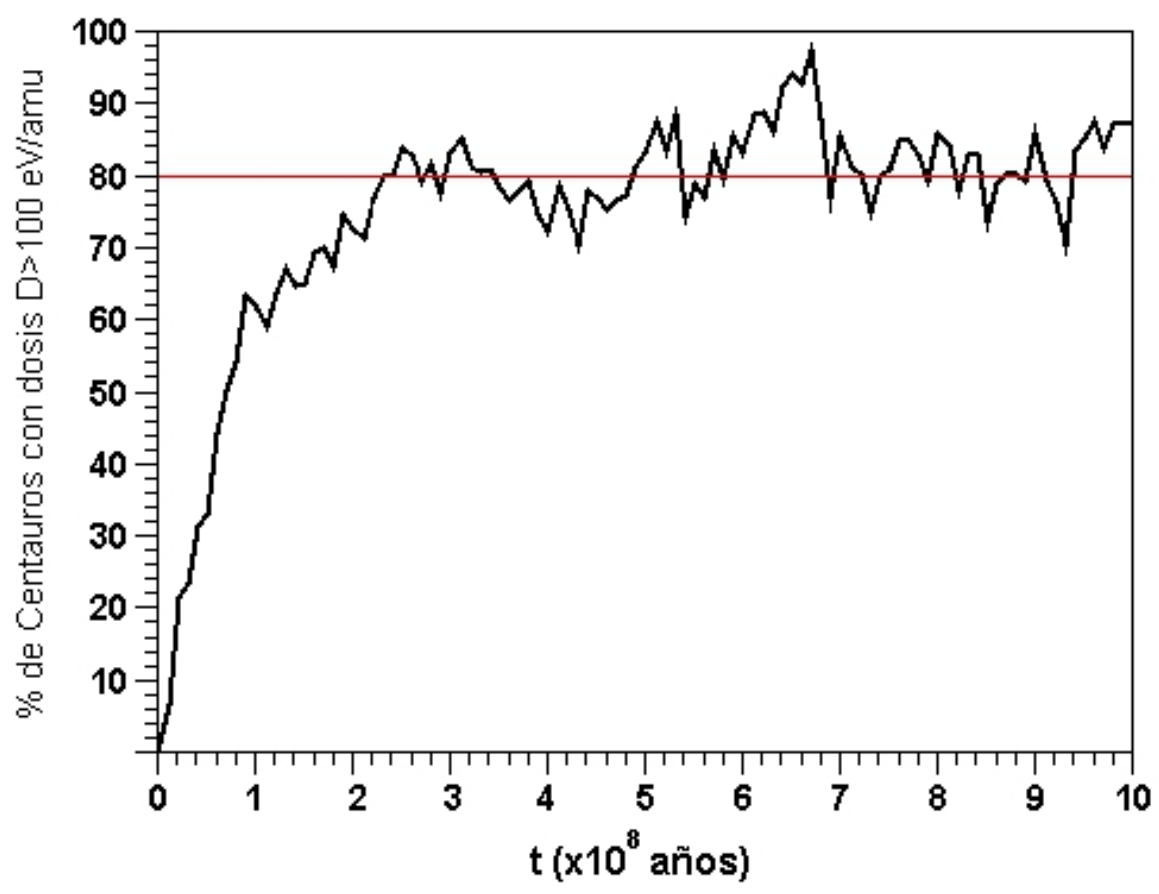

Figura 4.5.9. Experimento 3: Evolución temporal del porcentaje de Centauros con dosis mayores que $100 \mathrm{eV} / 16 a m u$ a lo largo de $10^{9}$ años. Se observa una estabilización de los porcentajes alrededor del $80 \%$.

Luego de transcurrido el $20 \%$ del tiempo total de integración el porcentaje de PS se estabiliza con cierta dispersión alrededor del $80 \%$, indicando que la cantidad de Centauros sobredosificados no crece de manera continua a medida que pasa el tiempo, despejando así nuestra duda inicial. La dispersión mencionada es debida a que la población de Centauros se renueva permanentemente y como siempre es una población muy pequeña en relación al total de las partículas que sobreviven, una pequeña variación en su número de miembros provoca las bruscas fluctuaciones que observamos. Por lo tanto, según nuestros resultados, alrededor del $80 \%$ de las partículas terminan con superficies irradiadas y fuertemente irradiadas.

En principio, este último porcentaje contradice los datos observacionales. En efecto, nuestro experimento indicaría que las dosis recibidas ayudan a formar superficies muy o poco irradiadas en porcentajes cercanos al $80 \%$ y al $20 \%$, respectivamente. Si se asume que la 
irradiación produce superficies enrojecidas, observacionalmente encontramos que sobre una muestra de 33 Centauros con $q<20 U A$, alrededor del $36 \%$ son rojos mientras que el $64 \%$ restante es neutro (Peixinho et al., 2012; Melita y Licandro, 2012) (tabla de la Figura 4.5.10). Esta diferencia puede deberse a diferentes razones. En primer lugar una sobreirradiación produce superficies de bajo albedo pero neutras, lo que podría modificar los porcentajes obtenidos considerando los colores producidos en lugar del grado de irradiación. Particularmente, si consideramos que se obtienen colores rojos con dosis de irradiación en el rango $100 \mathrm{eV} / 16 \mathrm{amu}<\mathrm{D}<1000 \mathrm{eV} / 16 \mathrm{amu}$, los porcentajes de objetos enrojecidos respecto de los neutros obtenidos en la simulación son similares a los observados.

\begin{tabular}{|c|c|c|c|}
\hline NombreNomenclatura & (B-R) & $\operatorname{err}(B-R)$ & q (UA) \\
\hline (2060) Chiron & 1.010 & 0.044 & 8.46 \\
\hline $2002 \mathrm{DH} 5$ & 1.054 & 0.075 & 13.94 \\
\hline 2007 UM126 & 1.080 & 0.096 & 8.55 \\
\hline (119315) $20015 Q 73$ & 1.130 & 0.020 & 14.47 \\
\hline$(87555) 2000$ QB243 & 1.134 & 0.144 & 15.28 \\
\hline (10370) Hylonome & 1.153 & 0.081 & 18.83 \\
\hline (54598) Bienor & 1.158 & 0.075 & 13.21 \\
\hline $2000 \mathrm{FZ} 53$ & 1.170 & 0.050 & 12.33 \\
\hline (32532) Thereus & 1.190 & 0.032 & 8.59 \\
\hline (63252) 2001 BL41 & 1.199 & 0.045 & 6.83 \\
\hline (95626) 2002 GZ32 & 1.199 & 0.075 & 18.01 \\
\hline (8405) Asbolus & 1.228 & 0.057 & 6.88 \\
\hline (136204) $2003 \mathrm{WL} 7$ & 1.230 & 0.040 & 14.96 \\
\hline (52872) Okyrhoe & 1.237 & 0.086 & 5.78 \\
\hline $2007 \mathrm{RH} 283$ & 1.237 & 0.069 & 10.57 \\
\hline (120061) $2003 \mathrm{CO}$ & 1.240 & 0.040 & 10.91 \\
\hline (49036) Pelion & 1.248 & 0.096 & 17.32 \\
\hline (342842) 2008 YB3 & 1.260 & 0.017 & 6.49 \\
\hline$(73480) 2002$ PN34 & 1.280 & 0.022 & 13.37 \\
\hline (10199) Chariklo & 1.299 & 0.065 & 13.05 \\
\hline \multirow{2}{*}{ (60558) Echeclus } & 1.376 & 0.072 & 5.82 \\
\hline & salto & & \\
\hline (31824) Elatus & 1.672 & 0.071 & 7.29 \\
\hline$(121725) 1999 \times \times 143$ & 1.734 & 0.145 & 9.69 \\
\hline (281371) $2008 \mathrm{FC7} 6$ & 1.756 & 0.024 & 10.18 \\
\hline (52975) Cyllarus & 1.803 & 0.102 & 16.34 \\
\hline (88269) $2001 \mathrm{KF} 77$ & 1.810 & 0.040 & 19.78 \\
\hline (55576) Amycus & 1.814 & 0.044 & 15.17 \\
\hline (44594) 1999 0X3 & 1.832 & 0.112 & 17.58 \\
\hline$(7066)$ Nessus & 1.847 & 0.165 & 11.80 \\
\hline (83982) Crantor & 1.864 & 0.044 & 14.03 \\
\hline (111444) $2001 \times Z 255$ & 1.910 & 0.070 & 15.44 \\
\hline $1994 \mathrm{TA}$ & 1.930 & 0.155 & 11.79 \\
\hline (5145) Pholus & 1.970 & 0.108 & 8.65 \\
\hline
\end{tabular}

Figura 4.5.10. Centauros con índices (B-R) determinados. Índices extraídos de Peixinho et al. (2012) y de Melita y Licandro (2012), estos últimos destacados en negrita. Se delimita el salto en color entre $1.4<(B-R)<1.7$ que manifiesta la bimodalidad de colores en la población. Calculamos las distancias perihélicas con datos de Bowell (2012).

En segundo término, siendo que la mayor cantidad de Centauros poseerían $20 U A<q<$ $30 U A$ (Di Sisto y Brunini, 2007), la característica compartida de $q<20 U A$ por todos los 
Centauros de la muestra nos lleva a pensar en un sesgo observacional consistente en que los Centauros que tienen distancias perihélicas más pequeñas no sólo tienen más probabilidades de ser descubiertos sino que además son más propensos a activarse y renovar en parte su superficie (Melita y Licandro, 2012). Particularmente, en el gráfico de la Figura 4.5.11 podemos ver la evolución del sistema en este experimento a lo largo de toda la integración en función de la distancia perihélica y de las dosis recibidas por las partículas, donde se aprecia que las partículas con mayores $q$ son las que acumulan las dosis de radiación más altas, por lo cual sería de esperar que a medida que se vaya determinando el índices de color de Centauros con distancias perihélicas mayores que $20 U A$, es muy probable que la proporción neutros/rojos observada en la actualidad se modifique.

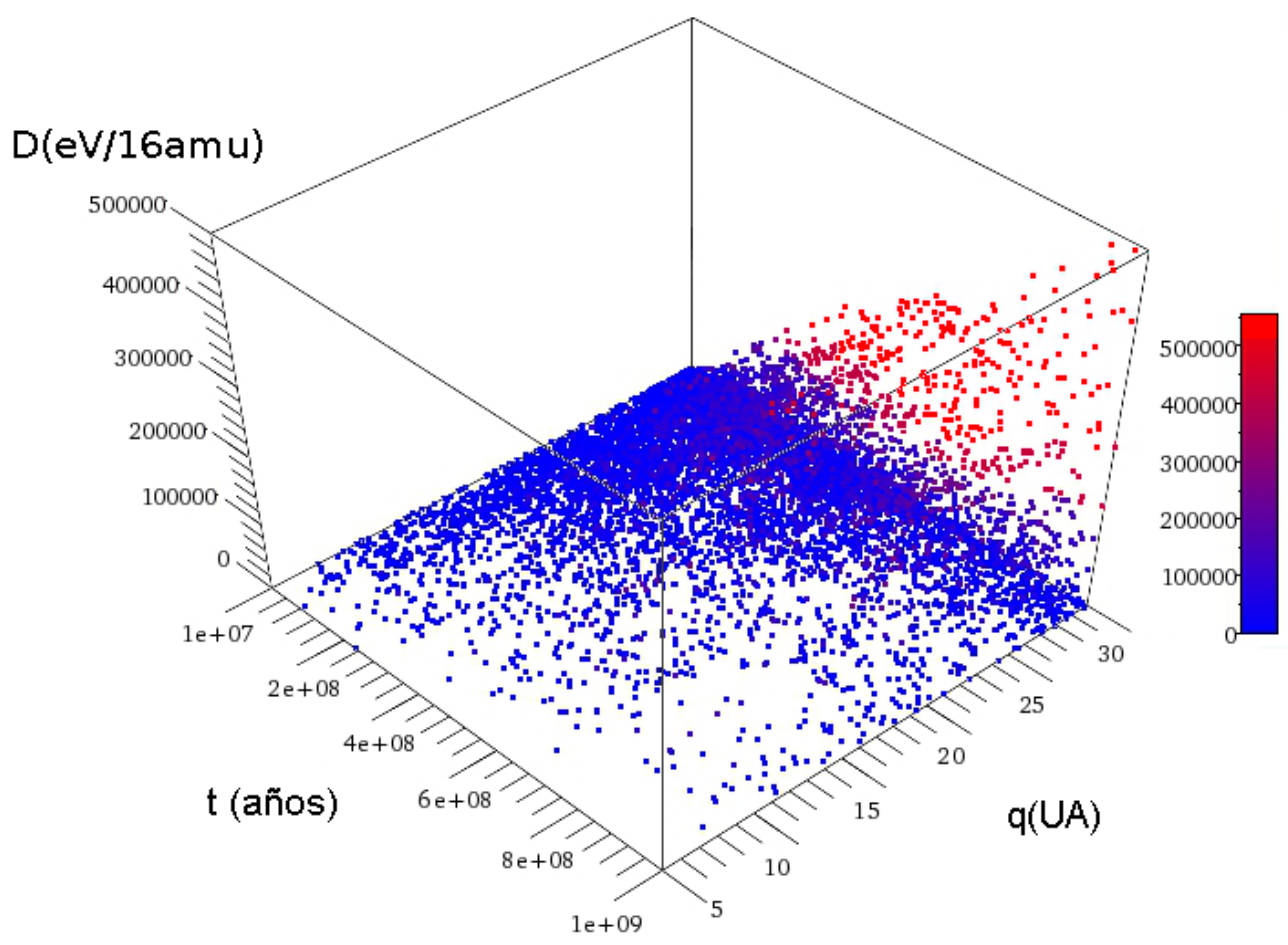

Figura 4.5.11. Experimento 3: Gráfico de $q$ vs. $D$ a lo largo de toda la integración de $10^{9}$ años. Se observa que los objetos que reciben dosis más altas son los que poseen mayores distancias perihélicas, y por lo tanto, los más difíciles de detectar.

Finalmente, los tres experimentos confirman que la mera existencia de la heliosfera -incluso una heliosfera estática- y su propiedad protectora ante las partículas cargadas provenientes del ISM, sería suficiente para definir dos ambientes diferentes capaces de generar una bimodalidad de colores en una población con miembros cuyas órbitas son lo suficientemente alargadas para que los objetos visiten ambos ambientes, si se integra durante tiempos suficientemente prolongados.

Por otro lado, en cuanto a las partículas que al final de la integración forman la población del SD, los resultados se muestran en la Figura 4.5.12 donde se observa que las PS inicialmente experimentan un crecimiento brusco, para rápidamente estabilizarse alrededor del $35 \%$ 
durante la mayor parte del tiempo total integrado. Nuevamente queda en evidencia, esta vez para el caso de los SDOs, que no todas las partículas terminan sobredosificadas por más que se integre por tiempos muy prolongados. Incluso en éste caso, luego de $10^{9}$ años los SDOs sobredosificados conforman una minoría respecto de los SDOs que han recibido muy poca dosificación o ninguna. Es de notar que muchos de los SDOs grises que se convertirán en un futuro en Centauros, eventualmente podrán seguir su proceso de enrojecimiento en su nuevo hábitat; pero también es destacable que ya hay en el SD $~ 35 \%$ de objetos con superficies irradiadas listos para inyectarse en la región de Centauros, hecho que aportaría una cantidad extra de miembros al grupo de los Centauros rojos, sin necesidad de esperar procesos de evolución superficial in situ.

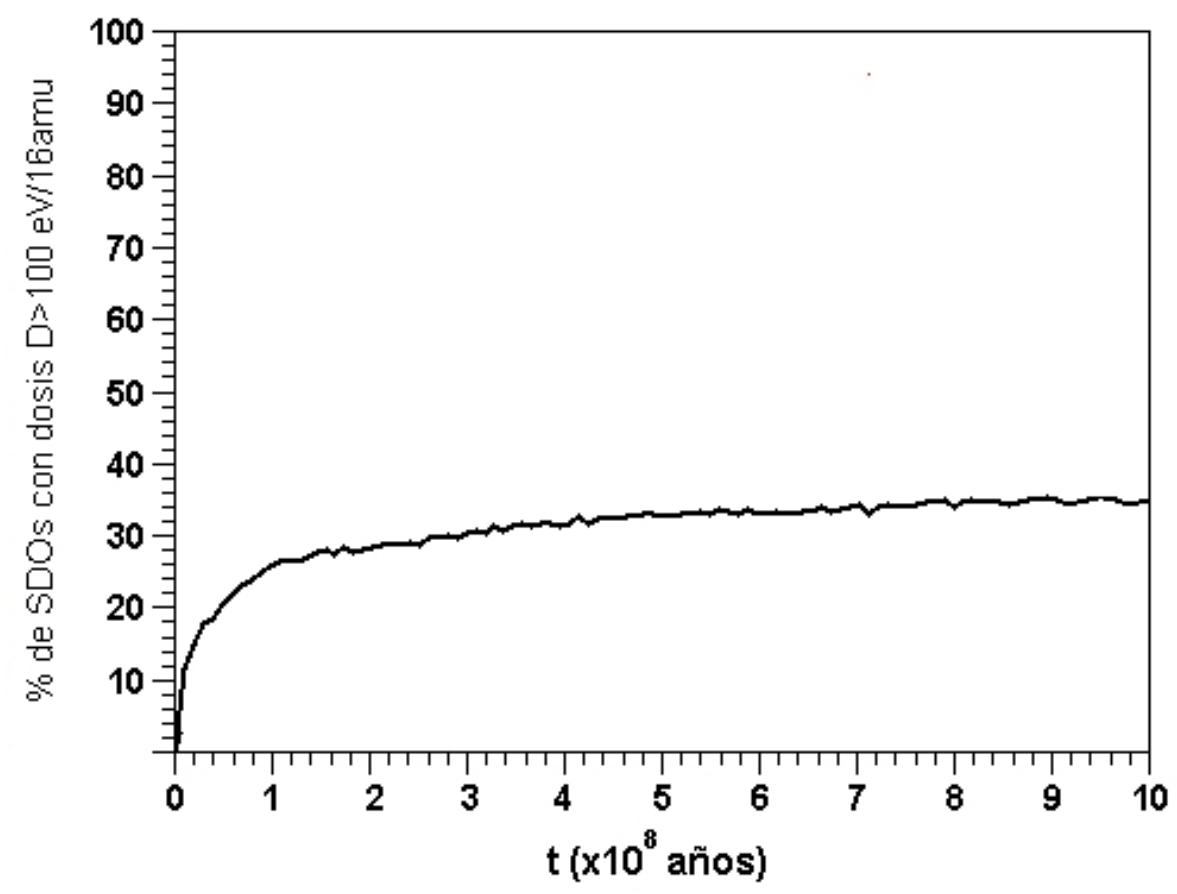

Figura 4.5.12. Experimento 3: Evolución temporal del porcentaje de SDOs con dosis mayores que $100 \mathrm{eV} / 16 a m u$ a lo largo de $10^{9}$ años. Se observa un crecimiento cada vez más atenuado. 


\section{Capítulo 5}

\section{Conclusiones y perspectivas futuras}

En esta tesis se estudió la relación de la población de Centauros con las poblaciones de TNOs y JFCs, caracterizando su distribución de tamaños y estudiando los posibles efectos de la variación de la heliosfera en sus albedos y colores.

Se llevó adelante un programa de búsqueda enfocado a objetos con velocidades compatibles con Centauros moviéndose en la oposición, cubriéndose un área total de 14.17 grados $^{2}$ con un límite de detección de $R m a g=22.3$. Este programa arrojó como resultado el descubrimiento de 3 Centauros y, colateralmente, 63 asteroides del MBA.

Aplicando los resultados obtenidos en este programa conjuntamente con los puntos aportados por los programas de búsqueda bien condicionados que fueran previamente seleccionados, se realizó un nuevo ajuste de la CLF de Centauros con una ley de potencias simple de la forma dada por la ecuación (1.7.1), encontrando que el mejor ajuste se logra con los parámetros $\alpha=0.57 \pm 0.06$ y $\operatorname{Rmag}_{0}=24.9_{-4.4}^{+5.4}$. La pendiente obtenida para la CLF está en concordancia con los tres únicos valores estimados para esta población a partir de datos observacionales de Jedicke y Herron (1996) ( $\alpha=0.61)$, Sheppard et al. (2000) $(\alpha=0.6)$ y Larsen et al. (2001) $(\alpha=0.54)$. Partiendo de la nueva CLF estimada y asumiendo un albedo constante, se ajustó una nueva CSD para la población de Centauros con una ley de potencias simple como la expresada por la ecuación (1.8.5), con $q=3.85$ y $k=7.6 \times 10^{6}$. Utilizando este resultado se estimó que la población de Centauros con radios mayores que $1 \mathrm{~km}$ es $\approx 1.1 \times 10^{6}$ objetos, y que la masa total actual de dicha población en el mismo rango es $\approx 1.5 \times 10^{-5} M_{\oplus}$, todos resultados que están en muy buen acuerdo con lo hallado por los mencionados autores.

Si bien el método de búsqueda empleado se basa en el proceso usual de comparar imágenes coadicionadas, se desarrolló una técnica para detectar objetos a partir de los rastros débiles que los mismos dejan en las imágenes para, a partir de éstos, reconstruir metódicamente la imagen puntual que resulta de concentrar la señal que cada imagen aporta en una única imagen final.

Ello le confiere al método una robustez y una gran ventaja en relación a los otros programas de búsqueda porque dicha forma de coadicionar imágenes compensa la pérdida de flujo por efecto de Trailing Loss. Dicha ventaja es evidente y notoria particularmente en objetos que se desplazan en la oposición a velocidades en el rango 11 arcsechs $^{-1} \lesssim \dot{\theta} \lesssim 20$ arcsechs $^{-1}$, 
ya que los objetos lejanos que se mueven lentamente no sufren Trailing Loss y son detectados por programas de búsqueda, por ej. de TNOs. En el otro extremo, los objetos que se desplazan a mayores velocidades que $20 \operatorname{arcsechs}^{-1}$ y por lo tanto son más cercanos, aunque pierden brillo por estar afectados fuertemente por Trailing Loss, igualmente son tan brillantes que son detectados por casi cualquier programa de búsqueda.

Por lo tanto, dicha compensación que caracteriza al metodo que se diseñó y desarrolló en esta tesis, es la principal causa por la cual se pudo encontrar una importante densidad de Centauros por grado cuadrado, permitiendo detectar en 14.17 grados $^{2}$ tres objetos con velocidades entre $12 \operatorname{arcsech}^{-1}<\dot{\theta}<18 \operatorname{arcsec}^{-1} s^{-1}$, lo que posibilitó llenar el importante vacío observado en la ventana $21.2<\operatorname{Rmag}_{\text {lím }}<24.2$.

Como puntos a objetar del método empleado podemos mencionar que la detección visual que propone se dificulta cada vez más a medida que nos adentramos en las profundidades de la zona de Centauros, dado que se llega a un punto donde los trazos estelares tienen longitudes de tan pocos pixeles que se hace cada vez más dificultoso diferenciarlos de pequeñas anomalías u objetos puntuales, lo que genera un sesgo observacional relacionado con la distancia. En estos casos es necesario comparar imágenes obtenidas en diferentes noches. Por otro lado, como se señaló en su momento, existen casos puntuales excepcionales donde el método se revela como ineficaz, pero creemos que la baja probabilidad de ocurrencia de los mismos no constituye una amenaza seria a la hora de juzgar su eficacia.

Respecto al programa de búsqueda implementado, por último podemos concluir que el punto aportado abre la posibilidad nunca antes planteada de que estemos frente a una CLF para la población de Centauros que necesite ser ajustada mediante una doble ley de potencia, análogamente a lo que parece ocurrir con las poblaciones de TNOs (Weissman y Levison, 1996; Bernstein et al., 2004; Fraser et al., 2008; Fuentes y Holman, 2008; etc.) y JFCs (Weissman, 1982; Bailey y Stagg, 1988; Weissman, 1990; Fernández et al., 1999; Meech et al., 2004; etc.), poblaciones que están en los extremos evolutivos de la dinámica de todo Centauro (Fernández, 1980; Duncan et al., 1988; Holman y Wisdom, 1993; Levison y Duncan, 1997; Morbidelli, 1997; Jewitt, 2002; Di Sisto y Brunini, 2007; Volk y Malhotra, 2008; Bailey y Malhotra, 2009; Melita y Licandro, 2012; Perna et al., 2014; Duffard et al., 2014b; etc.).

Dado que, como se discutió oportunamente, la variación de los albedos afecta la relación entre la CLF y la CSD de una población -lo que tendrá un impacto en los resultados de todo programa de búsqueda-, se estimó necesario en el marco de la presente tesis realizar un estudio sobre la posible influencia del comportamiento de la heliosfera ante encuentros con medios de distintas densidades con el fin de dar una posible explicación a la bimodalidad de colores observada en la población de Centauros. Fue así que se realizaron tres tipos de experimentos numéricos en los que se integraron 2000 partículas del SD interactuando con el Sol y los cuatro planetas gigantes a lo largo de diferentes tiempos de integración e incluyendo un modelo de heliosfera de estructura variable para el primer experimento y de estructura estática para los otros dos, la cual ejercía su propiedad protectora a la radiación proveniente desde el ISM a toda partícula que estuviera en su interior.

El estudio deja claro que la cantidad de Centauros que supera las dosis necesarias para oscurecer sus superficies no crece de manera continua por simple acumulación a medida que pasa el tiempo. Otra conclusión que surge de los experimentos es que por sí sola una reducción de tamaño experimentada por la heliosfera en el cruce de un medio dado, no alcanza para 
que se genere una bimodalidad de colores en la población de Centauros. Sin embargo, los experimentos muestran que la mera existencia de la heliosfera -incluso una heliosfera estáticay su propiedad protectora ante los rayos provenientes del ISM, sería suficiente para definir dos ambientes diferentes capaces de generar una bimodalidad de colores en una población con miembros cuyas órbitas son lo suficientemente alargadas para que los objetos visiten ambos ambientes, si se integra durante tiempos suficientemente prolongados. En estos casos, nuestros experimentos indicarían que las dosis recibidas por los miembros de dicha población ayudan a formar superficies enrojecidas y neutras/grises en porcentajes cercanos al $80 \% \mathrm{y}$ al $20 \%$ respectivamente, donde los más afectados por la radiación son aquellos con distancias perihélicas $q>20 U A$.

Finalmente, en cuanto a las perspectivas futuras, se continuará con la búsqueda de Centauros mediante la aplicación de los códigos y del método de búsqueda desarrollados, valiéndonos en principio de un importante paquete observacional de varios grados cuadrados en el cielo que ya se dispone y que se podrá incrementar para cubrir un área total cercana a la eclíptica de más de 50 grados $^{2}$. Principalmente se tratará de explotar la potencialidad del método buscando objetos entre $5 U A<R<10 U A$, rango de distancias heliocéntricas donde los otros programas de búsqueda se revelan más ineficientes.

El método de búsqueda desarrollado podría también aplicárselo a otro tipo de búsquedas preferentemente dentro del mencionado rango, como por ejemplo de JFCs en las cercanías de Júpiter con el fin de hallar cometas que puedan a futuro protagonizar eventos del tipo Shoemaker-Levy 9 o a un programa enfocado a confirmar o refutar la no existencia de Troyanos de Saturno.

También resulta de interés continuar estudiando la posibilidad de que la población de Centauros posea una distribución en doble ley de potencias, lo que permitirá ajustar mejor el número total de objetos de la población y su masa total, y aportar así más información sobre las propiedades de la CSD de los TNOs verificando en parte la hipótesis de doble pendiente de autores como Bernstein et al. (2004). Esto permitirá comprender mejor cómo se modifican las poblaciones de TNOs, Centauros y JFCs y bajo qué condiciones lo hacen.

Por otra parte, los efectos producidos por la variación de la heliosfera que se estudian en esta tesis pueden ser utilizados del mismo modo para estudiar los efectos de la variación heliosférica en estrellas con sistemas exoplanetarios. Como el resultado principal de esta variación es la interacción de partículas muy energéticas con cuerpos que orbitan alrededor de la estrella y que quedan desprotegidos, es posible que en condiciones extremas de retracción se vean afectados planetas relativamente cercanos a la estrella o dentro de la zona de habitabilidad, lo que podría tener consecuencias astrobiológicas importantes.

Por último, agreguemos que se continuará reportando el enorme número de posiciones de asteroides del MBA detectado por el método desarrollado. Naturalmente se le dará prioridad a los nuevos asteroides descubiertos y a los ya catalogados, pero con órbitas pobremente determinadas. 



\section{Bibliografía}

1. Adachi I, Hayashi C y Nakazawa K. 1976. Prog. Theor. Phys., 56, 1756.

2. Adelson E, Anderson C, Bergen J, Burt P y Ogden J. 1984. RCA Engineer, 29(6), 33.

3. Agnor C, Canup R y Levison H. 1999. Icarus, 142, 219.

4. Alard, C. 2000. ISIS (Image Subtraction). 5.http://www.iap.fr/users/alard/package.html

5. Albrecht R, Barbieri C, Adorf H, Corrain G, Gemmo A, Greenfield P, Hainaut O, Hook R, Tholen D, Blades J y Sparks W. 1994. Astrophys. J., 435, 75.

6. Alexandersen M, Gladman B, Greenstreet S, Kavelaars J, Petit J y Gwyn, S. 2013. Science, 341, 994 .

7. Allen R, Bernstein G y Malhotra R. 2002. Astron. J., 124, 2949.

8. Alvarez-Candal A y Licandro J. 2006. A\&A, 458, $100 \%$.

9. Anders E y Grevesse N. 1989. Geochim. Cosmochim. Acta 53, 197.

10. Andrews S, Wilner D, Hughes A, Qi Ch y Dullemond C. 2010. Astrophys. J., 723, Issue 2, 1241.

11. Antonov V y Latyshev I. 1972. En: The Motion, Evolution of Orbits, and Origin of Comets. Chebotatev G, Kazimirchak-Polonskaya E, Mardsen B., eds. IAU Symp. 45. pp. 341-345.

12. Artymowicz, P. 1988. Astrophys. J. Lett., 335, 79.

13. Armitage, Ph. J. 2014. Última revisión (v4). eprint arXiv:astro-ph/0701485v4, 27.

14. Asphaug E y Benz W. 1996. Icarus, 121, 225.

15. Asphaug E, Ryan E y Zuber M. 2002. En: Asteroids III (W. F. Bottke Jr. et al., eds.), Univ. of Arizona, Tucson, pp. 463-484.

16. Aumann, H. 1984. Bulletin of the American Astronomical Society, 16, 483.

17. Aumann H, Beichman C, Gillett F, de Jong T, Houck J, Low F, Neugebauer G, Walker R y Wesselius P. 1984. Astrophys. J., Part 2-Letters to the Editor, 278, March 1, 23. 
18. Backman D y Paresce F. 1993. En: Protostars and Planets III, ed. E. Levy y J. Lunine, pp. 1253-1304.

19. Bailey B y Malhotra R. 2009. Icarus, 203, 155.

20. Bailey M. 1994. En: Asteroids Comets Meteors 1993 (A. Milani et al., eds.), pp. 443459. IAU Symposium 160, Kluwer, Dordrecht.

21. Bailey B y Stagg C. 1988. MNRAS, 235, 1.

22. Bailey M. 1994. En: Asteroids Comets Meteors 1993 (A. Milani et al., eds.), pp. 443459. IAU Symposium 160, Kluwer, Dordrecht.

23. Ball W. 1888. En: A Short Account of the History of Mathematics, 343-344, pp. 439.

24. Baranov V, Krasnobaev K y Kulikovskii A. 1971. Soviet Phys.-Dokl., 15, 791.

25. Barucci M, Romon J, Doressoundiram A y Tholen D. 2000. Astron. J., 120, 496.

26. Barucci M, Belskaya I, Fulchignoni M y Birlan M. 2005. Astron. J., 130, 1291.

27. Barucci M, Boehnhardt H, Dotto E, Doressoundiram A, Romon J, Lazzarin M, Fornasier S, de Bergh C, Tozzi G, Delsanti A y 10 coautores. 2002. A\&A, 392, 335.

28. Bash, F. 1986. En: Galaxy and the Solar System. University of Arizona Press, pp. 35-46.

29. Bauer J, Meech K, Fernández Y, Pittichova J, Hainaut O, Boehnhardt H y Delsanti A. 2003. Icarus, 166, 195.

30. Beckwith S y Sargent A. 1993. Astrophys. J., 402, 280.

31. Begelman M, McKee C y Shields, G. 1983. Astrophys. J., 271, 70.

32. Benz W y Asphaug E. 1999. Icarus, 142, 5.

33. Berghöfer y Breitschwerdt. 2002. A\&A, 390, 299.

34. Bernstein G, Trilling D, Allen R, Brown M y Holman M. 2004. Astron. J., 128, 1364 .

35. Bertin E y Arnouts S. 1996. SExtractor: Software for source extraction. A\&A Supplement, 117, 393.

36. Bertoldi F, Altenho W, Weis A, Menten K y Thum C. 2006. Nature, 439, 563.

37. Bessell M. 2005. Annual Rev. A\&A, 43, 293.

38. Biver N. 2001. International Comet Quarterly, 23, No. 3, (No. 119), p. 85-93.

39. Boehnhardt H, Tozzi G, Birkle K, Hainaut O, Sekiguchi T, Vair M, Watanabe J, Rupprecht G y FORS Instrument Team. 2001. A\&A, 378, 653.

40. Bowell E. 2012. The Asteroid Orbital Elements Database (ASTORB) (Flagstaff: Lowell 
Obs). Online at: ftp://ftp.lowell.edu/pub/elgb/astorb.html

41. Bowell E, Hapke B, Domingue D, Lumme K, Peltoniemi J y Harris A. 1989. En: Asteroids II; Proceedings of the Conference, Tucson, AZ, Mar. 8-11, 1988 (A9027001 10-91). Tucson, AZ, University of Arizona Press, pp. 524-556.

42. Braga-Ribas F, Sicardy B, Ortiz J, Snodgrass C, Roques F, Vieira-Martins R, Camargo J, Assafin M, Duffard R, Gil-Hutton R y 54 coautores. 2014. Nature, 508, 72.

43. Bramich D. 2008. MNRAS, 386, 77.

44. Brasser R, Duncan M y Levison H. 2006. Icarus, 184, 59.

45. Brasser R, Schwamb M, Lykawka P y Gomes R. 2012. Mon. Not. Roy. Astron. Soc., 420, 3396.

46. Brasser R, Mikkola S, Huang T, Wiegert P y Innanen K. 2004. Mon. Not. Roy. Astron. Soc., 347, 833.

47. Brown M. 2001. Astron. J., 121, 2804.

48. Brown M y Trujillo Ch. 2003. Astron. J., 127, 2413.

49. Brown M, Trujillo Ch. y Rabinowitz D. 2005. Astrophys. J., 635, 97.

50. Brown M, Barkume K, Ragozzine D y Schaller E. 2007. Nature, 446, 294.

51. Brown M, Schaller E, Roe H, Rabinowitz D y Trujillo Ch. 2006. Astrophys. J., 643,61 .

52. Brunetto R, Barucci M, Dotto E y Strazzulla G. 2006. Astrophys. J., 644, 646.

53. Brunini A. 2014. Mon. Not. Roy. Astron. Soc., 437, 2297.

54. Brück M. 1996. Irish Astron. J., 23, 3.

55. Buie M. 1995. SwRI (Space Science Department). Retrieved 2008-10-21. http://www.boulder.swri.edu/buie/kbo/astrom/95SN55.html

56. Buratti B, Hicks M, Dalba P, Chu D, O'Neill A, Hillier J, Masiero1 J, Banholzer S y Rhoades H. 2015. Astrophys. J., 804, 6.

57. Burlaga L, Ness N, Acuña M, Lepping R, Connerney J, Stone E y McDonald F. 2005. Science, 309, $202 \%$.

58. Burns J, Lamy P y Soter S. 1979. Radiation. Icarus, 40, 1.

59. Cameron A y Truran J. 1977. Icarus, 30, 447.

60. Canup R y Ward W. 2002. Astron. J., 124, 3404.

61. Canup R y Ward W. 2006. Nature, 441, 834.

62. Carusi A y Valsecchi G. 1987. En: Interplanetary Matter. Ed: Ceplecha Z and Pecina P. Czechoslovak Academy of Sciences, Ondrejov, pp. 21-28. 
63. Chesley S, Chodas P, Milani A, Valsecchi G y Yoemans D. 2002. Icarus, 159, 423.

64. Chiang E y Brown M. 1999, Astron. J., 118, 1411.

65. Chiang E, Lithwick Y, Murray-Clay R, Buie M, Grundy W y Holman M. 200\%. En: Protostars and Planets V, B. Reipurth, D. Jewitt, and K. Keil (eds.), University of Arizona Press, Tucson, 951 pp., pp. 895-911.

66. Chiang E, Jordan A, Millis R, Buie M, Wasserman L, Elliot J, Kern S, Trilling D, Meech K y Wagner R. 2003. Astron. J., 126, 430.

67. Clarke C, Gendrin A y Sotomayor M. 2001. Mon. Not. Roy. Astron. Soc., 328, 485.

68. Clube S y Napier W. 1986. En: The Galaxy and the Solar System (A87-34101 14-90). Tucson, AZ, University of Arizona Press, pp. 260-285.

69. Cochran A, Levison H, Stern S y Duncan M. 1995, Astrophys. J., 455, 342.

70. Cooper J, Christian E, Richardson J y Wang C. 2003. Earth, Moon, and Planets, 92, 261.

71. Cruikshank D, Roush T, Bartholomew M, Geballe T, Pendleton Y, White S, Bell J, Davies J, Owen T, de Bergh C y 5 coautores. 1998. Icarus, 135, 389.

72. Davis D y Farinella P. 1997. Icarus, 125, 50.

73. Davis D, Chapman C, Weidenschilling S y Greenberg R. 1985. Icarus, 63, 30.

74. Davies J, McFarland J, Bailey M, Marsden B e Ip W. 2008. En: The Solar System Beyond Neptune, M. A. Barucci, H. Boehnhardt, D. P. Cruikshank, and A. Morbidelli (eds.), University of Arizona Press, Tucson, 592 pp., pp. 11-23.

75. de Avillez M y Breitschwerdt D. 2004. FUSE ASP Conference Series, 348, Proceedings of the Conference held 2-6 August, Victoria, Canada. Edited by G. Sonneborn, 430.

76. de la Fuente Marcos C y Barge P. 2001. Mon. Not. R. Astron. Soc., 323, 601.

77. Decker R, Krimigis S, Roelof E, Hill M, Armstrong T, Gloeckler G, Hamilton D y Lanzerotti L. 2005. Science, 309, 2020.

78. Delahodde C, Hainaut O y Nakano S. 2000, IAU Circ., 7467, 3. Edited by Green, D. W. E.

79. Delsanti A y Jewitt D. 2006. En: Solar System Update (Ph. Blondel and J. Mason, eds.), Springer-Praxis, Germany, pp. 267-294.

80. Delsanti A, Hainaut O, Jourdeuil E, Meech K, Boehnhardt H y Barrera L. 2004. A\&A, 417, 1145.

81. De Morgan A. 1872. En: A Budget of Paradoxes. Sophia Elizabeth De Morgan (ed). Londres: Longmans, Green \& Co, 249-250, pp. 511. 
82. Descartes R. 1644. Principia Philosophiae.

83. de Zeeuw P, Hoogerwerf R, de Bruijne J, Brown A y Blaauw A. 1999. Astron. J., 117,354 .

84. Di Sisto R y Brunini A. 200\%. Icarus, 190, 224.

85. Di Sisto R, Brunini A y de Elía G. 2010. A\&A, 519, id.A112, 7 pp.

86. Di Sisto R, Ramos X y Beaugé, C 2013. Icarus, 243, 287

87. Díaz C y Gil-Hutton R. 2008. A\&A, 487, 363.

88. Dohnanyi J. 1969. J. Geophys. Res., 74, 2531.

89. Donahue T. 1991. Planetary Sciences: American and Soviet Research, Proceedings from the U.S.-U.S.S.R. Workshop on Planetary Sciences. Kathleen Kearney Trivers, and David M. Abramson. National Academy Press, 251.

90. Dones L, Levison H y Duncan M. 1996. En: Completing the Inventory of the Solar System. Rettig T y Hahn J (Eds). Astronomical Society of the Pacific Conference Series, 107, pp. 233-244.

91. Donnison J. 2006. Planet. Space Sci., 54, 243.

92. Doressoundiram A, Peixinho N, Doucet C, Mousis O, Barucci M, Petit J y Veillet C. 2005. Icarus, 174, 90.

93. Doressoundiram A, Peixinho N, Moullet A, Fornasier S, Barucci M, Beuzit J y Veillet C. 2007. Astron. J., 134, 2186.

94. Duffard R, Pinilla-Alonso N, Ortiz J, Alvarez-Candal A, Sicardy B, SantosSanz P, Morales N, Colazo C, Fernández-Valenzuela E y Braga-Ribas F. 2014a. A\&A, 568, id.A79, 7 pp.

95. Duffard R, Pinilla-Alonso N, Santos-Sanz P, Vilenius E, Ortiz J, Mueller T, Fornasier S, Lellouch E, Mommert M, Pal A, Kiss C, Mueller M, Stansberry J, Delsanti A, Peixinho N y Trilling D 2014b. A\&A, 564, id.A92, $17 p p$.

96. Dullemond C y Dominik C. 2005. A\&A, 434, 971.

97. Duncan M y Levison H. 1997. Science, 276, 1670.

98. Duncan M, Quinn T y Tremaine S. 1988. Astrophys. J., 328, 69.

99. Duncan M, Levison H y Budd S. 1995, Astron. J., 110, 3073.

100. Edgeworth K. 1938. The evolution of the solar system. Un-published manuscript, Trustees of the National Library of Ireland, Dublin. Manuscript Nos. 16869/47 and /48. $226 \mathrm{pp}$.

101. Edgeworth K. 1943. The evolution of our planetary system. J. Brit. Astr. Assoc., 53, 181-188.

102. Edgeworth K. 1949. Mon. Not. R. Astron. Soc., 109, 600. 
103. Edgeworth K. 1961. The Earth, the Planets and the Stars: Their Birth and Evolution. Macmillan, New York.

104. Elmegreen D. 1998. In: Galaxies and Galactic Structure. Prentice Hall, Upper Saddle River, New Jersey, 306 pp.

105. Elliot J, Kern S, Clancy K, Gulbis A, Millis R, Buie M, Wasserman L, Chiang E, Jordan A, Trilling D y Meech K. 2005. Astron. J., 129, 1117.

106. Emel'yanenko V, Asher D y Bailey M. 2003. Mon. Not. R. Astron. Soc., 338, pp. 443.

107. Emel'yanenko V, Asher D y Bailey M. 2005. Mon. Not. R. Astron. Soc., 361, 1345 .

108. Emery J y Brown R. 2004. Icarus, 170, 131.

109. Everhart E. 1972. Astrophysical Letters, 10, 131.

110. Farinella P y Davis D. 1996. Science, 273, 938.

111. Fahr H. 1980. Mitt. Astron. Gesellschaft, 47, 233.

112. Ferlet R. 1999. A\&A Rev., 9, 153.

113. Fernández J. 1980. Mon. Not. Royal Astr. Soc., 192, 481.

114. Fernández J. 199\%. Icarus, 129, 106.

115. Fernández J. 2005. Comets. Nature, Dynamics, Origin y their Cosmogonical Relevance. Ed. Springer. Dordrecht, The Netherlands.

116. Fernández J. 2010. Conferencia. Cometas: Aspectos físicos y dinámicos y su relevancia para la astrobiología. Taller de Ciencias Planetarias V, La Plata.

117. Fernández J e Ip W. 1981. International Astronomical Union and American Astronomical Society, Colloquium on Comets: Gases, Ices, Grains, and Plasma, 61st, Tucson, AZ, Mar. 11-14, 1981. Icarus, 47, pp. 470-479.

118. Fernández J e Ip W. 1983a. Asteroids, comets, meteors; Proceedings of the Meeting, Uppsala Universitet, Uppsala, Sweden, June 20-22, $38 \%$.

119. Fernández J e Ip W. 1983b. Upps. Astron. Obs. Rep., No. 25, Abstr. 26.

120. Fernández J e Ip W. 1983c. Upps. Astron. Obs. Rep., No. 25, Abstr. 40.

121. Fernández J e Ip W. 1983d. Icarus, 54, 377.

122. Fernández J e Ip W. 1984. Icarus, 58, 109.

123. Fernández J e Ip W. 1987. Icarus, 71, 46.

124. Fernández J e Ip W. 1988. Conference on the Origin and Evolution of Planetary and Satellite Atmospheres, Tucson, AZ, Mar. 10-14, Icarus, 74, April 1988, pp. 47-61.

125. Fernández J e Ip W. 1991a. En: Comets in the post-Halley era. 1 (A93-13551 02-90), 
pp. $487-535$.

126. Fernández J e Ip W. 1991b. Icarus, 92, 185.

127. Fernández J e Ip W. 1996a. Planetary and Space Science, 44, 431.

128. Fernández J e Ip W. 1996b. American Astronomical Society, DPS meeting N28, N07.07; Bulletin of the American Astronomical Society, 28, 1082.

129. Fernández J e Ip W. 1997a. Conference Paper, Astronomical and Biochemical Origins and the Search for Life in the Universe, IAU Colloquium 161, Publisher: Bologna, Italy, 235.

130. Fernández J e Ip W. 1997b. A\&A, 324, 778.

131. Fernández J y Brunini A. 2000. Icarus, 145, 580.

132. Fernández J, Gallardo T y Brunini A. 2002. Icarus, 159, 358.

133. Fernández J, Gallardo T y Brunini A. 2004. Icarus, 172, 372.

134. Fernández J, Tancredi G, Rickman H y Licandro J. 1999. A\&A, 352, 327.

135. Ferrin I, Rabinowitz D, Schaefer B, Snyder J, Ellman N, Vicente B, Rengstorf A, Depoy D, Salim S, Andrews P y 38 coautores. 2001. Astrophys. J., $548,243$.

136. Fesenkov V. 1922. Publ. Russian Astrophys. Observatory, 1, 186.

137. Filippenko A y Chornock R. 2000. IAU Circ., 7468, 3. Edited by Green, D. W. E.

138. Florinski V y Zank G. 2006. En: Solar Journey: The Significance of our Galactic Environment for the Heliosphere and Earth. Edited by Priscilla C. Frisch, University of Chicago, IL, USA. Astrophysics and Space Science Library, 338. Springer Dordrecht, pp. 281-316.

139. Fogg M y Nelson R. 200\%. A\&A, 472, 1003.

140. Fornasier S, Lellouch E, Müller T, Santos-Sanz P, Panuzzo P, Kiss C, Lim T, Mommert M, Bockelée-Morvan D, Vilenius E y 10 coautores. 2013. A\&A, 555, id.A15, 22 $p p$.

141. Fraser W, Kavelaars J, Holman M, Pritchet C, Gladman B, Grav T, Jones R, MacWilliams J y Petit J. 2008. Icarus, 195, 82\%.

142. Frisch P. 2000a. Geophys. Res., 105, 10279.

143. Frisch P. 2000b. American Scientist, 88, 52.

144. Frisch P. 2003. Astrophys. J., 593, 868.

145. Frisch P. 2006. En: Solar Journey: The Significance of our Galactic Environment for the Heliosphere and Earth. Edited by Priscilla C. Frisch, University of Chicago, IL, USA. Astrophysics and Space Science Library, 338. Springer Dordrecht, pp. 1-22. 
146. Frisch P y Slavin J. 2006. En: Solar Journey: The Significance of our Galactic Environment for the Heliosphere and Earth. Edited by Priscilla C. Frisch, University of Chicago, IL, USA. Astrophysics and Space Science Library, 338. Springer Dordrecht, pp. 133-194.

147. Fuchs B, Breitschwerdt D, de Avillez M y Dettbarn C. 2009. Origin of the Local Bubble. Space Science Reviews, 143, pp. 437-448.

148. Fuentes C y Holman M. 2008. Astron. J., 136, 83.

149. Giblin I, Davis D y Ryan E. 2004. Icarus, 171, $48 \%$.

150. Gil-Hutton R. 2002. Planet. Space Sci., 50, 57.

151. Gil-Hutton R. 2012. Comunicación personal.

152. Gil-Hutton R y Licandro J. 2001. Icarus, 152, 246.

153. Gil-Hutton R, Licandro J, Pinilla-Alonso N y Brunetto R. 2009. A\&A, 500, 909.

154. Gladman B y Chan C. 2006. Astrophys. J.. Lett., 643, 135.

155. Gladman B, Marsden B y Van Laerhoven Ch. 2008. En: The Solar System Beyond Neptune, M. A. Barucci, H. Boehnhardt, D. P. Cruikshank, and A. Morbidelli (eds.), University of Arizona Press, Tucson, 592 pp., pp. 43-5\%.

156. Gladman B, Kavelaars J, Nicholson Ph., Loredo T y Burns J. 1998. Astron. J., 116, 2042.

157. Gladman B, Kavelaars J, Petit J, Morbidelli A, Holman M y Loredo Y. 2001. Astron. J., 122, 1051.

158. Goldreich P y Ward W. 1973. Astrophys. J., 183, 1051.

159. Goldreich P, Lithwick Y y Sari R. 2004. Annu. Rev. Astron. Astrophys., 42, 549.

160. Gomes R. S. 2003. Icarus, 161, 404.

161. Gomes R, Matese J y Lissauer J. 2006. Icarus, 184, 589.

162. Gomes R, Levison H, Tsiganis K y Morbidelli A. 2005a. Nature, 435, 466.

163. Gomes R, Gallardo T, Fernández J y Brunini A. 2005b. Cel. Mech. Dyn. Astron., 91, 109.

164. Gomes R, Fernández J, Gallardo T y Brunini A. 2008. En: The Solar System Beyond Neptune, M. A. Barucci, H. Boehnhardt, D. P. Cruikshank, and A. Morbidelli (eds.), University of Arizona Press, Tucson, 592 pp., pp. 259-273.

165. Green D. 1999. Intl. Comet Quarterly, 21, 44.

166. Green D. 2004. Intl. Comet Quarterly, 26, 115.

167. Greenberg R, Weidenschilling S, Chapman C y Davis D. 1984. Icarus, 59, 87. 
168. Greenzweig Y y Lissauer J. 1990. Icarus, 87, 40.

169. Grosser M. 1964. The Search For A Planet Beyond Neptune. Isis, 55, Number 2. 163-183.

170. Grundy W, Noll K y Stephens D. 2005. Icarus, 176, 184.

171. Guinan E y Ribas I. 2002. En: The evolving Sun and its influence on planetary environments, Eds., Montesinos, B., Gimenez, A., Guinan, E.F., ASP Conf. Series, 269, pp. 85-106.

172. Guilbert-Lepoutre A. 2012. Astron. J., 144, 97.

173. Gulbis A, Emery J, Ruprecht J, Bosh A, Person M, Bianco F, Bus S y Zangari A. 2014. En: Asteroids, Comets, Meteors 2014. Editors: Muinonen K, Penttilä A, Granvik M, Virkki A, Fedorets G, Wilkman O, and Kohout T. Helsinki, Finlandia.

174. Gurnett D y Kurth W. 2005. Science, 309, 2025.

175. Hahn J y Malhotra R. 1999. Astron. J., 117, 3041.

176. Hainaut O, West R, Smette A y Mardsen B. 1994. A\&A, 289, 311.

177. Hainaut O y Delsanti A. 2002. A\&A, 389, 641 .

178. Hartmann W, Tholen D, Cruikshank D. 198\%. Icarus, 69, 33.

179. Hills J. G. 1981. Astrophys. J., 86, 1730.

180. Hollenbach D, Yorke H y Johnstone D. 2000. En: Protostars and Planets IV, Manning et al. Eds, Univ. of Arizona Press, pp. 401-428.

181. Hollenbach D, Johnstone D, Lizano S y Shu F. 1994. Astrophys. J., 428, 654.

182. Holman M y Wisdom J. 1993. Astron. J., 105, $198 \%$.

183. Horner J y Lykawka P. 2010. Mon. Not. Roy. Astron. Soc., 402, 13.

184. Horner J, Evans N y Bailey M. 2004. Mon. Not. Roy. Astron. Soc., 354, 798.

185. Hou X, Scherees D y Liu J. 2014. MNRAS, 437, 1420.

186. Hueso R y Guillot T. 2005. A\&A, 442, 703.

187. Hudson R, Palumbo M, Strazzulla G, Moore M, Cooper J y Sturner S. 2008. En: The Solar System Beyond Neptune, M. A. Barucci, H. Boehnhardt, D. P. Cruikshank, and A. Morbidelli (eds.), University of Arizona Press, Tucson, 592 pp., pp. 507-523.

188. Inaba S y Barge P. 2006. Astrophys. J., 649, 415.

189. Ip W. 1989. Icarus, 80, $16 \%$.

190. Irwin M, Tremaine S y Zytkow A. 1995, Astron. J., 110, 3082.

191. Jedicke R y Herron J. 1997. Icarus, 127, 494. 
192. Jedicke R y Metcalfe T. 1998, Icarus, 131, 245.

193. Jewitt D. 2002. Astron. J., 123, 1039.

194. Jewitt D. 2003. Earth, Moon, and Planets, 92, 465.

195. Jewitt D. 2005. Astron. J., 129, 530.

196. Jewitt D. 2009. Astron. J., 137, 4296.

197. Jewitt D. 2012. Astron. J., 143. 66 .

198. Jewitt D y Luu J. 1993. Nature, 362, 730.

199. Jewitt D y Luu J. 1995. Astron. J., 109, 1867.

200. Jewitt D y Luu J. 1998. Astron. J., 115, $166 \%$.

201. Jewitt D y Luu J. 2001. Astron. J., 122, 2099.

202. Jewitt D, Luu J y Chen J. 1996. Astron. J., 112, 1225.

203. Jewitt D, Luu J y Trujillo Ch. 1998. Astron. J., 115, 2125.

204. Jones D, Read M, Saunders W, Colless M, Jarrett T, Parker Q, Fairall A, Mauch T, Sadler E, Watson F y 23 coautores. 2009. Monthly Notices of the Royal Astronomical Society, 399, 683.

205. Joss P. 1973. $A \& A, 25,271$.

206. JPL. 2014. http://ssd.jpl.nasa.gov

207. Kaib N, Becker A, Jones R, Puckett A, Bizyaev D, Dilday B, Frieman J, Oravetz D, Pan K, Quinn T, Schneider D y Watters S. 2009. Astrophys. J. 695, 268.

208. Kant I. 1755. Allgemeine Naturgeschichte und Theorie des Himmels oder Versuch von der Verfassung und dem mechanischen Ursprunge des ganzen Weltgebäudes nach Newtonischen Grundsätzen abgehandelt. Petersen, Königsberg und Leipzig.

209. Kavelaars J, Jones R, Gladman B, Petit J, Parker J, Van Laerhoven Ch., Nicholson P, Rousselot P, Scholl H, Mousis O y 8 coautores. 2009. Astron. J., 137, 4917 .

210. Kazimirchak-Polonskaya E 1972. En: The Motion, Evolution of Orbits, and Origin of Comets: IAU Symposium 45 (G. A. Chebotarev, E. I. Kazimirchak-Polonskaya, and B. G. Marsden, Eds.), pp. 156-166.

211. Kenyon S y Luu J. 1998. Astron. J., 115, 2136.

212. Kenyon S y Luu J. 1999a. Astron. J., 118, 1101.

213. Kenyon S y Luu J. 1999b. Astrophys. J., 526, 465.

214. Kenyon S y Windhorst R. 2001, Astrophys. J. Lett, 547, 69. 
215. Kenyon S y Bromley B. 2002. Astron. J., 123, $175 \%$.

216. Kenyon S y Bromley B. 2004a. Astron. J., 127, 513.

217. Kenyon S y Bromley B. 2004b. Astron. J., 128, 1916.

218. Kenyon S y Bromley B. 2004c. Astrophys. J. Lett, 602, 133.

219. Kenyon S y Bromley B. 2004d. Nature, 432, 598.

220. Kenyon S, Bromley B, O'Brien D y Davis D. 2008. En: The Solar System Beyond Neptune, M. A. Barucci, H. Boehnhardt, D. P. Cruikshank, and A. Morbidelli (eds.), University of Arizona Press, Tucson, 592 pp., pp. 293-313.

221. Kokubo E e Ida S. 1996. Lunar and Planetary Science, 27, 683.

222. Kokubo E e Ida S. 1998. Icarus, 131, 171.

223. Kokubo E e Ida S. 2002. Astrophys. J.,581, 666.

224. Kowal C. 1989. Icarus, 77, 118.

225. Kresák L. 1979. En: Asteroids. (A80-24551 08-91) Tucson, Ariz., University of Arizona Press, 1979, pp. 289-309.

226. Kuiper G. 1951a. En: Astrophysics: A Topical Symposium (J. A. Hynek et al., eds.). McGraw-Hill, New York, pp. 357-424.

227. Kuiper G. 1951b. Proceedings of the National Academy of Sciences of the United States of America, 37, pp. 1-14.

228. Kuiper G. 1956. Part III. Journal of the Royal Astronomical Society of Canada, 50, 158.

229. Kuntz K y Snowden S. 2000. Astrophys. J., 543, 195.

230. Lacerda P y Luu J. 2006. Astron. J., 131, 2314.

231. Lada E. 1992. Astrophys. J., 393, 25.

232. Lallement R. 2001. Astrophys. Space. Sci., 277, 205.

233. Lallement R. 2004. A\&A, 418, 143 .

234. Lallement R, Welsh B, Vergely J, Crifo F y Sfeir D. 2003. A\&A, 411, $44 \%$.

235. Lamy P y Toth I. 2009. Icarus 201, 674

236. Lamy P, Toth I, Fernández Y y Weaver H. 2005. En: Festou M, Keller H, Weaver $H$ (Eds.), Comets II. Univ. of Arizona Press, Tucson, pp. 223-264.

237. Landolt A. 1992. Astron. J., 104, 340.

238. Laplace P. 1769. Exposition du système du monde. Tome 1.

239. Larsen J, Gleason A, Danzl N, Descour A, McMillan R, Gehrels T, Jedicke 
R, Montani J y Scotti J. 2001, Astron. J., 121, 579.

240. Lecar M, Podolak M, Sasselov D y Chiang E. 2006. Astrophys. J., 640, 1115.

241. Leinhardt Z y Richardson D. 2002. Icarus, 159, 306.

242. Leinhardt Z y Richardson D. 2005. Astrophys. J., 625, 42\%.

243. Leonard F. 1930. Astronomical Society of the Pacific Leaflets, 1, No. 30, 121.

244. Levison H y Duncan M. 1990. Astron. J., 100, 1669.

245. Levison H y Duncan M. 1994. Icarus, 108, 18.

246. Levison H y Duncan M. 1997. Icarus, 127, 13.

247. Levison H y Stern S. 2001. Astron. J., 121, 1730.

248. Levison H y Morbidelli A. 2003. Nature, 426, 419.

249. Levison H y Donnes L. 2007. En: Encyclopedia of the Solar System (2nd ed.). Amsterdam; Boston: Academic Press, pp. 575-588.

250. Levison H, Dones L y Duncan M. 2001. Astrophys. J.,121, 4, 2253.

251. Levison H, Morbidelli A, Van Laerhoven Ch., Gomes R y Tsiganis, K. 2008. Icarus, 196, 258.

252. Licandro J, de León J, Pinilla-Alonso N y Serra-Ricart M. 2005. Adv. Space Res., 38, 1991.

253. Licandro J, Grundy W, Pinilla-Alonso N y Leysi P. 2006a. A\&A, 458, 5.

254. Licandro J, Pinilla-Alonso N, Pedani M, Oliva E, Tozzi G y Grundy W. 2006b. A\&A, 445, 35.

255. Licandro J, Guerra J, Campins H, Di Martino M, Lara L, Gil-Hutton R y Tozzi G. 2002. Earth, Moon, and Planets, 90, 495.

256. Liffman K. 2003. Publications of the Astronomical Society of Australia, 20, 337.

257. Lin D, Bodenheimer P y Richardson D. 1996. Nature, 380, 606.

258. Lissauer J. 1987. Icarus, 69, 249.

259. Lodders K. 2003. Meteoritics \& Planetary Science, 38, Supplement, abstract no.5272

260. Lowry H, Fitzsimmons A y Collander-Brown S. 2003. A\&A, 397, 329.

261. Luu J y Jewitt D. 1988, Astron. J., 95, 1256.

262. Luu J y Jewitt D. 1996a. Astron. J., 111, 499.

263. Luu J y Jewitt D. 1996b. Astron. J., 112, 2310.

264. Luu J y Jewitt D. 1998. Astrophys. J., 502, 91. 
265. Luu J, Jewitt D y Trujillo Ch. 2000. Astrophys. J., 531, 151.

266. Luyten W. 1938. Letter to K. E. Edgeworth, dated June 6th, 1938. Trustees of the National Library of Ireland, Dublin. Manuscript No. 16869/45. 2 pp.

267. Lykawka P y Mukai T. 200\%. Icarus, 189, 213.

268. Lykawka P y Horner J. 2010. MNRAS, 405, 1375.

269. Lynden-Bell D y Pringle J. 1974. Mon. Not. Roy. Astron. Soc., 168, 603.

270. Lyttleton R. 1936. Mon. Not. R. Astron. Soc., 97, 108.

271. Malhotra R. 1993. Nature, 365, 819.

272. Malhotra R. 1995. Astron. J., 110, 420.

273. Malhotra R. 1996. Astron. J., 111, 504.

274. Malhotra R, Duncan M y Levison H. 2000. En: Protostars and Planets IV (Book - Tucson: University of Arizona Press; eds Mannings, V., Boss, A.P., Russell, S. S.), pp. 1231-1254.

275. Mammana L y Gil-Hutton R. 2008. BAAA (51 Reunión Anual de la AAA, septiembre de 2008).

276. Mammana L, Gil-Hutton R, Morales N y Ortiz J. 2015a. Minor Planet Observations. IAU Minor Planet Circular 93565.

277. Mammana L, Gil-Hutton R, Morales N y Ortiz J. 2015b. Minor Planet Observations. IAU Minor Planet Circular 94240.

278. Mammana L, Gil-Hutton R, Morales N, Ortiz J y de la Cueva I. 2015c. Minor Planet Observations. IAU Minor Planet Circular 94653.

279. Marsden B y Williams G. 2003. Catalogue of Cometary Orbits. 15th edition. Smithsonian Astrophysical Observatory, Cambridge, $169 \mathrm{pp}$.

280. Marzari F, Tricarico P y Scholl H. 2003. A\&A, 410, 725.

281. Matese J, Whitman P, Innanen K y Valtonen M. 1995. Icarus, 116, 255.

282. Mayer L, Quinn Th, Wadsley J y Stadel J. 2002. Science, 298, 1756.

283. McComas D, Dayeh M, Funsten H, Livadiotis G y Schwadron N. 2013. Astrophys. J., 771, article id. 77, 9 pp.

284. McComas D, Alexashov D, Bzowski M, Fahr H, Heerikhuisen J, Izmodenov V, Lee M, Möbius E, Pogorelov N, Schwadron N y Zank G. 2012. Science, 336, no. 6086, 1291.

285. McFarland J. 1996. Vistas in Astronomy, 40, 343.

286. McFarland J. 2004. En: Proceedings of Ceres 2001 Workshop. Linstitut de mécanique céleste et de calcul des éphémérides, Paris, France, pp. 19-23. 
287. Meech K. 2004. Physical properties of cometary nuclei. En: Proc. of Asteroids, Comets, Meteors '96 COSPAR Conference.

288. Meech K, Hainaut O y Marsden B. 2004. Icarus, 170, 463.

289. Melita M y Brunini A. 2000. Icarus, 147, 205.

290. Melita M y Licandro J. 2012. A\&A, 539, id.A144, 6 pp.

291. Merlin F, Barucci M, Dotto E, de Bergh C y Lo Curto G. 2005. A\&A, 444, 977.

292. Michel P, Benz W, Tanga P y Richardson D. 2001. Science, 294, 1696.

293. Millis R, Buie M, Wasserman L, Elliot J y Wagner R. 1999, BAAS, 31, 2601.

294. Moffat, A. 1969. A\&A, 3, 455.

295. Morais M y Namouni F. 2013. Mon. Not. Roy. Astron. Soc. Letters, 436, 30.

296. Morbidelli A. 1997. Icarus, 127, 1.

297. Morbidelli A. 2005. eprint arXiv:astro-ph/0512256.

298. Morbidelli A y Brown M. 2004. En: Comets II, M. C. Festou, H. U. Keller, and H. A. Weaver (eds.), University of Arizona Press, Tucson, 745 pp., pp. 175-191.

299. Morbidelli A y Levison H. 2004. Astron. J., 128, 2564.

300. Morbidelli A, Thomas F y Moons M. 1995. Icarus, 118, 322.

301. Morbidelli A, Emel'yanenko V y Levison H. 2004. Mon. Not. R. Astron. Soc., $355,935$.

302. Morbidelli A, Levison H y Gomes R. 2008. En: The Solar System Beyond Neptune, M. A. Barucci, H. Boehnhardt, D. P. Cruikshank, and A. Morbidelli (eds.), University of Arizona Press, Tucson, 592 pp., pp. 275-292.

303. Morbidelli A, Levison H, Tsiganis K y Gomes R. 2005. Nature, 435, 462.

304. Moroz L, Baratta G, Distefano E, Strazzulla G, Starukhina L, Dotto E y Barucci M. 2003. Earth, Moon, and Planets, 92, 279.

305. Moroz L, Baratta G, Strazzulla G, Starukhina L, Dotto E, Barucci M, Arnold G y Distefano E. 2004. Icarus, 170, 214.

306. $\mathbf{M P C}_{0}:$ http://www.minorplanetcenter.net/iau/lists/MPLists.html

307. $\mathbf{M P C}_{1}$ : http://www.minorplanetcenter.net/iau/lists/Unusual.html

308. $\mathbf{M P C}_{2}$ : http://www.minorplanetcenter.net/iau/lists/Trojans.html

309. $\mathbf{M P C}_{3}$ : http://www.minorplanetcenter.net/iau/lists/Centaurs.html

310. Murray C y Dermott S. 1999. En: Solar System Dynamics. Cambridge University Press, pp. 10\%-109. 
311. Nesvorný D, Vokrouhlick D y Morbidelli A. 200\%. Astron. J., 133, 1962.

312. O'Brien D y Greenberg R. 2003. Icarus, 164, 334.

313. Oort J. H. 1950. The structure of the cloud of comets surrounding the solar system, and a hypothesis concerning its origin. Bull. Astron. Inst. Netherlands, 11, 91-110.

314. Ortiz J, Sugerman B, de la Cueva I, Santos-Sanz P, Duffard R, Gil-Hutton R, Melita M y Morales N. 2010. A\&A, 519, id.A7, 8 pp.

315. Ortiz J, Cikota A, Hestroffer S, Thirouin1 A, Morales N , Duffard R, GilHutton R, Santos-Sanz P y de la Cueva I. 2011. A\&A, 525, id.A31, 12 pp.

316. Öpik E. 1932. Proc. Am. Acad. Arts Sci., 67, 169.

317. Pál A, Kiss C, Müller T, Santos-Sanz P, Vilenius E, Szalai N, Mommert M, Lellouch E, Rengel M, Hartogh $\mathbf{P}$ y 7 coautores. 2012. A\&A, 541, 6.

318. Parker E. 2006. En: Solar Journey: The Significance of our Galactic Environment for the Heliosphere and Earth. Edited by Priscilla C. Frisch, University of Chicago, IL, USA. Astrophysics and Space Science Library, 338. Springer Dordrecht, pp. 87-98.

319. Peixinho N, Delsanti A, Guilbert-Lepoutre A, Gafeira R y Lacerda P. 2012. $A \& A, \mathbf{5 4 6}, i d . A 86,12 \mathrm{pp}$.

320. Peixinho N, Doressoundiram A, Delsanti A, Boehnhardt H, Barucci M, Belskaya I. 2003. $A \& A, 410,29$.

321. Peixinho N, Boehnhardt H, Belskaya I, Doressoundiram A, Barucci M y Delsanti A. 2004. Icarus, 170, 153.

322. Perna D, Mazzotta Epifani E, Barucci M, Brucato J, Dall'Ora M, Dotto E, Licandro J, Palumbo P y Tozzi G. 2014. En: Asteroids, Comets, Meteors 2014. Proceedings of the conference held 30 June - 4 July, in Helsinki, Finland. Edited by K. Muinonen, Penttilä A, Granvik M, Virkki A, Fedorets G, Wilkman O, and Kohout T.

323. Petit J y Mousis O. 2004. Icarus, 168, 409.

324. Petit J, Morbidelli A y Valsecchi G. 1999. Icarus, 141, 367.

325. Petit J, Kavelaars J, Gladman B y Loredo T. 2008. En: The Solar System Beyond Neptune, M. A. Barucci, H. Boehnhardt, D. P. Cruikshank, and A. Morbidelli (eds.), University of Arizona Press, Tucson, 592 pp., pp. 71-87.

326. Petit J, Holman M, Gladman B, Kavelaars J, Scholl H y Loredo T. 2006. Mon. Not. R. Astron. Soc., 365, 429.

327. Pinilla-Alonso N, Licandro J, Gil-Hutton R y Brunetto R. 2007. A\&A, 468, 25.

328. Pogorelov N y Zank G. 2006. En: Solar Journey: The Significance of our Galactic Environment for the Heliosphere and Earth. Edited by Priscilla C. Frisch, University of Chicago, IL, USA. Astrophysics and Space Science Library, 338. Springer Dordrecht, pp. 53-86. 
329. Quinn T, Tremaine S y Duncan M. 1990. Astrophys. J., 355, 667-679.

330. Rabinowitz D, Helin E, Lawrence K y Pravdo S. 2000, Nature, 403, pp. 165-166.

331. Rafikov R. 2003. Astron. J., 126, 2529.

332. Ruprecht J, Bosh A, Person M, Bianco F, Fulton B, Gulbis A, Bus S, Zangari A. 2015. Icarus, 252, 271

333. Ryan E, Davis D y Giblin I. 1999. Icarus, 142, 56.

334. Roques F, Georgevits G y Doressoundiram A. 2008. En: The Solar System Beyond Neptune, M. A. Barucci, H. Boehnhardt, D. P. Cruikshank, and A. Morbidelli (eds.), University of Arizona Press, Tucson, 592 pp., pp. 545-556.

335. Safronov V. 1969. NASA,TTF-677, US Dept.of Commerce.

336. Sasaki S, Nakamura K, Hamabe Y, Kurahashi E y Hiroi T. 2001. Nature, 410, 555.

337. Sasaki T, Kanno A, Ishiguro M, Kinoshita D y Nakamura R. 2005. Astrophys. $J ., 618,5 \%$.

338. Schmidt O. 1958. A Theory of Earth's Origin-Four Lectures. 3ra. edition, Foreigin Languages Publishing House, Moscu.

339. Scoville N y Sanders D. 1986. En: The Galaxy and the Solar System (A87-34101 14-90). Tucson, AZ, University of Arizona Press, pp. 69-82.

340. Sekanina Z. 1997. A\&A, 318, 5 .

341. Sfeir D, Lallement R, Crifo F y Welsh B. 1999. A\&A, 346, 785

342. Shaviv N. 2006. En: Solar Journey: The Significance of our Galactic Environment for the Heliosphere and Earth. Edited by Priscilla C. Frisch, University of Chicago, IL, USA. Astrophysics and Space Science Library, 338. Springer Dordrecht, pp. 99-132.

343. Sheppard S, Jewitt D, Trujillo Ch., Brown M y Ashley M. 2000, Astron. J., 120, $268 \%$.

344. Sheppard S y Trujillo Ch. 2006. Science, 313, 511.

345. Shoemaker E y Wolfe R. 1982. En: Satellites of Jupiter, ed. Morrison D (Tucson: Univ. de Arizona Press), pp. 277-339.

346. Shul'Man L. 1972. En: Chebotarev G, Kazimirchak-Polonskaia E y Marsden B (Eds.) The Motion, Evolution of Orbits, and Origin of Comets, 45 of IAU Symposium, pp. 265-270.

347. Sicardy B, Ortiz J, Assafin M, Jehin E, Maury A, Lellouch E, Gil-Hutton R, Braga-Ribas F, Colas F, Hestroffer D y 52 coautores. 2011. Nature, 478, 493.

348. Snodgrass C, Tubiana C, Bramich D, Meech K, Boehnhardt H y Barrera L. 
2013. $A \& A, \mathbf{5 5 7}, A 33$.

349. Snowden S, Egger R, Finkbeiner D, Freyberg M y Plucinsky P. 1998. Astroph. J., 493, 715 .

350. Sosa A, Fernández J y Pais P. 2012. A\&A, 548, 64.

351. Sosa A, Mammana L y Fernández J. 2014. En: Asteroids, Comets, Meteors 2014. Editors: Muinonen K, Penttilä A, Granvik M, Virkki A, Fedorets G, Wilkman O, and Kohout T. Helsinki, Finlandia.

352. Spaute D, Weidenschilling S, Davis D y Marzari F. 1991. Icarus, 92, 14 \%

353. Standish, E. 1993. Astron. J., 105, no. 5, 2000.

354. Stansberry J, Grundy W, Brown M, Cruikshank D, Spencer J, Trilling D y Margot J. 2008. En: The Solar System Beyond Neptune, M. A. Barucci, H. Boehnhardt, D. P. Cruikshank, and A. Morbidelli (eds.), University of Arizona Press, Tucson, 592 pp., pp. 161-179.

355. Stern S. 1988. Icarus, 73, 499.

356. Stern S. 1996a. A\&A, 310, 999.

357. Stern S. 1996b. Astron. J., 112, 1203.

358. Stern S y Colwell J. 1997a. Astron. J., 114, 841.

359. Stern S y Colwell J. 1997b. Astrophys. J., 490, 879.

360. Stern S y Weissman P. 2001. Nature, 409, 589.

361. Stern S y Trafton L. 2008. En: The Solar System Beyond Neptune, M. A. Barucci, H. Boehnhardt, D. P. Cruikshank, and A. Morbidelli (eds.), University of Arizona Press, Tucson, 592 pp., pp. 365-380.

362. Stone E, Cummings A, McDonald F, Heikkila B, Lal N y Webber W. 2005. Voyager 1 Explores the Termination Shock Region and the Heliosheath Beyond. Science, $309,201 \%$.

363. Stothers R. 1998. Mon. Not. Roy. Astr. Soc., 300, 1098.

364. Strazzulla G y Johnson R. 1991. En: R. L. Newburn, Jr., M. Neugebauer, \& J. Rahe (Eds.) IAU Colloq. 116: Comets in the post-Halley era, 167 of Astrophysics and Space Science Library, pp. 243-275.

365. Strazzulla G, Baratta G, Johnson R y Donn B. 1991. Icarus, 91, 101.

366. Strazzulla G, Cooper J, Christian E y Johnson R. 2003. Comptes Rendus Physique 4, 791.

367. Strom S, Strom K y Grasdalen G. En: Annual review of astronomy and astrophysics 13. (A76-10076 01-88) Palo Alto, Calif., Annual Reviews, Inc., 1975, pp. 187-216.

368. Stuart J. 2001, Science, 294, 1691. 
369. Sunkavalli K, Johnson M, Matusik W y Pfister H. 2010. ACM Transactions on Graphics (Proceedings of SIGGRAPH), 29 (4).

370. Swedenborg E. 1734. Opera Philosophica et Mineralia. 1.

371. Tachibana S, Huss G, Kita N, Shimoda G y Morishita Y. 2006. Astrophys. J., $639,87$.

372. Takeuchi T y Artymowicz P. 2001. Astrophys. J., 557, 990.

373. Talbot R y Newman M. 197\%. Astrophys. J. Supplement Series, 34, 295.

374. Tanaka H y Ida S. 1999. Icarus, 139, 350.

375. Tanaka H, Takeuchi T y Ward W. 2002. Astrophys. J., 565, 1257.

376. Tancredi G, Fernández J, Rickman H y Licandro J. 2006. Icarus, 182, $52 \%$.

377. Tanga P, Weidenschilling S, Michel P y Richardson D. 2004. A\&A, 427, 1105.

378. Tedesco E. 1989. En: Asteroid II, edited by Binzel, Gehrels and Matthews; University of Arizona, Tucson, pp. 12-30.

379. Tegler S y Romanishin W. 1998. Nature, 392, 49.

380. Tegler S y Romanishin W. 2000. Nature, 407, 979.

381. Tegler S, Romanishin W, Consolmagno G. 2003. Astrophys. J., 599, 49.

382. Tegler S, Bauer J, Romanishin W, Peixinho N. 2008. En: The Solar System Beyond Neptune, M. A. Barucci, H. Boehnhardt, D. P. Cruikshank, and A. Morbidelli (eds.), University of Arizona Press, Tucson, 592 pp., pp. 105-114.

383. Tegler S, Grundy W, Romanishin W, Consolmagno G, Mogren K y Vilas F. 200\%. Astron. J., 133, 526 .

384. Tera F, Papanastassiou D y Wasserburg G. 1974. Earth and Planetary Science Letters, 22, 1.

385. Tiscareno S y Malhotra R. 2003. Astron. J., 126, 3122.

386. Tody D. 1986. En: Instrumentation in astronomy VI; Proceedings of the Meeting, Tucson, AZ, Mar. 4-8. Part 2 (A87-36376 15-35). Bellingham, WA, Society of PhotoOptical Instrumentation Engineers, 1986, p. 733. (IRAF es distribuido por la National Optical Astronomy Observatories, que es operada por la Association of Universities for Research in Astronomy, Inc., bajo un acuerdo de cooperación con la National Science Foundation).

387. Tombaugh C. 1961. Planets and Satellites, edited by Gerard P. Kuiper and Barbara M. Middlehurst Chicago: The University of Chicago Press, 12

388. Trilling D y Bernstein G. 2006. Astron. J., 131, 1149.

389. Trujillo Ch. 2008. En: The Solar System Beyond Neptune, M. A. Barucci, H. Boehnhardt, D. P. Cruikshank, and A. Morbidelli (eds.), University of Arizona Press, Tucson, 
592 pp., pp. 573-585.

390. Trujillo Ch. y Brown M. 2003. Earth, Moon, and Planets, 92, 99.

391. Trujillo Ch., Jewitt D y Luu J. 2001a. Astron. J., 122, $45 \%$.

392. Trujillo Ch., Luu J, Bosh A y Elliot J. 2001b. Astron. J., 122, 2740.

393. Trujillo Ch., Brown M, Barkume K, Schaller E y Rabinowitz D. 200\%. Astrophys. J., 655, 1172.

394. Tsiganis K, Gomes R, Morbidelli A y Levison H. 2005. Nature, 435, 459.

395. Vandervoort P y Sather E 1993. Icarus, 105. 26.

396. Volk K y Malhotra R. 2008, Astrophys. J., 687, 714.

397. Volk K y Malhotra R. 2013. Icarus, 224, 66.

398. Weidenschilling S. 1977a. Mon. Not. R. Astron. Soc., 180, 57.

399. Weidenschilling S. 1977b. Astrophys. Space Sci. 51, 153.

400. Weidenschilling S. 1980. Icarus, 44, 172.

401. Weidenschilling S. 1984. Icarus, 60, 553.

402. Weidenschilling S. 1995. Icarus, 116, 433.

403. Weidenschilling S. 199\%. Icarus, 127, 290.

404. Weidenschilling S. 2003. Icarus, 165, 438.

405. Weidenschilling S. 2006. Icarus, 181, 572.

406. Weissman P. 1982. En: Geological Implications of Impacts of Large Asteroids and Comets on the Earth. Silver y Schultz eds., GSA SP, 190, pp. 15-24.

407. Weissman P. 1983. A\&A, 118, no. 1, 90.

408. Weissman P. 1984. Lunar and Planetary Science, 15, 904.

409. Weissman P. 1990. En: Global Catastrophes in Earth History. Sharpton y Ward eds., GSA SP, 247, pp. 171-180.

410. Weissman P y Levison H. 1996. Lunar and Planetary Science, 27, 1409.

411. Weissman P y Lowry H. 2001. Bull. Am. Astron. Soc., 33, 1094.

412. Weissman P y Lowry H. 2002. En: Cometary Science After Hale-Bopp, IAU Colloquium 186, Tenerife, Spain (abstract).

413. Weissman P y Lowry H. 2003. En: The size distribution of Jupiter-family cometary nuclei, Proc. Lunar Planet. Sci. Conf. 34th. Abstracts N34.

414. Welsh B, Sfeir D, Sirk M y Lallement R. 1999. A\&A, 352, 308. 
415. Wetherill G y Stewart G. 1989. Icarus, 77, 330.

416. Wetherill G y Stewart G. 1993. Icarus, 106, 190.

417. Whipple F. 1950a. Astron. J., 55, 83.

418. Whipple F. 1950b. Astrophys. J., 111, 375.

419. Whipple F. 1964. Proceedings of the National Academy of Sciences of the United States of America, 51, pp. 711-718.

420. Wilkin F. 1996. Astrophys. J., 459, 31.

421. Williams D y Wetherill G. 1994. Icarus, 107, $11 \%$.

422. Wilson R, Jefferts K y Penzias A. 1970. Astrophys. J., 161, 43.

423. Woods D, Klein R, Castor J, McKee C y Bell J. 1996. Astrophys. J., 461, 767.

424. Wurm G y Schnaiter M. 2002. Astrophys. J., 567, 370.

425. Wurm G, Paraskov G y Krauss O. 2004. Astrophys. J., 606, 983.

426. Yeghikyan A y Fahr H. 2006. En: Solar Journey: The Significance of our Galactic Environment for the Heliosphere and Earth. Edited by Priscilla C. Frisch, University of Chicago, IL, USA. Astrophysics and Space Science Library, 338. Springer Dordrecht, 2006, pp. 317-348.

427. Youdin A y Shu F. 2002. Astrophys. J., 580, 494.

428. Young E, Binzel R y Crane K. 2001. Astron. J., 121, 552.

429. Yu Q y Tremaine S. 1999, Astrophys. J., 118, 1873.

430. Yun J y Clemens D. 1990. Astrophys. J., 365, 73.

431. Zahnle K, Schenk P, Levison H y Dones L. 2003. Icarus, 163, 263.

432. Zank G, Müller H, Florinski V y Frisch P. 2006. En: Solar Journey: The Significance of our Galactic Environment for the Heliosphere and Earth. Edited by Priscilla C. Frisch, University of Chicago, IL, USA. Astrophysics and Space Science Library, 338. Springer Dordrecht, pp. 23-52. 